\title{
S3-Leitlinie „Prophylaxe, Diagnostik und Therapie der Hepatitis-C-Virus (HCV) -Infektion“
}

\author{
AWMF-Register-Nr.: 021/012
}

Autoren

Tim Zimmermann ${ }^{1}$, Petra Lynen Jansen², Christoph Sarrazin ${ }^{3}$, Johanna Vollmar ${ }^{1}$, Stefan Zeuzem ${ }^{4}$

Institute

1 I. Medizinische Klinik und Poliklinik, Gastroenterologie und Hepatologie, Universitätsmedizin Mainz

2 Deutsche Gesellschaft für Gastroenterologie, Verdauungsund Stoffwechselkrankheiten, Berlin

3 St. Josefs-Hospital Wiesbaden

4 Medizinische Klinik 1, Universitätsklinikum Frankfurt am Main
Bibliografie

DOI https://doi.org/10.1055/a-0598-5242

Z Gastroenterol 2018; 56: e53-e115

(c) Georg Thieme Verlag KG, Stuttgart · New York

ISSN 0044-2771

Korrespondenzadresse

Prof. Dr. med. Tim Zimmermann, MHBA

Wissenschaftlicher Sekretär der S3-Leitlinie Hepatitis C

Universitätsmedizin Mainz

I. Medizinische Klinik und Poliklinik, Gastroenterologie und

Hepatologie, Langenbeckstr. 1, 55131 Mainz

tim.zimmermann@unimedizin-mainz.de

\begin{tabular}{|c|c|c|}
\hline \multicolumn{2}{|c|}{ Inhaltsverzeichnis } & \multirow{2}{*}{$\begin{array}{l}\text { Seite } \\
\text { e54 }\end{array}$} \\
\hline 1. & Geltungsbereich und Zweck & \\
\hline 1.1 & Begründung für die Auswahl des Leitlinienthemas & e54 \\
\hline 1.2 & Zielorientierung der Leitlinie & e54 \\
\hline 1.3 & Patientenzielgruppe & e54 \\
\hline 1.4 & Versorgungsbereich & e54 \\
\hline 1.5 & Anwenderzielgruppe/Adressaten & e54 \\
\hline 2. & $\begin{array}{l}\text { Zusammensetzung der Leitliniengruppe: } \\
\text { Beteiligung von Interessensgruppen }\end{array}$ & e54 \\
\hline 3. & Methodologische Exaktheit & e55 \\
\hline 3.1 & $\begin{array}{l}\text { Recherche, Auswahl und Bewertung wissenschaft- } \\
\text { licher Belege (Evidenzbasierung) }\end{array}$ & e55 \\
\hline 3.2 & $\begin{array}{l}\text { Formulierung der Empfehlungen und strukturierte } \\
\text { Konsensfindung }\end{array}$ & e56 \\
\hline 4. & Externe Begutachtung und Verabschiedung & e58 \\
\hline 4.1 & Pilottestung & e58 \\
\hline 4.2 & Externe Begutachtung & e58 \\
\hline 4.3 & $\begin{array}{l}\text { Verabschiedung durch die Vorstände der } \\
\text { herausgebenden } \\
\text { Fachgesellschaften und Organisationen }\end{array}$ & e58 \\
\hline 5. & Redaktionelle Unabhängigkeit & e58 \\
\hline 5.1 & Finanzierung der Leitlinie & e58 \\
\hline
\end{tabular}

\begin{tabular}{|c|c|c|}
\hline \multicolumn{2}{|c|}{ Inhaltsverzeichnis } & \multirow{2}{*}{$\begin{array}{l}\text { Seite } \\
\text { e58 }\end{array}$} \\
\hline 5.2 & $\begin{array}{l}\text { Darlegung von und Umgang mit potenziellen } \\
\text { Interessenkonflikten }\end{array}$ & \\
\hline 6. & Verbreitung und Implementierung & e58 \\
\hline 6.1 & Konzept zur Verbreitung und Implementierung & e58 \\
\hline 6.2 & $\begin{array}{l}\text { Unterstützende Materialien für die Anwendung } \\
\text { der Leitlinie }\end{array}$ & e58 \\
\hline 6.3 & $\begin{array}{l}\text { Messgrößen für das Monitoring: Qualitätsziele, } \\
\text { Qualitätsindikatoren }\end{array}$ & e58 \\
\hline 7. & Gültigkeitsdauer und Aktualisierungsverfahren & e58 \\
\hline 7.1 & $\begin{array}{l}\text { Datum der letzten inhaltlichen Überarbeitung } \\
\text { und Status }\end{array}$ & e58 \\
\hline 7.2 & Aktualisierungsverfahren & e58 \\
\hline 8. & Appendix & e59 \\
\hline 8.1 & Zeitplan & e59 \\
\hline 8.2 & Interessenkonflikterklärungen & e59 \\
\hline 8.3 & Aufgabenverteilung & e67 \\
\hline 8.4 & Schlüsselfragen & e68 \\
\hline 8.5 & Literatursuche & e70 \\
\hline 8.6 & Evidenztabellen & e73 \\
\hline 8.7 & $\begin{array}{l}\text { Oxford Centre for Evidence Based Medicine } 2011 \\
\text { Levels of Evidence }\end{array}$ & e115 \\
\hline
\end{tabular}




\section{Geltungsbereich und Zweck}

\subsection{Begründung für die Auswahl des Leitlinienthemas}

Die Aktualisierung der Leitlinie wurde aufgrund der raschen Weiterentwicklung, widersprüchlicher Informationen aus internationalen Leitlinien und fehlenden eindeutigen Therapiealgorithmen aus den Fachinformationen bei hohen Therapiekosten notwendig und wird von den beteiligten Fachgesellschaften als besonders wichtig erachtet.

\subsection{Zielorientierung der Leitlinie}

Thema dieser Leitlinie sind die Prophylaxe, Diagnostik und Therapie der Hepatitis C. Die Leitlinie fokussiert sich dabei auf die typischen Fragestellungen, wie sie in der Behandlung dieser Patienten auftreten.

Durch die neu verfügbaren direkt antiviralen Therapien wurden die Therapieoptionen deutlich erweitert, sodass eine grundlegende Überarbeitung der Leitlinie erfolgte. Die in der Leitlinie aufgeführten Themen sollen mit Ausnahme des Therapieteils in fünf Jahren bei der Überarbeitung dieser Leitlinie bearbeitet werden. Durch die rasante Entwicklung wurden und werden ggf. 1 - 2 jährliche Updates des Therapieteils notwendig.

\subsection{Patientenzielgruppe}

Patienten mit Hepatitis C jeden Alters.

\subsection{Versorgungsbereich}

Ambulant und stationär, haus- und fachärztlich.

\subsection{Anwenderzielgruppe/Adressaten}

An der Beratung, Diagnostik und Therapie der Erkrankung beteiligte Ärzte werden adressiert (Internisten, Gastroenterologen, Kinder- und Jugendmediziner, Suchtmediziner, Infektionsmediziner, Virologen, Pathologen und Transplantationsmediziner). Die Leitlinie dient darüber hinaus zur Information der Primärärzte (Hausärzte).

\section{Zusammensetzung der Leitliniengruppe: Beteiligung von Interessensgruppen}

Die Leitung der Leitlinienüberarbeitung erfolgte durch zwei Koordinatoren (C. Sarrazin, Frankfurt/Wiesbaden und S. Zeuzem, Frankfurt), unterstützt durch einen wissenschaftlichen Sekretär (T. Zimmermann, Mainz), in enger Abstimmung mit den Leitern der einzelnen Arbeitsgruppen (AGs). Insgesamt wurden sieben AGs gebildet. Diese wurden von jeweils ein bis zwei AG-Leitern geleitet ( $\triangleright$ Tab. 1$)$.

In die AGs wurden in einem ausgewogenen Verhältnis universitäre und nicht-universitäre Ärzte, Klinikärzte und niedergelassene Ärzte eingeladen.

Entsprechend der Expertisen der jeweiligen AGs wurden Personen aus den folgenden Gruppierungen eingebunden:

- Internisten

- Gastroenterologen

- Virologen

- Infektionsmediziner

- Pathologen

- Pädiater

- Patientenvertreter

An der initialen Bearbeitung der einzelnen Abschnitte und der dazugehörigen Literatur sowie der Empfehlungen nahmen alle AG-Mitglieder teil ( $\bullet$ Tab. 2).

Aus jeder AG wurden alle Mitglieder zur Konsensuskonferenz und zur Onlineabstimmung mittels zwei Delphi-Runden eingeladen. Dieses Vorgehen wurde gewählt, um möglichst viele Experten einschließlich Patientenvertreter mit Stimmrecht einzubinden.

Bei der Erstellung der Leitlinie waren folgende Fachgesellschaften und Organisationen/Institute inhaltlich und personell beteiligt:

- Deutsche Gesellschaft für Gastroenterologie, Verdauungs- und Stoffwechselkrankheiten (DGVS)

- Deutsche Gesellschaft für Pathologie e. V. (DGP) und Berufsverband Deutscher Pathologen (BDP)

- Deutsche Leberstiftung

- Gesellschaft für Virologie e. V. (GfV)

- Gesellschaft für Pädiatrische Gastroenterologie und Ernährung (GPGE)

- Tab. 1 AGs und AG-Leiter.

\begin{tabular}{|l|l|l|l|}
\hline AG & Inhalt & Name & Ort \\
\hline 1 & $\begin{array}{l}\text { Definition der Hepatitis-C-Virus (HCV) -Infektion und Empfehlungen zu deren } \\
\text { Diagnostik }\end{array}$ & $\begin{array}{l}\text { P. Schirmacher } \\
\text { J. Timm }\end{array}$ & $\begin{array}{l}\text { Heidelberg } \\
\text { Düsseldorf }\end{array}$ \\
\hline 2 & Prävention der HCV-Übertragung und Prophylaxe der Chronifizierung & H. Wedemeyer & Essen \\
\hline 3 & natürlicher Verlauf und Therapieindikation inklusive extrahepatische Manifestationen & T. Berg & Leipzig \\
\hline 4 & Therapie der chronischen Hepatitis C & C. Sarrazin & Wiesbaden \\
\hline 5 & $\begin{array}{l}\text { Infektionen mit HCV im Zusammenhang mit einer Transplantation } \\
\text { (prä- und postoperatives Management) }\end{array}$ & U. Neumann & Aachen \\
\hline 6 & Ko-Infektionen bei Hepatitis-C-Virusinfektion & U. Spengler & Münster \\
\hline 7 & Hepatitis-C-Virusinfektion bei Kindern und Jugendlichen & S. Wirth & Bonn \\
\hline
\end{tabular}


- Tab. 2 Mitglieder der Leitliniengruppe.

\begin{tabular}{|c|c|c|}
\hline $\begin{array}{l}\text { Arbeits- } \\
\text { gruppe }\end{array}$ & Funktion & Name \\
\hline \multirow[t]{2}{*}{1} & Leiter & $\begin{array}{l}\text { Schirmacher, P (Heidelberg) } \\
\text { Timm, J* (Düsseldorf) }\end{array}$ \\
\hline & $\begin{array}{l}\text { weitere } \\
\text { Mitglieder }\end{array}$ & $\begin{array}{l}\text { Drebber, } \mathrm{U}^{*} \text { (Köln) } \\
\text { Friedrich-Rust, M (Frankfurt) } \\
\text { Holzmann, } \mathrm{H}^{*} \text { (Wien) } \\
\text { Kasper, HU (Münster) } \\
\text { Kessler, } \mathrm{H}^{*} \text { (Graz) } \\
\text { Niederau, C (Oberhausen) } \\
\text { Petersen, J* (Hamburg) } \\
\text { Protzer, U* (München) } \\
\text { Zeichhardt, H (Berlin) }\end{array}$ \\
\hline \multirow[t]{2}{*}{2} & Leiter & Wedemeyer, $\mathrm{H}^{*}$ (Essen) \\
\hline & $\begin{array}{l}\text { weitere } \\
\text { Mitglieder }\end{array}$ & $\begin{array}{l}\text { Ciesek, S* (Essen) } \\
\text { Gschwantler, M (Wien) } \\
\text { Reimer, J (Hamburg) } \\
\text { Schulze zur Wiesch, J* (Hamburg) } \\
\text { Steinmann, E* (Hannover) } \\
\text { Thimme, } \text { R }^{*} \text { (Freiburg) } \\
\text { Wiegand, J (Leipzig) } \\
\text { Zimmermann, R* (Berlin) }\end{array}$ \\
\hline \multirow[t]{2}{*}{3} & Leiter & Berg, T (Leipzig) \\
\hline & $\begin{array}{l}\text { weitere } \\
\text { Mitglieder }\end{array}$ & $\begin{array}{l}\text { Berg, C* (Tübingen) } \\
\text { Hinrichsen, } H^{*} \text { (Kiel) } \\
\text { Hüppe, D* (Herne) } \\
\text { Kautz, A* (Köln) } \\
\text { Kraus, M* (Burghausen) } \\
\text { Moradpour, D* (Lausanne) } \\
\text { Schäfer, M (Essen) } \\
\text { Teubner, G (Frankfurt) } \\
\text { Trauner, M* (Wien) }\end{array}$ \\
\hline \multirow[t]{2}{*}{4} & Leiter & Sarrazin, $C^{*}$ (Wiesbaden) \\
\hline & $\begin{array}{l}\text { weitere } \\
\text { Mitglieder }\end{array}$ & $\begin{array}{l}\text { Backmund, M (München) } \\
\text { Buggisch, P* (Hamburg) } \\
\text { Cornberg, } \text { M* (Hannover) }^{*} \\
\text { Ferenci, } \mathrm{P}^{*} \text { (Wien) } \\
\text { Langhorst, J (Essen) } \\
\text { Müllhaupt, B (Zürich) } \\
\text { Stauber, } \text { R }^{*} \text { (Graz) } \\
\text { Van Thiel, I* (Köln) } \\
\text { Vermehren, J* (Frankfurt) } \\
\text { Zimmermann, } \text { T* (Mainz) }^{*}\end{array}$ \\
\hline \multirow[t]{2}{*}{5} & Leiter & $\begin{array}{l}\text { Neumann, } U^{*} \text { (Aachen) } \\
\text { Schmidt, } \mathrm{HH}^{*} \text { (Münster) }\end{array}$ \\
\hline & $\begin{array}{l}\text { weitere } \\
\text { Mitglieder }\end{array}$ & $\begin{array}{l}\text { Beckebaum, S* (Münster) } \\
\text { Graziadei, I* (Hall) } \\
\text { Heinzow, } \text { H* (Münster) }^{*} \\
\text { Herzer, K* (Essen) } \\
\text { Sterneck, M* (Hamburg) } \\
\text { Strassburg, C (Bonn) } \\
\text { Welker, MW* (Frankfurt) }\end{array}$ \\
\hline
\end{tabular}

Tab. 2 (Fortsetzung)

\begin{tabular}{|c|c|c|}
\hline $\begin{array}{l}\text { Arbeits- } \\
\text { gruppe }\end{array}$ & Funktion & Name \\
\hline \multirow[t]{2}{*}{6} & Leiter & Spengler, U* (Bonn) \\
\hline & $\begin{array}{l}\text { weitere } \\
\text { Mitglieder }\end{array}$ & $\begin{array}{l}\text { Boesecke, C* (Bonn) } \\
\text { Christensen, } S^{*} \text { (Münster) } \\
\text { Ingiliz, P* (Berlin) } \\
\text { Klinker, H (Würzburg) } \\
\text { Mauss, S* (Düsseldorf) } \\
\text { Peck, M* (Klagenfurt) } \\
\text { Rauch, A (Bern) } \\
\text { Rockstroh, J (Bonn) }\end{array}$ \\
\hline \multirow[t]{2}{*}{7} & Leiter & Wirth, S* (Wuppertal) \\
\hline & $\begin{array}{l}\text { weitere } \\
\text { Mitglieder }\end{array}$ & $\begin{array}{l}\text { Gerner, P (Freiburg) } \\
\text { Lang, T (Starnberg) } \\
\text { Melter, M (Regensburg) } \\
\text { Pfister, ED (Hannover) }\end{array}$ \\
\hline \multicolumn{2}{|c|}{ AG-übergreifend } & Manns, M* (Hannover) \\
\hline \multicolumn{2}{|c|}{ Koordinatoren } & $\begin{array}{l}\text { Sarrazin, } C^{*} \text { (Wiesbaden) } \\
\text { Zeuzem, S (Frankfurt) }\end{array}$ \\
\hline \multicolumn{2}{|c|}{ Wissenschaftlicher Sekretär } & Zimmermann, $T^{*}$ (Mainz) \\
\hline
\end{tabular}

- Österreichische Gesellschaft für Gastroenterologie und Hepatologie (ÖGGH)

- Schweizerische Gesellschaft für Gastroenterologie (SGG)

- Deutsche Transplantationsgesellschaft e. V. (DTG)

- Deutsche Leberhilfe e. V.

- Deutsche Gesellschaft für Infektiologie e. V. (DGI)

- Deutsche Gesellschaft für Suchtmedizin e. V. (DGS)

- Deutsche AIDS-Gesellschaft e. V. (DAIG)

- Deutsche Arbeitsgemeinschaft niedergelassener Ärzte für die Versorgung HIV-Infizierter (DAGNÄ)

- Robert Koch-Institut (RKI)

\section{Methodologische Exaktheit}

Vor Beginn der Überarbeitung wurde das Procedere in einem Protokoll festgelegt.

\subsection{Recherche, Auswahl und Bewertung wissenschaftlicher Belege (Evidenzbasierung)}

\subsubsection{Formulierung von Schlüsselfragen}

Es wurde eine Priorisierung innerhalb der Leitlinie durchgeführt. Die AG-Leiter definierten dafür je AG Schlüsselfragen, die mit besonderer methodischer Sorgfalt bearbeitet werden sollten (siehe 3.1.5 und 3.1.6). Kriterien für die Auswahl von Schlüsselfragen waren: 
- besondere klinische Wichtigkeit,

- besondere klinische Häufigkeit,

- besondere Strittigkeit der Empfehlung zu dieser Frage oder

- besonders häufige fehlerhafte Anwendung in der klinischen Praxis.

Die Schlüsselfragen sind im Appendix (siehe 8.4) aufgeführt.

\subsubsection{Verwendung existierender Leitlinien zum Thema}

Bereits existierende Leitlinien (DGVS, ÖGGH, SGG, DGP, GfV, GPGE, AWMF, AASLD, EASL, ECC, EVHEI, APASL), die für die Erstellung der Vorversion der S3-Leitlinie verwendet wurden, wurden für die Aktualisierung dieser Leitlinie erneut gescreent. Da diese Leitlinien zum größten Teil jedoch zeitlich mit der alten Leitlinie überlappen, wurde auf eine Leitlinienadaptation verzichtet und die Beantwortung der Schlüsselfragen auf Basis einer De-novoRecherche durchgeführt.

\subsubsection{Systematische Literaturrecherche}

Eine orientierende Literaturrecherche zu den einzelnen Leitlinienkapiteln wurde zunächst von den einzelnen AGs selbstständig durchgeführt und an die Leitlinienkoordination übermittelt. Im Anschluss erfolgte für die Schlüsselfragen eine erneute zentrale Suche durch die Leitlinienkoordination mit den im Appendix angegebenen Suchstrings in Medline (siehe 8.5.2). Zu Fragestellungen, für die interventionelle Studien existierten, wurden keine Beobachtungsstudien erfasst und bewertet. Arbeiten, die bisher nur in Abstractform veröffentlicht waren, konnten grundsätzlich in die Leitlinie mit einfließen, wenn aus dem Abstract die Qualität der Methodik erkennbar und der Effekt groß war. Empfehlungen der alten Leitlinie, für die keine neue oder höhere Evidenz vorlag, wurden unverändert aus der alten Leitlinie übernommen. Daraufhin erfolgte eine zentrale Bewertung der Evidenz (siehe 3.1.4 und 8.6). Abschließend wurde die Literatur durch die einzelnen AGs kontrolliert und ergänzt.

\subsubsection{Auswahl der Evidenz}

Nach Durchführung der systematischen Literaturrecherche erfolgte ein Abstract- und Volltextscreening, welches zentral durchgeführt wurde. Im Verlauf der Leitlinienerstellung wurden allen Mitgliedern zu jeder Empfehlung die systematisch erfassten Originalzitate inklusive deren Bewertung zur Verfügung gestellt.

\subsubsection{Bewertung der Evidenz}

Die Bewertung der einzelnen Literaturstellen erfolgte anhand des Oxford-Schemas von 2011 (Details siehe Appendix 8.7).

\subsubsection{Erstellung von Evidenztabellen}

Zu den Schlüsselfragen der Empfehlungen wurden Evidenztabellen erstellt, die alle kontrollierten Arbeiten der jeweils höchsten Evidenzklasse erfassen (siehe Appendix 8.6). Wenn eine Empfehlung im Vergleich zur Vorversion der Leitlinie unverändert übernommen wurde, erfolgte keine erneute Aufnahme in die Evidenztabelle.

\subsection{Formulierung der Empfehlungen und strukturierte Konsensfindung}

Die Leitlinienentwicklung wurde innerhalb des Portals der Clinical Guidelines Services (www.leitlinienentwicklung.de) durchgeführt. Im Portal fanden die Teilnehmerverwaltung, Erfassung der Interessenkonflikterklärungen und die Onlineabstimmung über die Delphi-Runden statt.

\subsubsection{Formale Konsensfindung: Verfahren und Durchführung}

Zunächst erstellten die Arbeitsgruppen auf dem Boden der deutschen Leitlinie von 29.01.2010 und des Addendums vom Dezember 2016 einen ersten Entwurf für Empfehlungen. Nach einer Durchsicht der Empfehlungen durch die Leitlinien-Koordination, die dazu diente, Dopplungen auszuschließen und widersprüchliche Aussagen festzustellen, wurden die einzelnen Empfehlungen, falls notwendig, durch die AG-Leiter revidiert, bevor eine Abstimmung aller Empfehlungen durch die Leitlinienmitglieder auf dem Konsensustreffen erfolgte.

Die Konsensuskonferenz fand am 23.01.2016 in Düsseldorf statt. Dabei wurden die Empfehlungen im Plenum einzeln diskutiert. Hierfür wurden die Empfehlungen für alle Teilnehmer sichtbar auf eine Leinwand projiziert, Änderungen dokumentiert und dann mittels eines TED-Systems abgestimmt. Empfehlungen, die unverändert von der alten Leitlinie übernommen und in der Folge nicht geändert wurden, wurden nicht erneut abgestimmt.

Die Moderation der Konsensuskonferenz erfolgte durch P. Lynen, Berlin.

Empfehlungen, die keinen Konsens erzielten oder Empfehlungen, die aufgrund neuer Medikamentenzulassungen nach der Konsensuskonferenz überarbeitet werden mussten, wurden in zwei weiteren Delphi-Runden konsentiert.

Bei der Online-Abstimmung konnte bei allen Empfehlungen, denen die Teilnehmer nicht uneingeschränkt zustimmten, ein Kommentar mit einer Begründung abgegeben werden. Die Ergebnisse der Abstimmung einschließlich der Kommentare wurden an die Arbeitsgruppen zurückgespiegelt.

Nach Abschluss der Konsensusverfahren wurden die konsentierten Empfehlungen erneut in die Arbeitsgruppen und die gesamte Leitliniengruppe geschickt. Dabei wurden keine Einsprüche gegen einzelne Empfehlungen erhoben (siehe 3.2.4).

\subsubsection{Berücksichtigung von Nutzen, Nebenwirkungen- relevanten Outcomes}

Die Abwägung von möglichem Nutzen und Schaden einer Therapie bestimmten als primäres Kriterium die Stärke der Empfehlungen.

\subsubsection{Formulierung der Empfehlungen und Vergabe von Evidenzgraden und Empfehlungsstärken}

Die Evidenzgrade wurden auf dem Boden der Evidenzklassen entsprechend der Graduierung durch das Oxford Centre for Evidencebased Medicine von 2011 vergeben (Details siehe Appendix 8.7). 
- Tab. 3 Formulierung in Abhängigkeit der Evidenz- und Empfehlungsgrade.

\begin{tabular}{|l|l|l|l|}
\hline Formulierung & Evidenzgrad & Empfehlungsgrad & Empfehlungsstärke \\
\hline soll & I & A & starke Empfehlung \\
\hline sollte & II & B & Empfehlung \\
\hline kann & III und schlechter & 0 & Empfehlung offen \\
\hline
\end{tabular}

Die Stärke der Empfehlung drückt sich in der standardisierten Formulierung aus ( $\vee$ Tab. 3 ) und richtete sich nach den folgenden Kriterien:

- einer Nutzen-/Schaden-Abwägung zusammen mit

- dem Evidenzgrad,

- der vermuteten Patientenpräferenz sowie Konfidenz und Varianz derselben,

- der Anwendbarkeit im deutschen Gesundheitswesen und

- den Kosten.

Alle Empfehlungen mussten eine „soll“-, „sollte“- oder „kann“Formulierung, die Angabe des Evidenz- (I-V) und des Empfehlungsgrades (A, B, 0), sowie die entsprechenden Literaturstellen enthalten und wurden so zur Abstimmung gestellt ( $\downarrow$ Tab. 3). Bei fehlender Evidenz wurde die Empfehlung als Expertenkonsens klassifiziert.

Der Evidenzgrad kann dabei durchaus vom Empfehlungsgrad abweichen (das heißt eine A-Empfehlung bei Evidenzgrad II oder umgekehrt). Gründe wären zum Beispiel Inkonsistenz der Studienergebnisse, klinische Relevanz der Endpunkte und Effektstärken, Nutzen-Risiko-Verhältnis, Patientenpräferenz etc. und sollten dann angegeben werden. Bei fehlender Evidenz wurde die Empfehlung als Expertenkonsens klassifiziert.

Bei einem Evidenzgrad III oder schlechter konnte eine starke Empfehlung nur vergeben werden, wenn...

- eine sehr gute Evidenz für hohe Nebenwirkungen oder Kosten besteht,

- bei alternativen Therapien, für die eine gute Evidenz ihrer Wirksamkeit besteht, eine schwache Evidenz für vermehrte Risiken oder Kosten einer der beiden Therapien besteht,

- die Empfehlung sich auf eine lebensbedrohliche Situation bezieht oder

- bei einer alternativen Therapie mit nur schwacher Evidenz für eine bessere Wirkung eine starke Evidenz für Risiken oder Kosten besteht.

Die Konsensstärke ( $\triangleright$ Tab. 4) wurde aus der Zahl der abgegebenen Stimmen (ohne Enthaltungen) berechnet.

Bei einem starken Konsens konnte auf eine erneute Abstimmung verzichtet werden. Da die in die Empfehlungsstärke einfließenden Parameter nur implizit abgewogen wurden, soll die Konsensstärke die den einzelnen Faktoren zugrundeliegende Unsicherheit ausdrücken. Bei jeder Empfehlung wurden der Evidenzgrad, die Konsensstärke und die Empfehlungsstärke angegeben. Den Statements, die den aktuellen Wissensstand wieder-
- Tab. 4 Konsensstärken bei Abstimmung auf der Konsensuskonferenz oder in Delphi-Runden.

\begin{tabular}{|l|l|}
\hline starker Konsens & $\geq 95 \%$ Zustimmung \\
\hline Konsens & $\geq 75$ bis $95 \%$ Zustimmung \\
\hline mehrheitliche Zustimmung & 50 bis $75 \%$ Zustimmung \\
\hline kein Konsens & $<50 \%$ Zustimmung \\
\hline
\end{tabular}

geben, ohne eine Empfehlung zu formulieren, wurde keine Empfehlungsstärke zugeordnet.

\subsubsection{Manuskript}

Die AG-Leiter erstellten in Zusammenarbeit mit weiteren Mitgliedern der jeweiligen AG ein Manuskript, in dem die Empfehlungen kommentiert werden. Aufgabe der Erläuterungen und Kommentare sollte es sein, die einzelnen Empfehlungen zu begründen. Dies beinhaltete

- die gesamte der Empfehlung zugrundeliegende Literatur zu nennen und eventuell zu diskutieren, einschließlich der Diskussion nicht empfohlener, alternativer Vorgehensweisen,

- die der Empfehlung zugrundeliegenden Annahmen zu Nutzen-/Risiko-Abwägung, Patientenpräferenzen, Kosten und Umsetzbarkeit zu nennen, wo sich diese nicht offensichtlich ergeben,

- bei schwachen Empfehlungen zu diskutieren, welche Subgruppe von Patienten besonders von der Intervention profitieren oder nicht profitieren könnte und

- bei starker Inkongruenz von Evidenzgrad und Empfehlungsstärke diesen Unterschied zu begründen.

Im Kommentar sollten keine weiteren Therapieempfehlungen gegeben werden. Hinweise zur Umsetzung der Empfehlung sollten ebenfalls nicht im Text des Kommentares ausgeführt, sondern zum Beispiel als Referenz zu einer externen Quelle eingefügt werden. So sollte in den Kommentaren zwar diskutiert werden, warum alternative Therapien nicht empfohlen werden; in den Kommentaren sollten aber keine zusätzlichen versteckten Empfehlungen erscheinen und auch keine umfangreichen Hintergrundinformationen. Der wissenschaftliche Sekretär fügte die einzelnen Teile zu einem Gesamtmanuskript zusammen. 


\section{Externe Begutachtung und Verabschiedung}

\subsection{Pilottestung}

Eine Pilottestung ist nicht vorgesehen.

\subsection{Externe Begutachtung und Verabschiedung durch die Vorstände der herausgebenden Fachgesellschaf- ten und Organisationen}

Die vollständige Leitlinie wurde von allen Fachgesellschaften und der AWMF begutachtet und genehmigt.

\section{Redaktionelle Unabhängigkeit}

\subsection{Finanzierung der Leitlinie}

Die Finanzierung der Leitlinienerstellung erfolgte über die Deutsche Gesellschaft für Verdauungs- und Stoffwechselkrankheiten. Ohne das ehrenamtliche Engagement der Leitlinienteilnehmer wäre die Erstellung dieser Leitlinie nicht möglich gewesen. Eine Vergütung für die Mitarbeit an der Leitlinie erfolgte nicht. Reisekosten und rein projektbezogene Auslagen wurden dokumentiert und nach den üblichen Richtlinien abgerechnet. Eine finanzielle Unterstützung durch Dritte, insbesondere pharmazeutische Unternehmen, fand nicht statt.

\subsection{Darlegung von und Umgang mit potenziellen Interessenkonflikten}

Im Einklang mit dem AWMF-Regelwerk zum Umgang mit Interessenkonflikten gaben alle Teilnehmer Erklärungen dazu auf dem entsprechenden AWMF-Formular ab. Die Interessenkonflikte wurden von den Koordinatoren der Leitlinie und P. Lynen gesichtet und der Leitliniengruppe präsentiert. Die Mandatsträger der Leitlinie gaben eine Vielzahl potenzieller, direkter Interessenkonflikte an. Nach Einschätzung der Leitliniengruppe stellen die interdisziplinäre Besetzung der Leitliniengruppe und die systematische, extern durchgeführte Literaturrecherche und Bewertung wichtige Maßnahmen zum Ausgleich dieser potenziellen Interessenkonflikte dar. Mandatsträger mit personenbezogenen Zuwendungen (Zugehörigkeit zu Advisory Boards, Gutachter- und Vortragstätigkeit) wurden daher nach kritischer Bewertung durch die Leitliniengruppe nicht von den Abstimmungen ausgeschlossen, wenn die Art der Zuwendungen nicht einseitig (z. B. Zugehörigkeit zu mehreren Advisory Boards) und die wissenschaftliche Expertise nicht verzichtbar war. Finanzielle Zuwendungen, die ausschließlich wissenschaftlichen Institutionen zugeordnet werden konnten, führten nicht zu einer Stimmenthaltung (Drittmittel, Studienbeteili- gung). Mandatsträger, deren Interessenkonflikte nicht vorlagen, oder Mandatsträger mit Eigentümerinteressen (z. B. Patente, Aktienbesitz, Firmenzugehörigkeit) erhielten kein Stimmrecht.

\section{Verbreitung und Implementierung}

\subsection{Konzept zur Verbreitung und Implementierung}

Die Leitlinie wird in der Zeitschrift für Gastroenterologie, der Fachzeitschrift der Deutschen Gesellschaft für Gastroenterologie, Stoffwechsel- und Verdauungskrankheiten (DGVS), abgedruckt und somit bei allen Mitgliedern der Fachgesellschaft bekannt gemacht. Zusätzlich wird die Leitlinie auf der Homepage der DGVS und der AWMF kostenlos allen interessierten Personen zur Verfügung stehen.

\subsection{Unterstützende Materialien für die Anwendung der Leitlinie}

Unterstützende Materialien sind für die Anwendung der Leitlinie nicht vorgesehen. Der Therapieteil wird für Anwender regelmäßig aktualisiert.

\subsection{Messgrößen für das Monitoring: Qualitätsziele, Qualitätsindikatoren}

Nicht vorgesehen.

\section{Gültigkeitsdauer und Aktualisierungs- verfahren}

\subsection{Datum der letzten inhaltlichen Überarbeitung und Status}

Die systematische Literatursuche erfolgte vom 01.01.2013 bis zum 23.01.2016, für die AG4 (Therapie) bis zum Stichtag 31.07.2016. Die letzte inhaltliche Überarbeitung erfolgte zum Stichtag 31.12.2017.

\subsection{Aktualisierungsverfahren}

Die Gültigkeit der Leitlinie wird auf fünf Jahre geschätzt. Der Therapieteil (Kapitel 4) wird in Abhängigkeit von Neuzulassungen kurzfristig in Form eines Addendums aktualisiert. Dies ist notwendig aufgrund der raschen Weiterentwicklung, widersprüchlicher Informationen aus internationalen Leitlinien und fehlenden eindeutigen Therapiealgorithmen aus den Fachinformationen bei hohen Therapiekosten. Die Überarbeitung der Leitlinie wird durch den Leitlinienbeauftragten der DGVS initiiert werden. 


\section{Appendix}

\subsection{Zeitplan}

Tab. 5 Zeitplan der Leitlinie.

\begin{tabular}{|c|c|c|}
\hline Rubrik & Teilpunkt & Zeitraum \\
\hline \multirow[t]{4}{*}{ Initiierung } & Auftragserteilung durch den DGVS-Vorstand & $11 / 2015$ \\
\hline & Benennung der AG-Leiter & $11 / 2015$ \\
\hline & Festlegung eines Termins für die Konsensus-Konferenz & $11 / 2015$ \\
\hline & Auswahl der Leitlinienmitglieder & $12 / 2015$ \\
\hline Literaturrecherche & $\begin{array}{l}\text { Entwurf zu den Empfehlungen, Erstellung von Suchbegriffen für die } \\
\text { Literaturrecherche } \\
\text { Definition von priorisierten Schlüsselfragen }\end{array}$ & $01 / 2016$ \\
\hline Konferenz & $\begin{array}{l}\text { Konsensus-Konferenz } \\
\text { Abstimmung der Empfehlungen }\end{array}$ & 23.01 .2016 \\
\hline Nachbearbeitung & systematische Literaturrecherche und -auswertung & $01 / 2016-04 / 2016$ \\
\hline Online-Befragung & Delphi-Runden zur finalen Konsentierung & $09 / 2016-11 / 2016$ \\
\hline \multirow[t]{4}{*}{$\begin{array}{l}\text { Erstellung der Kommentare } \\
\text { und Erläuterungen in den AGs }\end{array}$} & $\begin{array}{l}\text { Überarbeitung der Empfehlungen durch die AG-Leiter und Diskussion } \\
\text { innerhalb der AGs }\end{array}$ & $01 / 2016-05 / 2017$ \\
\hline & Update Therapie nach Zulassungen & $11 / 2016$ \\
\hline & Online-Veröffentlichung des Addendums zur Therapie & $12 / 2016$ \\
\hline & Zusammenstellung der Leitlinie und des Leitlinienreports & $05 / 2017-08 / 2017$ \\
\hline \multirow[t]{2}{*}{ Nachbereitung } & $\begin{array}{l}\text { Durchsicht durch die Koordinatoren, AG-Leiter } \\
\text { Vorlage der Leitlinie bei der Leitlinienkommission der DGVS } \\
\text { Freigabe durch die Fachgesellschaften }\end{array}$ & $08 / 2017-12 / 2017$ \\
\hline & finale Version der Leitlinie & $12 / 2017$ \\
\hline
\end{tabular}

AG: Arbeitsgruppen. DGVS - Deutsche Gesellschaft für Gastroenterologie, Verdauungs- und Stoffwechselkrankheiten.

\subsection{Interessenkonflikterklärungen}

Vor Beginn der Leitlinien-Konferenz wurden potenzielle Interessenkonflikte mit Hilfe eines Formblattes über das Leitlinienportal (https://www.guideline-service.de) erfasst. Eine Teilnahme an der Leitlinie bei Nicht-Vorliegen der Interessenkonflikte war ausgeschlossen. Die Interessenkonflikte sind in $>$ Tab. 6 offengelegt.

- Tab. 6 Interessenkonflikte (Stand 04.10.2017).

1 Berater- bzw. Gutachtertätigkeit oder bezahlte Mitarbeit in einem wissenschaftlichen Beirat eines Unternehmens der Gesundheitswirtschaft (z. B. Arzneimittelindustrie, Medizinproduktindustrie), eines kommerziell orientierten Auftragsinstituts oder einer Versicherung

2 Honorare für Vortrags- und Schulungstätigkeiten oder bezahlte Autoren- oder Co-Autorenschaften im Auftrag eines Unternehmens der Gesundheitswirtschaft, eines kommerziell orientierten Auftragsinstituts oder einer Versicherung

3 finanzielle Zuwendungen (Drittmittel) für Forschungsvorhaben oder direkte Finanzierung von Mitarbeitern der Einrichtung vonseiten eines Unternehmens der Gesundheitswirtschaft, eines kommerziell orientierten Auftragsinstituts oder einer Versicherung

4 Eigentümerinteresse an Arzneimitteln/Medizinprodukten (z. B. Patent, Urheberrecht, Verkaufslizenz)

5 Besitz von Geschäftsanteilen, Aktien, Fonds mit Beteiligung von Unternehmen der Gesundheitswirtschaft

6 persönliche Beziehungen zu einem Vertretungsberechtigten eines Unternehmens der Gesundheitswirtschaft

7 Mitglied von in Zusammenhang mit der Leitlinienentwicklung relevanten Fachgesellschaften/Berufsverbänden, Mandatsträger im Rahmen der Leitlinienentwicklung

8 politische, akademische (z. B. Zugehörigkeit zu bestimmten „Schulen“), wissenschaftliche oder persönliche Interessen, die mögliche Konflikte begründen könnten

9 gegenwärtiger Arbeitgeber, relevante frühere Arbeitgeber der letzten 3 Jahre 


\begin{tabular}{|c|c|c|c|c|}
\hline & Friedrich-Rust, Mireen & Niederau, Claus & Berg, Christoph & Berg, Thomas \\
\hline 1 & nein & $\begin{array}{l}\text { ja: MSD, BMS, Falk, Genzyme, } \\
\text { Shire, Janssen, Roche, Gilead, } \\
\text { Alexion, Abbvie }\end{array}$ & $\begin{array}{l}\text { ja: Abbvie, BMS, Gilead, Janssen, } \\
\text { MSD, Roche }\end{array}$ & $\begin{array}{l}\text { ja: Advisory Board: Abbvie, BMS, } \\
\text { Boehringer-Ingelheim, Gilead, } \\
\text { Janssen, Novartis, Merck/Schering- } \\
\text { Plough (Merck), Roche, Vertex }\end{array}$ \\
\hline 2 & nein & $\begin{array}{l}\text { ja: MSD, BMS, Falk, Genzyme, } \\
\text { Shire, Janssen, Roche, Gilead, } \\
\text { Alexion, Abbvie }\end{array}$ & $\begin{array}{l}\text { ja: Abbvie, BMS, Gilead, Janssen, } \\
\text { MSD, Roche }\end{array}$ & $\begin{array}{l}\text { ja: Honorare für Vortragstätigkei- } \\
\text { ten: Abbvie, BMS, Boehringer- } \\
\text { Ingelheim, Gilead, Janssen, } \\
\text { Novartis, Merck/Schering-Plough } \\
\text { (Merck), Roche, Vertex }\end{array}$ \\
\hline 3 & nein & ja: MSD & $\begin{array}{l}\text { ja: Abbvie, BMS, Gilead, Janssen, } \\
\text { MSD, Roche }\end{array}$ & $\begin{array}{l}\text { ja: Finanzielle Zuwendungen } \\
\text { (Drittmittel) für Forschungsvor- } \\
\text { haben: Abbvie, BMS, Boehringer- } \\
\text { Ingelheim, Gilead, Janssen, } \\
\text { Novartis, Roche, }\end{array}$ \\
\hline 4 & nein & nein & nein & nein \\
\hline 5 & nein & nein & nein & nein \\
\hline 6 & nein & nein & nein & nein \\
\hline 7 & nein & ja: DGVS & ja: DGVS, GASL, BVGD & ja: Mitglied der DGVS \\
\hline 8 & nein & nein & nein & nein \\
\hline 9 & Universitätsklinikum Frankfurt & $\begin{array}{l}\text { Katholische Kliniken Oberhausen } \\
\text { GmbH }\end{array}$ & Universitätsklinikum Tübingen & Universitätsklinikum Leipzig \\
\hline & Trauner, Michael & Buggisch, Peter & Müllhaupt, Beat & van Thiel, Ingo \\
\hline 1 & $\begin{array}{l}\text { ja: Abbvie, Albireo, BMS, Falk, } \\
\text { Gilead, Intercept, MSD, Phenex }\end{array}$ & $\begin{array}{l}\text { ja: Berater für AbbVie, BMS, } \\
\text { Gilead, Janssen, MSD }\end{array}$ & $\begin{array}{l}\text { ja: Gilead, Janssen, Intercept, } \\
\text { BMS, Abbvie, MSD, Bayer, Roche, } \\
\text { Novartis, Boehringer-Ingelheim, } \\
\text { Biotest }\end{array}$ & nein \\
\hline 2 & ja: MSD & $\begin{array}{l}\text { ja: Vortragstätigkeit AbbVie, BMS, } \\
\text { Gilead, Janssen, MSD }\end{array}$ & $\begin{array}{l}\text { ja: Gilead, Janssen, BMS, Abbvie, } \\
\text { Bayer, Roche, Novartis, Boehrin- } \\
\text { ger-Ingelheit }\end{array}$ & nein \\
\hline 3 & ja: Albireo, Falk, Intercept & nein & ja: Roche, Gilead & nein \\
\hline 4 & $\begin{array}{l}\text { ja: Miterfinder, Patent der medizi- } \\
\text { nischen Universität Graz zur klini- } \\
\text { schen Anwendung der norUDCA }\end{array}$ & nein & nein & nein \\
\hline 5 & nein & nein & nein & nein \\
\hline 6 & nein & nein & nein & nein \\
\hline 7 & ja: ÖGGH & ja: Mitglied im BNG & $\begin{array}{l}\text { ja: Vorstandsmitglied der } \\
\text { Schweizerischen Gesellschaft für } \\
\text { Gastroenterologie (SGG) und der } \\
\text { Schweizerischen Arbeitsgemein- } \\
\text { schaft zum Studium der Leber } \\
\text { (SASL) }\end{array}$ & ja: Deutsche Leberhilfe e. V. \\
\hline 8 & nein & nein & nein & $\begin{array}{l}\text { ja: Keine persönlichen finanziellen } \\
\text { Zuwendungen durch Herstellerfir- } \\
\text { men. Der Arbeitgeber Deutsche } \\
\text { Leberhilfe e. V. erhält projektbe- } \\
\text { zogenes Sponsoring von Herstel- } \\
\text { lerfirmen (Auflistung auf: http:// } \\
\text { www.leberhilfe.org/dokumenta- } \\
\text { tion-zusammenarbeit-wirtschaft. } \\
\text { html). }\end{array}$ \\
\hline 9 & Medizinische Universität Wien & IFI-Institut Hamburg & Universitätsspital Zürich & $\begin{array}{l}\text { Deutsche Leberhilfe e. V. Krieler } \\
\text { Str. } 10050935 \text { Köln Tel.: 0221/28 } \\
29980 \text { E-Mail (allgemein): in- } \\
\text { fo@leberhilfe.org Internet: } \\
\text { www.leberhilfe.org }\end{array}$ \\
\hline
\end{tabular}


- Tab.6 (Fortsetzung)

\begin{tabular}{|c|c|c|c|c|}
\hline & Schmidt, Hartmut & Graziadei, Ivo & Herzer, Kerstin & Strassburg, Christian P. \\
\hline 1 & nein & $\begin{array}{l}\text { ja: Teilnahme an Advisory Bo- } \\
\text { ards: Gilead, MSD, AbbVie, BMS }\end{array}$ & $\begin{array}{l}\text { ja: Bristol-Myers Squibb, Janssen } \\
\text { Pharmaceuticals, Novartis, Chiesi }\end{array}$ & nein \\
\hline 2 & nein & $\begin{array}{l}\text { ja: Vortragstätigkeit für folgende } \\
\text { Firmen: Gilead, MSD, AbbVie, } \\
\text { BMS, Janssen }\end{array}$ & $\begin{array}{l}\text { ja: AbbVie, Biotest, Bristol-Myers } \\
\text { Squibb, Gilead Sciences, Janssen } \\
\text { Pharmaceuticals, Roche, Novar- } \\
\text { tis, Astellas }\end{array}$ & $\begin{array}{l}\text { ja: Vortragshonorare BMS, } \\
\text { Abbvie, Gilead. }\end{array}$ \\
\hline 3 & nein & nein & $\begin{array}{l}\text { ja: Novartis, Biotest, Astellas, } \\
\text { Bristol-Myers Squibb, Gilead Sci- } \\
\text { ences, Janssen Pharmaceuticals }\end{array}$ & nein \\
\hline 4 & nein & nein & nein & nein \\
\hline 5 & nein & nein & nein & nein \\
\hline 6 & nein & nein & nein & nein \\
\hline 7 & nein & ja: Mitglied ÖGGH & ja: DGVS, DTG & ja: DGVS, DTG \\
\hline 8 & nein & nein & $\begin{array}{l}\text { ja: Mitglied der AG Richtlinien/ } \\
\text { Lebertransplantation der STÄKO } \\
\text { der BÄK }\end{array}$ & $\begin{array}{l}\text { ja: wissenschaftlicher Beirat } \\
\text { BÄK, Federführung AG RiLi } \\
\text { BÄK Leber StäKO }\end{array}$ \\
\hline \multirow[t]{2}{*}{9} & Universitätsklinikum Münster & $\begin{array}{l}\text { Tirol Kliniken + Medizinische Uni- } \\
\text { versität Innsbruck }\end{array}$ & Universitätsklinikum Essen & Universitätsklinikum Bonn \\
\hline & Spengler, Ulrich & Wirth, Stefan & Gerner, Patrick & Melter, Michael \\
\hline 1 & $\begin{array}{l}\text { ja: Beratung für verschiedene Fir- } \\
\text { men bzgl. HCV-Therapie (Gilead, } \\
\text { Janssen, MSD, Abbvie, BMS) }\end{array}$ & $\begin{array}{l}\text { ja: Beratung Novartis, Roche, } \\
\text { Nestlé }\end{array}$ & nein & nein \\
\hline 2 & $\begin{array}{l}\text { ja: Vorträge zur HCV-Therapie } \\
\text { (Gilead, Janssen, MSD, Abbvie, } \\
\text { BMS) }\end{array}$ & nein & ja: AbbVie, Vortragshonorare & nein \\
\hline 3 & nein & nein & nein & nein \\
\hline 4 & nein & nein & nein & nein \\
\hline 5 & nein & nein & nein & nein \\
\hline 6 & nein & nein & nein & nein \\
\hline 7 & ja: Mitglied der DGVS & $\begin{array}{l}\text { ja: GPGE-Mitglied Vorsitzender } \\
\text { der Leitlinienkommission der } \\
\text { DGKJ }\end{array}$ & ja: GPGE & nein \\
\hline 8 & nein & nein & nein & nein \\
\hline \multirow[t]{2}{*}{9} & UK Bonn & $\begin{array}{l}\text { 1. HELIOS Klinikum Wuppertal } \\
\text { 2. Universität Witten/Herdecke }\end{array}$ & $\begin{array}{l}\text { Universitätskinderklinik Freiburg, } \\
\text { Mathildenstraße 1, } 79106 \text { Frei- } \\
\text { burg }\end{array}$ & $\begin{array}{l}\text { Uniklinikum Regensburg Franz- } \\
\text { Josef-Strauß-Allee } 11 \text { Regensburg } \\
93053 \text { und Klinik St. Hedwig der } \\
\text { Barmherzigen Brüder Regens- } \\
\text { burg Steinmetzstraße 1-3, } \\
93049 \text { Regensburg }\end{array}$ \\
\hline & Pfister, Eva-Doreen & Vermehren, Johannes & Cornberg, Markus & Timm, Jörg \\
\hline 1 & nein & ja: Abbott Molecuar AbbVie & $\begin{array}{l}\text { ja: Beratertätigkeit Abbvie, } \\
\text { Bristol-Myers-Squibb, Gilead, } \\
\text { Janssen-Cilag, MSD Sharp \& } \\
\text { Dohme (Merck), Roche }\end{array}$ & nein \\
\hline 2 & nein & $\begin{array}{l}\text { ja: Abbott Molecuar AbbVie Bris- } \\
\text { tol-Myers Squibb Covidien Gilead } \\
\text { Sciences }\end{array}$ & $\begin{array}{l}\text { ja: Vortragshonorare Abbvie, } \\
\text { Boehringer Ingelheim, Bristol- } \\
\text { Myers-Squibb, Gilead, Janssen- } \\
\text { Cilag, MSD Sharp \& Dohme } \\
\text { (Merck), Roche }\end{array}$ & $\begin{array}{l}\text { ja: Honorar für Vortragstätigkeit } \\
\text { von BMS }\end{array}$ \\
\hline
\end{tabular}




\section{- Tab. 6 (Fortsetzung)}

\begin{tabular}{|c|c|c|c|c|}
\hline 3 & nein & nein & $\begin{array}{l}\text { ja: Drittmittel für Forschungsvor- } \\
\text { haben (Forschungspreis) Gilead, } \\
\text { Drittmittel für Forschungsvorha- } \\
\text { ben MSD Sharp \& Dohme } \\
\text { (Merck), Roche }\end{array}$ & nein \\
\hline 4 & nein & nein & nein & nein \\
\hline 5 & nein & nein & nein & nein \\
\hline 6 & nein & nein & nein & nein \\
\hline 7 & $\begin{array}{l}\text { ja: Mitglied in der GPGE, Degum, } \\
\text { DGKJ sowie ESPGHAN, involviert } \\
\text { auch in der LL Entwicklung neo- } \\
\text { natale Cholestase der GPGE }\end{array}$ & nein & $\begin{array}{l}\text { ja: Mitglied der Deutschen Gesell- } \\
\text { schaft für Gastroenterologie, Ver- } \\
\text { dauungs- und Stoffwechselkrank- } \\
\text { heiten (DGVS), Medizinischer } \\
\text { Geschäftsführer der Deutschen } \\
\text { Leberstiftung, Mitglied in der } \\
\text { Deutschen Gesellschaft für } \\
\text { Infektiologie (DGI), Mitglied in } \\
\text { der Paul-Ehrlich-Gesellschaft für } \\
\text { Chemotherapie (p-e-g), Mitglied } \\
\text { in der Deutschen Gesellschaft für } \\
\text { Innere Medizin (DGIM), Mitglied } \\
\text { der European Association for the } \\
\text { Study of The Liver (EASL). }\end{array}$ & $\begin{array}{l}\text { ja: Gesellschaft für Virologie } \\
\text { Deutsche Gesellschaft für } \\
\text { Hygiene und Mikrobiologie }\end{array}$ \\
\hline 8 & nein & nein & nein & nein \\
\hline \multirow[t]{2}{*}{9} & $\begin{array}{l}\text { Pädiatrische Gastroenterologie } \\
\text { und Hepatologie Kinderklinik der } \\
\text { Med. Hochschule Hannover }\end{array}$ & Universitätsklinikum Frankfurt & $\begin{array}{l}\text { Medizinische Hochschule } \\
\text { Hannover }\end{array}$ & $\begin{array}{l}\text { seit 8/2014 Universitätsklinikum } \\
\text { Düsseldorf, vorher Universitäts- } \\
\text { klinikum Essen }\end{array}$ \\
\hline & Beckebaum, Susanne & Zimmermann, Ruth & Peck, Markus & Ciesek, Sandra \\
\hline 1 & $\begin{array}{l}\text { ja: siehe meine Erklärung bei AILE } \\
\text { LL }\end{array}$ & nein & $\begin{array}{l}\text { ja: AbbVie, Bayer, Boehringer- } \\
\text { Ingelheim, BMS, Gilead, MSD }\end{array}$ & nein \\
\hline 2 & nein & nein & $\begin{array}{l}\text { ja: AbbVie, Bayer, Boehringer-In- } \\
\text { gelheim, BMS, Gilead, MSD, Ro- } \\
\text { che }\end{array}$ & nein \\
\hline 3 & ja: siehe AILE LL & nein & ja: AbbVie, Gilead, Roche, MSD & nein \\
\hline 4 & nein & nein & nein & nein \\
\hline 5 & nein & nein & nein & nein \\
\hline 6 & nein & nein & nein & nein \\
\hline 7 & ja: siehe Erklärung AILE-LL & nein & ja: ÖGGH, EASL & ja: DGVS Mitglied \\
\hline 8 & nein & nein & nein & nein \\
\hline \multirow[t]{2}{*}{9} & siehe AILE-LL & Robert Koch-Institut (seit 2008) & $\begin{array}{l}\text { - KABEG, Klinikum Klagenfurt am } \\
\text { Wörthersee } \\
\text { - Medizinische Universität Wien }\end{array}$ & $\begin{array}{l}\text { Uniklinikum Essen (seit 03/2016), } \\
\text { Medizinische Hochschule Hanno- } \\
\text { ver (bis } 02 / 2016 \text { ) }\end{array}$ \\
\hline & Schirmacher, Peter & Christensen, Stefan & Ross, Stefan & Kessler, Harald \\
\hline 1 & ja: MSD, BMS, Novartis & $\begin{array}{l}\text { ja: Abbvie, BMS, Gilead, Janssen- } \\
\text { Cilag, MSD, ViiV-Healthcare }\end{array}$ & nein & $\begin{array}{l}\text { ja: Beratertätigkeit für Roche } \\
\text { Molecular Systems, Hologic, } \\
\text { Beckman-Coulter und GenMark }\end{array}$ \\
\hline 2 & nein & $\begin{array}{l}\text { ja: Abbvie, BMS, Gilead, Hexal., } \\
\text { Janssen-Cilag, MSD, Reckitt- } \\
\text { Benckiser, ViiV-Healthcare }\end{array}$ & $\begin{array}{l}\text { ja: Siemens Healthcare Abbott } \\
\text { Molecular }\end{array}$ & nein \\
\hline 3 & Ja: Novartis & nein & $\begin{array}{l}\text { ja: Siemens Healthcare Abbott } \\
\text { Molecular }\end{array}$ & nein \\
\hline 4 & nein & nein & nein & nein \\
\hline 5 & k.A. & nein & nein & nein \\
\hline 6 & nein & nein & nein & nein \\
\hline
\end{tabular}




\section{- Tab. 6 (Fortsetzung)}

\begin{tabular}{|c|c|c|c|c|}
\hline 7 & $\begin{array}{l}\text { ja: Deutsche Gesellschaft } \\
\text { für Pathologie, ESMO, ILCA, EASL, } \\
\text { ESP }\end{array}$ & $\begin{array}{l}\text { ja: Mitglied: DGI, DAIG, AGNÄ- } \\
\text { WL, assoziierter Arzt der Deut- } \\
\text { schen Leberstiftung, Vorstands- } \\
\text { mitglied der dagnä e. V. }\end{array}$ & $\begin{array}{l}\text { ja: Deutsche Gesellschaft für } \\
\text { Virologie, Deutsche Vereinigung } \\
\text { zur Bekämpfung der Viruskrank- } \\
\text { heiten, Deutsche Vereinte Ge- } \\
\text { sellschaft für Klinische Chemie } \\
\text { und Laboratoriumsmedizin }\end{array}$ & nein \\
\hline 8 & nein & nein & nein & nein \\
\hline \multirow[t]{2}{*}{9} & $\begin{array}{l}\text { Land Baden-Württemberg, } \\
\text { Universitätsklinik Heidelberg } \\
\text { (seit 2004) }\end{array}$ & Selbstständig tätig & Universitätsklinikum Essen; keine & Medizinische Universität Graz \\
\hline & Ferenci, Peter & Welker, Martin Walter & Gschwantler, Michael & Wedemeyer, Hans Heinrich \\
\hline 1 & $\begin{array}{l}\text { ja: Gilead Austria Merck/MSD } \\
\text { global., Europe Abbvie global., } \\
\text { Austria BMS Europe, Austria } \\
\text { Roche Global Rottapharm Idenix } \\
\text { Achilleon }\end{array}$ & nein & ja: BMS, MSD, Gilead, AbbVie & $\begin{array}{l}\text { ja: Abbvie, Abbott, BMS, Boehrin- } \\
\text { ger Ingelheim, Eiger, Gilead, } \\
\text { Janssen Cilag, Norgine, Roche, } \\
\text { Merck, Roche Diagnostics, }\end{array}$ \\
\hline 2 & $\begin{array}{l}\text { ja: Gilead Austria, Abbvie Austria, } \\
\text { Merz }\end{array}$ & $\begin{array}{l}\text { ja: Consultancies/speakers fees: } \\
\text { Amgen, Bayer, BMS, Gilead, } \\
\text { Novartis, Roche. Travel Support: } \\
\text { Astellas, Bayer, BMS, Novartis, } \\
\text { Janssen, Roche }\end{array}$ & ja: BMS, MSD, Gilead, AbbVie & $\begin{array}{l}\text { ja: Abbvie, Abbott, BMS, Boehrin- } \\
\text { ger Ingelheim, Eiger, Gilead, } \\
\text { Janssen Cilag, Norgine, Roche, } \\
\text { Merck, Roche Diagnostics, }\end{array}$ \\
\hline 3 & ja: Roche bis 2014 Gliead 2015- & nein & nein & $\begin{array}{l}\text { ja: Abbvie, Abbott, BMS, Boehrin- } \\
\text { ger Ingelheim, Gilead, Janssen } \\
\text { Cilag, Roche, Merck, Roche Diag- } \\
\text { nostics, }\end{array}$ \\
\hline 4 & $\begin{array}{l}\text { ja: iv. Silibinin für HCV, } \\
\text { Rottapharm }\end{array}$ & nein & nein & nein \\
\hline 5 & nein & nein & nein & nein \\
\hline 6 & nein & nein & nein & nein \\
\hline 7 & nein & ja: DGVS, BDI, Hartmannbund & nein & $\begin{array}{l}\text { ja: DGVS, Deutsche Leberstif- } \\
\text { tung, EASL, AASLD, Paul-Ehrlich } \\
\text { Gesellschaft, DGIM }\end{array}$ \\
\hline 8 & nein & nein & nein & nein \\
\hline \multirow[t]{2}{*}{9} & Medizinische Universität Wien & $\begin{array}{l}\text { Universitätsklinikum Frankfurt } \\
\text { (seit 2007) }\end{array}$ & Gemeinde Wien & $\begin{array}{l}\text { Medizinische Hochschule } \\
\text { Hannover }\end{array}$ \\
\hline & Reimer, Jens & Rockstroh, Jürgen & Kraus, Michael & Wiegand, Johannes \\
\hline 1 & ja: Gilead Sciences & nein & $\begin{array}{l}\text { ja: Abbvie, BMS, Gilead, Janssen, } \\
\text { Merck/MSD }\end{array}$ & ja: Gilad, BMS, Abbvie, Janssen \\
\hline 2 & ja: Gilead, Janssen Cilag, MSD & $\begin{array}{l}\text { ja: Honorare für Vorträge bei } \\
\text { Fortbildungsveranstaltungen von } \\
\text { Abbvie, BMS, Gilead, Merck, } \\
\text { Janssen und ViiV. }\end{array}$ & $\begin{array}{l}\text { ja: Abbvie, BMS, Gilead, Janssen, } \\
\text { Merck/MSD }\end{array}$ & ja: Gilad, BMS, Abbvie, Janssen \\
\hline 3 & $\begin{array}{l}\text { ja: Gilead, Janssen Cilag, Bristol } \\
\text { Myers Squibb }\end{array}$ & nein & nein & ja: Siemens \\
\hline 4 & nein & nein & nein & nein \\
\hline 5 & nein & nein & nein & nein \\
\hline 6 & nein & nein & nein & nein \\
\hline 7 & ja: Erstellung der HCV-Leitlinie & $\begin{array}{l}\text { ja: Mitglied bei EACS Hepatitis } \\
\text { Ko-Infektions-Leitlinie }\end{array}$ & nein & nein \\
\hline 8 & nein & nein & nein & nein \\
\hline 9 & $\begin{array}{l}\text { Gesundheit Nord Bremen, } \\
\text { Universitätsklinikum Hamburg- } \\
\text { Eppendorf }\end{array}$ & Universitätsklinikum Bonn & $\begin{array}{l}\text { Kreiskliniken Altötting- } \\
\text { Burghausen }\end{array}$ & Universität Leipzig \\
\hline
\end{tabular}




\section{- Tab. 6 (Fortsetzung)}

\begin{tabular}{|c|c|c|c|c|}
\hline & Klinker, Hartwig & Thimme, Robert & Sterneck, Martina & Petersen, Jörg \\
\hline 1 & $\begin{array}{l}\text { ja: Beratertätigkeit/Mitarbeit in } \\
\text { Advisory Boards für die Firmen } \\
\text { AbbVie, BMS, Boehringer, Gilead, } \\
\text { Hexal., Janssen, MSD }\end{array}$ & $\begin{array}{l}\text { ja: Beratertätigkeit für AbbVie, } \\
\text { Gilead, MSD }\end{array}$ & nein & $\begin{array}{l}\text { ja: Grant/Research Support BMS, } \\
\text { Novartis, Roche Consultant/Advi- } \\
\text { sor Abbott, AbbVie, BMS, Boeh- } \\
\text { ringer, Gilead, GSK, Kedrion, Jans- } \\
\text { sen, Merck, Merz, MSD, Novartis, } \\
\text { Roche }\end{array}$ \\
\hline 2 & $\begin{array}{l}\text { ja: Vortragstätigkeit für die Firmen } \\
\text { AbbVie, BMS, Boehringer, Falk, } \\
\text { Gilead, Janssen, MSD, Roche, ViiV }\end{array}$ & ja: AbbVie, Gilead, MSD & $\begin{array}{l}\text { ja: Tätigkeit im oben genannten } \\
\text { Rahmen für Janssen, Bristol- } \\
\text { Myers Squibb, Gilead, Abbvie, } \\
\text { Roche, Novartis, Astellas }\end{array}$ & $\begin{array}{l}\text { ja: Sponsored lectures (National } \\
\text { or International) Abbott, BMS, } \\
\text { Boehringer, Falk, Gilead, Kedrion, } \\
\text { Janssen, Merck, Merz, MSD, } \\
\text { Novartis, Roche }\end{array}$ \\
\hline 3 & $\begin{array}{l}\text { ja: Drittmittel für Forschungsvor- } \\
\text { haben/klinische Studien der Fir- } \\
\text { men AbbVie, Arrowhead, Boeh- } \\
\text { ringer, BMS, Gilead, GSK, Janssen, } \\
\text { MSD, Novartis, Roche, ScheBo, } \\
\text { ViiV }\end{array}$ & nein & $\begin{array}{l}\text { ja: Teilnahme an Phase-III-Studie } \\
\text { zur Therapie von Transplantati- } \\
\text { onspatienten. Sponsor: Janssen }\end{array}$ & nein \\
\hline 4 & nein & nein & nein & nein \\
\hline 5 & nein & nein & nein & nein \\
\hline 6 & nein & nein & nein & nein \\
\hline 7 & ja: DGI, DGIM, DGVS & nein & $\begin{array}{l}\text { ja: Mitglied der DTG und Mitglied } \\
\text { der DGVS }\end{array}$ & ja: Mitglied bng, DGVS \\
\hline 8 & nein & nein & nein & nein \\
\hline 9 & $\begin{array}{l}\text { Universitätsklinikum Würzburg } \\
\text { seit } 1982\end{array}$ & $\begin{array}{l}\text { Uniklinik Freiburg } \\
\text { Hugstetter Str. } 5579106 \text { Freiburg }\end{array}$ & $\begin{array}{l}\text { Universitätskrankenhaus Ham- } \\
\text { burg Eppendorf (UKE) und Medi- } \\
\text { zinisches Versorgungszentrum } \\
\text { des UKE }\end{array}$ & $\begin{array}{l}\text { selbstständig: Prof. Dr. Jörg } \\
\text { Petersen Ärztliche Leitung Leber- } \\
\text { zentrum Hamburg im IFI Institut } \\
\text { für Interdisziplinäre Medizin an } \\
\text { der Asklepios Klinik St. Georg } \\
\text { Haus L Lohmühlenstr. } 520099 \\
\text { Hamburg Tel.: + } 49402840760 \\
\text { 0 Fax: + } 49402840760222 \\
\text { email: petersen@ifi-medizin.de }\end{array}$ \\
\hline & Kautz, Achim & Mauss, Stefan & Vogel, Wolfgang & Boesecke, Christoph \\
\hline 1 & nein & $\begin{array}{l}\text { ja: AbbVie, Boehringer-Ingel- } \\
\text { heim, BMS, Gilead, Janssen, MSD, } \\
\text { ViiV }\end{array}$ & nein & $\begin{array}{l}\text { ja: Honorare für Beratertätigkeit } \\
\text { von abbvie, BMS, Gilead, Janssen, } \\
\text { MSD, ViiV. }\end{array}$ \\
\hline 2 & $\begin{array}{l}\text { ja: Vortragshonorare von Abbvie, } \\
\text { BMS, Gilead, Janssen, }\end{array}$ & $\begin{array}{l}\text { ja: AbbVie, Boehringer- } \\
\text { Ingelheim, BMS, Gilead, Janssen, } \\
\text { MSD, ViiV }\end{array}$ & nein & $\begin{array}{l}\text { ja: Honorare für Vorträge von } \\
\text { abbvie, BMS, Gilead, Janssen, } \\
\text { MSD, ViiV. }\end{array}$ \\
\hline 3 & $\begin{array}{l}\text { ja: Zuwendungen von Abbvie, } \\
\text { BMS, Gilead }\end{array}$ & nein & nein & $\begin{array}{l}\text { ja: Grants von NEAT ID und } \\
\text { Deutsche Leberstiftung. }\end{array}$ \\
\hline 4 & nein & nein & nein & nein \\
\hline 5 & nein & nein & nein & nein \\
\hline 6 & nein & nein & nein & nein \\
\hline 7 & nein & $\begin{array}{l}\text { ja: Berufsverband niedergelasse- } \\
\text { ner Gastroenterologen, dagnä, } \\
\text { DGVS }\end{array}$ & ja: ÖGGH & $\begin{array}{l}\text { ja: Mitglied Deutsche AIDS Ge- } \\
\text { sellschaft (DAIG), Schatzmeister } \\
\text { der Sektion KAAD der DAIG, } \\
\text { Mitglied Deutschen Gesellschaft } \\
\text { für Infektiologie (DGI) }\end{array}$ \\
\hline 8 & nein & nein & nein & nein \\
\hline 9 & $\begin{array}{l}\text { Deutsche Leberhilfe e. V., ELPA } \\
\text { (European LIver Patient Associa- } \\
\text { tion), Leberhilfe Projekt gUG }\end{array}$ & selbstständig & $\begin{array}{l}\text { Medizinische Universität } \\
\text { Innsbruck }\end{array}$ & Universitätsklinikum Bonn \\
\hline
\end{tabular}


- Tab. 6 (Fortsetzung)

\begin{tabular}{|c|c|c|c|c|}
\hline & Steinmann, Eike & Langhorst, Jost & Ingiliz, Patrick & Schäfer, Martin \\
\hline 1 & $\begin{array}{l}\text { ja: Wissenschaftlicher Beirat } \\
\text { Dr. Brill und Partner }\end{array}$ & $\begin{array}{l}\text { ja: Medizinverlage Stuttgart; } \\
\text { Steigerwald Arzneimittelwerke } \\
\text { GmbH; Repha GmbH, CGC } \\
\text { Gesundheitsconsulting, Ferring } \\
\text { Arzneimittel GmbH }\end{array}$ & ja: Gilead, Abbvie & ja: Abbvie Deutschland, Servier \\
\hline 2 & nein & $\begin{array}{l}\text { ja: Falk Foundation, MSD Sharp \& } \\
\text { Dohme GmbH, Repha GmbH } \\
\text { biologische Arzneimittel, Ardey- } \\
\text { pharm GmbH, Celgene GmbH, } \\
\text { Dr. Wilmar Schwabe GmbH }\end{array}$ & $\begin{array}{l}\text { ja: Gilead, Abbvie, BMS, MSD, } \\
\text { Janssen-Cilag }\end{array}$ & ja: Hexal., Servier, Janssen, Roche \\
\hline 3 & nein & $\begin{array}{l}\text { ja: Steigerwald Arzneimittelwer- } \\
\text { ke GmbH; Falk Foundation; Tech- } \\
\text { Lab, Dr. Wilmar Schwabe; Repha } \\
\text { GmbH biologische Arzneimittel }\end{array}$ & nein & nein \\
\hline 4 & nein & nein & nein & nein \\
\hline 5 & nein & nein & nein & nein \\
\hline 6 & nein & nein & nein & nein \\
\hline 7 & $\begin{array}{l}\text { ja: Deutsche Gesellschaft für } \\
\text { Virologie }\end{array}$ & $\begin{array}{l}\text { ja: Leitlinienbeauftragter der Ge- } \\
\text { sellschaft für Phytotherapie und } \\
\text { der Deutschen Gesellschaft für } \\
\text { Naturheilkunde, Sprecher der AG } \\
\text { Psychosomatik in der Gastroente- } \\
\text { rologie der Deutschen Gesell- } \\
\text { schaft für Gastroenterologie, } \\
\text { Deutsche Schmerzgesellschaft, } \\
\text { Deutsches Kollegium für Psycho- } \\
\text { somatische Medizin }\end{array}$ & nein & nein \\
\hline 8 & nein & $\begin{array}{l}\text { ja: Leitlinienbeauftragter der } \\
\text { Gesellschaft für Phytotherapie } \\
\text { und der Deutschen Gesellschaft } \\
\text { für Naturheilkunde, Deutsche } \\
\text { Gesellschaft für Gastroenterolo- } \\
\text { gie, Deutsche Schmerzgesell- } \\
\text { schaft, Deutsches Kollegium für } \\
\text { Psychosomatische Medizin }\end{array}$ & nein & nein \\
\hline \multirow[t]{2}{*}{9} & $\begin{array}{l}\text { Helmholtz Zentrum für Infekti- } \\
\text { onsforschung, Twincore }\end{array}$ & $\begin{array}{l}\text { Kliniken Essen-Mitte, Knapp- } \\
\text { schafts-Krankenhaus Essen }\end{array}$ & $\begin{array}{l}\text { Zentrum für Infektiologie } \\
\text { Berlin-Prenzlauer Berg }\end{array}$ & Kliniken Essen-Mitte \\
\hline & Hinrichsen, Holger & Stauber, Rudolf & Rauch, Andri & Neumann, Ulf Peter \\
\hline 1 & $\begin{array}{l}\text { ja: Advisory Board-Teilnahme bei } \\
\text { folgenden Firmen: MSD, Gilead, } \\
\text { Abbvie, Janssen, BMS, Roche }\end{array}$ & $\begin{array}{l}\text { ja: Beratertätigkeit für Abbvie, } \\
\text { BMS, Gilead, Janssen, Merz, MSD }\end{array}$ & $\begin{array}{l}\text { ja: Board member/Advisory pa- } \\
\text { nel: Janssen-Cilag, MSD, Gilead } \\
\text { Sciences, Abbvie, Bristol-Myers } \\
\text { Squibb }\end{array}$ & nein \\
\hline 2 & $\begin{array}{l}\text { ja: Vortragshonorare: MSD, Gile- } \\
\text { ad, Abbvie, Janssen, BMS, Roche }\end{array}$ & $\begin{array}{l}\text { ja: Vortragshonorare von Abbvie, } \\
\text { BMS, Gilead, Merz }\end{array}$ & nein & $\begin{array}{l}\text { ja: Amgen, Merck, Roche, Falk, } \\
\text { Ethicon, Astellas, Novartis }\end{array}$ \\
\hline 3 & nein & $\begin{array}{l}\text { ja: Sponsoring durch MSD, } \\
\text { Abbvie }\end{array}$ & $\begin{array}{l}\text { ja: unrestricted research grant } \\
\text { Gilead Sciences }\end{array}$ & Ethicon, Merck \\
\hline 4 & nein & nein & nein & nein \\
\hline 5 & nein & nein & nein & nein \\
\hline 6 & nein & nein & nein & nein \\
\hline 7 & ja: Mitglied DGVS Mitglied BNG & ja: Mitglied der ÖGGH & nein & nein \\
\hline 8 & nein & nein & nein & nein \\
\hline 9 & $\begin{array}{l}\text { Selbstständig niedergelassener } \\
\text { Arzt seit 01.01.2007 }\end{array}$ & Medizinische Universität Graz & Universitätsspital Bern & $\begin{array}{l}\text { Uniklinik RWTH Aachen, UMC+ } \\
\text { Maastricht }\end{array}$ \\
\hline
\end{tabular}


- Tab. 6 (Fortsetzung)

\begin{tabular}{|c|c|c|c|c|}
\hline & Moradpour, Darius & Lang, Thomas & Kasper, Hans-Udo & Schulze zur Wiesch, Julian \\
\hline 1 & nein & $\begin{array}{l}\text { ja: Drug Safety Monitoring Board } \\
\text { Astellas Pharma }\end{array}$ & nein & nein \\
\hline 2 & nein & nein & ja: 2016 Abbvie & $\begin{array}{l}\text { ja: Vortragshonorare MSD, } \\
\text { Abbvie, Roche, Gilead }\end{array}$ \\
\hline 3 & $\begin{array}{l}\text { ja: Forschungsgelder von BMS, } \\
\text { Gilead und Roche (als Repräsen- } \\
\text { tant der CHUV) }\end{array}$ & nein & nein & nein \\
\hline 4 & nein & nein & nein & nein \\
\hline 5 & nein & nein & ja: Merck Gmbh & nein \\
\hline 6 & nein & nein & nein & nein \\
\hline 7 & nein & nein & $\begin{array}{l}\text { ja: DGVS, DGP, Bundesverband } \\
\text { Pathologen }\end{array}$ & nein \\
\hline 8 & nein & nein & nein & nein \\
\hline \multirow[t]{2}{*}{9} & $\begin{array}{l}\text { Universitätsklinik Lausanne } \\
\text { (CHUV), Lausanne, Schweiz }\end{array}$ & Klinikum Starnberg & niedergelassen & $\begin{array}{l}\text { Universitätsklinikum } \\
\text { Hamburg Eppendorf }\end{array}$ \\
\hline & Zeichhardt, Heinz & Backmund, Markus & Sarrazin, Christoph & Protzer, Ulrike \\
\hline 1 & nein & $\begin{array}{l}\text { ja: Maricann; Beratung als wis- } \\
\text { senschaftlicher Beirat im Hinblick } \\
\text { auf Cannabis als Medizinprodukt }\end{array}$ & $\begin{array}{l}\text { ja: Advisory Boards für: Abbott, } \\
\text { Abbvie, BMS, Gilead, Janssen, } \\
\text { Merck/MSD, Roche }\end{array}$ & $\begin{array}{l}\text { ja: Fa. GILEAD, Fa. Roche, } \\
\text { Fa. Medimmune, Fa. Janssen }\end{array}$ \\
\hline 2 & $\begin{array}{l}\text { ja: BioMérieux GmbH, (REMMDI; } \\
\text { Regensburg, März 2015); Abbott } \\
\text { GmbH, (Anwenderforum; Wies- } \\
\text { baden, April 2015); Helmholtz } \\
\text { Centre for Infection Research } \\
\text { (Spring School; Braunschweig, } \\
\text { April 2016) }\end{array}$ & nein & $\begin{array}{l}\text { ja: Vorträge für: Abbott, Abbvie, } \\
\text { Achillion, BMS, Gilead, Janssen, } \\
\text { Merck/MSD, Qiagen, Roche, } \\
\text { Sieme }\end{array}$ & ja: Fa. Roche, Fa. Janssen \\
\hline 3 & $\begin{array}{l}\text { ja: GBD-Gesellschaft für Biotech- } \\
\text { nologische Diagnostik mbH, } \\
\text { Berlin }\end{array}$ & nein & $\begin{array}{l}\text { ja: Forschungsunterstützung } \\
\text { von: Abbott, Gilead, Janssen, } \\
\text { Qiagen, Roche, Siemens }\end{array}$ & $\begin{array}{l}\text { ja: Fa. Roche, Fa. Janssen, } \\
\text { Fa. GILEAD, Fa. Alnylam }\end{array}$ \\
\hline 4 & nein & nein & nein & nein \\
\hline 5 & $\begin{array}{l}\text { ja: GBD-Gesellschaft für Biotech- } \\
\text { nologische Diagnostik mbH, } \\
\text { Berlin }\end{array}$ & nein & nein & nein \\
\hline 6 & nein & nein & nein & nein \\
\hline 7 & $\begin{array}{l}\text { ja: Deutsche Vereinigung zur } \\
\text { Bekämpfung der Viruskrankhei- } \\
\text { ten (DVV e.V.), Gesellschaft für } \\
\text { Virologie (GfV e. V.) }\end{array}$ & nein & $\begin{array}{l}\text { ja: Mitglied in folgenden Fachge- } \\
\text { sellschaften: Deutsche Gesell- } \\
\text { schaft für Innere Medizin (DGIM) } \\
\text { Deutsche Gesellschaft für Gas- } \\
\text { troenterologie, Verdauungs- und } \\
\text { Stoffwechselkrankheiten (DGVS) } \\
\text { Deutsche Gesellschaft zur Erfor- } \\
\text { schung der Leber (GASL) }\end{array}$ & $\begin{array}{l}\text { ja: Gesellschaft für Virologie, } \\
\text { EASL, GASL }\end{array}$ \\
\hline 8 & nein & $\begin{array}{l}\text { ja: Fakultätsmitglied der Ludwig- } \\
\text { Maximilians-Universität München }\end{array}$ & nein & nein \\
\hline \multirow[t]{2}{*}{9} & $\begin{array}{l}\text { Charité-Universitätsmedizin Berlin } \\
\text { (bis September 2015), GBD-Ge- } \\
\text { sellschaft für Biotechnologische } \\
\text { Diagnostik mbH (ab März 2016) }\end{array}$ & Selbstständig tätig & $\begin{array}{l}\text { Ordentliche Professur an der } \\
\text { Goethe-Universität Frankfurt am } \\
\text { Main, Fachbereich Medizin, Uni- } \\
\text { versitätsklinikum }\end{array}$ & $\begin{array}{l}\text { Helmholtz Zentrum München - } \\
\text { Deutsches Zentrum für Gesund- } \\
\text { heit und Umwelt }\end{array}$ \\
\hline & Heinzow, Hauke & Lynen Jansen, Petra & Hüppe, Dietrich & Manns, Michael P. \\
\hline 1 & nein & nein & $\begin{array}{l}\text { ja: Mitglied in Advisory Boards } \\
\text { der Firmen: Abbvie Janssen BMS } \\
\text { Gilead }\end{array}$ & $\begin{array}{l}\text { ja: Roche, Bristol Myers Squibb, } \\
\text { Gilead, Boehringer Ingelheim, } \\
\text { Novartis, Merck (MSD), Janssen, } \\
\text { Idenix, GlaxoSmithKline, Biotest, } \\
\text { Achillion }\end{array}$ \\
\hline
\end{tabular}




\begin{tabular}{|c|c|c|c|c|}
\hline 2 & $\begin{array}{l}\text { ja: Abbvie: Erstellen von Patien- } \\
\text { tenkasuistiken, Schulung von He- } \\
\text { patitis-Study-Nurses }\end{array}$ & nein & $\begin{array}{l}\text { ja: Vorträge, die von folgenden } \\
\text { firmen finanziell unterstützt wor- } \\
\text { den sind: Abbvie Janssen, BMS } \\
\text { Gilead Falk }\end{array}$ & $\begin{array}{l}\text { ja: Roche, Bristol Myers Quibb, } \\
\text { Gilead, Merck (MSD), Janssen }\end{array}$ \\
\hline 3 & nein & nein & nein & $\begin{array}{l}\text { ja: Roche, Bristol Myers Squibb, } \\
\text { Gilead, Boehringer Ingelheim, } \\
\text { Novartis, GlaxoSmithKline, Bio- } \\
\text { test }\end{array}$ \\
\hline 4 & nein & nein & nein & nein \\
\hline 5 & nein & nein & nein & nein \\
\hline 6 & nein & nein & nein & nein \\
\hline 7 & ja: DGVS, DEGUM, DGIM & nein & $\begin{array}{l}\text { ja: Mitglied der Hepatologischen } \\
\text { Arbeitsgruppe des bng DGVS, } \\
\text { wissenschaftlicher Leiter des } \\
\text { Deutschen Hepatitis C Registers } \\
\text { (DHC-R) }\end{array}$ & ja: DGVS, DGIM, EASL, UEG \\
\hline 8 & nein & nein & nein & nein \\
\hline \multirow[t]{2}{*}{9} & Universitätsklinikum Münster & DGVS, RWTH Aachen & Selbst. Vertragsarzt & $\begin{array}{l}\text { Medizinische Hochschule Hanno- } \\
\text { ver (MHH), Hannover Helmholtz- } \\
\text { Zentrum für Infektionsforschung } \\
\text { (HZI), Braunschweig }\end{array}$ \\
\hline & Drebber, Uta & Holzmann, Heidemarie & Zeuzem, Stefan & Zimmermann, Tim \\
\hline 1 & nein & nein & $\begin{array}{l}\text { ja: Abbvie, BMS, Gilead, Janssen, } \\
\text { Merck/MSD }\end{array}$ & ja: Abbvie, Novartis \\
\hline 2 & $\begin{array}{l}\text { ja: Schulungstätigkeit für } \\
\text { Alexion und Novartis }\end{array}$ & nein & $\begin{array}{l}\text { ja: Abbvie, BMS, Gilead, Janssen, } \\
\text { Merck/MSD }\end{array}$ & ja: Abbvie, BMS, Janssen, Roche \\
\hline 3 & nein & nein & nein & nein \\
\hline 4 & nein & nein & nein & nein \\
\hline 5 & nein & nein & nein & nein \\
\hline 6 & nein & nein & nein & nein \\
\hline 7 & $\begin{array}{l}\text { ja: Deutsche Gesellschaft für } \\
\text { Pathologie, Berufsverband } \\
\text { Deutscher Pathologen }\end{array}$ & nein & $\begin{array}{l}\text { ja: Mitglied DGVS, Vorstand } \\
\text { Leitlinien }\end{array}$ & ja: DGVS, DTG \\
\hline 8 & nein & nein & nein & nein \\
\hline 9 & Uniklinik Köln & $\begin{array}{l}\text { Department für Virologie, } \\
\text { Medizinische Universität Wien }\end{array}$ & Universität Frankfurt & Universitätsmedizin Mainz \\
\hline
\end{tabular}

\subsection{Aufgabenverteilung}

\subsubsection{Koordinatoren}

- Ansprechpartner für Fachgesellschaften und Leitliniengruppe

- Unterstützung der AG-Leiter, Zusammenstellung und Koordination der AGs

- Einberufung der Konsensuskonferenz

- Moderation der Konsensuskonferenz

- Begutachtung der Empfehlungen vor der Online-Abstimmung mittels Delphi-Runden

- Kritische Durchsicht und Korrektur des kompletten Leitlinienmanuskripts sowie des Leitlinienreports inklusive der Evidenztabellen

\subsubsection{Wissenschaftlicher Sekretär}

- Wissenschaftlicher Sekretär für die Koordinatoren

- Ansprechpartner für die Leitliniengruppe

- Unterstützung der Koordinatoren und der AG-Leiter bei der Zusammenstellung und Koordination der AGs, der Empfehlungen und der einzelnen Leitlinienkapitel

- Organisation und Koordination der Konsensuskonferenz

- Redaktion der Empfehlungen vor der Konsensuskonferenz

- Live-Änderungen der Empfehlungen auf der Konsensuskonferenz

- Vorbereitung der Empfehlungen und Durchführung der Online-Abstimmung mittels Delphi-Runden

- Überarbeitung, Literatursuche, Einfügen von Literatur für einzelne AGs der jeweiligen Leitlinienkapitel

- systematische Literaturrecherche

- Literaturbewertung

- Evidenztabellen 
- Zuordnung der Literatur zu Empfehlungen

- iterative Überarbeitung der Empfehlungen

- Zusammenstellen und Kursieren des kompletten Manuskripts

- Erstellen des Leitlinienreports

\subsubsection{AG-Leiter}

- Auswahl der priorisierten Schlüsselfragen

- Erstellen und Vorstellung der Empfehlungen für die Konsensuskonferenz

- Auswahl der Literatur

- Zuordnung der Literatur zu Empfehlungen

- Schreiben der Erläuterungen und Kommentare

- kritische Durchsicht, Korrektur und Ergänzung des kompletten Leitlinienmanuskripts sowie des Leitlinienreports inklusive der Evidenztabellen

\subsubsection{AG-Mitglieder}

- Unterstützung der AG-Leiter bei

- dem Erstellen der Empfehlungen für die Konsensuskonferenz

- der Auswahl der Literatur und teilweise Vorbereitung der Evidenztabellen

- dem Erstellen der Erläuterungen und Kommentare zu den Empfehlungen

- Teilnahme und Abstimmung der Empfehlungen auf der Konsensuskonferenz und in den Delphi-Runden

- kritische Durchsicht der Leitlinie und der Evidenztabellen

\subsubsection{Teilnehmer Konsensuskonferenz}

- Überarbeitung und Konsentierung der Empfehlungen während der Konsensuskonferenz

\subsection{Schlüsselfragen}

AG 1: Definition der Hepatitis-C-Virus (HCV) -Infektion und Empfehlungen zu deren Diagnostik

- 1.1 Indikation und Durchführung einer HCV-Diagnostik Bei welchen Personen sollte ein „HCV-Screening“ erfolgen?

- 1.2 Virologische Diagnostik der HCV-Infektion Wie wird eine Infektion mit dem HCV diagnostiziert? Welche Parameter sollten initial, welche im Verlauf bestimmt werden?

- 1.3 HCV-Resistenztestung Wann sollte eine genotypische HCV-Resistenztestung durchgeführt werden?

- 1.4 Weitere Diagnostik bei Erstdiagnose einer HCV-Infektion Welche weitere Diagnostik ist bei der Erstdiagnose einer HCVInfektion erforderlich?

- 1.5 Bestimmung des Grads der Leberfibrose Bei welchen Patienten und mit welcher Methode soll der Grad der Leberfibrose bestimmt werden?

- 1.6 Follow-up bei nicht behandelter HCV-Infektion Welches Follow-up ist bei nicht behandelter HCV-Infektion, Therapieversagern und/oder Leberzirrhose indiziert?
AG 2: Prävention der HCV-Übertragung und Prophylaxe der Chronifizierung

- 2.1 Hepatitis C und Nadelstich Welches Vorgehen ist nach Verletzung mit einer möglicherweise HCV-kontaminierten Nadel oder nach Exposition mit HCV-kontaminierter Flüssigkeit zu empfehlen?

- 2.2 Maßnahmen zur Vermeidung nosokomialer HCV-Infektionen Welche präventiven Maßnahmen müssen bei medizinischen Eingriffen bei HCV-positiven Patienten ergriffen werden?

- 2.3 Vorsichtsmaßnahmen bei HCV-RNA-positiven Mitarbeitern in medizinischen Berufen Welche Vorsichtsmaßnahmen sind bei HCV-RNA-positiven Mitarbeitern in medizinischen Berufen indiziert?

- 2.4 Vorsichtsmaßnahmen bei intrafamiliärem oder sexuellem Kontakt mit HCV-positiven Personen Welche Verhaltensmaßnahmen sind für Personen im Umfeld von Patienten mit chronischer Hepatitis C zu beachten?

Wie kann eine sexuelle Übertragung des HCV verhindert werden?

- 2.5 Vorsichts- und Überwachungsmaßnahmen bei Drogenkonsumierenden

Welche Vorsichts- und Überwachungsmaßnahmen sind bei Drogenkonsumierenden indiziert?

- 2.6 Therapie der akuten Hepatitis C

Sollte eine akute Hepatitis C mit antiviralen Medikamenten behandelt werden?

Wie kann eine Therapie der akuten Hepatitis C durchgeführt werden?

AG 3: Natürlicher Verlauf und Therapieindikation inklusive extrahepatische Manifestationen

- 3.1 Prognoseparameter für den natürlichen Verlauf

- 3.2 Therapieindikation der chronischen Hepatitis C...

- 3.2.1 im kompensierten Stadium der Lebererkrankung Wann ist eine antivirale Therapie bei Patienten mit einer chronischen Hepatitis C im kompensierten Stadium der Lebererkrankung indiziert?

- 3.2.2 im dekompensierten Stadium der Lebererkrankung Wann ist eine antivirale Therapie bei Patienten mit einer chronischen Hepatitis C im dekompensierten Stadium der Lebererkrankung (Child-Pugh B/C) bzw. auf der Warteliste zur Lebertransplantation indiziert?

- 3.2.3 beim hepatozellulären Karzinom Wann ist eine antivirale Therapie bei Patienten mit einer chronischen Hepatitis C und hepatozellulärem Karzinom (HCC) indiziert?

- 3.2.4 mit extrahepatischen Manifestationen Wann ist eine antivirale Therapie bei Patienten mit einer chronischen Hepatitis C mit extrahepatischen Manifestationen indiziert?

- 3.2 .5 bei Patienten mit Niereninsuffizienz bzw. Dialyse Wann ist eine antivirale Therapie bei Patienten mit einer chronischen Hepatitis C mit Niereninsuffizienz bzw. Dialyse indiziert?

- 3.2.6 bei Patienten mit Suchterkrankungen Was sind Besonderheiten bei der Therapie-Indikationsstellung von Patienten mit Suchterkrankungen? 
- 3.3 Indikation zur Re-Therapie

Wann ist eine Re-Therapie indiziert?

- 3.4 Kontraindikationen, Einschränkungen und Interaktionen einer DAA-basierten Therapie

Wann bestehen Kontraindikationen bzw. Einschränkungen für eine DAA-basierte Therapie?

\section{AG 4: Therapie der chronischen Hepatitis C}

- 4.1 Aktuell verfügbare Therapieoptionen

- 4.2 Ersttherapie von Patienten mit DAA in allen Fibrosestadien bis einschließlich kompensierter Zirrhose Wie sollen Patienten mit einer DAA-Ersttherapie in allen Fibrosestadien bis einschließlich kompensierter Zirrhose behandelt werden?

- 4.2.1 HCV-Genotyp 1

- 4.2.2 HCV-Genotyp 2

- 4.2.3 HCV-Genotyp 3

- 4.2.4 HCV-Genotyp 4

- 4.2.5 HCV-Genotyp 5 und 6

- 4.3 Ersttherapie von Patienten mit DAA bei dekompensierter Zirrhose

Wie sollen Patienten mit einer DAA-Ersttherapie bei dekompensierter Zirrhose behandelt werden?

- 4.4 Therapie von Patienten nach einem Versagen einer DAATherapie Wie sollen Patienten nach einem Versagen einer DAA-Therapie behandelt werden?

- 4.5 Resistenzanalyse Wann sollte eine Resistenzanalyse erfolgen?

- 4.6 Nebenwirkungen, Medikamenteninteraktionen und Niereninsuffizienz

- 4.6.1 Behandlung von Nebenwirkungen Wie sollen Nebenwirkungen behandelt werden?

- 4.6.2 Medikamenteninteraktionen Was soll hinsichtlich möglicher Medikamenteninteraktionen beachtet werden?

- 4.6.3 Behandlung von Patienten mit Niereninsuffizienz Wie sollen Patienten mit einer Niereninsuffizienz behandelt werden?

- 4.7 Überwachung der Therapie

Wie soll die Therapie überwacht werden?

AG 5: Infektionen mit HCV im Zusammenhang mit einer Transplantation (prä- und postoperatives Management)

- 5.1 Indikation zur Lebertransplantation bei HCV-Infektion Bei welchen Patienten mit HCV-Infektion ist eine Lebertransplantation indiziert?

Wann ist eine Re-Transplantation bei Hepatitis C indiziert?

- 5.2 Präoperatives Management auf der Warteliste zur Transplantation

Wie ist das Management der Patienten mit HCV-Infektion auf der Warteliste zur Lebertransplantation?

Wie ist das Management der Patienten mit HCV-Infektion auf der Warteliste zur Nierentransplantation und zur Transplantation sonstiger Organe (Herz, Lunge, Pankreas, Darm)?
- 5.3 Verlauf und Behandlung nach Lebertransplantation Welche Patienten mit einer Hepatitis-C-assoziierten Leberzirrhose nach Lebertransplantation bei Hepatitis C sollten behandelt werden?

Wann sollte eine antivirale Therapie post transplantationem begonnen werden?

Wie wird die antivirale Therapie nach Lebertransplantation durchgeführt?

Wie erfolgt die immunsuppressive Therapie nach Lebertransplantation bei chronischer Hepatitis C?

- 5.4 Vermittlung HCV-positiver Spenderorgane Wann können HCV-positive Spenderorgane akzeptiert werden?

- 5.5. Transplantation anderer solider Organe (Herz, Niere, Lunge, Pankreas und Dünndarm) und Knochenmark- bzw. Stammzelltransplantation in HCV-positiven Patienten Wie sollen Patienten mit Organ- und Stammzelltransplantation (SZT) behandelt werden?

Wie und wann erfolgt die Therapie HCV-positiver Patienten im Falle einer Knochenmark- bzw. Stammzelltransplantation (KMT/SZT)?

Wie und wann erfolgt die Therapie HCV-positiver Patienten post Nierentransplantation und Transplantation anderer solider Organe (Herz, Lunge, Pankreas und Dünndarm)?

- 5.6 Interaktionen mit Calcineurin-Inhibitoren und mTOR-Inhibitoren

Welche Kombinationen der Immunsuppression mit DAA sollten vermieden oder nicht eingesetzt werden?

\section{AG 6: Ko-Infektionen bei Hepatitis C-Virusinfektion}

- 6.1 Besonderheiten bei Patienten mit Hepatitis B-Virus (HBV) und HCV-Ko-Infektionen

Welche Besonderheiten ergeben sich bei Patienten mit HBV/HCVKo-Infektionen?

- 6.2 Besonderheiten bei Patienten mit Humanes Immundefizienz-Virus (HIV)- und HCV-Ko-Infektionen

Welche Besonderheiten ergeben sich bei Patienten mit HIV/HCVKo-Infektionen?

- 6.3 Akute Hepatitis C bei Patienten mit bekannter HIV- bzw. HBV-Ko-Infektion Wie ist das Vorgehen, wenn es bei einem Patienten mit bekannter HIV- bzw. HBV-Infektion zu einer akuten Hepatitis C kommt?

- 6.4 Therapie der chronischen Hepatitis C bei HBV/HCV-koinfizierten Patienten

Wie erfolgt die Therapie der chronischen Hepatitis C beim HBV/ HCV-ko-infizierten Patienten?

- 6.5 Therapie der chronischen Hepatitis bei HBV/HCV/HDVko-infizierten Patienten Wie erfolgt die Therapie der chronischen Hepatitis C beim HBV/ HCVHDV-ko-infizierten Patienten?

- 6.6 Therapie der chronischen Hepatitis bei HIV/HCV-ko-infizierten Patienten Wie erfolgt die Therapie der chronischen Hepatitis C beim HIV/ HCV-ko-infizierten Patienten? Was muss berücksichtigt werden, wenn bei HIV-positiven Patienten eine Hepatitis C therapiert werden soll? 
- 6.7 Besonderheiten hinsichtlich einer Lebertransplantation bei HCV/HIV-ko-infizierten Patienten

Welche Besonderheiten ergeben sich hinsichtlich einer Lebertransplantation bei HIV/HCV-ko-infizierten Patienten?

- 6.8 Maßnahmen der Prophylaxe bei HIV/HCV- bzw. bei HBV/ HCV-ko-infizierten Patienten

Welche Maßnahmen der Prophylaxe sind bei HIV/HCV- bzw. bei HBV/HCV-ko-infizierten Patienten sinnvoll?

\section{AG 7: Hepatitis C-Virusinfektion bei Kindern und Jugendlichen}

- 7.1 Diagnosestellung im Kindesalter Wie wird die Diagnose im Kindesalter gestellt?

- 7.2 Therapieoptionen und Therapieziele im Kindesalter Welche Therapiemöglichkeiten und -ziele bestehen bei einer Hepatitis C im Kindesalter?

Wer sollte die Indikation zur Behandlung stellen und die Therapie überwachen?

\subsection{Literatursuche}

\subsubsection{Leitlinien}

Da eine Aktualisierung der S3-Leitlinie durchgeführt wurde, konnte die Suche aus der Vorgängerversion übernommen werden. Die Leitlinien der DGVS, ÖGGH, SGG, DGP, GfV, GPGE, AWMF, AASLD, EASL, ECC, EVHEI, APASL, welche für die Erstellung verwendet wurden, wurden für die Aktualisierung erneut berücksichtigt.

\subsubsection{Systematische Literatursuche}

\section{Suchwörter}

\begin{tabular}{|c|c|c|c|c|}
\hline $\begin{array}{l}\text { Arbeits- } \\
\text { gruppe }\end{array}$ & Fragestellung & Datenbank & Suchstrings & Filter \\
\hline \multirow[t]{3}{*}{ AG 1} & $\begin{array}{l}\text { Indikationen zur } \\
\text { HCV-Diagnostik }\end{array}$ & PubMed & (hepatitis c OR HCV) AND prevalence & \multirow[t]{3}{*}{$\begin{array}{l}\text { Zeitraum: } 01.01 .2013- \\
\text { 23.01.2016 }\end{array}$} \\
\hline & $\begin{array}{l}\text { virologische Diagnostik } \\
\text { der HCV-Infektion }\end{array}$ & PubMed & (hepatitis c OR HCV) AND (HCV-RNA test) & \\
\hline & HCV-Resistenz-testung & PubMed & (hepatitis c OR HCV) AND (resistance) & \\
\hline \multirow[t]{5}{*}{ AG 2} & Hepatitis C und Nadelstich & PubMed & $\begin{array}{l}\text { acute hepatitis C AND needle stick AND } \\
\text { transmission }\end{array}$ & \multirow[t]{4}{*}{$\begin{array}{l}\text { Zeitraum: } 01.01 .2000- \\
\text { 30.04.2017 }\end{array}$} \\
\hline & $\begin{array}{l}\text { Vermeidung nosokomialer } \\
\text { Infektion }\end{array}$ & PubMed & nosocomial infection AND HCV AND hepatitis & \\
\hline & $\begin{array}{l}\text { intrafamiliäre und sexuelle } \\
\text { Übertragung }\end{array}$ & PubMed & $\begin{array}{l}\text { HCV AND transmission AND intrafamilial acute } \\
\text { HCV AND HIV AND systematic review }\end{array}$ & \\
\hline & $\begin{array}{l}\text { Vorsichts- und Überwa- } \\
\text { chungsmaßnahmen bei } \\
\text { Drogenkonsumierenden }\end{array}$ & PubMed & HCV AND PWID AND systematic review & \\
\hline & Therapie der akuten Hepatitis C & PubMed & acute hepatitis C AND treatment & $\begin{array}{l}\text { Zeitraum: 01.01.2014- } \\
\text { aktuell }\end{array}$ \\
\hline \multirow[t]{4}{*}{ AG 3} & natürlicher Verlauf der HCV & PubMed & (hepatitis c OR HCV) AND natural history & \multirow{4}{*}{$\begin{array}{l}\text { Zeitraum: } 01.01 .2013- \\
\text { 23.01.2016 }\end{array}$} \\
\hline & Prognoseparameter & PubMed & $\begin{array}{l}\text { ((hepatitis c OR HCV) AND osteoporosis) OR } \\
\text { ((hepatitis c OR HCV) AND cardiovascular disease) } \\
\text { OR ((hepatitis c OR HCV) AND extrahepatic mani- } \\
\text { festation) OR ((hepatitis c OR HCV) AND gene } \\
\text { variants) }\end{array}$ & \\
\hline & Antivirale Therapie und HCC & PubMed & (hepatitis c therapy) AND hcc & \\
\hline & $\begin{array}{l}\text { Patienten mit Suchterkran- } \\
\text { kungen }\end{array}$ & PubMed & (hepatitis c therapy) AND substance users & \\
\hline
\end{tabular}

- 7.3 Ko-Infektionen im Kindesalter

- 7.4 Prophylaktische Maßnahmen im Kindesalter bei einer HCVInfektion

Welche prophylaktischen Maßnahmen sind bei einer HCV-Infektion im Kindesalter sinnvoll?

- 7.5 Postnatales Management Bei wem sollte anti-HCV in der Schwangerschaft bestimmt werden? Wann ist die Durchführung einer Sectio caesarea indiziert? Wann und wie kann die HCV-Infektion des Kindes nachgewiesen bzw. ausgeschlossen werden? Kann eine HCV-infizierte Frau stillen?
- 7.6 Hepatitis C und Schwangerschaft 


\begin{tabular}{|c|c|c|c|c|}
\hline $\begin{array}{l}\text { Arbeits- } \\
\text { gruppe }\end{array}$ & Fragestellung & Datenbank & Suchstrings & Filter \\
\hline AG 4 & antivirale Therapie & $\begin{array}{l}\text { PubMed und web } \\
\text { of science }\end{array}$ & $\begin{array}{l}\text { Hepatitis C AND (Sofosbuvir OR Simeprevir OR } \\
\text { Daclatasvir OR Telaprevir OR Boceprevir OR GS- } \\
7977 \text { OR PSI-7977 OR TMC435 OR BMS790052 } \\
\text { OR Ledipasvir OR Paritaprevir OR Ombitasvir OR } \\
\text { Dasabuvir OR GS-5885 OR ABT-450 OR ABT-267 } \\
\text { OR ABT-333 OR Grazoprevir OR MK-5172 OR El- } \\
\text { basvir OR MK-8742 OR Velpatasvir OR GS-5816) } \\
\text { AND (therapy OR treatment OR prophylaxis OR } \\
\text { prevention) NOT (animals (mh) NOT humans } \\
\text { (mh)) AND clinical trial). }\end{array}$ & $\begin{array}{l}\text { Zeitraum: 01.01.2013- } \\
\text { 31.07.2016 }\end{array}$ \\
\hline \multirow[t]{6}{*}{ AG 5} & LTx-Warteliste & PubMed & $\begin{array}{l}\text { (hepatitis c OR HCV) AND (cirrhosis OR trans- } \\
\text { plantation) }\end{array}$ & \multirow[t]{6}{*}{$\begin{array}{l}\text { Zeitraum: 01.01.2013- } \\
\text { 23.01.2016 }\end{array}$} \\
\hline & $\begin{array}{l}\text { NTx-Warteliste und andere } \\
\text { Organe }\end{array}$ & PubMed & $\begin{array}{l}\text { (kidney disease OR renal transplantation) AND } \\
\text { (hepatitis c OR HCV) } \\
\text { und } \\
\text { (lung disease OR lung transplantation) AND } \\
\text { (hepatitis c or HCV) und (heart disease OR heart } \\
\text { transplantation) AND (hepatitis C or HCV) }\end{array}$ & \\
\hline & $\begin{array}{l}\text { Verlauf und Behandlung nach } \\
\text { Lebertransplantation }\end{array}$ & PubMed & $\begin{array}{l}\text { (hepatitis c or HCV) AND (therapy after liver } \\
\text { transplantation) }\end{array}$ & \\
\hline & $\begin{array}{l}\text { Transplantation anderer soli- } \\
\text { der Organe und Knochen- } \\
\text { mark- bzw. Stammzelltrans- } \\
\text { plantation in HCV-positiven } \\
\text { Patienten }\end{array}$ & PubMed & $\begin{array}{l}\text { (hepatitis c OR HCV) AND (hematopoietic stem } \\
\text { cell transplantation OR peripheral blood stem cell } \\
\text { transplantation OR peripheral stem cell trans- } \\
\text { plantation OR marrow transplantation OR bone } \\
\text { marrow transplantation) } \\
\text { und } \\
\text { (hepatitis c OR HCV) AND (nonliver solid organ } \\
\text { transplantation OR kidney transplantation OR } \\
\text { renal transplantation OR lung transplantation OR } \\
\text { heart transplantation OR small bowel transplan- } \\
\text { tation OR intestine transplantation) } \\
\text { und } \\
\text { (Hepatitis C OR HCV) AND pancreas transplanta- } \\
\text { tion }\end{array}$ & \\
\hline & $\begin{array}{l}\text { Interaktionen mit Calcineurin- } \\
\text { Inhibitoren oder mTor-Inhibi- } \\
\text { toren }\end{array}$ & PubMed & $\begin{array}{l}\text { (drug interaction AND direct acting antivirals) und } \\
\text { (direct acting antivirals) AND (cyclosporine OR } \\
\text { tacrolimus OR mTor inhibitors) und (direct acting } \\
\text { antivirals AND liver transplantation) }\end{array}$ & \\
\hline & & $\begin{array}{l}\text { Fachinformation aller } \\
\text { bewerteten Substan- } \\
\text { zen }\end{array}$ & & \\
\hline \multirow[t]{5}{*}{ AG 6} & HIV/HCV-Ko-Infektionen & PubMed & $\begin{array}{l}\text { (hepatitis c OR HCV) AND co-infection with } \\
\text { (human immunodeficiency virus OR HIV) }\end{array}$ & \multirow[t]{5}{*}{$\begin{array}{l}\text { Zeitraum: } 01.01 .2013- \\
23.01 .2016\end{array}$} \\
\hline & $\begin{array}{l}\text { akute Hepatitis C bei Patienten } \\
\text { mit bekannter HIV- bzw. HBV- } \\
\text { Infektion }\end{array}$ & PubMed & $\begin{array}{l}\text { (acute hepatitis c OR acute HCV) AND (chronic } \\
\text { hepatitis b OR chronic HBV) OR (human immu- } \\
\text { nodeficiency virus OR HIV) }\end{array}$ & \\
\hline & $\begin{array}{l}\text { Therapie der chronischen } \\
\text { Hepatitis C bei HBV/HCV-ko- } \\
\text { infizierten Patienten }\end{array}$ & PubMed & $\begin{array}{l}\text { therapy of (chronic hepatitis c OR chronic HCV) } \\
\text { AND co-infection with (human immunodeficiency } \\
\text { virus OR HIV) }\end{array}$ & \\
\hline & LTX bei HCV/HIV-Ko-Infektion & PubMed & $\begin{array}{l}\text { liver transplantation AND (hepatitis c or HCV) } \\
\text { AND (human immunodeficiency virus OR HIV) }\end{array}$ & \\
\hline & $\begin{array}{l}\text { Prophylaxe bei HIV/HCV- bzw. } \\
\text { HBV/HCV-Ko-Infektion }\end{array}$ & PubMed & $\begin{array}{l}\text { prophylaxis AND (hepatitis c OR HCV) OR (hepa- } \\
\text { titis b OR HBV) AND (human immunodeficiency } \\
\text { virus OR HIV) }\end{array}$ & \\
\hline AG 7 & $\begin{array}{l}\text { Keine Änderung im Vergleich } \\
\text { zur Vorversion der S3-Leitlinie }\end{array}$ & & & \\
\hline
\end{tabular}




\section{Auswahl}

\begin{tabular}{|c|c|c|c|c|}
\hline $\begin{array}{l}\text { Arbeits- } \\
\text { gruppe }\end{array}$ & Fragestellung & $\begin{array}{l}\text { Zahl der bei der Literatursu- } \\
\text { che identifizierten Quellen }\end{array}$ & $\begin{array}{l}\text { Zahl der ausgeschlossenen } \\
\text { Quellen (Gründe) }\end{array}$ & $\begin{array}{l}\text { Zahl der eingeschlossenen } \\
\text { Quellen }\end{array}$ \\
\hline \multirow[t]{3}{*}{ AG 1} & $\begin{array}{l}\text { Indikationen zur } \\
\text { HCV-Diagnostik }\end{array}$ & 4430 & $\begin{array}{l}4421 \text { (anderer Publikationstyp, } \\
\text { thematischer Fokus) }\end{array}$ & 9 Vollpublikationen \\
\hline & $\begin{array}{l}\text { virologische Diagnostik } \\
\text { der HCV-Infektion }\end{array}$ & 303 & $\begin{array}{l}290 \text { (anderer Publikationstyp, } \\
\text { thematischer Fokus) }\end{array}$ & 13 Vollpublikationen \\
\hline & HCV-Resistenztestung & 1217 & $\begin{array}{l}1205 \text { (thematischer Fokus, Dup- } \\
\text { likate, anderer Publikationstyp) }\end{array}$ & 12 Vollpublikationen \\
\hline \multirow[t]{5}{*}{ AG 2} & Hepatitis C und Nadelstich & 265 & $\begin{array}{l}257 \text { (anderer Publikationstyp, } \\
\text { thematischer Fokus) }\end{array}$ & 8 Vollpublikationen \\
\hline & $\begin{array}{l}\text { Vermeidung nosokomialer } \\
\text { Infektion }\end{array}$ & 2612 & $\begin{array}{l}2610 \text { (thematischer Fokus, Dup- } \\
\text { likate, anderer Publikationstyp) }\end{array}$ & 2 Vollpublikationen \\
\hline & $\begin{array}{l}\text { intrafamiliäre und sexuelle } \\
\text { Übertragung }\end{array}$ & 182 & $\begin{array}{l}164 \text { (thematischer Fokus, } \\
\text { Duplikate) }\end{array}$ & 18 Vollpublikationen \\
\hline & $\begin{array}{l}\text { Vorsichts- und Überwa- } \\
\text { chungsmaßnahmen bei } \\
\text { Drogenkonsumierenden }\end{array}$ & 58 & 49 (zu kleine Fallzahlen) & 9 Vollpublikationen \\
\hline & $\begin{array}{l}\text { Therapie der akuten } \\
\text { Hepatitis C }\end{array}$ & 564 & $\begin{array}{l}556 \text { (Fallberichte, Reviews, } \\
\text { chronische Hepatitis C, andere } \\
\text { Themen) }\end{array}$ & 8 Vollpublikationen \\
\hline \multirow[t]{4}{*}{ AG 3} & natürlicher Verlauf der HCV & 197 & 193 (thematischer Fokus) & 4 Vollpublikationen \\
\hline & Prognoseparameter & 881 & $\begin{array}{l}848 \text { (thematischer Fokus, Dupli- } \\
\text { kate, anderer Publikationstyp) }\end{array}$ & 33 Vollpublikationen \\
\hline & antivirale Therapie und HCC & 573 & 596 (thematischer Fokus) & 4 Vollpublikationen \\
\hline & $\begin{array}{l}\text { Patienten mit Suchter- } \\
\text { krankungen }\end{array}$ & 163 & 156 (thematischer Fokus) & 4 Vollpublikationen, 1 Abstract \\
\hline AG 4 & antivirale Therapie & 454 & $\begin{array}{l}337 \text { (anderer Publikationstyp, } \\
\text { thematischer Fokus) }\end{array}$ & 117 Vollpublikationen \\
\hline \multirow[t]{5}{*}{ AG 5} & LTx-Warteliste & 4723 & $\begin{array}{l}4697 \text { (anderer Publikationstyp, } \\
\text { thematischer Fokus) }\end{array}$ & $\begin{array}{l}21 \text { Vollpublikationen, } \\
3 \text { Abstracts }\end{array}$ \\
\hline & $\begin{array}{l}\text { NTx-Warteliste und andere } \\
\text { Organe }\end{array}$ & 1043 & $\begin{array}{l}1038 \text { (anderer Publikationstyp, } \\
\text { thematischer Fokus, veraltete } \\
\text { Daten) }\end{array}$ & 5 Vollpublikationen \\
\hline & $\begin{array}{l}\text { Verlauf und Behandlung nach } \\
\text { Lebertransplantation }\end{array}$ & 536 & $\begin{array}{l}527 \text { (anderer Publikationstyp, } \\
\text { thematischer Fokus) }\end{array}$ & 9 Vollpublikationen \\
\hline & $\begin{array}{l}\text { Transplantation anderer } \\
\text { solider Organe und Knochen- } \\
\text { mark- bzw. Stammzelltrans- } \\
\text { plantation in HCV-positiven } \\
\text { Patienten }\end{array}$ & 441 & $\begin{array}{l}417 \text { (anderer Publikationstyp, } \\
\text { thematischer Fokus) }\end{array}$ & 24 Vollpublikationen \\
\hline & $\begin{array}{l}\text { Interaktionen mit Calcineurin- } \\
\text { Inhibitoren oder mTor-Inhibi- } \\
\text { toren }\end{array}$ & 358 & $\begin{array}{l}353 \text { (thematischer Fokus, Dupli- } \\
\text { kate, anderer Publikationstyp) }\end{array}$ & 5 Vollpublikationen \\
\hline \multirow[t]{3}{*}{ AG 6} & HIV/HCV-Ko-Infektionen & 1338 & $\begin{array}{l}1334 \text { (anderer Publikationstyp, } \\
\text { thematischer Fokus) }\end{array}$ & 4 Vollpublikationen \\
\hline & $\begin{array}{l}\text { akute Hepatitis C bei Patienten } \\
\text { mit bekannter HIV- bzw. HBV- } \\
\text { Infektion }\end{array}$ & 50469 & $\begin{array}{l}50465 \text { (anderer Publikations- } \\
\text { typ, thematischer Fokus, veral- } \\
\text { tete Daten, Duplikate) }\end{array}$ & 4 Vollpublikationen \\
\hline & $\begin{array}{l}\text { Therapie der chronischen } \\
\text { Hepatitis C bei HBV/HCV- } \\
\text { ko-infizierten Patienten }\end{array}$ & 378 & $\begin{array}{l}368 \text { (anderer Publikationstyp, } \\
\text { thematischer Fokus) }\end{array}$ & 2 Vollpublikationen, 8 Abstracts \\
\hline
\end{tabular}




\begin{tabular}{|l|l|l|l|}
\hline $\begin{array}{l}\text { Arbeits- } \\
\text { gruppe }\end{array}$ & Fragestellung & $\begin{array}{l}\text { Zahl der bei der Literatursu- } \\
\text { che identifizierten Quellen }\end{array}$ & $\begin{array}{l}\text { Zahl der ausgeschlossenen } \\
\text { Quellen (Gründe) }\end{array}$ \\
\hline & $\begin{array}{l}\text { LTX bei HCV/HIV-Ko-Infektion } \\
\text { Quellen }\end{array}$ & 147 & $\begin{array}{l}140 \text { (anderer Publikationstyp, } \\
\text { thematischer Fokus) }\end{array}$ \\
\hline & $\begin{array}{l}\text { Prophylaxe bei HIV/HCV- bzw. } \\
\text { HBV/HCV-Ko-Infektion }\end{array}$ & 2192 & $\begin{array}{l}2181 \text { (anderer Publikationstyp, } \\
\text { thematischer Fokus) }\end{array}$ \\
\hline & $\begin{array}{l}\text { Keine Änderung im Vergleich } \\
\text { Zur Vorversion der S3-Leitlinie }\end{array}$ & & \\
\hline
\end{tabular}

\subsection{Evidenztabellen}

AG 1 Definition der Hepatitis C-Virus (HCV) -Infektion und Empfehlungen zu deren Diagnostik

\section{AG 1.1 Indikationen zur Durchführung einer HCV-Diagnostik}

Bei welchen Personen sollte ein „HCV-Screening“ erfolgen?

\begin{tabular}{|c|c|c|c|c|c|c|c|}
\hline $\begin{array}{l}\text { Referenz- } \\
\text { autor, Jahr }\end{array}$ & $\begin{array}{l}\text { Thema, } \\
\text { Intervention }\end{array}$ & Studientyp & Kontrolle & n gesamt & $\begin{array}{l}\text { Zielparameter, } \\
\text { Beobachtungsdauer }\end{array}$ & $\begin{array}{l}\text { Ergebnis, } \\
\text { Bemerkungen }\end{array}$ & $\begin{array}{l}\text { Evidenzgrad, } \\
{ }^{*} \text { Oxford-Schema }\end{array}$ \\
\hline $\begin{array}{l}\text { de Martel C } \\
\text { et al., } 2015\end{array}$ & HCC bei HCV & Review & keine & 119000 & HCC-Inzidenz & HCV causes HCC & Level 1 \\
\hline $\begin{array}{l}\text { Poethko- } \\
\text { Müller C } \\
\text { et al., } 2013\end{array}$ & HCV-Prävalenz & $\begin{array}{l}\text { prospektive } \\
\text { Studie }\end{array}$ & keine & 7238 & $\begin{array}{l}\text { Anti-HCV- und } \\
\text { HCV-RNA-Prävalenz }\end{array}$ & DEGS1 & Level 1 \\
\hline $\begin{array}{l}\text { Bruggmann } \\
\text { P et al., } 2014\end{array}$ & HCV-Prävalenz & Review & - & - & $\begin{array}{l}\text { Anti-HCV- und } \\
\text { HCV-RNA-Prävalenz }\end{array}$ & $\begin{array}{l}\text { Allgemeinbevöl- } \\
\text { kerung }\end{array}$ & Level 1 \\
\hline $\begin{array}{l}\text { Wolffram I } \\
\text { et al., } 2015\end{array}$ & HCV-Prävalenz & $\begin{array}{l}\text { prospektive } \\
\text { Studie }\end{array}$ & keine & 21008 & $\begin{array}{l}\text { Anti-HCV- und } \\
\text { HCV-RNA-Prävalenz }\end{array}$ & Check-up $35+$ & Level 1 \\
\hline $\begin{array}{l}\text { Zimmer- } \\
\text { mann R } \\
\text { et al., } 2015\end{array}$ & HCV-Prävalenz & $\begin{array}{l}\text { prospektive } \\
\text { Studie }\end{array}$ & keine & 2077 & $\begin{array}{l}\text { Anti-HCV- und } \\
\text { HCV-RNA-Prävalenz }\end{array}$ & $\begin{array}{l}\text { DRUCK-Studie } \\
\text { (HCVin PWID) }\end{array}$ & Level 1 \\
\hline $\begin{array}{l}\text { Carney K } \\
\text { et al., } 2013\end{array}$ & HCV-Prävalenz & $\begin{array}{l}\text { Fall-Kontroll- } \\
\text { Studie }\end{array}$ & $\begin{array}{l}\mathrm{HCV} \text { neg- } \\
\text { ative Kon- } \\
\text { trollen }\end{array}$ & 3871 & $\begin{array}{l}\text { Anti-HCV- und } \\
\text { HCV-RNA-Prävalenz }\end{array}$ & $\begin{array}{l}\text { HCV-Risikofaktor } \\
\text { Tattoo }\end{array}$ & Level 4 \\
\hline $\begin{array}{l}\text { Tohme RA } \\
\text { et al., } 2012\end{array}$ & HCV-Prävalenz & Review & - & - & $\begin{array}{l}\text { Anti-HCV- und } \\
\text { HCV-RNA-Prävalenz }\end{array}$ & $\begin{array}{l}\text { HCV-Risikofaktor } \\
\text { Tattoo }\end{array}$ & Level 2 \\
\hline $\begin{array}{l}\text { Jansen K } \\
\text { et al., } 2015\end{array}$ & HCV-Prävalenz & $\begin{array}{l}\text { prospektive } \\
\text { Studie }\end{array}$ & keine & 1838 & $\begin{array}{l}\text { Anti-HCV- und } \\
\text { HCV-RNA-Prävalenz }\end{array}$ & HCV bei HIV & Level 1 \\
\hline $\begin{array}{l}\text { Garcia-Teje- } \\
\text { dor A et al., } \\
2015\end{array}$ & HCV-Prävalenz & $\begin{array}{l}\text { retrospektive } \\
\text { Studie }\end{array}$ & keine & 711 & $\begin{array}{l}\text { Anti-HCV- und } \\
\text { HCV-RNA-Prävalenz }\end{array}$ & $\begin{array}{l}\text { vertikale } \\
\text { HCV-Übertragung }\end{array}$ & Level 3 \\
\hline $\begin{array}{l}\text { Heidrich B } \\
\text { et al., } 2014\end{array}$ & HCV-Prävalenz & $\begin{array}{l}\text { prospektive } \\
\text { Studie }\end{array}$ & keine & 1313 & $\begin{array}{l}\text { Anti-HCV und } \\
\text { HCV-RNA-Prävalenz }\end{array}$ & HCV bei Migranten & Level 1 \\
\hline
\end{tabular}




\section{AG 1.2 Virologische Diagnostik der HCV-Infektion}

a) Wie wird eine Infektion mit dem HCV diagnostiziert?

b) Welche Parameter sollten initial, welche im Verlauf bestimmt werden?

\begin{tabular}{|c|c|c|c|c|c|c|c|}
\hline $\begin{array}{l}\text { Referenz- } \\
\text { autor, Jahr }\end{array}$ & $\begin{array}{l}\text { Thema, } \\
\text { Intervention }\end{array}$ & Studientyp & Kontrolle & n gesamt & $\begin{array}{l}\text { Zielparameter, } \\
\text { Beobachtungsdauer }\end{array}$ & $\begin{array}{l}\text { Ergebnis, } \\
\text { Bemerkungen }\end{array}$ & $\begin{array}{l}\text { Evidenzgrad, } \\
\text { *Oxford-Schema }\end{array}$ \\
\hline $\begin{array}{l}\text { Hajarizadeh B } \\
\text { et al., } 2015\end{array}$ & $\begin{array}{l}\text { HCV-RNA-Level } \\
\text { bei akuter HCV }\end{array}$ & $\begin{array}{l}\text { retrospektive } \\
\text { Studie }\end{array}$ & keine & 163 & HCV-RNA quant & $\begin{array}{l}\text { HCV-RNA bei } \\
\text { akuter HCV }\end{array}$ & Level 3 \\
\hline $\begin{array}{l}\text { Grebely J et al., } \\
2014\end{array}$ & $\begin{array}{l}\text { Outcome bei } \\
\text { akuter HCV }\end{array}$ & $\begin{array}{l}\text { prospektive } \\
\text { Studie }\end{array}$ & keine & 632 & $\begin{array}{l}\text { Outcome bei akuter } \\
\mathrm{HCV}\end{array}$ & & Level 1 \\
\hline $\begin{array}{l}\text { Vermehren J et } \\
\text { al., } 2016\end{array}$ & $\begin{array}{l}\text { Durchführung } \\
\text { des HCV-RNA- } \\
\text { Tests }\end{array}$ & $\begin{array}{l}\text { Methoden- } \\
\text { vergleich }\end{array}$ & keine & 740 & HCV-RNA quant & $\begin{array}{l}\text { Vergleich CAP/CTM } \\
\text { vs. Abbott }\end{array}$ & Level 3 \\
\hline $\begin{array}{l}\text { Fevery B et al., } \\
2015\end{array}$ & $\begin{array}{l}\text { Durchführung } \\
\text { des HCV-RNA- } \\
\text { Tests }\end{array}$ & $\begin{array}{l}\text { Methoden- } \\
\text { vergleich }\end{array}$ & keine & 543 & HCV-RNA quant & $\begin{array}{l}\text { Vergleich CAP/CTM } \\
\text { vs. Abbott }\end{array}$ & Level 3 \\
\hline $\begin{array}{l}\text { Wiesmann F et } \\
\text { al., } 2015\end{array}$ & $\begin{array}{l}\text { Durchführung } \\
\text { des HCV-RNA- } \\
\text { Tests }\end{array}$ & $\begin{array}{l}\text { Methoden- } \\
\text { vergleich }\end{array}$ & keine & & HCV-RNA quant & $\begin{array}{l}\text { Test von WHO und } \\
\text { PEI Standards }\end{array}$ & Level 2 \\
\hline $\begin{array}{l}\text { Yoshida EM } \\
\text { et al., } 2015\end{array}$ & $\begin{array}{l}\text { klinisches } \\
\text { Outcome nach } \\
\text { HCV-Therapie }\end{array}$ & $\begin{array}{l}\text { retrospektive } \\
\text { Studie }\end{array}$ & keine & 863 & HCV-RNA-Status & $\begin{array}{l}\text { Outcome nach } \\
\text { DAA-Therapie }\end{array}$ & Level 2 \\
\hline $\begin{array}{l}\text { Chen J et al., } \\
2013\end{array}$ & $\begin{array}{l}\text { klinisches } \\
\text { Outcome nach } \\
\text { HCV-Therapie }\end{array}$ & Review & - & - & HCV-RNA-Status & $\begin{array}{l}\text { Outcome nach } \\
\text { Therapie }\end{array}$ & Level 1 \\
\hline $\begin{array}{l}\text { Maasoumy B } \\
\text { et al., } 2016\end{array}$ & $\begin{array}{l}\text { klinisches Out- } \\
\text { come nach HCV- } \\
\text { Therapie }\end{array}$ & $\begin{array}{l}\text { retrospektive } \\
\text { Studie }\end{array}$ & keine & 298 & HCV-RNA quant & $\begin{array}{l}\text { Outcome nach } \\
\text { Therapie }\end{array}$ & Level 2 \\
\hline $\begin{array}{l}\text { Liu CH et al., } \\
2015\end{array}$ & $\begin{array}{l}\text { Durchführung } \\
\text { des HCV-RNA- } \\
\text { Tests }\end{array}$ & $\begin{array}{l}\text { Methoden- } \\
\text { vergleich }\end{array}$ & keine & 225 & HCV-Genotyp & Versant vs. Abbott & Level 2 \\
\hline $\begin{array}{l}\text { Yang R et al., } \\
2014\end{array}$ & $\begin{array}{l}\text { Durchführung } \\
\text { des HCV-RNA- } \\
\text { Tests }\end{array}$ & $\begin{array}{l}\text { Methoden- } \\
\text { vergleich }\end{array}$ & keine & 63 & HCV-Genotyp & nur HCV Genotyp 6 & Level 2 \\
\hline $\begin{array}{l}\text { Benedet M } \\
\text { et al., } 2014\end{array}$ & $\begin{array}{l}\text { Durchführung } \\
\text { des HCV-RNA- } \\
\text { Tests }\end{array}$ & $\begin{array}{l}\text { retrospektive } \\
\text { Studie }\end{array}$ & keine & 1052 & HCV-Genotyp & $\begin{array}{l}\text { Versagen der } \\
\text { Genotypisierung }\end{array}$ & Level 3 \\
\hline $\begin{array}{l}\text { Mokhtari C } \\
\text { et al., } 2016\end{array}$ & $\begin{array}{l}\text { Durchführung } \\
\text { des HCV-RNA- } \\
\text { Tests }\end{array}$ & $\begin{array}{l}\text { Methoden- } \\
\text { vergleich }\end{array}$ & keine & 3626 & HCV-Genotyp & $\begin{array}{l}\text { Abbott GTII vs. } \\
\text { GT plus }\end{array}$ & Level 2 \\
\hline $\begin{array}{l}\text { Mallory MA } \\
\text { et al., } 2014\end{array}$ & $\begin{array}{l}\text { Durchführung } \\
\text { des HCV-RNA- } \\
\text { Tests }\end{array}$ & $\begin{array}{l}\text { Methoden- } \\
\text { vergleich }\end{array}$ & keine & 162 & HCV Genotyp & $\begin{array}{l}\text { Abbott GTII vs. } \\
\text { sequencing }\end{array}$ & Level 2 \\
\hline $\begin{array}{l}\text { Hedskog C } \\
\text { et al., } 2015\end{array}$ & $\begin{array}{l}\text { Therapie von } \\
\text { HCV-Rekombi- } \\
\text { nanten }\end{array}$ & Fallserie & keine & 12 & Therapieerfolg & $\begin{array}{l}\text { Therapie mit SOF } \\
\text { bei HCV-Rekombi- } \\
\text { nanten }\end{array}$ & Level 4 \\
\hline $\begin{array}{l}\text { De Keukeleire S } \\
\text { et al., } 2015\end{array}$ & $\begin{array}{l}\text { Durchführung } \\
\text { des HCV-RNA- } \\
\text { Tests }\end{array}$ & Fallstudie & keine & 1 & HCV Genotyp & $\begin{array}{l}\text { HCV Genotypisie- } \\
\text { rung bei Rekombi- } \\
\text { nanten }\end{array}$ & Level 4 \\
\hline
\end{tabular}


c) Welche weitere Diagnostik ist bei der Erstdiagnose einer HCV-Infektion erforderlich?

- Die Literatur wurde aus der Vorversion der Leitlinie übernommen.

d) Bei welchen Patienten und mit welcher Methode soll der Grad der Leberfibrose bestimmt werden?

- Die Literatur wurde aus der Vorversion der Leitlinie übernommen.

e) Welches Follow-up ist bei nicht behandelter HCV-Infektion, Therapieversagern und/oder Leberzirrhose indiziert?

- Die Literatur wurde aus der Vorversion der Leitlinie übernommen.

\section{AG 1.3 HCV-Resistenztestung}

Wann sollte eine genotypische HCV-Resistenztestung durchgeführt werden?

\begin{tabular}{|c|c|c|c|c|c|c|c|}
\hline $\begin{array}{l}\text { Referenz- } \\
\text { autor, Jahr }\end{array}$ & $\begin{array}{l}\text { Thema, } \\
\text { Intervention }\end{array}$ & Studientyp & Kontrolle & n gesamt & $\begin{array}{l}\text { Zielparameter, } \\
\text { Beobachtungsdauer }\end{array}$ & $\begin{array}{l}\text { Ergebnis, } \\
\text { Bemerkungen }\end{array}$ & $\begin{array}{l}\text { Evidenzgrad, } \\
{ }^{*} \text { Oxford-Schema }\end{array}$ \\
\hline $\begin{array}{l}\text { Sarrazin C } \\
\text { et al., } 2016\end{array}$ & $\begin{array}{l}\text { Relevanz von } \\
\text { HCV-RAVs }\end{array}$ & Review & - & - & $\begin{array}{l}\text { Relevanz der } \\
\text { Häufigkeit von RAVs }\end{array}$ & & Level 2 \\
\hline $\begin{array}{l}\text { Ferenci P } \\
\text { et al., } 2015\end{array}$ & $\begin{array}{l}\text { Relevanz von } \\
\text { Zirrhose }\end{array}$ & Review & - & - & Relevanz der Zirrhose & & Level 5 \\
\hline $\begin{array}{l}\text { Lawitz E et al., } \\
2015\end{array}$ & SMV/SOF & $\begin{array}{l}\text { open-label, } \\
\text { single-arm }\end{array}$ & $\begin{array}{l}\text { historische } \\
\text { Kontrolle }\end{array}$ & 103 & SVR12 & $\begin{array}{l}\text { SMV/SOF bei } \\
\text { Zirrhose }\end{array}$ & Level 3 \\
\hline $\begin{array}{l}\text { Nelson DR } \\
\text { et al., } 2015\end{array}$ & $\begin{array}{l}\text { SOF/DCV bei } \\
\text { GT3 }\end{array}$ & $\begin{array}{l}\text { open-label, } \\
\text { single-arm }\end{array}$ & keine & 152 & SVR12 & ALLY-3 & Level 3 \\
\hline $\begin{array}{l}\text { Walker A et al., } \\
2015\end{array}$ & Y93H-Prävalenz & $\begin{array}{l}\text { retrospektive } \\
\text { Studie }\end{array}$ & keine & 110 & Y93H-Häufigkeit & Y93H bei GT3 & Level 3 \\
\hline $\begin{array}{l}\text { Jacobson IM } \\
\text { et al., } 2014\end{array}$ & SMV+peglFN & $\mathrm{RCT}$ & Placebo & 394 & SVR12 & Einfluss von Q80K & Level 2 \\
\hline $\begin{array}{l}\text { Manns M } \\
\text { et al., } 2014\end{array}$ & SMV+pegIFN & $\mathrm{RCT}$ & Placebo & 343 & SVR12 & Einfluss von Q80K & Level 2 \\
\hline $\begin{array}{l}\text { Kwo P et al., } \\
2016\end{array}$ & SMV/SOF & $\begin{array}{l}\text { randomized } \\
\text { open-label }\end{array}$ & $\begin{array}{l}\text { historische } \\
\text { Kontrolle }\end{array}$ & 310 & SVR12 & Einfluss von Q80K & Level 3 \\
\hline $\begin{array}{l}\text { Pawlotsky JM } \\
\text { et al., } 2016\end{array}$ & HCV-Resistenz & Review & - & - & Resistenzentwicklung & & Level 2 \\
\hline
\end{tabular}

AG 1.4 Weitere Diagnostik bei Erstdiagnose einer HCV-Infektion

Welche weitere Diagnostik ist bei der Erstdiagnose einer HCV-Infektion erforderlich?

Die Literatur wurde aus der Vorversion der Leitlinie übernommen.

AG 1.5 Bestimmung des Grads der Leberfibrose

Bei welchen Patienten und mit welcher Methode soll der Grad der Leberfibrose bestimmt werden?

Die Literatur wurde aus der Vorversion der Leitlinie übernommen.

AG 1.6 Follow-up bei nicht behandelter HCV-Infektion

Welches Follow-up ist bei nicht behandelter HCV-Infektion, Therapieversagern und/oder Leberzirrhose indiziert? Die Literatur wurde aus der Vorversion der Leitlinie übernommen. 


\section{AG 2: Prävention der HCV-Übertragung und Prophylaxe der Chronifizierung}

\section{AG 2.1 Hepatitis C und Nadelstich}

Welches Vorgehen ist nach Verletzung mit einer möglicherweise HCV-kontaminierten Nadel oder nach Exposition mit HCV-kontaminierter Flüssigkeit zu empfehlen?

\begin{tabular}{|c|c|c|c|c|c|c|c|}
\hline $\begin{array}{l}\text { Referenz- } \\
\text { autor, Jahr }\end{array}$ & $\begin{array}{l}\text { Thema, } \\
\text { Intervention }\end{array}$ & Studientyp & Kontrolle & n gesamt & $\begin{array}{l}\text { Zielparameter, } \\
\text { Beobachtungs- } \\
\text { dauer }\end{array}$ & $\begin{array}{l}\text { Ergebnis, } \\
\text { Bemerkungen }\end{array}$ & $\begin{array}{l}\text { Evidenzgrad, } \\
{ }^{*} \text { Oxford-Schema }\end{array}$ \\
\hline $\begin{array}{l}\text { Tomkins et al., } \\
\text { J Viral Hepatitis } \\
2012\end{array}$ & $\begin{array}{l}\text { occupational } \\
\text { HCV-transmission }\end{array}$ & case series & $\begin{array}{l}\text { Serocon- } \\
\text { version vs. } \\
\text { no conver- } \\
\text { sion }\end{array}$ & 626 & Serokonversion & $14 / 626(2,2 \%)$ & 4 \\
\hline $\begin{array}{l}\text { Frijstein et al., } \\
\text { Neth J Med } \\
2011\end{array}$ & $\begin{array}{l}\text { needle sticks and } \\
\text { occupational } \\
\text { HCV-transmission }\end{array}$ & $\begin{array}{l}\text { konsekutive } \\
\text { komplette } \\
\text { Fallserie }\end{array}$ & nein & $\begin{array}{l}1601 \text { Exposi- } \\
\text { tionen, da- } \\
\text { von } 53 \mathrm{HCV}+\end{array}$ & Serokonversion & 1/53 Serokonversion & 3 \\
\hline $\begin{array}{l}\text { Corey et al., } \\
\text { Infect Control } \\
2009\end{array}$ & $\begin{array}{l}\text { post-exposure } \\
\text { prophylaxis } \\
\text { mit PEG-IFNa } \\
\text { (4 Wochen) }\end{array}$ & $\begin{array}{l}\text { prospektive } \\
\text { Pilotstudie }\end{array}$ & nein & $\begin{array}{l}213 \text { ge- } \\
\text { samt; } 44 \\
\text { behandelt }\end{array}$ & Serokonversion & $\begin{array}{l}\text { keine Serokonver- } \\
\text { sion (behandelt und } \\
\text { unbehandelt) }\end{array}$ & 3 \\
\hline $\begin{array}{l}\text { Kubitschke } \\
\text { et al. Internist } \\
2007\end{array}$ & HCV-transmission & $\begin{array}{l}\text { systematic } \\
\text { review }\end{array}$ & ja & 6956 & $\begin{array}{l}\text { Serokonversion, } \\
\text { HCV-Infektion }\end{array}$ & $0,42 \%$ & 2 \\
\hline $\begin{array}{l}\text { Yazdanpanah } \\
\text { et al., Clin In- } \\
\text { fect Dis } 2005\end{array}$ & $\begin{array}{l}\text { Risikofaktoren für } \\
\text { HCV-transmission }\end{array}$ & $\begin{array}{l}\text { Fall-Kontroll- } \\
\text { Studie }\end{array}$ & ja & 66 vs. 204 & $\begin{array}{l}\text { Serokonversion, } \\
\text { HCV-Infektion }\end{array}$ & $\begin{array}{l}\text { Risikofaktoren } \\
\text { definiert }\end{array}$ & 3 \\
\hline $\begin{array}{l}\text { De Carli et al., } \\
2003 \text { Infection }\end{array}$ & HCV-transmission & $\begin{array}{l}\text { prospektive } \\
\text { Überwachung }\end{array}$ & nein & 4403 & $\begin{array}{l}\text { Serokonversion, } \\
\text { HCV-Infektion }\end{array}$ & $\begin{array}{l}14 \text { Infektionen } \\
(0,31)\end{array}$ & 3 \\
\hline $\begin{array}{l}\text { Chung et al., } \\
\text { J Gastroenterol } \\
2003\end{array}$ & $\begin{array}{l}\text { post-exposure } \\
\text { prophylaxis with } \\
\text { IFN ( } 1 \text { - } 3 \text { days) }\end{array}$ & $\begin{array}{l}\text { retrospektive } \\
\text { Analyse }\end{array}$ & ja & $\begin{array}{l}684 \text { (davon } \\
279 \text { behan- } \\
\text { delt) }\end{array}$ & $\begin{array}{l}\text { Serokonversion, } \\
\text { HCV-Infektion }\end{array}$ & $\begin{array}{l}2 \text { Infektionen } \\
\text { (1 behandelt, } \\
1 \text { unbehandelt) }\end{array}$ & 3 \\
\hline $\begin{array}{l}\text { Nukaya et al., } \\
\text { Hepatol Res } \\
2007\end{array}$ & $\begin{array}{l}\text { post-exposure } \\
\text { prophylaxis with } \\
\text { IFN 1x 10MU }\end{array}$ & $\begin{array}{l}\text { retrospektive } \\
\text { Analyse }\end{array}$ & ja & $\begin{array}{l}264 \text { (davon } \\
129 \text { behan- } \\
\text { delt) }\end{array}$ & $\begin{array}{l}\text { Serokonversion, } \\
\text { HCV-Infektion }\end{array}$ & $\begin{array}{l}1 \text { Infektion } \\
\text { (behandelt) }\end{array}$ & 4 \\
\hline
\end{tabular}

\section{AG 2.2 Maßnahmen zur Vermeidung nosokomialer HCV-Infektionen}

Welche präventiven Maßnahmen müssen bei medizinischen Eingriffen bei HCV-positiven Patienten ergriffen werden?

\begin{tabular}{|l|l|l|l|l|l|l|l|}
\hline $\begin{array}{l}\text { Referenz- } \\
\text { autor, Jahr }\end{array}$ & $\begin{array}{l}\text { Thema, } \\
\text { Intervention }\end{array}$ & Studientyp & Kontrolle & $\begin{array}{l}\text { n gesamt } \\
\text { Evidenzgrad, } \\
\text { Bemerkungen }\end{array}$ & $\begin{array}{l}\text { Zielparameter, } \\
\text { Beobachtungs- } \\
\text { dauer }\end{array}$ \\
\hline \begin{tabular}{l|l|l|} 
Ciesek, JID, \\
2010
\end{tabular} & Stabilität HCV & $\begin{array}{l}\text { experimentell } \\
\text { in vitro }\end{array}$ & Stabilität HCV \\
\hline $\begin{array}{l}\text { Doerbecker } \\
\text { et al., JID 2011 }\end{array}$ & $\begin{array}{l}\text { Inaktivierung } \\
\text { HCV auf Oberflä- } \\
\text { chen }\end{array}$ & $\begin{array}{l}\text { experimentell } \\
\text { in vitro }\end{array}$ & $\begin{array}{l}\text { Effekt von stabil bleiben } \\
\text { fektionslösungen } \\
\text { auf Infektivität }\end{array}$ \\
\hline
\end{tabular}

\section{AG 2.3 Vorsichtsmaßnahmen bei HCV-RNA-positiven Mitarbeitern in medizinischen Berufen}

\section{Welche Vorsichtsmaßnahmen sind bei Mitarbeitern in medizinischen Berufen indiziert?}

Die Literatur wurde aus der Vorversion der Leitlinie übernommen. 
AG 2.4 Vorsichtsmaßnahmen bei intrafamiliärem oder sexuellem Kontakt mit HCV-positiven Personen

Welche Verhaltensmaßnahmen sind für Personen im Umfeld von Patienten mit chronischer Hepatitis C zu beachten? Wie kann eine sexuelle Übertragung des HCV verhindert werden?

\begin{tabular}{|c|c|c|c|c|c|c|c|}
\hline $\begin{array}{l}\text { Referenz- } \\
\text { autor, Jahr }\end{array}$ & $\begin{array}{l}\text { Thema, } \\
\text { Intervention }\end{array}$ & Studientyp & Kontrolle & n gesamt & $\begin{array}{l}\text { Zielparameter, } \\
\text { Beobachtungs- } \\
\text { dauer }\end{array}$ & $\begin{array}{l}\text { Ergebnis, } \\
\text { Bemerkungen }\end{array}$ & $\begin{array}{l}\text { Evidenzgrad, } \\
\text { * Oxford-Schema }\end{array}$ \\
\hline $\begin{array}{l}\text { Said et al., } \\
\text { J Trop Pediatr }\end{array}$ & $\begin{array}{l}\text { intrafamilial } \\
\text { transmission }\end{array}$ & $\begin{array}{l}\text { prospective } \\
\text { testing }\end{array}$ & ja & 137 & $\begin{array}{l}\text { Anti-HCV in Fami- } \\
\text { lienmitgliedern }\end{array}$ & $\begin{array}{l}\text { höhere anti-HCV Prä- } \\
\text { valenz bei Familien- } \\
\text { mitgliedern von anti- } \\
\text { HCV-pos. Patienten } \\
\text { (14/24 vs. } 4 / 27)\end{array}$ & 4 \\
\hline $\begin{array}{l}\text { Paez Jiminze } \\
\text { et al. Gut } 2010\end{array}$ & $\begin{array}{l}\text { intrafamiliäre } \\
\text { HCV-Transmission }\end{array}$ & $\begin{array}{l}\text { Fall-Kontroll- } \\
\text { Studie }\end{array}$ & ja & $\begin{array}{l}100 \text { vs. } 678 \\
\text { Kontrollen }\end{array}$ & HCV-Transmission & $\begin{array}{l}\text { 18/100 HCV-positive } \\
\text { Familienmitglieder }\end{array}$ & 3 \\
\hline $\begin{array}{l}\text { Ndong-Atime } \\
\text { et al., J Clin Vi- } \\
\text { rol } 2009\end{array}$ & $\begin{array}{l}\text { Intrafamiliäre } \\
\text { HCV Transmission }\end{array}$ & $\begin{array}{l}\text { cross-sectional } \\
\text { screening }\end{array}$ & Nein & 195 & $\begin{array}{l}\text { Anti-HCV bei Fa- } \\
\text { milienmitgliedern }\end{array}$ & $\begin{array}{l}13 \text { anti-HCV positive } \\
\text { Familienmitglieder, } \\
\text { keine Kinder positive }\end{array}$ & 4 \\
\hline $\begin{array}{l}\text { Ackermann } \\
\text { et al. J Viral } \\
\text { Hepatitis } 2000\end{array}$ & $\begin{array}{l}\text { intrafamiliäre } \\
\text { HCV-Transmission }\end{array}$ & $\begin{array}{l}\text { systematic } \\
\text { review }\end{array}$ & & 4250 & HCV-Transmission & $\begin{array}{l}4 \% \text { HCV Prävalenz } \\
\text { vs. } 0 \% \text { bei anti-HCV- } \\
\text { positiven vs. neg. } \\
\text { Index-Patienten }\end{array}$ & 2 \\
\hline $\begin{array}{l}\text { Plancoulaine } \\
\text { et al., Gut } 2008\end{array}$ & $\begin{array}{l}\text { intrafamiliäre } \\
\text { HCV-Transmission }\end{array}$ & $\begin{array}{l}\text { epidemiol. } \\
\text { survey }\end{array}$ & ja & $\begin{array}{l}3994 \text { Patien- } \\
\text { ten in } 475 \\
\text { Familien }\end{array}$ & $\begin{array}{l}\text { familiäre HCV } \\
\text { Transmission }\end{array}$ & $\begin{array}{l}\text { höheres Risiko bei } \\
\text { HCV-positivem Va- } \\
\text { ter, geringeres zwi- } \\
\text { schen Geschwistern }\end{array}$ & 3 \\
\hline $\begin{array}{l}\text { La Torre et al., } \\
\text { BMC Public } \\
\text { Health } 2006\end{array}$ & $\begin{array}{l}\text { intrafamiliäre } \\
\text { HCV-Transmission }\end{array}$ & $\begin{array}{l}\text { cross-sectional } \\
\text { screening }\end{array}$ & Nein & $\begin{array}{l}175 \text { HCV } \\
+259 \text { Fami- } \\
\text { lienangehö- } \\
\text { rige }\end{array}$ & $\begin{array}{l}\text { familiäre HCV } \\
\text { Transmission }\end{array}$ & $\begin{array}{l}\text { Angehörige in 8,9\% } \\
\text { HCV-positiv; Haupt- } \\
\text { risikofaktor Drogen- } \\
\text { konsum des Index- } \\
\text { patienten }\end{array}$ & 4 \\
\hline $\begin{array}{l}\text { Mohammed } \\
\text { et al., Hepato- } \\
\text { logy } 2005\end{array}$ & $\begin{array}{l}\text { HCV incidence in } \\
\text { Ägypten }\end{array}$ & $\begin{array}{l}\text { prospektive } \\
\text { Kohorten- } \\
\text { studie }\end{array}$ & ja & 6734 & $\begin{array}{l}\text { HCV-Serokon- } \\
\text { version }\end{array}$ & $\begin{array}{l}\text { stärkster Prädiktor } \\
\text { für HCV-Serokonver- } \\
\text { sion positives Famili- } \\
\text { enmitglied }\end{array}$ & 2 \\
\hline $\begin{array}{l}\text { Keisermann } \\
\text { et al., Am J } \\
\text { Gastroenterol } \\
2003\end{array}$ & $\begin{array}{l}\text { intrafamiliäre } \\
\text { HCV-Transmission }\end{array}$ & $\begin{array}{l}\text { prospektive } \\
\text { Kohorten- } \\
\text { studie }\end{array}$ & ja & 347 & $\begin{array}{l}\text { HCV-Serokon- } \\
\text { version }\end{array}$ & $\begin{array}{l}\text { anti-HCV in } 2,2 \% \text { der } \\
\text { Familienmitglieder }\end{array}$ & 3 \\
\hline $\begin{array}{l}\text { Lock et al., } \\
\text { J Viral Hepatitis } \\
2006\end{array}$ & $\begin{array}{l}\text { HCV auf Zahn- } \\
\text { bürsten }\end{array}$ & $\begin{array}{l}\text { virologisches } \\
\text { Screening }\end{array}$ & nein & 30 & $\begin{array}{l}\text { HCV RNA in } \\
\text { Speichel und auf } \\
\text { der Zahnbürste }\end{array}$ & $\begin{array}{l}\text { Speichel und Zahn- } \\
\text { bürsten in } 30 \text { bzw. } \\
37 \% \text { HCV-RNA- } \\
\text { positiv }\end{array}$ & 4 \\
\hline $\begin{array}{l}\text { Heidrich et al., } \\
\text { J Clin Virol } 2016\end{array}$ & HCV im Stuhl & $\begin{array}{l}\text { virologisches } \\
\text { Screening }\end{array}$ & nein & 98 & $\begin{array}{l}\text { HCV-RNA- und } \\
\text { HCV-Core-Ag im } \\
\text { Stuhl }\end{array}$ & $68 / 98$ positiv & 4 \\
\hline $\begin{array}{l}\text { Xavier Santos } \\
\text { et al., J Infect } \\
\text { Publ Health } \\
2016\end{array}$ & HCV im Speichel & $\begin{array}{l}\text { virologisches } \\
\text { Screening }\end{array}$ & nein & 70 & $\begin{array}{l}\text { HCV-RNA in } \\
\text { Speichel }\end{array}$ & $\begin{array}{l}\text { 56/70 HCV-RNA- } \\
\text { positiv }\end{array}$ & 4 \\
\hline $\begin{array}{l}\text { Terrault et al., } \\
\text { Hepatology } \\
2013\end{array}$ & $\begin{array}{l}\text { sexuelle HCV- } \\
\text { Transmission, } \\
\text { heterosexuell, } \\
\text { monogam }\end{array}$ & $\begin{array}{l}\text { prospektive } \\
\text { Kohorten- } \\
\text { studie }\end{array}$ & nein & 500 & $\begin{array}{l}\text { sexuelle } \\
\text { Übertragung }\end{array}$ & $\begin{array}{l}\text { HCV-Transmission } \\
0,07 \% / J a h r\end{array}$ & 3 \\
\hline $\begin{array}{l}\text { Vandelli et al., } \\
\text { Am J Gastro- } \\
\text { enenterol } 2004\end{array}$ & $\begin{array}{l}\text { sexuelle HCV- } \\
\text { Transmission, } \\
\text { heterosexuell, } \\
\text { monogam }\end{array}$ & $\begin{array}{l}\text { prospektive } \\
\text { Kohorten- } \\
\text { studie }\end{array}$ & nein & 895 & $\begin{array}{l}\text { sexuelle } \\
\text { Übertragung }\end{array}$ & $\begin{array}{l}\text { keine HCV-Trans- } \\
\text { mission in } 10 \text { Jahren }\end{array}$ & 3 \\
\hline
\end{tabular}




\begin{tabular}{|c|c|c|c|c|c|c|c|}
\hline $\begin{array}{l}\text { Referenz- } \\
\text { autor, Jahr }\end{array}$ & $\begin{array}{l}\text { Thema, } \\
\text { Intervention }\end{array}$ & Studientyp & Kontrolle & n gesamt & $\begin{array}{l}\text { Zielparameter, } \\
\text { Beobachtungs- } \\
\text { dauer }\end{array}$ & $\begin{array}{l}\text { Ergebnis, } \\
\text { Bemerkungen }\end{array}$ & $\begin{array}{l}\text { Evidenzgrad, } \\
{ }^{*} \text { Oxford-Schema }\end{array}$ \\
\hline $\begin{array}{l}\text { Boesecke et al., } \\
\text { Liver Int } 2015\end{array}$ & $\begin{array}{l}\text { HCV serocon- } \\
\text { version in HIV } \\
\text { infection }\end{array}$ & $\begin{array}{l}\text { EUROSIDA } \\
\text { Kohorte/Re- } \\
\text { gisterstudie }\end{array}$ & nein & 16188 tests & $\begin{array}{l}\text { HCV-Serokon- } \\
\text { version }\end{array}$ & Risiko $4 \% / J a h r ~$ & 4 \\
\hline $\begin{array}{l}\text { Hagan et al., } \\
\text { AIDS } 2015\end{array}$ & $\begin{array}{l}\text { HCV serocon- } \\
\text { version in HIV } \\
\text { infection }\end{array}$ & $\begin{array}{l}\text { systematic } \\
\text { review }\end{array}$ & nein & 13000 & $\begin{array}{l}\text { HCV-Serokon- } \\
\text { version }\end{array}$ & $\begin{array}{l}\text { Zunahme der Sero- } \\
\text { konversion } 2010 \\
\text { und } 2012 \text { gegen- } \\
\text { über } 1991\end{array}$ & 3 \\
\hline $\begin{array}{l}\text { Yaphe et al., } \\
\text { Sex Transmi In- } \\
\text { fect } 2012\end{array}$ & $\begin{array}{l}\text { HCV serocon- } \\
\text { version in HIV } \\
\text { infection }\end{array}$ & $\begin{array}{l}\text { systematic } \\
\text { review }\end{array}$ & $\begin{array}{l}\text { ja (HIV } \\
\text { neg.) }\end{array}$ & 21 Studien & $\begin{array}{l}\text { HCV-Serokon- } \\
\text { version }\end{array}$ & $\begin{array}{l}\text { besonders hohes Ri- } \\
\text { siko für HIV-positive } \\
\text { MSM }\end{array}$ & 3 \\
\hline $\begin{array}{l}\text { Ingiliz et al., J } \\
\text { Hepatol } 2017\end{array}$ & $\begin{array}{l}\text { HCV reinfection } \\
\text { in HIV infection }\end{array}$ & $\begin{array}{l}\text { retrospektive } \\
\text { Analyse }\end{array}$ & nein & 606 & HCV-Reinfektion & $\begin{array}{l}\text { Reinfektions-Inzi- } \\
\text { dent 7,3/100 Perso- } \\
\text { nenjahre }\end{array}$ & 4 \\
\hline
\end{tabular}

AG 2.5 Vorsichts- und Überwachungsmaßnahmen bei Drogenkonsumierenden

Welche Vorsichts- und Überwachungsmaßnahmen sind bei Drogenkonsumierenden indiziert?

\begin{tabular}{|c|c|c|c|c|c|c|c|}
\hline $\begin{array}{l}\text { Referenz- } \\
\text { autor, Jahr }\end{array}$ & $\begin{array}{l}\text { Thema, } \\
\text { Intervention }\end{array}$ & Studientyp & Kontrolle & n gesamt & $\begin{array}{l}\text { Zielparameter, } \\
\text { Beobachtungs- } \\
\text { dauer }\end{array}$ & $\begin{array}{l}\text { Ergebnis, } \\
\text { Bemerkungen }\end{array}$ & $\begin{array}{l}\text { Evidenzgrad, } \\
{ }^{*} \text { Oxford-Schema }\end{array}$ \\
\hline $\begin{array}{l}\text { Esmaeili, J Viral } \\
\text { Hepatitis } 2017\end{array}$ & $\begin{array}{l}\text { HCV-Inzidenz } \\
\text { Frauen vs. } \\
\text { Männer }\end{array}$ & $\begin{array}{l}\text { systematic } \\
\text { review }\end{array}$ & $\mathrm{Ja}$ & $\begin{array}{l}28 \text { Studien, } \\
9325 \text { Perso- } \\
\text { nen }\end{array}$ & $\begin{array}{l}\text { HCV-Inzidenz bei } \\
\text { Drogengebrau- } \\
\text { chern Frauen vs. } \\
\text { Männer }\end{array}$ & $\begin{array}{l}\text { höhere HCV-Inzi- } \\
\text { denz bei Frauen }\end{array}$ & 3 \\
\hline $\begin{array}{l}\text { Fernandes, } \\
\text { et al., BMC Pu- } \\
\text { blic Health } 2017\end{array}$ & $\begin{array}{l}\text { Nadelaus- } \\
\text { tauschpro- } \\
\text { gramme }\end{array}$ & $\begin{array}{l}\text { Überblick sys- } \\
\text { tematische } \\
\text { reviews }\end{array}$ & & 133 Studien & $\begin{array}{l}\text { HCV- und HIV- } \\
\text { Transmission }\end{array}$ & $\begin{array}{l}\text { gute Evidenz für } \\
\text { HIV, unterschiedli- } \\
\text { che Ergebnisse für } \\
\text { HCV }\end{array}$ & 2 \\
\hline $\begin{array}{l}\text { Smith et al., } \\
\text { BMC Infect Dis } \\
2016\end{array}$ & $\begin{array}{l}\text { spontane Aus- } \\
\text { heilung der } \\
\text { HCV-Infektion }\end{array}$ & $\begin{array}{l}\text { systematic } \\
\text { review }\end{array}$ & $\mathrm{Ja}$ & $\begin{array}{l}28 \text { Studien, } \\
5569 \text { Patien- } \\
\text { ten }\end{array}$ & $\begin{array}{l}\text { spontane HCV- } \\
\text { Ausheilung }\end{array}$ & $\begin{array}{l}24,4 \% \text { bei PWID vs. } \\
1,54 \% \text { bei HIV+ } \\
\text { MSM }\end{array}$ & 2 \\
\hline $\begin{array}{l}\text { Smith et al., } \\
\text { Intern J Drug } \\
\text { Policy } 2015\end{array}$ & $\begin{array}{l}\text { Krankheits- } \\
\text { progression }\end{array}$ & Metaanalyse & & $\begin{array}{l}21 \text { Studien, } \\
8495 \text { Patien- } \\
\text { ten }\end{array}$ & $\begin{array}{l}\text { Zirrhose-Ent- } \\
\text { wicklung, De- } \\
\text { kompensation, } \\
\text { HCC }\end{array}$ & $\begin{array}{l}\text { 6,6 (Zirrhose), } 1,1 \\
\text { (Dekompensation) } \\
\text { bzw. 0,3 (HCC) pro } \\
1000 \text { Personenjahre }\end{array}$ & 2 \\
\hline $\begin{array}{l}\text { Wiessing et al., } \\
\text { PLOS one } 2014\end{array}$ & $\begin{array}{l}\text { HCV-Inzidenz } \\
\text { in PWID }\end{array}$ & $\begin{array}{l}\text { systematic } \\
\text { review }\end{array}$ & & 144 Studien & $\begin{array}{l}\text { HCV-Inzidenz } \\
\text { und Prävalenz in } \\
\text { PWID in Europa }\end{array}$ & $\begin{array}{l}\text { HCV-Prävalenz Me- } \\
\text { dian } 72 \% \text {, Inzidenz: } \\
\text { 13/100 Patienten- } \\
\text { jahre }\end{array}$ & 2 \\
\hline $\begin{array}{l}\text { Abdul-Quader } \\
\text { et al., AIDS } \\
\text { Behav } 2013\end{array}$ & $\begin{array}{l}\text { Nadelaus- } \\
\text { tauschpro- } \\
\text { gramme }\end{array}$ & $\begin{array}{l}\text { systematic } \\
\text { review }\end{array}$ & & 15 Studien & $\begin{array}{l}\text { HCV- und HIV- } \\
\text { Transmission }\end{array}$ & $\begin{array}{l}\text { Nadelaustauschpro- } \\
\text { gramme reduzieren } \\
\text { die HIV- und HCV- } \\
\text { Inzidenz }\end{array}$ & 2 \\
\hline $\begin{array}{l}\text { Palmateer } \\
\text { et al., Int J Drug } \\
\text { Policy } 2013\end{array}$ & $\begin{array}{l}\text { Übertragungs- } \\
\text { risiken }\end{array}$ & $\begin{array}{l}\text { systematic } \\
\text { review }\end{array}$ & & 16 Studien & $\begin{array}{l}\text { HCV-Inzidenz } \\
\text { und Prävalenz }\end{array}$ & $\begin{array}{l}\text { HCV-Prävalenz 59\%, } \\
\text { Inzidenz } 11 \%\end{array}$ & 2 \\
\hline $\begin{array}{l}\text { Nelson et al., } \\
\text { Lancet } 2011\end{array}$ & $\begin{array}{l}\text { HBV and HCV } \\
\text { epidemiology } \\
\text { in PWID }\end{array}$ & $\begin{array}{l}\text { systematic } \\
\text { review }\end{array}$ & & 1125 Studien & $\begin{array}{l}\text { HBV- und HCV- } \\
\text { Prävalenz }\end{array}$ & $\begin{array}{l}\text { HCV-Prävalenz } \\
60 \%-80 \% \text { in PWID }\end{array}$ & 2 \\
\hline $\begin{array}{l}\text { Jafari S et al., } \\
\text { Int J Infect Dis } \\
2010\end{array}$ & $\begin{array}{l}\text { Tattoing und } \\
\mathrm{HCV}\end{array}$ & $\begin{array}{l}\text { systematic } \\
\text { review }\end{array}$ & & 83 Studien & $\begin{array}{l}\text { HCV-Prävalenz| } \\
\text { Übertragung }\end{array}$ & $\begin{array}{l}\text { Tattoing ist mit } \\
\text { HCV-Infektionen } \\
\text { assoziiert }\end{array}$ & 2 \\
\hline
\end{tabular}


AG 2.6 Therapie der akuten Hepatitis C

Sollte eine akute Hepatitis C mit antiviralen Medikamenten behandelt werden? Wie kann eine Therapie der akuten Hepatitis C durchgeführt werden?

\begin{tabular}{|c|c|c|c|c|c|c|c|}
\hline $\begin{array}{l}\text { Referenz- } \\
\text { autor, Jahr }\end{array}$ & $\begin{array}{l}\text { Thema, } \\
\text { Intervention }\end{array}$ & Studientyp & Kontrolle & n gesamt & $\begin{array}{l}\text { Zielparameter, } \\
\text { Beobachtungs- } \\
\text { dauer }\end{array}$ & $\begin{array}{l}\text { Ergebnis, } \\
\text { Bemerkungen }\end{array}$ & $\begin{array}{l}\text { Evidenzgrad, } \\
{ }^{*} \text { Oxford-Schema }\end{array}$ \\
\hline $\begin{array}{l}\text { Fierer et al., } \\
\text { CID } 2014\end{array}$ & $\begin{array}{l}\text { acute hepatitis } \\
\text { C, Therapie } \\
\text { Telaprevir + IRN } \\
\text { + RBV }\end{array}$ & Fallserie & nein & 19 & $\begin{array}{l}\text { Ausheilung } \\
12 \text { Wochen } \\
\text { nach Therapie }\end{array}$ & SVR $84 \%$ & 4 \\
\hline $\begin{array}{l}\text { Hullegie et al. } \\
\text { J Hepatol } 2016\end{array}$ & $\begin{array}{l}\text { acute hepatitis } \\
\text { C, Bocprevir, } \\
\text { IFN + RBV }\end{array}$ & $\begin{array}{l}\text { prospektive } \\
\text { Studie }\end{array}$ & historisch & 65 & $\begin{array}{l}\text { Ausheilung } \\
12 \text { Wochen } \\
\text { nach Therapie }\end{array}$ & SVR $86 \%$ (ITT) & 3 \\
\hline $\begin{array}{l}\text { El-Sayed, HIV } \\
\text { Clin Trials } 2017\end{array}$ & $\begin{array}{l}\text { acute hepatitis } \\
\text { C, } 12 \text { weeks } \\
\text { SOF/RBV }\end{array}$ & Fallserie & nein & 12 & $\begin{array}{l}\text { Ausheilung } \\
12 \text { Wochen } \\
\text { nach Therapie }\end{array}$ & $\begin{array}{l}\text { SVR in } 11 / 12 \\
\text { Patienten }\end{array}$ & 4 \\
\hline $\begin{array}{l}\text { Deterding } \\
\text { et al., Lancet ID } \\
2017\end{array}$ & $\begin{array}{l}\text { acute hepatitis } \\
\text { C, Therapie Le- } \\
\text { dipasvir/Sofos- } \\
\text { buvir } 6 \text { Wochen }\end{array}$ & $\begin{array}{l}\text { prospektive } \\
\text { Studie }\end{array}$ & nein & 20 & $\begin{array}{l}\text { Ausheilung } \\
12 \text { Wochen } \\
\text { nach Therapie }\end{array}$ & SVR in $100 \%$ & 3 \\
\hline $\begin{array}{l}\text { Rockstroh et } \\
\text { al., Lancet GE } \\
2017\end{array}$ & $\begin{array}{l}\text { acute hepatitis } \\
\text { C in HIV, Thera- } \\
\text { pie Ledipasvir/ } \\
\text { Sofosbuvir } 6 \\
\text { Wochen }\end{array}$ & $\begin{array}{l}\text { prospektive } \\
\text { Studie }\end{array}$ & nein & 20 & $\begin{array}{l}\text { Ausheilung } \\
12 \text { Wochen } \\
\text { nach Therapie }\end{array}$ & $\begin{array}{l}\text { SVR in } 20 / 26 \\
\text { Patienten }\end{array}$ & 3 \\
\hline $\begin{array}{l}\text { Naggie et al., } \\
\text { Clin Infect Dis } \\
2017\end{array}$ & $\begin{array}{l}\text { acute Hepatitis } \\
\mathrm{C} \text { in HIV, Sofos- } \\
\text { buvir + Ribavi- } \\
\text { rin } 12 \text { Wochen }\end{array}$ & $\begin{array}{l}\text { prospektive } \\
\text { Studie }\end{array}$ & nein & 17 & $\begin{array}{l}\text { Ausheilung } \\
12 \text { Wochen } \\
\text { nach Therapie }\end{array}$ & $\begin{array}{l}\text { SVR in 10/17 } \\
\text { Patienten }\end{array}$ & 3 \\
\hline $\begin{array}{l}\text { Martinello et al., } \\
\text { Hepatology } \\
2016\end{array}$ & $\begin{array}{l}\text { Recent Hepati- } \\
\text { tis C, Sofosbu- } \\
\text { vir + Ribavirin } \\
6 \text { Wochen }\end{array}$ & $\begin{array}{l}\text { prospektive } \\
\text { Studie }\end{array}$ & nein & 19 & $\begin{array}{l}\text { Ausheilung } \\
12 \text { Wochen } \\
\text { nach Therapie }\end{array}$ & $\begin{array}{l}\text { SVR in 6/19 } \\
\text { Patienten }\end{array}$ & 3 \\
\hline $\begin{array}{l}\text { Boesecke et al., } \\
\text { Antiviral Thera- } \\
\text { py } 2017\end{array}$ & $\begin{array}{l}\text { acute hepatitis } \\
\text { C, Therapie Te- } \\
\text { laprevir + IFN + } \\
\text { RBV }\end{array}$ & $\begin{array}{l}\text { prospektive } \\
\text { Studie }\end{array}$ & nein & 34 & $\begin{array}{l}\text { Ausheilung } \\
12 \text { Wochen } \\
\text { nach Therapie }\end{array}$ & $\begin{array}{l}\text { SVR in } 27 / 34 \\
\text { Patienten }\end{array}$ & 3 \\
\hline
\end{tabular}

AG 3: Natürlicher Verlauf und Therapie-Indikation inklusive extrahepatische Manifestationen

AG 3.1 Natürlicher Verlauf der chronischen Hepatitis-C-Virus- (HCV-) Infektion

\begin{tabular}{|c|c|c|c|c|c|c|c|}
\hline $\begin{array}{l}\text { Referenz- } \\
\text { autor, Jahr }\end{array}$ & $\begin{array}{l}\text { Thema, } \\
\text { Intervention }\end{array}$ & Studientyp & Kontrolle & n gesamt & $\begin{array}{l}\text { Zielparameter, } \\
\text { Beobachtungsdauer }\end{array}$ & $\begin{array}{l}\text { Ergebnis, } \\
\text { Bemerkungen }\end{array}$ & $\begin{array}{l}\text { Evidenzgrad, } \\
{ }^{*} \text { Oxford-Schema }\end{array}$ \\
\hline $\begin{array}{l}\text { Wedemeyer } \\
\text { H et al., } 2014\end{array}$ & $\begin{array}{l}\text { Strategien zum } \\
\text { Management } \\
\text { der HCV-Krank- } \\
\text { heitslast }\end{array}$ & $\begin{array}{l}\text { Modellbe- } \\
\text { rechnung }\end{array}$ & - & - & HCV-Elimination & $\begin{array}{l}\text { Bei einer Therapiera- } \\
\text { te von } 10 \% \text { ist eine } \\
\text { HCV-Elimination } \\
\text { möglich. }\end{array}$ & Level 5 \\
\hline $\begin{array}{l}\text { Bruggmann } \\
\text { P et al., } 2014\end{array}$ & Epidemiologie & Review & - & - & HCV-Prävalenz & $\begin{array}{l}\text { höchste Prävalenz in } \\
\text { Ägypten }\end{array}$ & Level 1 \\
\hline $\begin{array}{l}\text { Razavi H } \\
\text { et al., } 2014\end{array}$ & $\begin{array}{l}\text { HCV-Krank- } \\
\text { heitslast und ak- } \\
\text { tuelle Therapie- } \\
\text { strategien }\end{array}$ & $\begin{array}{l}\text { Modellbe- } \\
\text { rechnung }\end{array}$ & - & - & $\begin{array}{l}\text { Therapierate und } \\
\text {-effektivität }\end{array}$ & $\begin{array}{l}\text { Die aktuelle Thera- } \\
\text { pierate und -effekti- } \\
\text { vität sind nicht aus- } \\
\text { reichend. }\end{array}$ & Level 5 \\
\hline $\begin{array}{l}\text { Cowie B } \\
\text { et al., } 2015\end{array}$ & Mortalität & $\begin{array}{l}\text { systemati- } \\
\text { sche Analyse }\end{array}$ & - & - & $\begin{array}{l}\text { Mortalität, Jahre } \\
1990-2013\end{array}$ & $\begin{array}{l}\text { Die Gesamtmortali- } \\
\text { tät nimmt ab. }\end{array}$ & Level 1 \\
\hline
\end{tabular}


a) Prognoseparameter für den natürlichen Verlauf

\begin{tabular}{|c|c|c|c|c|c|c|c|}
\hline $\begin{array}{l}\text { Referenz- } \\
\text { autor, Jahr }\end{array}$ & $\begin{array}{l}\text { Thema, } \\
\text { Intervention }\end{array}$ & Studientyp & Kontrolle & n gesamt & $\begin{array}{l}\text { Zielparameter, } \\
\text { Beobachtungsdauer }\end{array}$ & $\begin{array}{l}\text { Ergebnis, } \\
\text { Bemerkungen }\end{array}$ & $\begin{array}{l}\text { Evidenzgrad, } \\
{ }^{*} \text { Oxford-Schema }\end{array}$ \\
\hline $\begin{array}{l}\text { Rueger S } \\
\text { et al., } 2015\end{array}$ & $\begin{array}{l}\text { Einfluss von } \\
\text { allgemeinen } \\
\text { Risikofaktoren } \\
\text { auf die Fibrose- } \\
\text { progression } \\
\text { bei HCV }\end{array}$ & $\begin{array}{l}\text { retrospek- } \\
\text { tive Kohor- } \\
\text { tenanalyse }\end{array}$ & keine & 1461 & Fibroseprogression & $\begin{array}{l}\text { Risikofaktoren für } \\
\text { Fibroseprogression } \\
\text { waren Alter bei Infek- } \\
\text { tion, Geschlecht, } \\
\text { HCV-Genotyp und } \\
\text { Übertragungsweg. }\end{array}$ & Level 3 \\
\hline $\begin{array}{l}\text { Milano M } \\
\text { et al., } 2015\end{array}$ & $\begin{array}{l}\text { Einfluss der } \\
\text { TM6SF2 E167K } \\
\text { Genvariante auf } \\
\text { Steatose und Le- } \\
\text { berschaden bei } \\
\text { HCV-Infektion }\end{array}$ & $\begin{array}{l}\text { retrospek- } \\
\text { tive Kohor- } \\
\text { tenanalyse }\end{array}$ & 645 & 1460 & $\begin{array}{l}\text { Steatose, Inflamma- } \\
\text { tion und Fibrose bei } \\
\text { Vorliegen der TM6SF2 } \\
\text { E167K-Genvariante }\end{array}$ & $\begin{array}{l}\text { Die TM6SF2 E167K- } \\
\text { Genvariante hat } \\
\text { Einfluss auf Steatose, } \\
\text { Inflammation und } \\
\text { Fibrose bei HCV- } \\
\text { Infektion. }\end{array}$ & Level 3 \\
\hline $\begin{array}{l}\text { Eslam M } \\
\text { et al., } 2015\end{array}$ & $\begin{array}{l}\text { Interferon- } \lambda \\
\text { rs12979860 } \\
\text { Genotyp und } \\
\text { Leberfibrose }\end{array}$ & $\begin{array}{l}\text { retrospek- } \\
\text { tive Kohor- } \\
\text { tenanalyse }\end{array}$ & keine & 4172 & $\begin{array}{l}\text { Fibrose und Inflamma- } \\
\text { tion in Abhängigkeit } \\
\text { von rs12979860- } \\
\text { Genotyp }\end{array}$ & $\begin{array}{l}\text { Der rs12979860CC } \\
\text { Genotyp ist mit stär- } \\
\text { kerer Inflammation } \\
\text { und Fibrose assozi- } \\
\text { iert. }\end{array}$ & Level 3 \\
\hline $\begin{array}{l}\text { Burza MA } \\
\text { et al., } 2016\end{array}$ & $\begin{array}{l}\text { DEPDC5 Varia- } \\
\text { nte und Fibrose- } \\
\text { progression bei } \\
\text { cHCV }\end{array}$ & $\begin{array}{l}\text { retrospek- } \\
\text { tive Kohor- } \\
\text { tenanalyse }\end{array}$ & 415 & 912 & $\begin{array}{l}\text { Fibroseprogression } \\
\text { bei Vorliegen einer } \\
\text { DEPDC5-Variante }\end{array}$ & $\begin{array}{l}\text { Das Vorliegen mind. } \\
\text { einer DEPDC5-Varia- } \\
\text { nte führt zu ver- } \\
\text { mehrter Fibrosepro- } \\
\text { gression bei cHCV. }\end{array}$ & Level 3 \\
\hline $\begin{array}{l}\text { Younossi Z } \\
\text { et al., } 2016\end{array}$ & $\begin{array}{l}\text { subjektives Out- } \\
\text { come bei LDV/ } \\
\text { SOF: SIRIUS- } \\
\text { Studie }\end{array}$ & $\begin{array}{l}\text { randomi- } \\
\text { sierte Pha- } \\
\text { se-3-Studie }\end{array}$ & Placebo & 154 & $\begin{array}{l}\text { patient reported out- } \\
\text { come, Beobachtung } \\
\text { über } 48 \text { Wochen }\end{array}$ & $\begin{array}{l}\text { LDV/SOF verbessert } \\
\text { das subjektive Outco- } \\
\text { me bei vorbehandel- } \\
\text { ten HVC-Patienten } \\
\text { mit Leberzirrhose. }\end{array}$ & Level 1b \\
\hline $\begin{array}{l}\text { Younossi Z } \\
\text { et al., } 2016\end{array}$ & $\begin{array}{l}\text { patient reported } \\
\text { outcome bei } \\
\text { älteren HCV-Pa- } \\
\text { tienten mit IFN- } \\
\text { und RBV-freier } \\
\text { Therapie }\end{array}$ & $\begin{array}{l}\text { retrospek- } \\
\text { tive Kohor- } \\
\text { tenanalyse }\end{array}$ & keine & 229 & $\begin{array}{l}\text { patient reported } \\
\text { outcome }\end{array}$ & $\begin{array}{l}\text { IFN- und RBV-freie } \\
\text { Therapieregime füh- } \\
\text { ren zu einem verbes- } \\
\text { serten subjektiven } \\
\text { Outcome bei HCV- } \\
\text { Patienten > } 65 \text { Jahre. }\end{array}$ & Level 3 \\
\hline $\begin{array}{l}\text { Younossi Z } \\
\text { et al., } 2016\end{array}$ & $\begin{array}{l}\text { subjektives Out- } \\
\text { come bei SOF/ } \\
\text { Vel (ASTRAL-1) }\end{array}$ & $\begin{array}{l}\text { randomi- } \\
\text { sierte Pha- } \\
\text { se-3-Studie }\end{array}$ & 116 & 740 & $\begin{array}{l}\text { patient reported out- } \\
\text { come, Beobachtung } \\
\text { über } 24 \text { Wochen }\end{array}$ & $\begin{array}{l}\text { SOF/VEL verbessert } \\
\text { das subjektive } \\
\text { Outcome. }\end{array}$ & Level 1b \\
\hline $\begin{array}{l}\text { Younossi Z } \\
\text { et al., } 2016\end{array}$ & $\begin{array}{l}\text { HCV: klinische, } \\
\text { subjektive und } \\
\text { ökonomische } \\
\text { Konsequenzen }\end{array}$ & Review & - & - & $\begin{array}{l}\text { klinische, subjektive } \\
\text { und ökonomische Kon- } \\
\text { sequenzen von HCV }\end{array}$ & $\begin{array}{l}\text { Die HCV-Infektion } \\
\text { hat eine hohe klini- } \\
\text { sche, subjektive } \\
\text { und ökonomische } \\
\text { Relevanz. }\end{array}$ & Level 1 \\
\hline $\begin{array}{l}\text { Dedania B } \\
\text { et al., } 2015\end{array}$ & $\begin{array}{l}\text { dermatologi- } \\
\text { sche extrahepa- } \\
\text { tische Manifes- } \\
\text { tationen von } \\
\text { HCV }\end{array}$ & Review & - & - & $\begin{array}{l}\text { Pathophysiologie, Kli- } \\
\text { nik und Behandlung } \\
\text { von dermatologischen } \\
\text { extrahepatischen Ma- } \\
\text { nifestationen von HCV }\end{array}$ & $\begin{array}{l}\text { Pathophysiologie, Kli- } \\
\text { nik und Behandlung } \\
\text { von dermatologi- } \\
\text { schen extrahepati- } \\
\text { schen Manifestatio- } \\
\text { nen von HCV }\end{array}$ & Level 1 \\
\hline $\begin{array}{l}\text { Gill K et al., } \\
2015\end{array}$ & $\begin{array}{l}\text { extrahepatische } \\
\text { Manifestationen } \\
\text { von HCV }\end{array}$ & Review & - & - & $\begin{array}{l}\text { extrahepatische Mani- } \\
\text { festationen von HCV }\end{array}$ & $\begin{array}{l}\text { Extrahepatische } \\
\text { Manifestationen } \\
\text { von HCV }\end{array}$ & Level 1 \\
\hline $\begin{array}{l}\text { Grignoli R } \\
\text { et al., } 2015\end{array}$ & $\begin{array}{l}\text { extrahepatische } \\
\text { Manifestationen } \\
\text { von HCV }\end{array}$ & Review & - & - & $\begin{array}{l}\text { extrahepatische Mani- } \\
\text { festationen von HCV }\end{array}$ & $\begin{array}{l}\text { extrahepatische } \\
\text { Manifestationen } \\
\text { von } \mathrm{HCV}\end{array}$ & Level 1 \\
\hline $\begin{array}{l}\text { Metts J et al., } \\
2014\end{array}$ & $\begin{array}{l}\text { extrahepatische } \\
\text { Manifestationen } \\
\text { von HCV }\end{array}$ & Review & - & - & $\begin{array}{l}\text { extrahepatische Mani- } \\
\text { festationen von HCV }\end{array}$ & $\begin{array}{l}\text { extrahepatische } \\
\text { Manifestationen } \\
\text { von HCV }\end{array}$ & Level 1 \\
\hline
\end{tabular}




\begin{tabular}{|c|c|c|c|c|c|c|c|}
\hline $\begin{array}{l}\text { Referenz- } \\
\text { autor, Jahr }\end{array}$ & $\begin{array}{l}\text { Thema, } \\
\text { Intervention }\end{array}$ & Studientyp & Kontrolle & n gesamt & $\begin{array}{l}\text { Zielparameter, } \\
\text { Beobachtungsdauer }\end{array}$ & $\begin{array}{l}\text { Ergebnis, } \\
\text { Bemerkungen }\end{array}$ & $\begin{array}{l}\text { Evidenzgrad, } \\
{ }^{*} \text { Oxford-Schema }\end{array}$ \\
\hline $\begin{array}{l}\text { Caviglia G } \\
\text { et al., } 2015\end{array}$ & $\begin{array}{l}\text { endokrine Mani- } \\
\text { festationen von } \\
\text { HCV }\end{array}$ & Review & - & - & $\begin{array}{l}\text { endokrine Manifesta- } \\
\text { tionen von HCV }\end{array}$ & $\begin{array}{l}\text { endokrine Manifesta- } \\
\text { tionen von HCV }\end{array}$ & Level 1 \\
\hline $\begin{array}{l}\text { Negro F } \\
\text { et al., } 2015\end{array}$ & $\begin{array}{l}\text { extrahepatische } \\
\text { Morbidität und } \\
\text { Mortalität von } \\
\text { HCV }\end{array}$ & Review & - & - & $\begin{array}{l}\text { extrahepatische Mor- } \\
\text { bidität und Mortalität } \\
\text { von HCV }\end{array}$ & $\begin{array}{l}\text { extrahepatische Mor- } \\
\text { bidität und Mortalität } \\
\text { von HCV }\end{array}$ & Level 1 \\
\hline $\begin{array}{l}\text { Younossi Z } \\
\text { et al., } 2016\end{array}$ & $\begin{array}{l}\text { extrahepatische } \\
\text { Manifestationen } \\
\text { von HCV }\end{array}$ & $\begin{array}{l}\text { Meta- } \\
\text { analyse }\end{array}$ & - & $\begin{array}{l}102 \\
\text { Studien }\end{array}$ & $\begin{array}{l}\text { Prävalenz, Risiken und } \\
\text { Kosten von extrahepa- } \\
\text { tischen Manifestatio- } \\
\text { nen von HCV, Jahre } \\
1996-2014\end{array}$ & $\begin{array}{l}\text { Die häufigsten extra- } \\
\text { hepatischen Manifes- } \\
\text { tationen von HCV } \\
\text { sind Diabetes und } \\
\text { Depression. }\end{array}$ & Level 1 \\
\hline $\begin{array}{l}\text { Allison RD } \\
\text { et al., } 2015\end{array}$ & $\begin{array}{l}\text { erhöhte Krebs- } \\
\text { rate und Krebs- } \\
\text { assoziierte Mor- } \\
\text { talität bei HCV }\end{array}$ & $\begin{array}{l}\text { retrospekti- } \\
\text { ve Kohor- } \\
\text { tenanalyse }\end{array}$ & $\begin{array}{l}133795- \\
010\end{array}$ & 13391627 & $\begin{array}{l}\text { Inzidenz und Mortali- } \\
\text { tät von nicht Leber- } \\
\text { assoziierten Krebsar- } \\
\text { ten, Jahre } 2006 \text { - } 2010\end{array}$ & $\begin{array}{l}\text { Inzidenz und Morta- } \\
\text { lität von nicht Leber- } \\
\text { assoziierten Krebsar- } \\
\text { ten war bei HCV- } \\
\text { Patienten höher als } \\
\text { in der Gesamtbevöl- } \\
\text { kerung. }\end{array}$ & Level 3 \\
\hline $\begin{array}{l}\text { Mansueto P } \\
\text { et al., } 2013\end{array}$ & $\begin{array}{l}\text { Osteodystrophie } \\
\text { bei chronischen } \\
\text { Lebererkrankun- } \\
\text { gen }\end{array}$ & Review & - & - & $\begin{array}{l}\text { Osteodystrophie bei } \\
\text { chronischen Leberer- } \\
\text { krankungen }\end{array}$ & $\begin{array}{l}\text { Osteodystrophie bei } \\
\text { chronischen Leberer- } \\
\text { krankungen }\end{array}$ & Level 1 \\
\hline $\begin{array}{l}\text { Yadav A } \\
\text { et al., } 2013\end{array}$ & $\begin{array}{l}\text { Osteoporose bei } \\
\text { chronischen Le- } \\
\text { bererkrankun- } \\
\text { gen }\end{array}$ & Review & - & - & $\begin{array}{l}\text { Osteoporose bei chro- } \\
\text { nischen Lebererkran- } \\
\text { kungen }\end{array}$ & $\begin{array}{l}\text { Osteoporose bei } \\
\text { chronischen Leberer- } \\
\text { krankungen }\end{array}$ & Level 1 \\
\hline $\begin{array}{l}\text { Gatta A et } \\
\text { al., } 2014\end{array}$ & $\begin{array}{l}\text { hepatische Os- } \\
\text { teodystrophie }\end{array}$ & Review & - & - & $\begin{array}{l}\text { hepatische Osteodys- } \\
\text { trophie }\end{array}$ & $\begin{array}{l}\text { hepatische } \\
\text { Osteodystrophie }\end{array}$ & Level 1 \\
\hline $\begin{array}{l}\text { Nakchbandi } \\
\text { IA et al., } \\
2014\end{array}$ & $\begin{array}{l}\text { Osteoporose bei } \\
\text { chronischen Le- } \\
\text { bererkrankun- } \\
\text { gen }\end{array}$ & Review & - & - & $\begin{array}{l}\text { Relevanz, Pathogenese } \\
\text { und Therapie der Os- } \\
\text { teoporose bei chroni- } \\
\text { schen Lebererkrankun- } \\
\text { gen }\end{array}$ & $\begin{array}{l}\text { Relevanz, Pathoge- } \\
\text { nese und Therapie } \\
\text { der Osteoporose } \\
\text { bei chronischen } \\
\text { Lebererkrankungen }\end{array}$ & Level 1 \\
\hline $\begin{array}{l}\text { Castronuovo } \\
\text { D et al., } 2013\end{array}$ & $\begin{array}{l}\text { Knochenerkran- } \\
\text { kungen bei HIV }\end{array}$ & Review & - & - & $\begin{array}{l}\text { Knochenerkrankungen } \\
\text { bei HIV }\end{array}$ & $\begin{array}{l}\text { Knochenerkrankun- } \\
\text { gen bei HIV }\end{array}$ & Level 1 \\
\hline $\begin{array}{l}\text { Del Carpio- } \\
\text { Cano FE } \\
\text { et al., } 2013\end{array}$ & $\begin{array}{l}\text { Knochenerkran- } \\
\text { kungen bei HIV } \\
\text { und microRNAs }\end{array}$ & Review & - & - & Rolle der microRNAs & $\begin{array}{l}\text { Rolle der microRNAs } \\
\text { bei HIV-assoziierten } \\
\text { Knochenerkrankun- } \\
\text { gen }\end{array}$ & Level 1 \\
\hline $\begin{array}{l}\text { Compston J } \\
\text { et al., } 2015\end{array}$ & $\begin{array}{l}\text { Osteoporose bei } \\
\text { HIV }\end{array}$ & Review & - & - & Osteoporose bei HIV & Osteoporose bei HIV & Level 1 \\
\hline $\begin{array}{l}\text { Maalouf NM } \\
\text { et al., } 2013\end{array}$ & $\begin{array}{l}\text { Osteoporose bei } \\
\text { HIV/HCV-Ko-In- } \\
\text { fektion }\end{array}$ & $\begin{array}{l}\text { retrospek- } \\
\text { tive Kohor- } \\
\text { tenanalyse }\end{array}$ & keine & 56660 & $\begin{array}{l}\text { Assoziation von HCV/ } \\
\text { HIV-Ko-Infektion und } \\
\text { Frakturrate, Jahre } \\
1984-2009\end{array}$ & $\begin{array}{l}\text { Die Frakturrate war } \\
\text { höher bei HCV/HIV- } \\
\text { Ko-Infektion als bei } \\
\text { HIV-Monoinfektion. }\end{array}$ & Level 3 \\
\hline $\begin{array}{l}\text { Lo Re V } 3 \text { rd } \\
\text { et al., } 2015\end{array}$ & $\begin{array}{l}\text { strukturelle } \\
\text { Knochenerkran- } \\
\text { kungen bei HIV/ } \\
\text { HCV-ko-infizier- } \\
\text { ten und HIV- } \\
\text { oder HCV-mo- } \\
\text { noinfizierten } \\
\text { Frauen }\end{array}$ & $\begin{array}{l}\text { Quer- } \\
\text { schnitts- } \\
\text { studie }\end{array}$ & 263 & 414 & Knochendichte & $\begin{array}{l}\text { HIV/HCV-ko-infizier- } \\
\text { te Frauen hatte } \\
\text { geringere Knochen- } \\
\text { dichten als gesunde } \\
\text { Kontrollen. }\end{array}$ & Level 3 \\
\hline
\end{tabular}




\begin{tabular}{|c|c|c|c|c|c|c|c|}
\hline $\begin{array}{l}\text { Referenz- } \\
\text { autor, Jahr }\end{array}$ & $\begin{array}{l}\text { Thema, } \\
\text { Intervention }\end{array}$ & Studientyp & Kontrolle & n gesamt & $\begin{array}{l}\text { Zielparameter, } \\
\text { Beobachtungsdauer }\end{array}$ & $\begin{array}{l}\text { Ergebnis, } \\
\text { Bemerkungen }\end{array}$ & $\begin{array}{l}\text { Evidenzgrad, } \\
\text { "Oxford-Schema }\end{array}$ \\
\hline $\begin{array}{l}\text { Mazzotta E } \\
\text { et al., } 2015\end{array}$ & $\begin{array}{l}\text { Prävalenz und } \\
\text { Prädiktoren } \\
\text { geringer Kno- } \\
\text { chendichte und } \\
\text { Frakturen bei } \\
\text { HIV-Patienten }\end{array}$ & $\begin{array}{l}\text { prospektive } \\
\text { Kohorten- } \\
\text { analyse }\end{array}$ & keine & 163 & $\begin{array}{l}\text { Knochendichte, nicht- } \\
\text { traumatische Fraktu- } \\
\text { ren, April 2009-März } \\
2011\end{array}$ & $\begin{array}{l}\text { Bei allen HIV-Patien- } \\
\text { ten sollte eine Kno- } \\
\text { chendichtemessung } \\
\text { erfolgen. }\end{array}$ & Level 3 \\
\hline $\begin{array}{l}\text { Dong HV } \\
\text { et al., } 2014\end{array}$ & $\begin{array}{l}\text { Osteoporose } \\
\text { und Frakturen } \\
\text { bei HIV/HCV- } \\
\text { Ko-Infektion }\end{array}$ & $\begin{array}{l}\text { Meta- } \\
\text { analyse }\end{array}$ & - & 15 Studien & & $\begin{array}{l}\text { HCV/HIV-Ko-Infek- } \\
\text { tion ist mit einem } \\
\text { höheren Risiko für } \\
\text { Frakturen und Osteo- } \\
\text { porose assoziiert als } \\
\text { HIV-Monoinfektion. }\end{array}$ & Level 1 \\
\hline $\begin{array}{l}\text { Lai JC et al., } \\
2015\end{array}$ & $\begin{array}{l}\text { Knochendichte, } \\
\text { Knochenumsatz } \\
\text { und syst. Inflam- } \\
\text { mation bei HCV } \\
\text { ohne LCI }\end{array}$ & $\begin{array}{l}\text { prospektive } \\
\text { Kohorten- } \\
\text { analyse }\end{array}$ & keine & 60 & $\begin{array}{l}\text { Knochendichte, } \\
\text { Serummarker für } \\
\text { Inflammation }\end{array}$ & $\begin{array}{l}\text { Eine geringe Kno- } \\
\text { chendichte war bei } \\
40 \text { - 60-jährigen } \\
\text { Patienten mit cHCV } \\
\text { ohne LCI häufig, aber } \\
\text { nicht mit erhöhten } \\
\text { Serummarkern für } \\
\text { syst. Inflammation } \\
\text { assoziiert. }\end{array}$ & Level 3 \\
\hline $\begin{array}{l}\text { Marek B } \\
\text { et al., } 2015\end{array}$ & $\begin{array}{l}\text { GH, IGF-I Axe, } \\
\text { calciotrope Hor- } \\
\text { mone und Kno- } \\
\text { chendichte bei } \\
\text { jungen Patien- } \\
\text { ten mit cHCV }\end{array}$ & $\begin{array}{l}\text { Fall-Kon- } \\
\text { troll-Studie }\end{array}$ & $\begin{array}{l}40 \text { gesun- } \\
\text { de Pat. }\end{array}$ & 120 & $\begin{array}{l}\text { GH, IGF-I Axe, calcio- } \\
\text { trope Hormone, } \\
\text { Knochendichte }\end{array}$ & $\begin{array}{l}\text { cHCV führt zu ver- } \\
\text { minderter Knochen- } \\
\text { dichte durch verän- } \\
\text { derte calciotrope } \\
\text { Hormone und eine } \\
\text { gestörte Somatotro- } \\
\text { pin-Axe. }\end{array}$ & Level 3 \\
\hline $\begin{array}{l}\text { Chen } \mathrm{CH} \\
\text { et al., } 2015\end{array}$ & $\begin{array}{l}\text { HCV Exposition } \\
\text { und Osteopo- } \\
\text { roserisiko }\end{array}$ & $\begin{array}{l}\text { retrospek- } \\
\text { tive Kohor- } \\
\text { tenanalyse }\end{array}$ & 41228 & 51535 & $\begin{array}{l}\text { Osteoporoserisiko, } \\
\text { Jahre } 2000 \text { - } 2011\end{array}$ & $\begin{array}{l}\text { Das Osteoporose- } \\
\text { risiko war bei HCV- } \\
\text { Exposition höher, } \\
\text { jedoch nicht das } \\
\text { Frakturrisiko. }\end{array}$ & Level 3 \\
\hline $\begin{array}{l}\text { Hansen } A B \\
\text { et al., } 2014\end{array}$ & $\begin{array}{l}\text { Frakturrisiko bei } \\
\text { HCV (DANVIR- } \\
\text { Studie) }\end{array}$ & $\begin{array}{l}\text { retrospek- } \\
\text { tive Kohor- } \\
\text { tenanalyse }\end{array}$ & 60065 & $\begin{array}{l}72078 \\
(4500 \\
\text { cHCV, } \\
2656 \text { Z.n. } \\
\text { HCV) }\end{array}$ & Frakturrisiko & $\begin{array}{l}\text { Das Frakturrisiko war } \\
\text { bei HCV-Exposition } \\
\text { höher. Es gab keinen } \\
\text { Unterschied zwi- } \\
\text { schen cHCV und Z. n. } \\
\text { HCV. }\end{array}$ & Level 3 \\
\hline $\begin{array}{l}\text { Hsu YH et al., } \\
2015\end{array}$ & HCV und paVK & $\begin{array}{l}\text { retrospek- } \\
\text { tive Kohor- } \\
\text { tenanalyse }\end{array}$ & 30564 & 38205 & $\begin{array}{l}\text { paVK-Risiko, Beobach- } \\
\text { tung über } 9 \text { Jahre }\end{array}$ & $\begin{array}{l}\text { HCV-Patienten } \\
\text { haben ein höheres } \\
\text { paVK-Risiko. }\end{array}$ & Level 3 \\
\hline $\begin{array}{l}\text { Petta S et al., } \\
2016\end{array}$ & $\begin{array}{l}\text { HCV und kardio- } \\
\text { vaskuläre Morta- } \\
\text { lität }\end{array}$ & $\begin{array}{l}\text { Meta- } \\
\text { analyse }\end{array}$ & - & 22 Studien & $\begin{array}{l}\text { kardiovaskuläre } \\
\text { Mortalität }\end{array}$ & $\begin{array}{l}\text { Die kardiovaskuläre } \\
\text { Mortalität ist bei HCV } \\
\text { erhöht. }\end{array}$ & Level 1 \\
\hline
\end{tabular}


b) Wann ist eine antivirale Therapie bei Patienten mit einer chronischen Hepatitis C im kompensierten Stadium der Lebererkrankung indiziert?

Siehe Evidenztabelle AG 4.

c) Wann ist eine antivirale Therapie bei Patienten mit einer chronischen Hepatitis C im dekompensierten Stadium der Lebererkrankung (Child-Pugh B/C) bzw. auf der Warteliste zur Lebertransplantation indiziert?

Siehe Evidenztabelle AG 4 und AG 5.

d) Wann ist eine antivirale Therapie bei Patienten mit einer chronischen Hepatitis C und hepatozellulärem Karzinom (HCC) indiziert?

\begin{tabular}{|c|c|c|c|c|c|c|c|}
\hline $\begin{array}{l}\text { Referenz- } \\
\text { autor, Jahr }\end{array}$ & $\begin{array}{l}\text { Thema, } \\
\text { Intervention }\end{array}$ & Studientyp & Kontrolle & n gesamt & $\begin{array}{l}\text { Zielparameter, } \\
\text { Beobachtungsdauer }\end{array}$ & $\begin{array}{l}\text { Ergebnis, } \\
\text { Bemerkungen }\end{array}$ & $\begin{array}{l}\text { Evidenzgrad, } \\
\text { *oxford-Schema }\end{array}$ \\
\hline $\begin{array}{l}\text { Reig M et al., } \\
2016\end{array}$ & $\begin{array}{l}\text { HCC-Rekurrenz } \\
\text { nach IFN-freier } \\
\text { HCV-Therapie }\end{array}$ & $\begin{array}{l}\text { retrospek- } \\
\text { tive Kohor- } \\
\text { tenanalyse }\end{array}$ & keine & 58 & $\begin{array}{l}\text { HCC-Rekurrenz nach } \\
\text { SVR unter DAAs, Jahre } \\
2014-2015\end{array}$ & $\begin{array}{l}\text { Die HCC-Rekurrenz- } \\
\text { rate nach SVR unter } \\
\text { DAAs betrug } 27,6 \% \\
\text { nach } 5,7 \text { Monaten. }\end{array}$ & Level 3 \\
\hline $\begin{array}{l}\text { Conti F et al., } \\
2016\end{array}$ & $\begin{array}{l}\text { Auftreten von } \\
\text { HCC und Rekur- } \\
\text { renz nach DAA- } \\
\text { Therapie bei } \\
\text { HCV-LCI }\end{array}$ & $\begin{array}{l}\text { retrospek- } \\
\text { tive Kohor- } \\
\text { tenanalyse }\end{array}$ & keine & $\begin{array}{l}403(344 \\
\text { kein HCC, } \\
59 \text { Z. n. } \\
\text { HCC) }\end{array}$ & $\begin{array}{l}\text { Auftreten von HCC, } \\
\text { Beobachtung über } 24 \\
\text { Wochen }\end{array}$ & $\begin{array}{l}\text { Nach } 24 \text { Wochen } \\
\text { kam es in } 7,6 \% \text { zu } \\
\text { einem Neuauftreten } \\
\text { und in } 28,8 \% \text { zu einer } \\
\text { Rekurrenz von HCC } \\
\text { unter DAA-Therapie } \\
\text { bei HCV-LCl. }\end{array}$ & Level 3 \\
\hline $\begin{array}{l}\text { Pol S et al., } \\
2016\end{array}$ & $\begin{array}{l}\text { fehlender Effekt } \\
\text { von DAAs auf die } \\
\text { HCC-Rekurrenz } \\
\text { (3 ANRS Kohorten) }\end{array}$ & $\begin{array}{l}\text { retrospek- } \\
\text { tive Kohor- } \\
\text { tenanalyse }\end{array}$ & 144 & 660 & HCC-Rekurrenzrate & $\begin{array}{l}\text { Die HCC-Rekurrenz- } \\
\text { rate war nach DAA- } \\
\text { Therapie nicht } \\
\text { erhöht. }\end{array}$ & Level 3 \\
\hline $\begin{array}{l}\text { Cheung MC } \\
\text { et al., } 2016\end{array}$ & $\begin{array}{l}\text { Outcome von } \\
\text { Patienten mit } \\
\text { dekompensierter } \\
\text { LCI nach erfolgrei- } \\
\text { cher DAA- } \\
\text { Therapie }\end{array}$ & $\begin{array}{l}\text { prospektive } \\
\text { Kohorten- } \\
\text { analyse }\end{array}$ & 261 & 667 & $\begin{array}{l}\text { Endpunkte: Tod, LTx, } \\
\text { HCC, Dekompensation, } \\
\text { Sepsis, Hospitalisation } \\
\text { und MELD, Beobach- } \\
\text { tung über } 15 \text { Monate }\end{array}$ & $\begin{array}{l}\text { Die antivirale Thera- } \\
\text { pie führt bei Patien- } \\
\text { ten mit dekompen- } \\
\text { sierter LCI zu einer } \\
\text { verbesserten Leber- } \\
\text { funktion ohne erhöh- } \\
\text { tes Malignitätsrisiko. }\end{array}$ & Level 3 \\
\hline
\end{tabular}

e) Wann ist eine antivirale Therapie bei Patienten mit extrahepatischen Manifestationen indiziert?

Literatur wurde aus der vorherigen Leitlinie übernommen.

f) Wann ist eine Therapie bei Patienten mit Niereninsuffizienz bzw. Dialyse indiziert

Literatur wurde aus der vorherigen Leitlinie übernommen.

g) Was sind Besonderheiten bei der Therapie-Indikationsstellung von Patienten mit Suchterkrankungen?

\begin{tabular}{|c|c|c|c|c|c|c|c|}
\hline $\begin{array}{l}\text { Referenz- } \\
\text { autor, Jahr }\end{array}$ & $\begin{array}{l}\text { Thema, } \\
\text { Intervention }\end{array}$ & Studientyp & Kontrolle & n gesamt & $\begin{array}{l}\text { Zielparameter, } \\
\text { Beobachtungsdauer }\end{array}$ & $\begin{array}{l}\text { Ergebnis, } \\
\text { Bemerkungen }\end{array}$ & $\begin{array}{l}\text { Evidenzgrad, } \\
{ }^{*} \text { Oxford-Schema }\end{array}$ \\
\hline $\begin{array}{l}\text { Schaefer M } \\
\text { et al., } 2013\end{array}$ & $\begin{array}{l}\text { Management von } \\
\text { psychischen Proble- } \\
\text { men vor und während } \\
\text { antiviraler Therapie } \\
\text { bei drogenabhängi- } \\
\text { gen Patienten }\end{array}$ & Review & - & - & $\begin{array}{l}\text { psychische Probleme } \\
\text { vor und während anti- } \\
\text { viraler Therapie bei } \\
\text { drogenabhängigen } \\
\text { Patienten }\end{array}$ & $\begin{array}{l}\text { Es gab keinen Unter- } \\
\text { schied in SVR-Rate } \\
\text { und Komplikationen } \\
\text { bei antiviraler Thera- } \\
\text { pie von drogenab- } \\
\text { hängigen Patienten } \\
\text { und Kontrollen. }\end{array}$ & Level 1 \\
\hline $\begin{array}{l}\text { Robaeys G } \\
\text { et al., } 2013\end{array}$ & $\begin{array}{l}\text { Empfehlungen zum } \\
\text { Management von } \\
\text { HCV bei drogenab- } \\
\text { hängigen Patienten }\end{array}$ & Review & - & - & $\begin{array}{l}\text { Management von } \\
\text { HCV bei drogenab- } \\
\text { hängigen Patienten }\end{array}$ & $\begin{array}{l}\text { Drogenabhängige } \\
\text { HCV-Patienten } \\
\text { sollten antiviral } \\
\text { behandelt werden. }\end{array}$ & Level 1 \\
\hline $\begin{array}{l}\text { Grebely J } \\
\text { et al., } 2015\end{array}$ & $\begin{array}{l}\text { Empfehlungen zum } \\
\text { Management von } \\
\text { HCV bei drogenab- } \\
\text { hängigen Patienten }\end{array}$ & Review & - & - & $\begin{array}{l}\text { Management von } \\
\text { HCV bei drogenab- } \\
\text { hängigen Patienten }\end{array}$ & $\begin{array}{l}\text { Drogenabhängige } \\
\text { HCV-Patienten } \\
\text { sollten antiviral } \\
\text { behandelt werden. }\end{array}$ & Level 1 \\
\hline
\end{tabular}




\begin{tabular}{|c|c|c|c|c|c|c|c|}
\hline $\begin{array}{l}\text { Referenz- } \\
\text { autor, Jahr }\end{array}$ & $\begin{array}{l}\text { Thema, } \\
\text { Intervention }\end{array}$ & Studientyp & Kontrolle & n gesamt & $\begin{array}{l}\text { Zielparameter, } \\
\text { Beobachtungsdauer }\end{array}$ & $\begin{array}{l}\text { Ergebnis, } \\
\text { Bemerkungen }\end{array}$ & $\begin{array}{l}\text { Evidenzgrad, } \\
\text { *Oxford-Schema }\end{array}$ \\
\hline $\begin{array}{l}\text { Lalezari J } \\
\text { et al., } 2015\end{array}$ & $\begin{array}{l}\text { Paritaprevir/r-Ombi- } \\
\text { tasvir und Dasabuvir } \\
\text { + RBV bei HCV-GT-1- } \\
\text { Patienten unter } \\
\text { Methadon oder Bu- } \\
\text { prenorphin }\end{array}$ & $\begin{array}{l}\text { Open-label- } \\
\text { Phase-2- } \\
\text { Studie }\end{array}$ & keine & 37 & $\begin{array}{l}\text { SVR12, Beobachtung } \\
\text { über } 24 \text { Wochen }\end{array}$ & $\begin{array}{l}\text { Die SVR12-Rate von } \\
\text { Paritaprevir/r-Ombi- } \\
\text { tasvir und Dasabuvir } \\
\text { + RBV bei HCV-GT- } \\
\text { 1-Patienten unter } \\
\text { Methadon oder Bu- } \\
\text { prenorphin betrug } \\
\text { 97,4\%. }\end{array}$ & Level 2 \\
\hline $\begin{array}{l}\text { Mangia A } \\
\text { et al., } 2013\end{array}$ & $\begin{array}{l}\text { SVR-Rate von SOF- } \\
\text { basierten Regimen } \\
\text { bei Patienten mit } \\
\text { und ohne negative } \\
\text { prädiktive Faktoren }\end{array}$ & $\begin{array}{l}\text { mehrere } \\
\text { Phase-3- } \\
\text { Studien }\end{array}$ & - & - & SVR12 & $\begin{array}{l}\text { Die SVR-Raten von } \\
\text { SOF-basierten Re- } \\
\text { gimen bei Patienten } \\
\text { mit und ohne Sub- } \\
\text { stitutionstherapie } \\
\text { waren vergleichbar. }\end{array}$ & Level 1b \\
\hline $\begin{array}{l}\text { Puoti M } \\
\text { et al., } 2014\end{array}$ & $\begin{array}{l}\text { ABT-450/r-Ombitas- } \\
\text { vir und Dasabuvir } \pm \\
\text { RBV bei HCV-GT1- } \\
\text { Patienten unter } \\
\text { Opioidtherapie }\end{array}$ & $\begin{array}{l}2 \text { Phase-2- } \\
\text { und } 6 \\
\text { Phase-3- } \\
\text { Studien }\end{array}$ & - & 56 & $\begin{array}{l}\text { SVR12, Beobachtung } \\
\text { über } 24 \text { Wochen }\end{array}$ & $\begin{array}{l}\text { Die SVR12-Rate von } \\
\text { ABT-450/r-Ombitas- } \\
\text { vir und Dasabuvir } \pm \\
\text { RBV bei HCV-GT1- } \\
\text { Patienten unter } \\
\text { Opioidtherapie } \\
\text { betrug } 96,4 \% .\end{array}$ & Level 1b \\
\hline $\begin{array}{l}\text { Martin NK } \\
\text { et al., } 2015\end{array}$ & $\begin{array}{l}\text { HCV-Therapieraten } \\
\text { und SVR-Raten bei } \\
\text { drogenabhängigen } \\
\text { Patienten }\end{array}$ & $\begin{array}{l}\text { retrospek- } \\
\text { tive Kohor- } \\
\text { tenanalyse }\end{array}$ & - & 538 & $\begin{array}{l}\text { Therapierate und SVR- } \\
\text { Rate, Jahre } 2009 \text { - } 2015\end{array}$ & $\begin{array}{l}\text { HCV-Therapieraten } \\
\text { und SVR-Raten bei } \\
\text { drogenabhängigen } \\
\text { Patienten sind aktu- } \\
\text { ell zu niedrig. }\end{array}$ & Level 3 \\
\hline
\end{tabular}

h) Wann ist eine Re-Therapie indiziert?

Siehe Evidenztabelle AG 4.

i) Wann bestehen Kontraindikationen bzw. Einschränkungen einer DAA-basierten Therapie?

Keine Literaturangaben.

AG 4: Therapie der chronischen Hepatitis C

1. DAA-Ersttherapie in allen Fibrosestadien bis einschließlich kompensierter Zirrhose a) Genotyp 1

\begin{tabular}{|c|c|c|c|c|c|c|c|}
\hline $\begin{array}{l}\text { Referenz- } \\
\text { autor, Jahr }\end{array}$ & $\begin{array}{l}\text { Thema, } \\
\text { Intervention }\end{array}$ & Studientyp & Kontrolle & n gesamt & $\begin{array}{l}\text { Zielparameter, } \\
\text { Beobachtungsdauer }\end{array}$ & $\begin{array}{l}\text { Ergebnis, } \\
\text { Bemerkungen }\end{array}$ & $\begin{array}{l}\text { Evidenzgrad, } \\
{ }^{*} \text { Oxford-Schema }\end{array}$ \\
\hline $\begin{array}{l}\text { Afdhal N } \\
\text { et al., } 2014\end{array}$ & $\begin{array}{l}\text { LDV/SOF } \pm \text { RBV } \\
\text { über } 12-24 \text { Wo- } \\
\text { chen für unbehan- } \\
\text { delte HCV-Geno- } \\
\text { typ-1-Patienten }\end{array}$ & $\begin{array}{l}\text { Open-label- } \\
\text { Phase-3- } \\
\text { Studie }\end{array}$ & - & 865 & $\begin{array}{l}\text { SVR12, Beobachtung } \\
\text { über } 36 \text { Wochen }\end{array}$ & $\begin{array}{l}\text { Die SVR-Raten in } \\
\text { den verschiedenen } \\
\text { Therapiearmen } \\
\text { lagen zwischen } 97 \\
\text { und } 99 \% \text {. }\end{array}$ & Level 1b \\
\hline $\begin{array}{l}\text { Bourliere M } \\
\text { et al., } 2014\end{array}$ & $\begin{array}{l}\text { LDV/SOF } \pm \text { RBV } \\
\text { über } 12-24 \\
\text { Wochen bei LCI }\end{array}$ & $\begin{array}{l}\text { integrierte } \\
\text { Analyse der } \\
\text { Phase-2/3- } \\
\text { Studien }\end{array}$ & - & 513 & $\begin{array}{l}\text { SVR12, Beobachtung } \\
\text { über } 36 \text { Wochen }\end{array}$ & $\begin{array}{l}\text { SVR-Rate von } 96 \% \\
\text { bis } 100 \%\end{array}$ & Level 1b \\
\hline $\begin{array}{l}\text { Kowdley KV } \\
\text { et al., } 2014\end{array}$ & $\begin{array}{l}\text { LDV/SOF über } 8 \text { vs. } \\
12 \text { Wochen bei } \\
\text { therapienaiven } \mathrm{Pa} \text { - } \\
\text { tienten ohne LCl }\end{array}$ & $\begin{array}{l}\text { "post-hoc" } \\
\text { Subgruppen- } \\
\text { analyse }\end{array}$ & - & 634 & $\begin{array}{l}\text { SVR12, Beobachtung } \\
\text { über } 24 \text { Wochen }\end{array}$ & $\begin{array}{l}\text { SVR-Raten von } 93 \text { - } \\
96 \% \text { ohne signifi- } \\
\text { kante Unterschiede }\end{array}$ & Level 1b \\
\hline
\end{tabular}




\begin{tabular}{|c|c|c|c|c|c|c|c|}
\hline $\begin{array}{l}\text { Referenz- } \\
\text { autor, Jahr }\end{array}$ & $\begin{array}{l}\text { Thema, } \\
\text { Intervention }\end{array}$ & Studientyp & Kontrolle & n gesamt & $\begin{array}{l}\text { Zielparameter, } \\
\text { Beobachtungsdauer }\end{array}$ & $\begin{array}{l}\text { Ergebnis, } \\
\text { Bemerkungen }\end{array}$ & $\begin{array}{l}\text { Evidenzgrad, } \\
{ }^{*} \text { Oxford-Schema }\end{array}$ \\
\hline $\begin{array}{l}\text { Vermehren J } \\
\text { et al., } 2016\end{array}$ & $\begin{array}{l}\text { HCV-RNA Grenz- } \\
\text { werte bei 8-wöchi- } \\
\text { ger Therapie von } \\
\text { HCV-Genotyp-1- } \\
\text { Patienten }\end{array}$ & $\begin{array}{l}\text { prospektive } \\
\text { Kohorten- } \\
\text { studie }\end{array}$ & - & 740 & HCV-RNA-Level & $\begin{array}{l}\text { Die Auswahl von ge- } \\
\text { eigneten Patienten } \\
\text { für eine 8-wöchige } \\
\text { Therapie sollte nicht } \\
\text { auf einem einzigen } \\
\text { HCV-RNA-Messwert } \\
\text { beruhen. }\end{array}$ & Level 3 \\
\hline $\begin{array}{l}\text { Buggisch P } \\
\text { et al., } 2016\end{array}$ & $\begin{array}{l}\text { LDV/SOF über } \\
8 \text { Wochen bei } \\
\text { therapienaiven } \\
\text { Patienten }\end{array}$ & $\begin{array}{l}\text { Anwen- } \\
\text { dungsbeob- } \\
\text { achtung }\end{array}$ & - & 677 & $\begin{array}{l}\text { SVR12, Beobachtung } \\
\text { über } 16 \text { Wochen }\end{array}$ & SVR12 98\% & Level 3 \\
\hline $\begin{array}{l}\text { Afdhal } N \text { et } \\
\text { al., } 2014\end{array}$ & $\begin{array}{l}\text { LDV/SOF für vor- } \\
\text { behandelte HCV- } \\
\text { Genotyp-1-Patien- } \\
\text { ten }\end{array}$ & $\begin{array}{l}\text { Phase-3- } \\
\text { Studie }\end{array}$ & - & 440 & $\begin{array}{l}\text { SVR12, Beobachtung } \\
\text { über } 36 \text { Wochen }\end{array}$ & SVR12 $94-99 \%$ & Level 1b \\
\hline $\begin{array}{l}\text { Feld JJ et al., } \\
2015\end{array}$ & $\begin{array}{l}\text { VEL/SOF über } 12 \\
\text { Wochen vs. Place- } \\
\text { bo }\end{array}$ & $\begin{array}{l}\text { Phase-3- } \\
\text { Studie }\end{array}$ & 65 & 393 & $\begin{array}{l}\text { SVR12, Beobachtung } \\
\text { über } 24 \text { Wochen }\end{array}$ & $\begin{array}{l}\text { Die SVR-Raten } \\
\text { betrugen } 98-99 \% \text {. }\end{array}$ & Level 1b \\
\hline $\begin{array}{l}\text { Everson GT } \\
\text { et al., } 2015\end{array}$ & $\begin{array}{l}\text { VEL/SOF } \pm \text { RBV } \\
\text { über } 8 \text { Wochen }\end{array}$ & $\begin{array}{l}\text { Phase-2- } \\
\text { Studie }\end{array}$ & - & 60 & $\begin{array}{l}\text { SVR12, Beobachtung } \\
\text { über } 16 \text { Wochen }\end{array}$ & SVR12 $81-90 \%$ & Level 2 \\
\hline $\begin{array}{l}\text { Ferenci P } \\
\text { et al., } 2014\end{array}$ & $\begin{array}{l}\text { ABT-450/r-Ombi- } \\
\text { tasvir und Dasabu- } \\
\text { vir } \pm \text { RBV über } 12 \\
\text { Wochen für HCV }\end{array}$ & $\begin{array}{l}\text { Phase-3- } \\
\text { Studie }\end{array}$ & - & 724 & $\begin{array}{l}\text { SVR12, Beobachtung } \\
\text { über } 24 \text { Wochen }\end{array}$ & SVR12 $90-99 \%$ & Level 1b \\
\hline $\begin{array}{l}\text { Feld JJ et al., } \\
2014\end{array}$ & $\begin{array}{l}\text { HCV-Therapie mit } \\
\text { ABT-450/r-Ombi- } \\
\text { tasvir und Dasabu- } \\
\text { vir + RBV }\end{array}$ & $\begin{array}{l}\text { Phase-3- } \\
\text { Studie }\end{array}$ & 158 & 631 & $\begin{array}{l}\text { SVR12, Beobachtung } \\
\text { über } 24 \text { Wochen }\end{array}$ & SVR12 96\% & Level 1b \\
\hline $\begin{array}{l}\text { Poordad F } \\
\text { et al., } 2014\end{array}$ & $\begin{array}{l}\text { HCV-Therapie mit } \\
\text { ABT-450/r-Ombi- } \\
\text { tasvir und Dasabu- } \\
\text { vir + RBV über } 12 \text { - } \\
24 \text { Wochen bei LCI }\end{array}$ & $\begin{array}{l}\text { Phase-3- } \\
\text { Studie }\end{array}$ & - & 380 & $\begin{array}{l}\text { SVR12, Beobachtung } \\
\text { über } 36 \text { Wochen }\end{array}$ & SVR12 $92-95 \%$ & Level 1b \\
\hline $\begin{array}{l}\text { Everson GT } \\
\text { et al., } 2014\end{array}$ & $\begin{array}{l}\text { ABT-450/r-Ombi- } \\
\text { tasvir und Dasabu- } \\
\text { vir } \pm \text { RBV für HCV- } \\
\text { Genotyp 1a }\end{array}$ & $\begin{array}{l}\text { Effektivitäts- } \\
\text { analyse von } \\
4 \text { Phase-3- } \\
\text { Studien }\end{array}$ & - & & $\begin{array}{l}\text { SVR12, Beobachtung } \\
\text { über } 36 \text { Wochen }\end{array}$ & $\begin{array}{l}\text { SVR12 bei LCI } 92 \text { - } \\
95 \%\end{array}$ & Level 1b \\
\hline $\begin{array}{l}\text { Feld J et al., } \\
2016\end{array}$ & $\begin{array}{l}\text { Paritaprevir /r-Om- } \\
\text { bitasvir und Dasa- } \\
\text { buvir bei HCV-Ge- } \\
\text { notyp 1b und } \\
\text { kompensierter LCI }\end{array}$ & $\begin{array}{l}\text { einarmige } \\
\text { Phase-3- } \\
\text { Studie }\end{array}$ & - & 60 & $\begin{array}{l}\text { SVR12, Beobachtung } \\
\text { über } 24 \text { Wochen }\end{array}$ & SVR12 100\% & Level 1b \\
\hline $\begin{array}{l}\text { Zeuzem S } \\
\text { et al., } 2014\end{array}$ & $\begin{array}{l}\text { HCV-Re-Therapie } \\
\text { mit ABT-450/r- } \\
\text { Ombitasvir und } \\
\text { Dasabuvir + RBV }\end{array}$ & $\begin{array}{l}\text { doppel-blin- } \\
\text { de randomi- } \\
\text { sierte Phase- } \\
\text { 3-Studie }\end{array}$ & 97 & 394 & $\begin{array}{l}\text { SVR12, Beobachtung } \\
\text { über } 24 \text { Wochen }\end{array}$ & SVR12>95\% & Level 1b \\
\hline $\begin{array}{l}\text { Andreone P } \\
\text { et al., } 2014\end{array}$ & $\begin{array}{l}\text { ABT-450/r-Ombi- } \\
\text { tasvir und Dasa- } \\
\text { buvir } \pm \text { RBV für } \\
\text { vorbehandelte } \\
\text { HCV-Genotyp-1b- } \\
\text { Patienten }\end{array}$ & $\begin{array}{l}\text { Phase-3- } \\
\text { Studie }\end{array}$ & - & 179 & $\begin{array}{l}\text { SVR12, Beobachtung } \\
\text { über } 24 \text { Wochen }\end{array}$ & $\begin{array}{l}\text { SVR12 auch ohne } \\
\text { RBV } 100 \%\end{array}$ & Level 1b \\
\hline $\begin{array}{l}\text { Zeuzem S } \\
\text { et al., } 2015\end{array}$ & $\begin{array}{l}\text { GZR/EBR über } 12 \\
\text { Wochen für thera- } \\
\text { pienaive HCV-Ge- } \\
\text { notyp-1,4- oder } \\
\text { 6-Patienten }\end{array}$ & $\begin{array}{l}\text { randomisier- } \\
\text { te Phase-3- } \\
\text { Studie }\end{array}$ & 105 & 421 & $\begin{array}{l}\text { SVR12, Beobachtung } \\
\text { über } 24 \text { Wochen }\end{array}$ & SVR12 95\% & Level 1b \\
\hline
\end{tabular}




\begin{tabular}{|c|c|c|c|c|c|c|c|}
\hline $\begin{array}{l}\text { Referenz- } \\
\text { autor, Jahr }\end{array}$ & $\begin{array}{l}\text { Thema, } \\
\text { Intervention }\end{array}$ & Studientyp & Kontrolle & n gesamt & $\begin{array}{l}\text { Zielparameter, } \\
\text { Beobachtungsdauer }\end{array}$ & $\begin{array}{l}\text { Ergebnis, } \\
\text { Bemerkungen }\end{array}$ & $\begin{array}{l}\text { Evidenzgrad, } \\
{ }^{*} \text { Oxford-Schema }\end{array}$ \\
\hline $\begin{array}{l}\text { Kwo P et al., } \\
2015\end{array}$ & $\begin{array}{l}\text { GZR/EBR } \pm \text { RBV } \\
\text { über } 12-16 \\
\text { Wochen für vor- } \\
\text { therapierte HCV- } \\
\text { Genotyp-1- und } \\
\text { 4-Patienten }\end{array}$ & $\begin{array}{l}\text { randomisier- } \\
\text { te Phase-3- } \\
\text { Studie }\end{array}$ & - & 420 & $\begin{array}{l}\text { SVR12, Beobachtung } \\
\text { über } 28 \text { Wochen }\end{array}$ & SVR12 90\% & Level 1b \\
\hline $\begin{array}{l}\text { Peiffer KH } \\
\text { et al., } 2016\end{array}$ & $\begin{array}{l}\text { Interferon lambda } \\
4 \text { Genotypen und } \\
\text { RAVs bei HCV- } \\
\text { Genotyp } 1 \text { und } 3\end{array}$ & $\begin{array}{l}\text { retrospektive } \\
\text { Kohorte- } \\
\text { nanalyse }\end{array}$ & - & 633 & $\begin{array}{l}\text { IFNL4 SNPs und NS5A } \\
\text { RAVs }\end{array}$ & $\begin{array}{l}\text { Eine niedrige Aus- } \\
\text { gangsviruslast ist } \\
\text { ein Surrogatmarker } \\
\text { für das Fehlen der } \\
\text { Haupt-NS5A-Resis- } \\
\text { tenz Y93H. }\end{array}$ & Level 3 \\
\hline $\begin{array}{l}\text { Buti M et al., } \\
2016\end{array}$ & $\begin{array}{l}\text { GZR/EBR } \pm \text { RBV } \\
\text { über } 12 \text { Wochen } \\
\text { bei Versagen auf } \\
\text { eine Triple-Thera- } \\
\text { pie mit einem Pro- } \\
\text { tease-Inhibitor und } \\
\text { PEG-Interferon/ } \\
\text { Ribavirin }\end{array}$ & $\begin{array}{l}\text { Prospektive } \\
\text { einarmige } \\
\text { Open-label- } \\
\text { Studie }\end{array}$ & - & 79 & $\begin{array}{l}\text { SVR12, Beobachtung } \\
\text { über } 36 \text { Wochen }\end{array}$ & $\begin{array}{l}\text { Die SVR-Rate betrug } \\
96 \% .\end{array}$ & Level 1b \\
\hline $\begin{array}{l}\text { Sulkowski } \\
\text { MS et al., } \\
2014\end{array}$ & $\begin{array}{l}\text { DCV/SOF } \pm \text { RBV } \\
\text { über } 12-24 \text { Wo- } \\
\text { chen für therapie- } \\
\text { naive und vorbe- } \\
\text { handelte HCV-Pa- } \\
\text { tienten }\end{array}$ & $\begin{array}{l}\text { Phase-2- } \\
\text { Studie }\end{array}$ & - & 211 & $\begin{array}{l}\text { SVR12, Beobachtung } \\
\text { über } 36 \text { Wochen }\end{array}$ & SVR12 89-98\% & Level 2b \\
\hline $\begin{array}{l}\text { Poordad F } \\
\text { et al., } 2016\end{array}$ & $\begin{array}{l}\text { DCV/SOF + RBV bei } \\
\text { fortgeschrittener } \\
\text { LCl oder post-LTx }\end{array}$ & $\begin{array}{l}\text { Phase-3- } \\
\text { Studie }\end{array}$ & - & 113 & $\begin{array}{l}\text { SVR12, Beobachtung } \\
\text { über } 36 \text { Wochen }\end{array}$ & SVR12 $82-95 \%$ & Level 2b \\
\hline $\begin{array}{l}\text { Wyles DL } \\
\text { et al., } 2015\end{array}$ & $\begin{array}{l}\text { DCV/SOF über } \\
8-12 \text { Wochen } \\
\text { bei HCV/HIV- } \\
\text { Ko-Infektion }\end{array}$ & $\begin{array}{l}\text { Phase-3- } \\
\text { Studie }\end{array}$ & - & 203 & $\begin{array}{l}\text { SVR12, Beobachtung } \\
\text { über } 24 \text { Wochen }\end{array}$ & SVR12 $76-97 \%$ & Level 2b \\
\hline $\begin{array}{l}\text { Kwo P et al., } \\
2016\end{array}$ & $\begin{array}{l}\text { SMV/SOF über } \\
8-12 \text { Wochen bei } \\
\text { HCV-Genotyp } 1 \\
\text { ohne LCl }\end{array}$ & $\begin{array}{l}\text { randomisier- } \\
\text { te Phase-3- } \\
\text { Studie }\end{array}$ & - & 310 & $\begin{array}{l}\text { SVR12, Beobachtung } \\
\text { über } 24 \text { Wochen }\end{array}$ & SVR12 83 vs. $97 \%$ & Level 1b \\
\hline $\begin{array}{l}\text { Lawitz E } \\
\text { et al., } 2016\end{array}$ & $\begin{array}{l}\text { SMV/SOF über } \\
12-24 \text { Wochen } \\
\text { bei HCV-Genotyp } \\
1 \text { und LCI }\end{array}$ & $\begin{array}{l}\text { randomisier- } \\
\text { te Phase-3- } \\
\text { Studie }\end{array}$ & - & 103 & $\begin{array}{l}\text { SVR12, Beobachtung } \\
\text { über } 36 \text { Wochen }\end{array}$ & SVR12 83\% & Level 1b \\
\hline $\begin{array}{l}\text { Lawitz E } \\
\text { et al., } 2014\end{array}$ & $\begin{array}{l}\text { SMV/SOF +/+ RBV } \\
\text { über } 12-24 \text { Wo- } \\
\text { chen bei therapie- } \\
\text { naiven und vor- } \\
\text { behandelten } \\
\text { HCV-Genotyp-1- } \\
\text { Patienten }\end{array}$ & $\begin{array}{l}\text { randomisier- } \\
\text { te Phase-3- } \\
\text { Studie }\end{array}$ & - & 168 & $\begin{array}{l}\text { SVR12, Beobachtung } \\
\text { über } 36 \text { Wochen }\end{array}$ & SVR12 $92-94 \%$ & Level 1b \\
\hline $\begin{array}{l}\text { Dieterich D } \\
\text { et al., } 2014\end{array}$ & $\begin{array}{l}\text { Evaluation von } \\
\text { SMV/SOF im } \\
\text { TRIO-Netzwerk }\end{array}$ & $\begin{array}{l}\text { Anwen- } \\
\text { dungsbeob- } \\
\text { achtung }\end{array}$ & - & 1211 & $\begin{array}{l}\text { SVR12, Beobachtung } \\
\text { über } 24 \text { Wochen }\end{array}$ & SVR12 (ITT) 79\% & Level 3 \\
\hline $\begin{array}{l}\text { Jensen } \\
\text { DM et al., } \\
2014\end{array}$ & $\begin{array}{l}\text { Real world Experi- } \\
\text { ence von SOF-hal- } \\
\text { tigen Regimen }\end{array}$ & $\begin{array}{l}\text { Anwen- } \\
\text { dungsbeob- } \\
\text { achtung }\end{array}$ & - & 2330 & $\begin{array}{l}\text { SVR12, Beobachtung } \\
\text { über } 36 \text { Wochen }\end{array}$ & SVR12 $94-98 \%$ & Level 3 \\
\hline $\begin{array}{l}\text { Gane EJ } \\
\text { et al., } 2013\end{array}$ & $\begin{array}{l}\text { SOF/RBV für 8-12 } \\
\text { Wochen }\end{array}$ & $\begin{array}{l}\text { Open-label- } \\
\text { Phase-2- } \\
\text { Studie }\end{array}$ & - & 40 & $\begin{array}{l}\text { SVR24, Beobachtung } \\
\text { über } 36 \text { Wochen }\end{array}$ & SVR24 $10-100 \%$ & Level $2 b$ \\
\hline
\end{tabular}




\begin{tabular}{|c|c|c|c|c|c|c|c|}
\hline $\begin{array}{l}\text { Referenz- } \\
\text { autor, Jahr }\end{array}$ & $\begin{array}{l}\text { Thema, } \\
\text { Intervention }\end{array}$ & Studientyp & Kontrolle & n gesamt & $\begin{array}{l}\text { Zielparameter, } \\
\text { Beobachtungsdauer }\end{array}$ & $\begin{array}{l}\text { Ergebnis, } \\
\text { Bemerkungen }\end{array}$ & $\begin{array}{l}\text { Evidenzgrad, } \\
{ }^{*} \text { Oxford-Schema }\end{array}$ \\
\hline $\begin{array}{l}\text { Osinusi A } \\
\text { et al., } 2013\end{array}$ & $\begin{array}{l}\text { SOF/RBV für Geno- } \\
\text { typ-1-Patienten } \\
\text { mit negativen prä- } \\
\text { diktiven Faktoren }\end{array}$ & $\begin{array}{l}\text { Randomi- } \\
\text { sierte Open- } \\
\text { label-Phase- } \\
\text { 2-Studie }\end{array}$ & - & 60 & $\begin{array}{l}\text { SVR24, Beobachtung } \\
\text { über } 48 \text { Wochen }\end{array}$ & SVR24 $48-90 \%$ & Level 2b \\
\hline $\begin{array}{l}\text { Lalezari JP } \\
\text { et al., } 2013\end{array}$ & $\begin{array}{l}\text { SOF/RBV über } 12 \text { - } \\
24 \text { Wochen bei } \\
\text { therapienaiven } \\
\text { HCV-Patienten }\end{array}$ & $\begin{array}{l}\text { Randomi- } \\
\text { sierte Open- } \\
\text { label-Phase- } \\
\text { 2-Studie }\end{array}$ & - & 235 & $\begin{array}{l}\text { SVR12, Beobachtung } \\
\text { über } 36 \text { Wochen }\end{array}$ & SVR12 $52-56 \%$ & Level 2b \\
\hline $\begin{array}{l}\text { Zeuzem S } \\
\text { et al., } 2016\end{array}$ & $\begin{array}{l}\text { DCV/SMV } \pm \text { RBV } \\
\text { über } 12-24 \text { Wo- } \\
\text { chen zur Therapie } \\
\text { der HCV-Genotyp- } \\
\text { 1-Infektion }\end{array}$ & $\begin{array}{l}\text { Randomi- } \\
\text { sierte Open- } \\
\text { label-Phase- } \\
\text { 2-Studie }\end{array}$ & - & 168 & $\begin{array}{l}\text { SVR12, Beobachtung } \\
\text { über } 36 \text { Wochen }\end{array}$ & SVR12 $65-95 \%$ & Level 2b \\
\hline
\end{tabular}

\section{b) Genotyp 2}

\begin{tabular}{|c|c|c|c|c|c|c|c|}
\hline $\begin{array}{l}\text { Referenz- } \\
\text { autor, Jahr }\end{array}$ & $\begin{array}{l}\text { Thema, } \\
\text { Intervention }\end{array}$ & Studientyp & Kontrolle & n gesamt & $\begin{array}{l}\text { Zielparameter, } \\
\text { Beobachtungsdauer }\end{array}$ & $\begin{array}{l}\text { Ergebnis, } \\
\text { Bemerkungen }\end{array}$ & $\begin{array}{l}\text { Evidenzgrad, } \\
{ }^{*} \text { Oxford-Schema }\end{array}$ \\
\hline $\begin{array}{l}\text { Foster GR } \\
\text { et al., } 2015\end{array}$ & $\begin{array}{l}\text { SOF/VEL für die } \\
\text { HCV-Genotyp-2- } \\
\text { und 3-Infektion }\end{array}$ & $\begin{array}{l}2 \text { kontrollierte } \\
\text { Phase-3-Studien }\end{array}$ & 407 & 818 & $\begin{array}{l}\text { SVR12, Beobachtung } \\
\text { über } 24 \text { Wochen }\end{array}$ & SVR $1295-99 \%$ & Level 1b \\
\hline $\begin{array}{l}\text { Lawitz E } \\
\text { et al., } 2013\end{array}$ & $\begin{array}{l}\text { SOF / RBV über } 12 \\
\text { Wochen für thera- } \\
\text { pienaive HCV Pa- } \\
\text { tienten }\end{array}$ & $\begin{array}{l}2 \text { Open-label- } \\
\text { Phase-3-Studien }\end{array}$ & - & 826 & $\begin{array}{l}\text { SVR12, Beobachtung } \\
\text { über } 36 \text { Wochen }\end{array}$ & SVR12 $67-90 \%$ & Level 1b \\
\hline $\begin{array}{l}\text { Jacobson } \\
\text { IM et al., } \\
2013\end{array}$ & $\begin{array}{l}\text { SOF/RBV über } \\
12 \text { - } 16 \text { Wochen } \\
\text { für HCV-Genotyp } \\
2 \text { und } 3 \text { ohne The- } \\
\text { rapieoptionen }\end{array}$ & $\begin{array}{l}2 \text { randomisierte } \\
\text { Phase-3-Studien }\end{array}$ & 71 & 479 & $\begin{array}{l}\text { SVR12, Beobachtung } \\
\text { über } 28 \text { Wochen }\end{array}$ & $\begin{array}{l}\text { SVR12 } 50 \text { - } 78 \% \text {, bei } \\
\text { Vortherapie war die } \\
\text { 16-wöchige Thera- } \\
\text { pie einer } 12 \text {-wöchi- } \\
\text { gen überlegen. }\end{array}$ & Level 1b \\
\hline $\begin{array}{l}\text { Zeuzem S } \\
\text { et al., } 2014\end{array}$ & $\begin{array}{l}\text { SOF/RBV über } \\
12-24 \text { Wochen } \\
\text { bei HCV-Genotyp } \\
2 \text { und } 3\end{array}$ & $\begin{array}{l}\text { randomisierte } \\
\text { Placebo-kon- } \\
\text { trollierte Phase- } \\
\text { 3-Studie }\end{array}$ & 80 & 419 & $\begin{array}{l}\text { SVR12, Beobachtung } \\
\text { über } 36 \text { Wochen }\end{array}$ & SVR12 $85-93 \%$ & Level 1b \\
\hline $\begin{array}{l}\text { Hedskog C } \\
\text { et al., } 2015\end{array}$ & $\begin{array}{l}\text { HCV-Rekombinan- } \\
\text { ten und Anspre- } \\
\text { chen auf SOF/RBV }\end{array}$ & $\begin{array}{l}\text { retrospektive } \\
\text { Kohorten- } \\
\text { analyse }\end{array}$ & - & 2363 & $\begin{array}{l}\text { HCV-Rekombinanten } \\
\text { und Ansprechen auf } \\
\text { SOF/RBV }\end{array}$ & $\begin{array}{l}\text { Es wurden } 12 \text { neue } \\
\text { HCV -Genotyp-2- } \\
\text { Rekombinanten } \\
\text { charakterisiert. Die- } \\
\text { se zeigten ein ähnli- } \\
\text { ches Therapiean- } \\
\text { sprechen wie der } \\
\text { Genotyp } 1 .\end{array}$ & Level 3 \\
\hline $\begin{array}{l}\text { Susser S } \\
\text { et al., } 2016\end{array}$ & $\begin{array}{l}\text { Prävalenz und kli- } \\
\text { nische Relevanz } \\
\text { von HCV-Genotyp- } \\
\text { 2k/1b-Chimären }\end{array}$ & $\begin{array}{l}\text { retrospektive } \\
\text { Kohorten- } \\
\text { analyse }\end{array}$ & - & 279 & $\begin{array}{l}\text { Prävalenz und klini- } \\
\text { sche Relevanz von } \\
\text { HCV-Genotyp-2k/ } \\
\text { 1b-Chimären }\end{array}$ & $\begin{array}{l}\text { Die Prävalenz von } \\
\text { HCV-Genotyp-2k/ } \\
\text { 1b-Chimären be- } \\
\text { trägt } 17 \text { - } 25 \% \text {. Sie } \\
\text { sollten wie ein HCV- } \\
\text { Genotyp } 1 \text { behan- } \\
\text { delt werden. }\end{array}$ & Level 3 \\
\hline
\end{tabular}




\section{c) Genotyp 3}

\begin{tabular}{|c|c|c|c|c|c|c|c|}
\hline $\begin{array}{l}\text { Referenz- } \\
\text { autor, Jahr }\end{array}$ & $\begin{array}{l}\text { Thema, } \\
\text { Intervention }\end{array}$ & Studientyp & Kontrolle & n gesamt & $\begin{array}{l}\text { Zielparameter, } \\
\text { Beobachtungsdauer }\end{array}$ & $\begin{array}{l}\text { Ergebnis, } \\
\text { Bemerkungen }\end{array}$ & $\begin{array}{l}\text { Evidenzgrad, } \\
{ }^{*} \text { Oxford-Schema }\end{array}$ \\
\hline $\begin{array}{l}\text { Hezode C } \\
\text { et al., } 2016\end{array}$ & $\begin{array}{l}\text { Resistenzanalyse } \\
\text { bei HCV-Genotyp } \\
1-6 \text { und SOF/ } \\
\text { VEL-Therapie }\end{array}$ & $\begin{array}{l}\text { retrospektive } \\
\text { Kohorten- } \\
\text { analyse }\end{array}$ & - & 1284 & Resistenzanalyse & $\begin{array}{l}\text { Baseline-NS5A-Resis- } \\
\text { tenzen wurden bei } \\
16 \% \text { der Patienten } \\
\text { gefunden. Hier be- } \\
\text { trug die SVR12-Rate } \\
\text { nur } 88 \% .\end{array}$ & Level 3 \\
\hline $\begin{array}{l}\text { Curry MP } \\
\text { et al., } 2015\end{array}$ & $\begin{array}{l}\text { SOF/VEL über } \\
12-24 \text { Wochen } \\
\text { bei HCV-Patien- } \\
\text { ten mit dekom- } \\
\text { pensierter LCI }\end{array}$ & $\begin{array}{l}\text { randomisier- } \\
\text { te Open- } \\
\text { label-Phase- } \\
\text { 3-Studie }\end{array}$ & - & 267 & $\begin{array}{l}\text { SVR12, Beobachtung } \\
\text { über } 36 \text { Wochen }\end{array}$ & SVR12 $83 \%$ & Level 1b \\
\hline $\begin{array}{l}\text { Nelson DR } \\
\text { et al., } 2015\end{array}$ & $\begin{array}{l}12 \text { Wochen DCV/ } \\
\text { SOF bei HCV- } \\
\text { Genotyp } 3\end{array}$ & $\begin{array}{l}\text { Phase- } \\
\text { 3-Studie }\end{array}$ & - & 152 & $\begin{array}{l}\text { SVR12, Beobachtung } \\
\text { über } 24 \text { Wochen }\end{array}$ & SVR12 $63-96 \%$ & Level 1b \\
\hline $\begin{array}{l}\text { Leroy V et al., } \\
2016\end{array}$ & $\begin{array}{l}\text { DCV/SOF + RBV } \\
\text { über } 12 \text { - } 16 \\
\text { Wochen bei HCV- } \\
\text { Genotyp } 3 \text { und } \\
\text { fortgeschrittener } \\
\text { Lebererkrankung }\end{array}$ & $\begin{array}{l}\text { randomisier- } \\
\text { te Phase-3- } \\
\text { Studie }\end{array}$ & - & 50 & $\begin{array}{l}\text { SVR12, Beobachtung } \\
\text { über } 28 \text { Wochen }\end{array}$ & SVR12 (ITT) $90 \%$ & Level 1b \\
\hline $\begin{array}{l}\text { Link JO et al., } \\
2014\end{array}$ & LDV & Review & - & - & $\begin{array}{l}\text { Charakterisierung von } \\
\text { LDV }\end{array}$ & $\begin{array}{l}\text { SVR12 bis } 100 \% \text { in } \\
\text { Kombination mit } \\
\text { komplementär } \\
\text { wirksamen DAAs }\end{array}$ & Level 1 \\
\hline $\begin{array}{l}\text { Gane EJ } \\
\text { et al., } 2014\end{array}$ & $\begin{array}{l}\text { DDV/SOF über } 12 \\
\text { Wochen für HCV- } \\
\text { Genotyp } 3 \text { oder } 6\end{array}$ & $\begin{array}{l}\text { Phase- } \\
\text { 3-Studie }\end{array}$ & - & 75 & $\begin{array}{l}\text { SVR4, Beobachtung } \\
\text { über } 16 \text { Wochen }\end{array}$ & SVR4 $77-96 \%$ & Level 2 \\
\hline $\begin{array}{l}\text { Susser S } \\
\text { et al., } 2016\end{array}$ & $\begin{array}{l}\text { europäische RAVs } \\
\text { database }\end{array}$ & $\begin{array}{l}\text { retrospektive } \\
\text { Kohorten- } \\
\text { analyse }\end{array}$ & - & 3549 & $\begin{array}{l}\text { Häufigkeit und Cha- } \\
\text { rakteristika von RAVs }\end{array}$ & $\begin{array}{l}\text { Die Häufigkeit von } \\
\text { RAVs bei DAA-naiven } \\
\text { Patienten liegt zwi- } \\
\text { schen } 1 \text { und } 80 \% . \\
\text { Bei DAA-erfahrenen } \\
\text { Patienten sind RAVs } \\
\text { sehr häufig. }\end{array}$ & Level 3 \\
\hline
\end{tabular}

\section{d) Genotyp 4}

\begin{tabular}{|c|c|c|c|c|c|c|c|}
\hline $\begin{array}{l}\text { Referenz- } \\
\text { autor, Jahr }\end{array}$ & $\begin{array}{l}\text { Thema, } \\
\text { Intervention }\end{array}$ & Studientyp & Kontrolle & n gesamt & $\begin{array}{l}\text { Zielparameter, } \\
\text { Beobachtungsdauer }\end{array}$ & $\begin{array}{l}\text { Ergebnis, } \\
\text { Bemerkungen }\end{array}$ & $\begin{array}{l}\text { Evidenzgrad, } \\
{ }^{*} \text { Oxford-Schema }\end{array}$ \\
\hline $\begin{array}{l}\text { Kohli A et al., } \\
2015\end{array}$ & $\begin{array}{l}\text { LDV/SOF für } \\
12 \text { Wochen bei } \\
\text { HCV-Genotyp } 4\end{array}$ & $\begin{array}{l}\text { Open-label- } \\
\text { Phase-2- } \\
\text { Studie }\end{array}$ & - & 21 & $\begin{array}{l}\text { SVR12, Beobachtung } \\
\text { über } 24 \text { Wochen }\end{array}$ & SVR12 $100 \%$ & Level 2b \\
\hline $\begin{array}{l}\text { Abergel A } \\
\text { et al., } 2016\end{array}$ & $\begin{array}{l}\text { LDV/SOF für } \\
12 \text { Wochen bei } \\
\text { HCV-Genotyp } 4\end{array}$ & $\begin{array}{l}\text { Open-label- } \\
\text { Phase-2- } \\
\text { Studie }\end{array}$ & - & 44 & $\begin{array}{l}\text { SVR12, Beobachtung } \\
\text { über } 24 \text { Wochen }\end{array}$ & SVR12 93\% & Level 2b \\
\hline $\begin{array}{l}\text { Rockstroh JK } \\
\text { et al., } 2015\end{array}$ & $\begin{array}{l}\text { GZR/EBR über } \\
12 \text { Wochen bei } \\
\text { HCV/HIV-Ko- } \\
\text { Infektion }\end{array}$ & $\begin{array}{l}\text { nicht ran- } \\
\text { domisierte } \\
\text { Open-label- } \\
\text { Phase-3- } \\
\text { Studie }\end{array}$ & - & 218 & $\begin{array}{l}\text { SVR12, Beobachtung } \\
\text { über } 24 \text { Wochen }\end{array}$ & SVR12 96\% & Level 2b \\
\hline
\end{tabular}




\begin{tabular}{|c|c|c|c|c|c|c|c|}
\hline $\begin{array}{l}\text { Referenz- } \\
\text { autor, Jahr }\end{array}$ & $\begin{array}{l}\text { Thema, } \\
\text { Intervention }\end{array}$ & Studientyp & Kontrolle & n gesamt & $\begin{array}{l}\text { Zielparameter, } \\
\text { Beobachtungsdauer }\end{array}$ & $\begin{array}{l}\text { Ergebnis, } \\
\text { Bemerkungen }\end{array}$ & $\begin{array}{l}\text { Evidenzgrad, } \\
\text { *Oxford-Schema }\end{array}$ \\
\hline $\begin{array}{l}\text { Hezode C } \\
\text { et al., } 2015\end{array}$ & $\begin{array}{l}\text { Paritaprevir/r } \\
\text { und Ombitasvir } \pm \\
\text { RBV bei HCV- } \\
\text { Genotyp } 4\end{array}$ & $\begin{array}{l}\text { randomi- } \\
\text { sierte Open- } \\
\text { label-Phase- } \\
\text { 3-Studie }\end{array}$ & - & 135 & $\begin{array}{l}\text { SVR12, Beobachtung } \\
\text { über } 24 \text { Wochen }\end{array}$ & SVR12 $91-100 \%$ & Level 1b \\
\hline $\begin{array}{l}\text { Asselah T } \\
\text { et al., } 2016\end{array}$ & $\begin{array}{l}\text { Paritaprevir/r, } \\
\text { Ombitasvir und } \\
\text { Ribavirin bei } \\
\text { Patienten mit } \\
\text { kompensierter } \\
\text { LCI }\end{array}$ & $\begin{array}{l}\text { randomi- } \\
\text { sierte Open- } \\
\text { label-Phase- } \\
\text { 3-Studie }\end{array}$ & - & 120 & $\begin{array}{l}\text { SVR12, Beobachtung } \\
\text { über } 28 \text { Wochen }\end{array}$ & SVR12 $97-98 \%$ & Level 1b \\
\hline $\begin{array}{l}\text { Waked I } \\
\text { et al., } 2016\end{array}$ & $\begin{array}{l}\text { Paritaprevir/r, } \\
\text { Ombitasvir und } \\
\text { Ribavirin über } \\
12 \text { Wochen bei } \\
\text { Patienten mit } \\
\text { und ohne LCl }\end{array}$ & $\begin{array}{l}\text { Open-label- } \\
\text { Phase-3- } \\
\text { Studie }\end{array}$ & - & 160 & $\begin{array}{l}\text { SVR12, Beobachtung } \\
\text { über } 24 \text { Wochen }\end{array}$ & SVR12 $94-97 \%$ & Level 1b \\
\hline $\begin{array}{l}\text { Moreno C } \\
\text { et al., } 2014\end{array}$ & $\begin{array}{l}\text { SMV + PEG-IFN/ } \\
\text { RBV bei HCV- } \\
\text { Genotyp } 4\end{array}$ & $\begin{array}{l}\text { Open-label- } \\
\text { Phase-3- } \\
\text { Studie }\end{array}$ & - & 107 & $\begin{array}{l}\text { SVR12, Beobachtung } \\
\text { über } 48 \text { Wochen }\end{array}$ & SVR12 $70 \%$ & Level 1 \\
\hline $\begin{array}{l}\text { Lenz O et al., } \\
2013\end{array}$ & $\begin{array}{l}\text { SMV-Monothe- } \\
\text { rapie über } 7 \\
\text { Tage bei HCV- } \\
\text { Genotyp } 2 \text { - } 6\end{array}$ & $\begin{array}{l}\text { Phase-2- } \\
\text { Studie }\end{array}$ & - & 37 & $\begin{array}{l}\text { HCV-RNA, NS3- } \\
\text { Protease-Sequenz }\end{array}$ & $\begin{array}{l}\text { Identifizierung von } \\
\text { Polymorphismen }\end{array}$ & Level 2b \\
\hline $\begin{array}{l}\text { El Raziky M } \\
\text { et al., } 2015\end{array}$ & $\begin{array}{l}\text { SMV/SOF bei } \\
\text { HCV-Genotyp } 4\end{array}$ & $\begin{array}{l}\text { randomi- } \\
\text { sierte Open- } \\
\text { label-Phase- } \\
\text { 2-Studie }\end{array}$ & - & 63 & $\begin{array}{l}\text { SVR4, Beobachtung } \\
\text { über } 16 \text { Wochen }\end{array}$ & SVR4 $75-100 \%$ & Level 2b \\
\hline $\begin{array}{l}\text { Ruane PJ } \\
\text { et al., } 2014\end{array}$ & $\begin{array}{l}\text { SOF/RBV } \pm \text { PEG- } \\
\text { IFN über } 12-24 \\
\text { Wochen bei } \\
\text { HCV-Genotyp } 4\end{array}$ & $\begin{array}{l}\text { Open-label- } \\
\text { Phase-2- } \\
\text { Studie }\end{array}$ & - & 60 & $\begin{array}{l}\text { SVR12, Beobachtung } \\
\text { über } 36 \text { Wochen }\end{array}$ & SVR12 $59-87 \%$ & Level 2b \\
\hline
\end{tabular}

\section{e) Genotyp 5 und 6}

\begin{tabular}{|l|l|l|l|l|l|l|l|}
\hline $\begin{array}{l}\text { Referenz- } \\
\text { autor, Jahr }\end{array}$ & $\begin{array}{l}\text { Thema, } \\
\text { Intervention }\end{array}$ & Studientyp & Kontrolle & n gesamt & $\begin{array}{l}\text { Zielparameter, } \\
\text { Beobachtungsdauer }\end{array}$ & $\begin{array}{l}\text { Ergebnis, } \\
\text { Bemerkungen }\end{array}$ \\
\hline $\begin{array}{l}\text { Abergel A } \\
\text { et al., } 2016\end{array}$ & $\begin{array}{l}\text { LDV/SOF über } \\
\text { 12 Wochen bei } \\
\text { HCV-Genotyp }\end{array}$ & $\begin{array}{l}\text { Open-label- } \\
\text { Phase-2- } \\
\text { Studie }\end{array}$ & - & 41 & $\begin{array}{l}\text { SVR12, Beobachtung } \\
\text { über 24 Wochen }\end{array}$ & SVR12 89-95\% \\
\hline $\begin{array}{l}\text { Gane EJ } \\
\text { et al., 2015 }\end{array}$ & $\begin{array}{l}\text { LDV/SOF } \pm \text { RBV } \\
\text { über 12 Wochen } \\
\text { bei HCV-Geno- } \\
\text { typ-3- oder } \\
\text { 6-Infektion }\end{array}$ & $\begin{array}{l}\text { Open-label- } \\
\text { Phase-2- } \\
\text { Studie }\end{array}$ & - & 126 & $\begin{array}{l}\text { SVR12, Beobachtung } \\
\text { über 24 Wochen }\end{array}$ & SVR12 64-96\% \\
\hline
\end{tabular}




\section{DAA-Ersttherapie bei dekompensierter Zirrhose}

\begin{tabular}{|c|c|c|c|c|c|c|c|}
\hline $\begin{array}{l}\text { Referenz- } \\
\text { autor, Jahr }\end{array}$ & $\begin{array}{l}\text { Thema, } \\
\text { Intervention }\end{array}$ & Studientyp & Kontrolle & n gesamt & $\begin{array}{l}\text { Zielparameter, } \\
\text { Beobachtungsdauer }\end{array}$ & $\begin{array}{l}\text { Ergebnis, } \\
\text { Bemerkungen }\end{array}$ & $\begin{array}{l}\text { Evidenzgrad, } \\
{ }^{*} \text { Oxford-Schema }\end{array}$ \\
\hline $\begin{array}{l}\text { Poordad F } \\
\text { et al., } 2016\end{array}$ & $\begin{array}{l}\text { Paritaprevir/r, } \\
\text { Ombitasvir } \pm \\
\text { Dasabuvir } \pm \\
\text { Ribavirin bei } \\
\text { Patienten mit } \\
\text { kompensierter } \\
\text { LCl }\end{array}$ & $\begin{array}{l}\text { retrospek- } \\
\text { tive Kohor- } \\
\text { tenanalyse }\end{array}$ & & & $\begin{array}{l}\text { Sicherheit von Parita- } \\
\text { previr/r, Ombitasvir } \pm \\
\text { Ribavirin bei Patienten } \\
\text { mit kompensierter LCl }\end{array}$ & $\begin{array}{l}\text { HCV-NS3-Protease- } \\
\text { Inhibitoren sollten } \\
\text { bei Patienten mit } \\
\text { dekompensierter } \\
\text { Zirrhose nicht einge- } \\
\text { setzt werden }\end{array}$ & Level 3 \\
\hline $\begin{array}{l}\text { Padegimas A } \\
\text { et al., } 2016\end{array}$ & $\begin{array}{l}\text { Peri-Myokarditis } \\
\text { bei LDV/SOF- } \\
\text { Therapie }\end{array}$ & Fallbericht & - & 1 & $\begin{array}{l}1 \text { Fall von Peri-Myokar- } \\
\text { ditis bei LDV/SOF- } \\
\text { Therapie }\end{array}$ & $\begin{array}{l}\text { LDV/SOF kann } \\
\text { kardiotoxisch sein. }\end{array}$ & Level 4 \\
\hline $\begin{array}{l}\text { Marchan- } \\
\text { Lopez A } \\
\text { et al., } 2016\end{array}$ & $\begin{array}{l}\text { Leberversagen } \\
\text { bei HIV/HCV- } \\
\text { Ko-Infektion } \\
\text { und LDV/SOF, } \\
\text { sowie antiretro- } \\
\text { viraler Therapie }\end{array}$ & Fallbericht & - & 1 & $\begin{array}{l}1 \text { Fall von Leberversa- } \\
\text { gen bei HIV/HCV-Ko- } \\
\text { Infektion und LDV/SOF, } \\
\text { sowie antiretroviraler } \\
\text { Therapie }\end{array}$ & $\begin{array}{l}\text { LDV/SOF kann } \\
\text { hepatotoxisch sein. }\end{array}$ & Level 4 \\
\hline $\begin{array}{l}\text { Welker MW } \\
\text { et al., } 2016\end{array}$ & $\begin{array}{l}\text { Laktatazidose } \\
\text { bei HCV-LCl- } \\
\text { und SOF/RBV- } \\
\text { Therapie }\end{array}$ & $\begin{array}{l}\text { prospektive } \\
\text { Kohorten- } \\
\text { studie }\end{array}$ & - & 35 & $\begin{array}{l}\text { Nebenwirkungen } 24 \\
\text { Wochen vor und wäh- } \\
\text { rend der antiviralen } \\
\text { Therapie }\end{array}$ & $\begin{array}{l}\text { SOF/RBV kann zu } \\
\text { Laktatazidose bei } \\
\text { HCV-LCl führen. }\end{array}$ & Level 3 \\
\hline $\begin{array}{l}\text { Hoofnagle JH } \\
\text { et al., } 2016\end{array}$ & $\begin{array}{l}\text { hepatische } \\
\text { Dekompensa- } \\
\text { tion unter DAA- } \\
\text { Therapie }\end{array}$ & Review & - & - & $\begin{array}{l}\text { Komplikationen unter } \\
\text { DAA-Therapie }\end{array}$ & $\begin{array}{l}\text { Bei dekompensierter } \\
\text { Zirrhose wird das } \\
\text { Risiko für Kompli- } \\
\text { kationen unter DAA- } \\
\text { Therapie generell } \\
\text { leicht erhöht. }\end{array}$ & Level 1 \\
\hline $\begin{array}{l}\text { Zimmer- } \\
\text { mann T et al., } \\
2016\end{array}$ & $\begin{array}{l}\text { Expertenemp- } \\
\text { fehlungen zu } \\
\text { HCV und LTx }\end{array}$ & Review & - & - & $\begin{array}{l}\text { Expertenempfehlun- } \\
\text { gen zu HCV und LTx }\end{array}$ & $\begin{array}{l}\text { Expertenempfehlun- } \\
\text { gen zu HCV und LTx }\end{array}$ & Level 1 \\
\hline $\begin{array}{l}\text { Cheung MC } \\
\text { et al., } 2016\end{array}$ & $\begin{array}{l}\text { DAA-Therapie } \\
\text { bei Patienten } \\
\text { mit dekompen- } \\
\text { sierter LCI }\end{array}$ & $\begin{array}{l}\text { prospektive } \\
\text { Kohorten- } \\
\text { studie }\end{array}$ & $\begin{array}{l}261 \text { unbe- } \\
\text { handelte } \\
\text { Patienten }\end{array}$ & 667 & $\begin{array}{l}\text { Outcome, Beobach- } \\
\text { tung über } 15 \text { Monate }\end{array}$ & $\begin{array}{l}\text { DAA-Therapie führt } \\
\text { bei Patienten mit de- } \\
\text { kompensierter } \mathrm{LCl} \text { zu } \\
\text { einer prolongierten } \\
\text { Erholung der Leber- } \\
\text { funktion. }\end{array}$ & Level 3 \\
\hline $\begin{array}{l}\text { Belli LS et al., } \\
2016\end{array}$ & $\begin{array}{l}\text { De-Listung von } \\
\text { LTx-Kandidaten } \\
\text { nach HCV-Eradi- } \\
\text { kation }\end{array}$ & $\begin{array}{l}\text { prospektive } \\
\text { Kohorten- } \\
\text { studie }\end{array}$ & - & 103 & $\begin{array}{l}\text { De-Listung, Beobach- } \\
\text { tung über } 60 \text { Wochen }\end{array}$ & $\begin{array}{l}\text { Ein Drittel der Warte- } \\
\text { listenpatienten konn- } \\
\text { ten nach erfolgrei- } \\
\text { cher DAA-Therapie } \\
\text { inaktiviert und ein } \\
\text { Fünftel de-gelistet } \\
\text { werden. }\end{array}$ & Level 3 \\
\hline $\begin{array}{l}\text { Charlton M } \\
\text { et al., } 2015\end{array}$ & $\begin{array}{l}\text { SOF/RBV über } \\
24 \text { Wochen bei } \\
\text { kompensierter } \\
\text { rekurrenter } \\
\text { HCV-Infektion } \\
\text { nach LTx }\end{array}$ & $\begin{array}{l}\text { prospektive, } \\
\text { multizentri- } \\
\text { sche, Open- } \\
\text { label-Pilot- } \\
\text { studie }\end{array}$ & - & 40 & $\begin{array}{l}\text { SVR 12, Beobachtung } \\
\text { über } 36 \text { Wochen }\end{array}$ & SVR12 $70 \%$ & Level 2 \\
\hline $\begin{array}{l}\text { Manns M } \\
\text { et al., } 2016\end{array}$ & $\begin{array}{l}\text { LDV/SOF + RBV } \\
\text { bei HCV-Geno- } \\
\text { typ-1- oder 4- } \\
\text { Infektion und } \\
\text { fortgeschritte- } \\
\text { ner Lebererkran- } \\
\text { kung }\end{array}$ & $\begin{array}{l}\text { Open-label- } \\
\text { Phase-2- } \\
\text { Studie }\end{array}$ & - & 333 & $\begin{array}{l}\text { SVR 12, Beobachtung } \\
\text { über } 36 \text { Wochen }\end{array}$ & SVR12 $50-100 \%$ & Level 2b \\
\hline
\end{tabular}




\section{Therapie nach einem Versagen einer DAA-Therapie}

\begin{tabular}{|c|c|c|c|c|c|c|c|}
\hline $\begin{array}{l}\text { Referenz- } \\
\text { autor, Jahr }\end{array}$ & $\begin{array}{l}\text { Thema, } \\
\text { Intervention }\end{array}$ & Studientyp & Kontrolle & n gesamt & $\begin{array}{l}\text { Zielparameter, } \\
\text { Beobachtungsdauer }\end{array}$ & $\begin{array}{l}\text { Ergebnis, } \\
\text { Bemerkungen }\end{array}$ & $\begin{array}{l}\text { Evidenzgrad, } \\
{ }^{*} \text { Oxford-Schema }\end{array}$ \\
\hline $\begin{array}{l}\text { Hezode C } \\
\text { et al., } 2016\end{array}$ & $\begin{array}{l}\text { Re-Therapie mit } \\
\text { SOF/SMV bei } \\
\text { Genotyp } 1 \text { oder } \\
4 \text { und Therapie- } \\
\text { versagen auf } \\
\text { DCV }\end{array}$ & $\begin{array}{l}\text { prospektive } \\
\text { Kohorten- } \\
\text { studie }\end{array}$ & - & 16 & $\begin{array}{l}\text { SVR 12, Beobachtung } \\
\text { über } 24 \text { Wochen }\end{array}$ & SVR12 87,5\% & Level 3 \\
\hline $\begin{array}{l}\text { Kwo P et al., } \\
2016\end{array}$ & $\begin{array}{l}\text { SOF/SMV über } \\
8-12 \text { Wochen } \\
\text { bei HCV-Geno- } \\
\text { typ } 1 \text { ohne LCI }\end{array}$ & $\begin{array}{l}\text { randomi- } \\
\text { sierte Open- } \\
\text { label-Phase- } \\
\text { 3-Studie }\end{array}$ & - & 310 & $\begin{array}{l}\text { SVR 12, Beobachtung } \\
\text { über } 24 \text { Wochen }\end{array}$ & SVR12 $83-97 \%$ & Level 1 \\
\hline $\begin{array}{l}\text { Sarrazin C } \\
\text { et al., } 2016\end{array}$ & $\begin{array}{l}\text { Bedeutung von } \\
\text { Resistenzen ge- } \\
\text { gen DAAs }\end{array}$ & Review & - & - & RAVs & Bedeutung von RAVs & Level 1 \\
\hline $\begin{array}{l}\text { Lenz O et al., } \\
2014\end{array}$ & $\begin{array}{l}\text { virologische } \\
\text { Analysen von } \\
\text { HCV-Genotyp-1 } \\
\text { infizierten-Pa- } \\
\text { tienten, die mit } \\
\text { SMV + peg-IFN/ } \\
\text { RBV behandelt } \\
\text { wurden }\end{array}$ & $\begin{array}{l}\text { retrospek- } \\
\text { tive Kohor- } \\
\text { tenanalyse }\end{array}$ & - & 2007 & RAVs und SVR-Rate & $\begin{array}{l}\text { SMV-Therapiever- } \\
\text { sagen ist mit RAVs } \\
\text { assoziiert }\end{array}$ & Level 3 \\
\hline $\begin{array}{l}\text { Krishnan P } \\
\text { et al., } 2015\end{array}$ & $\begin{array}{l}\text { antivirale Aktivi- } \\
\text { tät und Resis- } \\
\text { tenzprofil von } \\
\text { Ombitasvir }\end{array}$ & $\begin{array}{l}\text { prospektive } \\
\text { Kohorten- } \\
\text { studie }\end{array}$ & - & 12 & $\begin{array}{l}\text { antivirale Aktivität und } \\
\text { Resistenzprofil, Beob- } \\
\text { achtung über } 3 \text { Tage }\end{array}$ & $\begin{array}{l}\text { antivirale Aktivität } \\
\text { und Resistenzprofil } \\
\text { von Ombitasvir }\end{array}$ & Level 3 \\
\hline $\begin{array}{l}\text { Krishnan P } \\
\text { et al., } 2014\end{array}$ & $\begin{array}{l}\text { Resistenzanalyse } \\
\text { von Patienten, } \\
\text { die mit Parita- } \\
\text { previr/r, Ombi- } \\
\text { tasvir und Dasa- } \\
\text { buvir } \pm \text { RBV } \\
\text { behandelt wur- } \\
\text { den }\end{array}$ & $\begin{array}{l}\text { retrospek- } \\
\text { tive Kohor- } \\
\text { tenanalyse }\end{array}$ & - & 74 & RAVs & $\begin{array}{l}\text { Das Vorhandensein } \\
\text { von Baseline-RAVs } \\
\text { hat keinen Einfluss } \\
\text { auf das Therapie- } \\
\text { Outcome. }\end{array}$ & Level 3 \\
\hline $\begin{array}{l}\text { Svarovskaia } \\
\text { ES et al., } 2014\end{array}$ & $\begin{array}{l}\text { seltene Resis- } \\
\text { tenzentwicklung } \\
\text { bei HCV-Geno- } \\
\text { typ } 1-6 \text { unter } \\
\text { SOF-Therapie }\end{array}$ & $\begin{array}{l}\text { retrospek- } \\
\text { tive Kohor- } \\
\text { tenanalyse }\end{array}$ & - & 1645 & RAVs & $\begin{array}{l}\text { SOF-resistente HCV } \\
\text { ist selten. }\end{array}$ & Level 3 \\
\hline $\begin{array}{l}\text { Svarovskaia } \\
\text { ES et al., } 2016\end{array}$ & $\begin{array}{l}\text { L159F und } \\
\text { V321A-SOF- } \\
\text { assoziierte } \\
\text { HCV-NS5B- } \\
\text { Varianten }\end{array}$ & $\begin{array}{l}\text { retrospek- } \\
\text { tive Kohor- } \\
\text { tenanalyse }\end{array}$ & - & 353 & L159F und V321A & $\begin{array}{l}\text { Das Vorkommen der } \\
\text { NS5B-Varianten } \\
\text { L159F und V321A } \\
\text { hatte keinen Einfluss } \\
\text { auf den Erfolg einer } \\
\text { Re-Therapie mit SOF/ } \\
\text { RBV + peg-IFN. L159F } \\
\text { bei HCV-Genotyp } 1 \\
\text { hatte keinen Einfluss } \\
\text { auf den Therapieer- } \\
\text { folg mit LDV/SOF. }\end{array}$ & Level 3 \\
\hline
\end{tabular}




\begin{tabular}{|c|c|c|c|c|c|c|c|}
\hline $\begin{array}{l}\text { Referenz- } \\
\text { autor, Jahr }\end{array}$ & $\begin{array}{l}\text { Thema, } \\
\text { Intervention }\end{array}$ & Studientyp & Kontrolle & n gesamt & $\begin{array}{l}\text { Zielparameter, } \\
\text { Beobachtungsdauer }\end{array}$ & $\begin{array}{l}\text { Ergebnis, } \\
\text { Bemerkungen }\end{array}$ & $\begin{array}{l}\text { Evidenzgrad, } \\
{ }^{*} \text { Oxford-Schema }\end{array}$ \\
\hline $\begin{array}{l}\text { Hedskog C } \\
\text { et al., } 2015\end{array}$ & $\begin{array}{l}\text { HCV-Viruspopu- } \\
\text { lation eines } \\
\text { Patienten mit } \\
\text { S282 T und Re- } \\
\text { lapse nach SOF- } \\
\text { Monotherapie }\end{array}$ & Fallstudie & - & 1 & $\begin{array}{l}\text { Deep-Sequence- } \\
\text { Analyse }\end{array}$ & $\begin{array}{l}\text { Ein sehr geringer } \\
\text { Baseline-Level von } \\
\text { S282T stieg unter } \\
\text { SOF-Monotherapie } \\
\text { und war wiederholt } \\
\text { nachweisbar. Den- } \\
\text { noch war eine Re- } \\
\text { Therapie mit SOF/ } \\
\text { RBV über } 12 \text { Wochen } \\
\text { erfolgreich. }\end{array}$ & Level 4 \\
\hline $\begin{array}{l}\text { Krishnan P } \\
\text { et al., } 2015\end{array}$ & $\begin{array}{l}\text { NS3, NS5A und } \\
\text { NS5B RAVs bei } \\
\text { Therapie mit } \\
\text { Paritaprevir/r, } \\
\text { Ombitasvir und } \\
\text { Dasabuvir }\end{array}$ & $\begin{array}{l}\text { retrospek- } \\
\text { tive Kohor- } \\
\text { tenanalyse }\end{array}$ & - & 69 & $\begin{array}{l}\text { NS3, NS5A und NS5B } \\
\text { RAVs, Beobachtung } \\
\text { über } 72 \text { Wochen }\end{array}$ & $\begin{array}{l}\text { Bei HCV-Genotyp 1a } \\
\text { nahmen die NS3 } \\
\text { RAVs unter Therapie } \\
\text { mit Paritaprevir/r, } \\
\text { Ombitasvir und Da- } \\
\text { sabuvir ab, während } \\
\text { NS5A und NS5B RAVs } \\
\text { auch } 48 \text { Wochen } \\
\text { nach Therapieende } \\
\text { noch nachweisbar } \\
\text { waren. }\end{array}$ & Level 3 \\
\hline $\begin{array}{l}\text { Lawitz E } \\
\text { et al., } 2015\end{array}$ & $\begin{array}{l}\text { Re-Therapie für } \\
\text { Patienten mit } \\
\text { Therapieversa- } \\
\text { gen auf } 8 \text { oder } \\
12 \text { Wochen LDV/ } \\
\text { SOF mit LDV/ } \\
\text { SOF über } 24 \\
\text { Wochen }\end{array}$ & $\begin{array}{l}\text { Open-label- } \\
\text { Phase-3- } \\
\text { Studie }\end{array}$ & - & 41 & $\begin{array}{l}\text { SVR } 12 \text {, Beobachtung } \\
\text { über } 48 \text { Wochen }\end{array}$ & SVR12 $71 \%$ & Level 1 \\
\hline $\begin{array}{l}\text { Wyles D } \\
\text { et al., } 2015\end{array}$ & $\begin{array}{l}\text { LDV/SOF + RBV } \\
\text { für SOF vorthe- } \\
\text { rapierte HCV- } \\
\text { Genotyp-1-Pa- } \\
\text { tienten }\end{array}$ & $\begin{array}{l}\text { Open-label- } \\
\text { Phase-3- } \\
\text { Studie }\end{array}$ & - & 51 & $\begin{array}{l}\text { SVR } 12 \text {, Beobachtung } \\
\text { über } 24 \text { Wochen }\end{array}$ & SVR12 98\% & Level 1 \\
\hline $\begin{array}{l}\text { Vermehren J } \\
\text { et al., } 2016\end{array}$ & $\begin{array}{l}\text { Re-Therapie von } \\
\text { Patienten mit } \\
\text { Therapieversa- } \\
\text { gen auf DAAs }\end{array}$ & $\begin{array}{l}\text { retrospek- } \\
\text { tive Kohor- } \\
\text { tenanalyse }\end{array}$ & - & 310 & $\begin{array}{l}\text { Resistenzanalyse, } \\
\text { SVR12 bei Re-Therapie }\end{array}$ & $\begin{array}{l}\text { SVR12 bei Re-Thera- } \\
\text { pie } 90-100 \%\end{array}$ & Level 3 \\
\hline $\begin{array}{l}\text { Wilson EM } \\
\text { et al., } 2016\end{array}$ & $\begin{array}{l}\text { erfolgreiche Re- } \\
\text { Therapie bei } \\
\text { HCV-Genotyp- } \\
\text { 1-Infektion und } \\
\text { DAA-Kurzzeit- } \\
\text { therapie }\end{array}$ & $\begin{array}{l}\text { Open-label- } \\
\text { Phase-2- } \\
\text { Studie }\end{array}$ & - & 34 & $\begin{array}{l}\text { SVR 12, Beobachtung } \\
\text { über } 24 \text { Wochen }\end{array}$ & SVR12 $91 \%$ & Level 2 \\
\hline $\begin{array}{l}\text { Gane E et al., } \\
2015\end{array}$ & $\begin{array}{l}\text { Effektivität von } \\
12 \text { oder } 18 \text { Wo- } \\
\text { chen GZR/EBR + } \\
\text { RBV bei thera- } \\
\text { pienaiven HCV- } \\
\text { Genotyp-3-Pa- } \\
\text { tienten ohne LCI }\end{array}$ & $\begin{array}{l}\text { randomi- } \\
\text { sierte Open- } \\
\text { label-Phase- } \\
\text { 2-Studie }\end{array}$ & - & 41 & $\begin{array}{l}\text { SVR } 12 \text {, Beobachtung } \\
\text { über } 28 \text { Wochen }\end{array}$ & $\begin{array}{l}\text { Breakthrough oder } \\
\text { Rebound in } 41 \%\end{array}$ & Level 2 \\
\hline $\begin{array}{l}\text { Pawlotsky JM } \\
\text { et al., } 2016\end{array}$ & $\begin{array}{l}\text { HCV-Resistenz } \\
\text { gegen DAAs }\end{array}$ & review & - & - & RAVs & $\begin{array}{l}\text { Die Strategien zur } \\
\text { Erstlinientherapie } \\
\text { sollten verbessert } \\
\text { werden. }\end{array}$ & Level 2 \\
\hline
\end{tabular}




\begin{tabular}{|c|c|c|c|c|c|c|c|}
\hline $\begin{array}{l}\text { Referenz- } \\
\text { autor, Jahr }\end{array}$ & $\begin{array}{l}\text { Thema, } \\
\text { Intervention }\end{array}$ & Studientyp & Kontrolle & n gesamt & $\begin{array}{l}\text { Zielparameter, } \\
\text { Beobachtungsdauer }\end{array}$ & $\begin{array}{l}\text { Ergebnis, } \\
\text { Bemerkungen }\end{array}$ & $\begin{array}{l}\text { Evidenzgrad, } \\
{ }^{*} \text { Oxford-Schema }\end{array}$ \\
\hline $\begin{array}{l}\text { Poordad F } \\
\text { et al., } 2016\end{array}$ & $\begin{array}{l}\text { Ombitasvir/Pari- } \\
\text { taprevir/r, Dasa- } \\
\text { buvir und Sofos- } \\
\text { buvir über } 12 \text { - } \\
24 \text { Wochen für } \\
\text { HCV-Genotyp- } \\
\text { 1-Patienten mit } \\
\text { Therapieversa- } \\
\text { gen auf DAAs }\end{array}$ & $\begin{array}{l}\text { Open-label- } \\
\text { Phase-2- } \\
\text { Studie }\end{array}$ & - & 22 & $\begin{array}{l}\text { SVR 12, Beobachtung } \\
\text { über } 36 \text { Wochen }\end{array}$ & SVR12 $93-100 \%$ & Level 2 \\
\hline $\begin{array}{l}\text { Lawitz E } \\
\text { et al., } 2016\end{array}$ & $\begin{array}{l}\text { SOF/VEL + GS- } \\
9857 \text { über } 12 \\
\text { Wochen bei } \\
\text { vorbehandelten } \\
\text { HCV-Genotyp- } \\
\text { 1 -6-Patienten }\end{array}$ & $\begin{array}{l}2 \text { Phase-2- } \\
\text { Studien }\end{array}$ & - & 128 & $\begin{array}{l}\text { SVR 12, Beobachtung } \\
\text { über } 24 \text { Wochen }\end{array}$ & SVR12 $97-100 \%$ & Level 2 \\
\hline $\begin{array}{l}\text { Lawitz E } \\
\text { et al., } 2016\end{array}$ & $\begin{array}{l}\text { erfolgreiche } \\
\text { Re-Therapie von } \\
\text { HCV-GT1-Pa- } \\
\text { tienten mit } 12 \\
\text { Wochen EBR/ } \\
\text { GZR + SOF/RBV }\end{array}$ & $\begin{array}{l}\text { Open-label- } \\
\text { Phase-2- } \\
\text { Studie }\end{array}$ & - & 25 & $\begin{array}{l}\text { SVR 12, Beobachtung } \\
\text { über } 24 \text { Wochen }\end{array}$ & SVR12 $100 \%$ & Level 2 \\
\hline $\begin{array}{l}\text { Poordad F } \\
\text { et al., } 2016\end{array}$ & $\begin{array}{l}\text { ABT-493 und } \\
\text { ABT-530 bei } \\
\text { HCV-Genotyp- } \\
\text { 1-Patienten mit } \\
\text { Therapieversa- } \\
\text { gen auf DAAs }\end{array}$ & $\begin{array}{l}\text { Open-label- } \\
\text { Phase-2- } \\
\text { Studie }\end{array}$ & - & 50 & $\begin{array}{l}\text { SVR } 12 \text {, Beobachtung } \\
\text { über } 24 \text { Wochen }\end{array}$ & SVR12 $95-100 \%$ & Level 2 \\
\hline
\end{tabular}

\section{Bedeutung von viralen Resistenzen}

\begin{tabular}{|c|c|c|c|c|c|c|c|}
\hline $\begin{array}{l}\text { Referenz- } \\
\text { autor, Jahr }\end{array}$ & $\begin{array}{l}\text { Thema, } \\
\text { Intervention }\end{array}$ & Studientyp & Kontrolle & n gesamt & $\begin{array}{l}\text { Zielparameter, } \\
\text { Beobachtungsdauer }\end{array}$ & $\begin{array}{l}\text { Ergebnis, } \\
\text { Bemerkungen }\end{array}$ & $\begin{array}{l}\text { Evidenzgrad, } \\
{ }^{*} \text { Oxford-Schema }\end{array}$ \\
\hline $\begin{array}{l}\text { Jacobson IM } \\
\text { et al., } 2014\end{array}$ & $\begin{array}{l}\text { SMV + peg-IFN/ } \\
\text { RBV bei HCV- } \\
\text { GT1-Infektion }\end{array}$ & $\begin{array}{l}\text { randomi- } \\
\text { sierte kon- } \\
\text { trollierte } \\
\text { Phase-3- } \\
\text { Studie }\end{array}$ & 130 & 394 & $\begin{array}{l}\text { SVR 12, Beobachtung } \\
\text { über } 60 \text { Wochen }\end{array}$ & SVR12 80\% & Level 1 \\
\hline $\begin{array}{l}\text { Manns M } \\
\text { et al., } 2014\end{array}$ & $\begin{array}{l}\text { SMV + peg-IF- } \\
\text { Nalpha 2a oder } \\
\text { 2b/RBV bei } \\
\text { therapienaiven } \\
\text { HCV-GT1-Pa- } \\
\text { tienten }\end{array}$ & $\begin{array}{l}\text { randomi- } \\
\text { sierte kon- } \\
\text { trollierte } \\
\text { Phase-3- } \\
\text { Studie }\end{array}$ & 134 & 391 & $\begin{array}{l}\text { SVR 12, Beobachtung } \\
\text { über } 60 \text { Wochen }\end{array}$ & SVR12 $81 \%$ & Level 1 \\
\hline $\begin{array}{l}\text { Manns M } \\
\text { et al., } 2014\end{array}$ & $\begin{array}{l}\text { DCV + Asuna- } \\
\text { previr bei HCV } \\
\text { GT1b }\end{array}$ & $\begin{array}{l}\text { randomi- } \\
\text { sierte kon- } \\
\text { trollierte } \\
\text { Phase-3- } \\
\text { Studie }\end{array}$ & 102 & 307 & $\begin{array}{l}\text { SVR 12, Beobachtung } \\
\text { über } 24 \text { Wochen }\end{array}$ & SVR12 $82-90 \%$ & Level 1 \\
\hline $\begin{array}{l}\text { Sarrazi et al., } \\
2016\end{array}$ & $\begin{array}{l}\text { RAVs in HCV } \\
\text { NS5A, NS5B } \\
\text { oder NS3 und } \\
\text { Outcome der } \\
\text { Therapie mit } \\
\text { LDV/SOF }\end{array}$ & $\begin{array}{l}\text { retrospek- } \\
\text { tive Kohor- } \\
\text { tenanalyse }\end{array}$ & - & 2144 & $\begin{array}{l}\text { Prävalenz von RAVs in } \\
\text { HCV NS5A, NS5B oder } \\
\text { NS3 und Outcome der } \\
\text { Therapie mit LDV/SOF }\end{array}$ & $\begin{array}{l}\text { Baseline-RAVs in } \\
\text { NS5A haben nur mi- } \\
\text { nimale Effekte auf das } \\
\text { Outcome der Thera- } \\
\text { pie mit LDV/SOF. }\end{array}$ & Level 3 \\
\hline
\end{tabular}




\begin{tabular}{|c|c|c|c|c|c|c|c|}
\hline $\begin{array}{l}\text { Referenz- } \\
\text { autor, Jahr }\end{array}$ & $\begin{array}{l}\text { Thema, } \\
\text { Intervention }\end{array}$ & Studientyp & Kontrolle & n gesamt & $\begin{array}{l}\text { Zielparameter, } \\
\text { Beobachtungsdauer }\end{array}$ & $\begin{array}{l}\text { Ergebnis, } \\
\text { Bemerkungen }\end{array}$ & $\begin{array}{l}\text { Evidenzgrad, } \\
{ }^{*} \text { Oxford-Schema }\end{array}$ \\
\hline $\begin{array}{l}\text { Sarrazin C } \\
\text { et al., } 2015\end{array}$ & $\begin{array}{l}\text { NS5A RAVs bei } \\
\text { Patienten mit } \\
\text { kompensierter } \\
\text { LCl und LDV/ } \\
\text { SOF } \pm \text { RBV- } \\
\text { Therapie }\end{array}$ & $\begin{array}{l}\text { retrospek- } \\
\text { tive Kohor- } \\
\text { tenanalyse }\end{array}$ & - & 511 & $\begin{array}{l}\text { Prävalenz von RAVs } \\
\text { und Outcome der The- } \\
\text { rapie mit LDV/SOF } \pm \\
\text { RBV bei LCl }\end{array}$ & $\begin{array}{l}\text { LDV/SOF } \pm \text { RBV über } \\
12-24 \text { Wochen bei } \\
\text { therapienaiven HCV- } \\
\text { GT1-Patienten mit } \\
\text { LCl ist hoch effektiv, } \\
\text { selbst bei Vorliegen } \\
\text { von Baseline-RAVs. }\end{array}$ & Level 3 \\
\hline $\begin{array}{l}\text { Sarrazin C } \\
\text { et al., } 2016\end{array}$ & $\begin{array}{l}\text { Effekt von Baseli- } \\
\text { ne-RAVs auf eine } \\
\text { SVR mit dem } \\
\text { 3D-Regime } \pm \\
\text { RBV bei HCV- } \\
\text { GT1-Patienten }\end{array}$ & $\begin{array}{l}\text { retrospek- } \\
\text { tive Kohor- } \\
\text { tenanalyse }\end{array}$ & - & & $\begin{array}{l}\text { Baseline-RAVs und } \\
\text { SVR-Raten }\end{array}$ & $\begin{array}{l}\text { SVR12 } 96-100 \% \\
\text { unabhängig von } \\
\text { Baseline-RAVs }\end{array}$ & Level 3 \\
\hline $\begin{array}{l}\text { Dietz J et al., } \\
2015\end{array}$ & $\begin{array}{l}\text { Berücksichti- } \\
\text { gung viraler } \\
\text { Resistenzen zur } \\
\text { Optimierung der } \\
\text { antiviralen HCV- } \\
\text { GT1-Therapie }\end{array}$ & $\begin{array}{l}\text { retrospek- } \\
\text { tive Kohor- } \\
\text { tenanalyse }\end{array}$ & - & 312 & Baseline-RAVs & $\begin{array}{l}\text { Das Testen von Base- } \\
\text { line-RAVs erlaubt die } \\
\text { Selektion mind. einer } \\
\text { RAV-freien Therapie- } \\
\text { option. }\end{array}$ & Level 3 \\
\hline $\begin{array}{l}\text { Sarrazin C } \\
\text { et al., } 2014\end{array}$ & $\begin{array}{l}\text { Baseline und } \\
\text { post-Baseline } \\
\text { RAVs bei LDV/ } \\
\text { SOF } \pm \text { RBV-The- } \\
\text { rapie }\end{array}$ & $\begin{array}{l}\text { retrospek- } \\
\text { tive Kohor- } \\
\text { tenanalyse }\end{array}$ & - & 2137 & $\begin{array}{l}\text { Baseline- und post- } \\
\text { Baseline-RAVs }\end{array}$ & $\begin{array}{l}\text { Baseline-RAVs haben } \\
\text { einen schlechten } \\
\text { Vorhersagewert für } \\
\text { ein Therapieversa- } \\
\text { gen. }\end{array}$ & Level 3 \\
\hline $\begin{array}{l}\text { Reddy KR } \\
\text { et al., } 2014\end{array}$ & $\begin{array}{l}\text { Langzeit Follow- } \\
\text { up von Patien- } \\
\text { ten mit DCV- } \\
\text { Therapie }\end{array}$ & $\begin{array}{l}\text { prospektive } \\
\text { Kohorten- } \\
\text { analyse }\end{array}$ & - & 1503 & $\begin{array}{l}\text { SVR, RAVs, Leberfunk- } \\
\text { tion, Beobachtung } \\
\text { über } 144 \text { Wochen }\end{array}$ & $\begin{array}{l}\text { SVR12 war in 99\% } \\
\text { anhaltend. Eine } \\
\text { Verschlechterung } \\
\text { der Leberfunktion } \\
\text { war selten. NS3 RAVs } \\
\text { verschwanden wie- } \\
\text { der, während NS5A } \\
\text { RAVs persistierten, } \\
\text { besonders bei GT1b. }\end{array}$ & Level 3 \\
\hline
\end{tabular}

\section{Nebenwirkungen, Medikamenteninteraktionen und Niereninsuffizienz}

\begin{tabular}{|c|c|c|c|c|c|c|c|}
\hline $\begin{array}{l}\text { Referenz- } \\
\text { autor, Jahr }\end{array}$ & $\begin{array}{l}\text { Thema, } \\
\text { Intervention }\end{array}$ & Studientyp & Kontrolle & n gesamt & $\begin{array}{l}\text { Zielparameter, } \\
\text { Beobachtungsdauer }\end{array}$ & $\begin{array}{l}\text { Ergebnis, } \\
\text { Bemerkungen }\end{array}$ & $\begin{array}{l}\text { Evidenzgrad, } \\
{ }^{*} \text { Oxford-Schema }\end{array}$ \\
\hline $\begin{array}{l}\text { Desnoyer A } \\
\text { et al., } 2016\end{array}$ & $\begin{array}{l}\text { SOF bei HCV und } \\
\text { Dialyse }\end{array}$ & $\begin{array}{l}\text { prospektive } \\
\text { Beobach- } \\
\text { tungsstudie }\end{array}$ & - & 12 & $\begin{array}{l}\text { Pharmakokinetik, } \\
\text { Sicherheit und Effek- } \\
\text { tivität, Beobachtung } \\
\text { über } 24 \text { Wochen }\end{array}$ & $\begin{array}{l}\text { SOF kann bei Hämo- } \\
\text { dialyse in voller Dosis } \\
\text { täglich verabreicht } \\
\text { werden. }\end{array}$ & Level 3 \\
\hline $\begin{array}{l}\text { Bhamidimarri } \\
\text { KR et al., } 2015\end{array}$ & $\begin{array}{l}\text { SOF/SMV in } \\
\text { halber Dosis } \\
\text { bei ESRD }\end{array}$ & $\begin{array}{l}\text { prospektive } \\
\text { Open-label- } \\
\text { Studie }\end{array}$ & - & 15 & $\begin{array}{l}\text { Pharmakokinetik, } \\
\text { Sicherheit und Effek- } \\
\text { tivität, Beobachtung } \\
\text { über } 1 \text { Jahr }\end{array}$ & $\begin{array}{l}\text { SOF in halber Dosis } \\
\text { und SMV in voller } \\
\text { Dosis kann bei ESRD } \\
\text { verabreicht werden. }\end{array}$ & Level 3 \\
\hline $\begin{array}{l}\text { Saxena V et al., } \\
2016\end{array}$ & $\begin{array}{l}\text { SOF bei einge- } \\
\text { schränkter } \\
\text { Nierenfunktion }\end{array}$ & $\begin{array}{l}\text { retrospek- } \\
\text { tive Kohor- } \\
\text { tenanalyse }\end{array}$ & 1716 & 1789 & $\begin{array}{l}\text { SVR 12, Beobachtung } \\
\text { über } 48 \text { Wochen }\end{array}$ & SVR12 83\% & Level 3 \\
\hline $\begin{array}{l}\text { Perumpail RB } \\
\text { et al., } 2016\end{array}$ & $\begin{array}{l}\text { SOF in Standard- } \\
\text { dosierung bei } \\
\text { einem dialyse- } \\
\text { pflichtigen LTx- } \\
\text { Patienten }\end{array}$ & Fallbericht & - & 1 & $\begin{array}{l}\text { Pharmakokinetik, } \\
\text { Sicherheit und Effek- } \\
\text { tivität, Beobachtung } \\
\text { über } 36 \text { Wochen }\end{array}$ & $\begin{array}{l}\text { SOF/SMV kann bei } \\
\text { Dialyse in voller Dosis } \\
\text { gegeben werden. }\end{array}$ & Level 4 \\
\hline
\end{tabular}




\begin{tabular}{|c|c|c|c|c|c|c|c|}
\hline $\begin{array}{l}\text { Referenz- } \\
\text { autor, Jahr }\end{array}$ & $\begin{array}{l}\text { Thema, } \\
\text { Intervention }\end{array}$ & Studientyp & Kontrolle & n gesamt & $\begin{array}{l}\text { Zielparameter, } \\
\text { Beobachtungsdauer }\end{array}$ & $\begin{array}{l}\text { Ergebnis, } \\
\text { Bemerkungen }\end{array}$ & $\begin{array}{l}\text { Evidenzgrad, } \\
{ }^{*} \text { Oxford-Schema }\end{array}$ \\
\hline $\begin{array}{l}\text { Nazario HE } \\
\text { et al., } 2016\end{array}$ & $\begin{array}{l}\text { SOF/SMV bei } \\
\text { HCV-GT1- } \\
\text { Patienten mit } \\
\text { ESRD }\end{array}$ & $\begin{array}{l}\text { prospektive } \\
\text { Beobach- } \\
\text { tungsstudie }\end{array}$ & - & 17 & $\begin{array}{l}\text { Sicherheit und Effek- } \\
\text { tivität, Beobachtung } \\
\text { über } 24 \text { Wochen }\end{array}$ & $\begin{array}{l}\text { SOF/SMV kann bei } \\
\text { ESRD in voller Dosis } \\
\text { gegeben werden. }\end{array}$ & Level 3 \\
\hline $\begin{array}{l}\text { Singh T et al., } \\
2016\end{array}$ & SOF bei ESRD & Fallserie & - & 8 & $\begin{array}{l}\text { Sicherheit und Effek- } \\
\text { tivität, Beobachtung } \\
\text { über } 24 \text { Wochen }\end{array}$ & $\begin{array}{l}\text { SOF/SMV und SOF/ } \\
\text { LDV können bei ESRD } \\
\text { in voller Dosis verab- } \\
\text { reicht werden. }\end{array}$ & Level 4 \\
\hline $\begin{array}{l}\text { Hezode C } \\
\text { et al., } 2014\end{array}$ & $\begin{array}{l}\text { DCV + peg-IF- } \\
\text { Nalpha + RBV } \\
\text { bei HCV GT1 } \\
\text { oder } 4\end{array}$ & $\begin{array}{l}\text { randomi- } \\
\text { sierte kon- } \\
\text { trollierte } \\
\text { Phase-2- } \\
\text { Studie }\end{array}$ & 72 & 395 & $\begin{array}{l}\text { SVR 24, Beobachtung } \\
\text { über } 72 \text { Wochen }\end{array}$ & SVR24 $60-100 \%$ & Level 2 \\
\hline $\begin{array}{l}\text { Renet S et al., } \\
2015\end{array}$ & $\begin{array}{l}\text { ausgeprägte } \\
\text { Bradykardie } \\
\text { unter SOF/DCV } \\
\text { und Amiodaron }\end{array}$ & Fallstudie & - & 2 & $\begin{array}{l}2 \text { Fälle ausgeprägter } \\
\text { Bradykardie unter SOF/ } \\
\text { DCV und Amiodaron }\end{array}$ & $\begin{array}{l}\text { Patienten mit Amio- } \\
\text { daron-Therapie soll- } \\
\text { ten innerhalb der } \\
\text { ersten } 48 \mathrm{~h} \text { unter } \\
\text { SOF/DCV streng } \\
\text { überwacht werden. }\end{array}$ & Level 4 \\
\hline $\begin{array}{l}\text { Fontaine H } \\
\text { et al., } 2015\end{array}$ & $\begin{array}{l}\text { Bradyarrhythmie } \\
\text { unter SOF }\end{array}$ & Fallserie & - & 3 & $\begin{array}{l}3 \text { Fälle von schwerer } \\
\text { Bradyarrhythmie unter } \\
\text { SOF }\end{array}$ & $\begin{array}{l}\text { SOF ist poteztiell } \\
\text { kardiotoxisch. }\end{array}$ & Level 4 \\
\hline $\begin{array}{l}\text { Back DJ et al., } \\
2015\end{array}$ & $\begin{array}{l}\text { Interaktion von } \\
\text { SOF und Amio- } \\
\text { daron }\end{array}$ & Review & - & - & $\begin{array}{l}\text { Interaktion von SOF } \\
\text { und Amiodaron }\end{array}$ & $\begin{array}{l}\text { Es gibt eine klinisch } \\
\text { relevante Interaktion } \\
\text { von SOF und Amio- } \\
\text { daron. }\end{array}$ & Level 3 \\
\hline $\begin{array}{l}\text { Gane EJ et al., } \\
2014\end{array}$ & SOF bei ESRD & $\begin{array}{l}\text { prospektive } \\
\text { Open-label- } \\
\text { Phase-2- } \\
\text { Studie }\end{array}$ & - & 40 & $\begin{array}{l}\text { Pharmakokinetik, } \\
\text { Sicherheit und Effek- } \\
\text { tivität, Beobachtung } \\
\text { über } 36 \text { Wochen }\end{array}$ & $\begin{array}{l}\text { SOF/RBV in halber } \\
\text { Dosis ist sicher, aber } \\
\text { wenig effektiv bei } \\
\text { HCV-GT1-oder 3- } \\
\text { Patienten mit ESRD. }\end{array}$ & Level 2 \\
\hline $\begin{array}{l}\text { Roth D et al., } \\
2015\end{array}$ & $\begin{array}{l}\text { GZR/EBR bei } \\
\text { HCV GT1 und } \\
\text { ESRD }\end{array}$ & $\begin{array}{l}\text { randomi- } \\
\text { sierte kon- } \\
\text { trollierte } \\
\text { Phase-3- } \\
\text { Studie }\end{array}$ & 113 & 224 & $\begin{array}{l}\text { SVR 12, Beobachtung } \\
\text { über } 24 \text { Wochen }\end{array}$ & SVR12 99\% & Level 1 \\
\hline $\begin{array}{l}\text { Dore GJ et al., } \\
2016\end{array}$ & $\begin{array}{l}\text { Ombitasvir/Pari- } \\
\text { taprevir/r und } \\
\text { Dasabuvir bei } \\
\text { HCV GT1 }\end{array}$ & $\begin{array}{l}\text { randomi- } \\
\text { sierte kon- } \\
\text { trollierte } \\
\text { Open-label- } \\
\text { Phase-3- } \\
\text { Studie }\end{array}$ & 125 & 459 & $\begin{array}{l}\text { SVR } 12 \text {, Beobachtung } \\
\text { über } 60 \text { Wochen }\end{array}$ & SVR12 97 - $99 \%$ & Level 1 \\
\hline $\begin{array}{l}\text { Pockros PJ } \\
\text { et al., } 2016\end{array}$ & $\begin{array}{l}\text { DAAs bei HCV } \\
\text { GT1 und ESRD }\end{array}$ & $\begin{array}{l}\text { prospektive } \\
\text { Kohorten- } \\
\text { studie }\end{array}$ & - & 20 & $\begin{array}{l}\text { SVR } 12 \text {, Beobachtung } \\
\text { über } 24 \text { Wochen }\end{array}$ & SVR12 $90 \%$ & Level 3 \\
\hline $\begin{array}{l}\text { Bourliere M } \\
\text { et al., } 2014\end{array}$ & $\begin{array}{l}\text { SOF/LDV bei mit } \\
\text { Triple-Therapie } \\
\text { vorbehandelten } \\
\text { LCI-Patienten }\end{array}$ & $\begin{array}{l}\text { randomi- } \\
\text { sierte kon- } \\
\text { trollierte- } \\
\text { doppelblin- } \\
\text { de Phase-3- } \\
\text { Studie }\end{array}$ & 77 & 155 & $\begin{array}{l}\text { SVR 12, Beobachtung } \\
\text { über } 36 \text { Wochen }\end{array}$ & SVR12 $96-97 \%$ & Level 1 \\
\hline $\begin{array}{l}\text { Terrault N } \\
\text { et al., } 2015\end{array}$ & $\begin{array}{l}\text { SOF/LDV für } 8 \text {, } \\
12 \text { und } 24 \\
\text { Wochen }\end{array}$ & $\begin{array}{l}\text { prospektive } \\
\text { Beobach- } \\
\text { tungsstudie }\end{array}$ & - & 2321 & $\begin{array}{l}\text { SVR 12, Beobachtung } \\
\text { über } 36 \text { Wochen }\end{array}$ & SVR12 $92-98 \%$ & Level 3 \\
\hline
\end{tabular}




\begin{tabular}{|c|c|c|c|c|c|c|c|}
\hline $\begin{array}{l}\text { Referenz- } \\
\text { autor, Jahr }\end{array}$ & $\begin{array}{l}\text { Thema, } \\
\text { Intervention }\end{array}$ & Studientyp & Kontrolle & n gesamt & $\begin{array}{l}\text { Zielparameter, } \\
\text { Beobachtungsdauer }\end{array}$ & $\begin{array}{l}\text { Ergebnis, } \\
\text { Bemerkungen }\end{array}$ & $\begin{array}{l}\text { Evidenzgrad, } \\
{ }^{*} \text { Oxford-Schema }\end{array}$ \\
\hline $\begin{array}{l}\text { DeVreese L } \\
\text { et al., } 2016\end{array}$ & $\begin{array}{l}\text { Einfluss von PPIs } \\
\text { und H2-Blockern } \\
\text { auf die SVR-Rate } \\
\text { bei DAAs }\end{array}$ & $\begin{array}{l}\text { retrospek- } \\
\text { tive Kohor- } \\
\text { tenanalyse }\end{array}$ & - & 168 & SVR 12 & $\begin{array}{l}\text { Es gab keinen signifi- } \\
\text { kanten Unterschied } \\
\text { in den SVR-Raten mit } \\
\text { und ohne PPIs/H2- } \\
\text { Blockern. }\end{array}$ & Level 3 \\
\hline $\begin{array}{l}\text { Afdhal } N \text { et al., } \\
2016\end{array}$ & $\begin{array}{l}\text { kein Effekt von } \\
\text { PPIs auf die SVR- } \\
\text { Rate bei LDV/ } \\
\text { SOF }\end{array}$ & $\begin{array}{l}\text { retrospek- } \\
\text { tive Kohor- } \\
\text { tenanalyse }\end{array}$ & - & 2034 & SVR 12 & $\begin{array}{l}\text { Der tägliche Ge- } \\
\text { brauch von PPIs hatte } \\
\text { keinen Einfluss auf } \\
\text { die SVR-Rate bei } \\
\text { LDV/SOF-Therapie. }\end{array}$ & Level 3 \\
\hline
\end{tabular}

\section{Wie soll die Therapie überwacht werden?}

\begin{tabular}{|c|c|c|c|c|c|c|c|}
\hline $\begin{array}{l}\text { Referenz- } \\
\text { autor, Jahr }\end{array}$ & $\begin{array}{l}\text { Thema, } \\
\text { Intervention }\end{array}$ & Studientyp & Kontrolle & n gesamt & $\begin{array}{l}\text { Zielparameter, } \\
\text { Beobachtungsdauer }\end{array}$ & $\begin{array}{l}\text { Ergebnis, } \\
\text { Bemerkungen }\end{array}$ & $\begin{array}{l}\text { Evidenzgrad, } \\
{ }^{*} \text { Oxford-Schema }\end{array}$ \\
\hline $\begin{array}{l}\text { Maasoumy B } \\
\text { et al., } 2016\end{array}$ & $\begin{array}{l}\text { Bestimmung } \\
\text { des HCV-RNA- } \\
\text { Levels unter } \\
\text { SOF-Therapie }\end{array}$ & $\begin{array}{l}\text { retrospek- } \\
\text { tive Kohor- } \\
\text { tenanalyse }\end{array}$ & - & 298 & HCV-RNA & $\begin{array}{l}\text { Die Bestimmung der } \\
\text { HCV-RNA in der } 2 . \\
\text { Therapiewoche SOF/ } \\
\text { RBV kann bei GT3-Pa- } \\
\text { tienten einen Relapse } \\
\text { vorhersagen. }\end{array}$ & Level 3 \\
\hline $\begin{array}{l}\text { Sarrazin C } \\
\text { et al., } 2015\end{array}$ & $\begin{array}{l}\text { HCV-Re-Infek- } \\
\text { tion nach SOF- } \\
\text { Therapie }\end{array}$ & $\begin{array}{l}\text { retrospek- } \\
\text { tive Kohor- } \\
\text { tenanalyse }\end{array}$ & - & 12 & Genanalysen & $\begin{array}{l}\text { Die Hälfte der Relapse- } \\
\text { Fälle der SOF-Phase-3- } \\
\text { Studien hatte eine } \\
\text { HCV-Re-Infektion. }\end{array}$ & Level 3 \\
\hline
\end{tabular}

\section{AG 5: Transplantationsmedizin}

\section{Indikation zur Lebertransplantation bei HCV-Infektion}

a) Bei welchen Patienten mit HCV-Infektion ist eine Lebertransplantation indiziert?

b) Wann ist eine Re-Transplantation bei Hepatitis C indiziert?

Literatur wurde aus der vorherigen Leitlinie übernommen und punktuell ergänzt. 


\section{Transplantations-Warteliste}

a) Wie ist das Management der Patienten mit HCV-Infektion auf der Warteliste zur Lebertransplantation?

\begin{tabular}{|c|c|c|c|c|c|c|c|}
\hline $\begin{array}{l}\text { Referenz- } \\
\text { autor, Jahr }\end{array}$ & $\begin{array}{l}\text { Thema, } \\
\text { Intervention }\end{array}$ & Studientyp & Kontrolle & n gesamt & $\begin{array}{l}\text { Zielparameter, } \\
\text { Beobachtungsdauer }\end{array}$ & $\begin{array}{l}\text { Ergebnis, } \\
\text { Bemerkungen }\end{array}$ & $\begin{array}{l}\text { Evidenzgrad, } \\
{ }^{*} \text { Oxford-Schema }\end{array}$ \\
\hline $\begin{array}{l}\text { Ferenci P et al., } \\
2015\end{array}$ & $\begin{array}{l}\text { HCV-Behand- } \\
\text { lung bei Patien- } \\
\text { ten mit Zirrhose }\end{array}$ & Review & - & - & $\begin{array}{l}\text { aktuelle HCV-Thera- } \\
\text { piemöglichkeiten }\end{array}$ & $\begin{array}{l}\text { Die meisten HCV-Ge- } \\
\text { notyp-1 oder 4- Pa- } \\
\text { tienten können auch } \\
\text { bei kompensierter } \\
\text { Zirrhose und nach LTx } \\
\text { erfolgreich mit den } \\
\text { aktuellen Interferon- } \\
\text { freien Therapiere- } \\
\text { gimen über } 12 \text { Wo- } \\
\text { chen behandelt wer- } \\
\text { den. Für Genotyp } 3 \\
\text { sind bessere Medika- } \\
\text { mente nötig. }\end{array}$ & Level 1 \\
\hline $\begin{array}{l}\text { Ruiz I et al., } \\
2015\end{array}$ & $\begin{array}{l}\text { De-Listung einer } \\
\text { Patientin mit } \\
\text { dekompensier- } \\
\text { ter HCV-assozi- } \\
\text { ierter Leberzir- } \\
\text { rhose nach } \\
\text { erfolgreicher } \\
\text { Therapie mit } \\
\text { Sofosbuvir }\end{array}$ & Fallbericht & - & - & De-Listung & $\begin{array}{l}\text { Eine Patientin mit } \\
\text { dekompensierter } \\
\text { HCV-assoziierter } \\
\text { Leberzirrhose konnte } \\
\text { nach erfolgreicher } \\
\text { Therapie mit Sofos- } \\
\text { buvir de-gelistet } \\
\text { werden. }\end{array}$ & Level 4 \\
\hline $\begin{array}{l}\text { Coilly A et al., } \\
2015\end{array}$ & $\begin{array}{l}\text { Verbesserung } \\
\text { der Leberfunk- } \\
\text { tion und De-Lis- } \\
\text { tung von Warte- } \\
\text { listenpatienten } \\
\text { mit HCV-Zirrhose }\end{array}$ & $\begin{array}{l}\text { prospektive } \\
\text { Kohorten- } \\
\text { studie }\end{array}$ & keine & $\begin{array}{l}183 \text { (50 } \\
12 \text { Wo- } \\
\text { chen } 133 \\
24 \text { Wo- } \\
\text { chen) }\end{array}$ & $\begin{array}{l}\text { Verbesserung der } \\
\text { Leberfunktion und } \\
\text { De-Listung, Studien- } \\
\text { zeitraum: } 1,5 \text { Jahre }\end{array}$ & $\begin{array}{l}\text { Eine Sofosbuvir-ba- } \\
\text { sierte Therapie führ- } \\
\text { te in } 84 \% \text { zu einer } \\
\text { SVR12 bei Patienten } \\
\text { auf der Warteliste zur } \\
\text { LTx. In } 2 / 3 \text { kam es zu } \\
\text { einer Verbesserung } \\
\text { der Leberfunktion, } \\
\text { aber nur } 16 \% \text { der } \\
\text { Patienten konnten } \\
\text { de-gelistet werden. }\end{array}$ & Level 3 \\
\hline NCT02350569 & $\begin{array}{l}\text { Ledipasvir/ } \\
\text { Sofosbuvir zur } \\
\text { perioperativen } \\
\text { Therapie von } \\
\text { HCV- Genotyp- } \\
\text { 1- und 4-LTx- } \\
\text { Patienten }\end{array}$ & $\begin{array}{l}\text { multizentri- } \\
\text { sche Open- } \\
\text { label-Pha- } \\
\text { se-2-Studie }\end{array}$ & keine & $\begin{array}{l}\text { ausste- } \\
\text { hend }\end{array}$ & $\begin{array}{l}\text { SVR } 12 \text {, Studienzeit- } \\
\text { raum: } 1 \text { Jahr }\end{array}$ & ausstehend & Level 2 \\
\hline $\begin{array}{l}\text { Poordad F } \\
\text { et al., } 2015\end{array}$ & $\begin{array}{l}\text { Daclatasvir, } \\
\text { Sofosbuvir und } \\
\text { Ribavirin bei } \\
\text { Patienten mit } \\
\text { fortgeschritte- } \\
\text { ner HCV-Leber- } \\
\text { zirrhose oder } \\
\text { Rekurrenz nach } \\
\text { LTx }\end{array}$ & $\begin{array}{l}\text { multizentri- } \\
\text { sche Open- } \\
\text { label-Pha- } \\
\text { se-3-Studie }\end{array}$ & keine & $\begin{array}{l}113 \text { (60 } \\
\text { fortge- } \\
\text { schrittene } \\
\text { Zirrhose, } \\
53 \text { HCV- } \\
\text { Rekurrenz } \\
\text { post-LTx) }\end{array}$ & $\begin{array}{l}\text { SVR 12, Beobachtung } \\
\text { über } 36 \text { Wochen }\end{array}$ & $\begin{array}{l}\text { Daclatasvir, Sofosbu- } \\
\text { vir und Ribavirin über } \\
12 \text { Wochen führt zu } \\
\text { einer SVR } 12 \text { von } \\
83 \% \text { bei Patienten } \\
\text { mit fortgeschrittener } \\
\text { HCV-Leberzirrhose } \\
\text { und } 94 \% \text { bei HCV- } \\
\text { Rekurrenz nach LTx. }\end{array}$ & Level 1 \\
\hline
\end{tabular}




\begin{tabular}{|c|c|c|c|c|c|c|c|}
\hline $\begin{array}{l}\text { Referenz- } \\
\text { autor, Jahr }\end{array}$ & $\begin{array}{l}\text { Thema, } \\
\text { Intervention }\end{array}$ & Studientyp & Kontrolle & n gesamt & $\begin{array}{l}\text { Zielparameter, } \\
\text { Beobachtungsdauer }\end{array}$ & $\begin{array}{l}\text { Ergebnis, } \\
\text { Bemerkungen }\end{array}$ & $\begin{array}{l}\text { Evidenzgrad, } \\
{ }^{*} \text { Oxford-Schema }\end{array}$ \\
\hline $\begin{array}{l}\text { Terrault NSR } \\
\text { et al., } 2015\end{array}$ & $\begin{array}{l}\text { Prävention der } \\
\text { HCV-Rekurrenz } \\
\text { bei LTx-Patien- } \\
\text { ten: Ergebnisse } \\
\text { der Phase-3-Stu- } \\
\text { die mit Civacir }\end{array}$ & $\begin{array}{l}\text { randomi- } \\
\text { sierte Open- } \\
\text { label-Phase- } \\
\text { 3-Studie }\end{array}$ & $\begin{array}{l}21 \text { Patien- } \\
\text { ten mit } \\
\text { Standard- } \\
\text { therapie }\end{array}$ & $\begin{array}{l}63 \text { (je } 21 \\
\text { Patienten } \\
\text { mit } 200 \\
\text { oder } \\
300 \mathrm{mg} / \\
\text { kg HCV- } \\
\text { Immun- } \\
\text { globulin } \\
\text { direkt } \\
\text { post-LTx) }\end{array}$ & $\begin{array}{l}\text { SVR 12, Beobachtung } \\
\text { über } 22 \text { Wochen }\end{array}$ & $\begin{array}{l}\text { erfolgreich antiviral } \\
\text { behandelte Patienten } \\
\text { haben ein erhöhtes } \\
\text { Risiko der HCV-Re- } \\
\text { kurrenz post-LTx. } \\
\text { Eine Prophylaxe mit } \\
\text { HCV-Immunglobulin } \\
\text { kann eine HCV-Re- } \\
\text { kurrenz post-LTx bei } \\
\text { antiviral vorbehan- } \\
\text { delten Patienten } \\
\text { verhindern. }\end{array}$ & Level 1 \\
\hline $\begin{array}{l}\text { Foster GR } \\
\text { et al., } 2015\end{array}$ & $\begin{array}{l}\text { Sofosbuvir und } \\
\text { Velpatasvir bei } \\
\text { HCV-Genotyp-2- } \\
\text { und 3-Infektion }\end{array}$ & $\begin{array}{l}2 \text { randomi- } \\
\text { sierte Open- } \\
\text { label-Phase- } \\
\text { 3-Studien }\end{array}$ & $\begin{array}{l}407 \text { So- } \\
\text { fosbuvir } \\
\text { und Riba- } \\
\text { virin über } \\
12 \text { Wo- } \\
\text { chen }\end{array}$ & 818 & $\begin{array}{l}\text { SVR 12, Beobachtung } \\
\text { über } 24 \text { Wochen }\end{array}$ & $\begin{array}{l}12 \text { Wochen Therapie } \\
\text { mit Sofosbuvir und } \\
\text { Velpatasvir war der } \\
\text { Standardtherapie mit } \\
\text { Sofosbuvir und Riba- } \\
\text { virin bei Patienten } \\
\text { mit HCV-Genotyp-2 } \\
\text { und 3-Infektion über- } \\
\text { legen. }\end{array}$ & Level 1 \\
\hline $\begin{array}{l}\text { Feld JJ at al., } \\
2015\end{array}$ & $\begin{array}{l}\text { Sofosbuvir und } \\
\text { Velpatasvir für } \\
\text { HCV-Genotyp 1-, } \\
\text { 2-, 4-, 5-, und 6- } \\
\text { Infektion }\end{array}$ & $\begin{array}{l}\text { multizentri- } \\
\text { sche dop- } \\
\text { pel-blinde } \\
\text { Placebo- } \\
\text { kontrollierte } \\
\text { Phase-3- } \\
\text { Studie }\end{array}$ & $\begin{array}{l}116 \\
\text { Placebo }\end{array}$ & 740 & $\begin{array}{l}\text { SVR 12, Beobachtung } \\
\text { über } 24 \text { Wochen }\end{array}$ & $\begin{array}{l}\text { Die 1-mal tägliche } \\
\text { Gabe von Sofosbuvir } \\
\text { und Velpatasvir über } \\
12 \text { Wochen erreichte } \\
\text { hohe SVR-Raten bei } \\
\text { therapie-naiven und } \\
\text { vorbehandelten Pa- } \\
\text { tienten mit HCV-Ge- } \\
\text { notyp-1-, 2-, 4-, 5- } \\
\text { und 6-Infektion. }\end{array}$ & Level 1 \\
\hline $\begin{array}{l}\text { Curry MP } \\
\text { et al., } 2015\end{array}$ & $\begin{array}{l}\text { Sofosbuvir und } \\
\text { Velpatasvir bei } \\
\text { HCV-Patienten } \\
\text { mit dekompen- } \\
\text { sierter Zirrhose }\end{array}$ & $\begin{array}{l}\text { Open-label- } \\
\text { randomi- } \\
\text { sierte Pha- } \\
\text { se-3-Studie }\end{array}$ & keine & 267 & $\begin{array}{l}\text { SVR 12, Beobachtung } \\
\text { über } 36 \text { Wochen }\end{array}$ & $\begin{array}{l}\text { Sofosbuvir und } \\
\text { Velpatasvir mit und } \\
\text { ohne Ribavirin über } \\
12 \text { Wochen und So- } \\
\text { fosbuvir/Velpatasvir } \\
\text { über } 24 \text { Wochen } \\
\text { erreichten hohe } \\
\text { SVR12-Raten bei Pa- } \\
\text { tienten mit dekom- } \\
\text { pensierter Zirrhose. }\end{array}$ & Level 1 \\
\hline $\begin{array}{l}\text { Afdhal N EG } \\
\text { et al., } 2014\end{array}$ & $\begin{array}{l}\text { Sofosbuvir und } \\
\text { Ribavirin zur } \\
\text { Therapie der } \\
\text { chronischen He- } \\
\text { patitis C mit Zir- } \\
\text { rhose und por- } \\
\text { taler Hyperten- } \\
\text { sion }\end{array}$ & $\begin{array}{l}\text { prospektive } \\
\text { Open-label- } \\
\text { randomi- } \\
\text { sierte kon- } \\
\text { trollierte } \\
\text { Studie }\end{array}$ & $\begin{array}{l}10 \text { keine } \\
\text { Therapie }\end{array}$ & 35 & $\begin{array}{l}\text { Rapid-Virologic } \\
\text { Response (RVR) nach } \\
4 \text { und } 8 \text { Wochen, } \\
\text { Beobachtung über } 48 \\
\text { Wochen }\end{array}$ & $\begin{array}{l}\text { Die Therapie mit So- } \\
\text { fosbuvir und Ribavi- } \\
\text { rin über } 48 \text { Wochen } \\
\text { erreichte RVR bei Pa- } \\
\text { tienten mit HCV-Zir- } \\
\text { rhose mit und ohne } \\
\text { Dekompensation und } \\
\text { wurde gut vertragen. }\end{array}$ & Level 2 \\
\hline $\begin{array}{l}\text { Bourliere M } \\
\text { et al., } 2015\end{array}$ & $\begin{array}{l}\text { Ledipasvir/So- } \\
\text { fosbuvir mit und } \\
\text { ohne Ribavirin } \\
\text { zur Therapie von } \\
\text { HCV-Genotyp- } \\
\text { 1-Patienten mit } \\
\text { Zirrhose und } \\
\text { Non-Response } \\
\text { auf Vorthera- } \\
\text { pien mit Prote- } \\
\text { aseinhibitoren }\end{array}$ & $\begin{array}{l}\text { randomi- } \\
\text { sierte multi- } \\
\text { zentrische } \\
\text { doppel-blin- } \\
\text { de Phase-2- } \\
\text { Studie }\end{array}$ & keine & $\begin{array}{l}155 \text { ( } 77 \\
\text { Ledipasvir/ } \\
\text { Sofosbuvir } \\
\text { plus Riba- } \\
\text { virin, } 78 \\
\text { Ledipasvir/ } \\
\text { Sofosbu- } \\
\text { vir) }\end{array}$ & $\begin{array}{l}\text { SVR 12, Beobachtung } \\
\text { über } 36 \text { Wochen }\end{array}$ & $\begin{array}{l}\text { Ledipasvir/Sofosbuvir } \\
\text { plus Ribavirin für } 12 \\
\text { Wochen oder Ledi- } \\
\text { pasvir/Sofosbuvir für } \\
24 \text { Wochen erreichte } \\
\text { hohe SVR-Raten bei } \\
\text { HCV-Genotyp-1-Pa- } \\
\text { tienten mit kompen- } \\
\text { sierter Zirrhose und } \\
\text { Non-Response auf } \\
\text { Vortherapien mit } \\
\text { Proteaseinhibitoren. }\end{array}$ & Level 2 \\
\hline
\end{tabular}




\begin{tabular}{|c|c|c|c|c|c|c|c|}
\hline $\begin{array}{l}\text { Referenz- } \\
\text { autor, Jahr }\end{array}$ & $\begin{array}{l}\text { Thema, } \\
\text { Intervention }\end{array}$ & Studientyp & Kontrolle & n gesamt & $\begin{array}{l}\text { Zielparameter, } \\
\text { Beobachtungsdauer }\end{array}$ & $\begin{array}{l}\text { Ergebnis, } \\
\text { Bemerkungen }\end{array}$ & $\begin{array}{l}\text { Evidenzgrad, } \\
\text { *Oxford-Schema }\end{array}$ \\
\hline $\begin{array}{l}\text { Hezode C dLV } \\
\text { et al., } 2015\end{array}$ & $\begin{array}{l}\text { Daclatasvir und } \\
\text { Sofosbuvir mit } \\
\text { und ohne Riba- } \\
\text { virin bei Geno- } \\
\text { typ-3-Patienten }\end{array}$ & $\begin{array}{l}\text { retrospek- } \\
\text { tive Kohor- } \\
\text { tenanalyse }\end{array}$ & keine & 601 & $\begin{array}{l}\text { SVR 4, Beobachtung } \\
\text { über } 28 \text { Wochen }\end{array}$ & $\begin{array}{l}\text { Daclatasvir und So- } \\
\text { fosbuvir über } 12 \text { Wo- } \\
\text { chen erreichte hohe } \\
\text { SVR4-Raten bei Ge- } \\
\text { notyp-3-Patienten } \\
\text { ohne Zirrhose. Pa- } \\
\text { tienten mit Zirrhose } \\
\text { profitieren von einer } \\
\text { Verlängerung der } \\
\text { Therapie auf } 24 \text { Wo- } \\
\text { chen. }\end{array}$ & Level 3 \\
\hline $\begin{array}{l}\text { Lawitz E et al., } \\
2015\end{array}$ & $\begin{array}{l}\text { Sicherheit und } \\
\text { Effektivität von } \\
\text { Ombitasvir, Pari- } \\
\text { taprevir, und } \\
\text { Ritonavir bei } \\
\text { HCV-Genotyp- } \\
\text { 1b-Patienten } \\
\text { mit und ohne } \\
\text { Zirrhose }\end{array}$ & $\begin{array}{l}\text { randomi- } \\
\text { sierte Open- } \\
\text { label-Phase- } \\
\text { 2b-Studie }\end{array}$ & keine & $\begin{array}{l}181 \text { ( } 82 \\
\text { ohne und } \\
99 \text { mit } \\
\text { Zirrhose) }\end{array}$ & $\begin{array}{l}\text { SVR 12, Beobachtung } \\
\text { über } 36 \text { Wochen }\end{array}$ & $\begin{array}{l}\text { Ombitasvir, Parita- } \\
\text { previr, und Ritonavir } \\
\text { über } 12 \text { Wochen bei } \\
\text { HCV-Genotyp-1b-Pa- } \\
\text { tienten ohne Zirrhose } \\
\text { und über } 24 \text { Wochen } \\
\text { bei Patienten mit Zir- } \\
\text { rhose erreichte hohe } \\
\text { SVR12-Raten und } \\
\text { wurde gut vertragen. }\end{array}$ & Level 2 \\
\hline $\begin{array}{l}\text { Muir AJ et al., } \\
2015\end{array}$ & $\begin{array}{l}\text { Daclatasvir in } \\
\text { Kombination } \\
\text { mit Asunaprevir } \\
\text { und Beclabuvir } \\
\text { bei HCV-Geno- } \\
\text { typ-1-Infektion } \\
\text { und kompen- } \\
\text { sierter Zirrhose }\end{array}$ & $\begin{array}{l}\text { multizentri- } \\
\text { sche rando- } \\
\text { misierte } \\
\text { Open-label- } \\
\text { Studie }\end{array}$ & keine & $\begin{array}{l}202 \text { ( } 112 \\
\text { therapie- } \\
\text { naiv, } 90 \\
\text { vorbehan- } \\
\text { delt) }\end{array}$ & $\begin{array}{l}\text { SVR 12, Beobachtung } \\
\text { über } 36 \text { Wochen }\end{array}$ & $\begin{array}{l}\text { Eine 12-wöchige } \\
\text { Therapie mit Dacla- } \\
\text { tasvir in Kombination } \\
\text { mit Asunaprevir und } \\
\text { Beclabuvir mit und } \\
\text { ohne Ribavirin führte } \\
\text { zu hohen SVR12-Ra- } \\
\text { ten bei HCV-Geno- } \\
\text { typ-1-Infektion und } \\
\text { kompensierter Zir- } \\
\text { rhose. }\end{array}$ & Level 1 \\
\hline $\begin{array}{l}\text { Poordad F } \\
\text { et al., } 2016\end{array}$ & $\begin{array}{l}\text { Daclatasvir mit } \\
\text { Sofosbuvir und } \\
\text { Ribavirin bei } \\
\text { HCV-Infektion } \\
\text { mit fortgeschrit- } \\
\text { tener Leberzir- } \\
\text { rhose und post- } \\
\text { LTx-Rekurrenz }\end{array}$ & $\begin{array}{l}\text { multizentri- } \\
\text { sche Open- } \\
\text { label-Pha- } \\
\text { se-3-Studie }\end{array}$ & keine & $\begin{array}{l}113 \text { ( } 60 \\
\text { fortge- } \\
\text { schrittene } \\
\text { Zirrhose, } \\
53 \text { HCV- } \\
\text { Rekurrenz } \\
\text { post-LTx) }\end{array}$ & $\begin{array}{l}\text { SVR 12, Beobachtung } \\
\text { über } 36 \text { Wochen }\end{array}$ & $\begin{array}{l}\text { Daclatasvir, Sofosbu- } \\
\text { vir und Ribavirin über } \\
12 \text { Wochen führt zu } \\
\text { hohen SVR12-Raten } \\
\text { bei Patienten mit } \\
\text { fortgeschrittener } \\
\text { HCV-Leberzirrhose } \\
\text { und bei HCV-Rekur- } \\
\text { renz nach LTx bei den } \\
\text { Genotypen 1, 2, 3, } 4 \\
\text { und } 6 \text {. }\end{array}$ & Level 1 \\
\hline $\begin{array}{l}\text { Reddy KR } \\
\text { et al., } 2015\end{array}$ & $\begin{array}{l}\text { Ledipasvir und } \\
\text { Sofosbuvir bei } \\
\text { Patienten mit } \\
\text { HCV-Genotyp- } \\
\text { 1-Infektion und } \\
\text { kompensierter } \\
\text { Zirrhose }\end{array}$ & $\begin{array}{l}\text { Post-hoc- } \\
\text { Analyse von } \\
7 \text { klinischen } \\
\text { Studien }\end{array}$ & keine & 513 & $\begin{array}{l}\text { SVR 12, Beobachtung } \\
\text { über } 36 \text { Wochen }\end{array}$ & $\begin{array}{l}\text { Ledipasvir und Sofos- } \\
\text { buvir über } 12 \text { Wo- } \\
\text { chen ist sicher und } \\
\text { effektiv bei Patienten } \\
\text { mit HCV-Genotyp-1- } \\
\text { Infektion und kom- } \\
\text { pensierter Zirrhose. } \\
\text { Vorbehandelte Pa- } \\
\text { tienten könnten } \\
\text { von einer längeren } \\
\text { Therapiedauer von } \\
24 \text { Wochen oder ei- } \\
\text { ner Kombination mit } \\
\text { Ribavirin profitieren. }\end{array}$ & Level 2 \\
\hline
\end{tabular}




\begin{tabular}{|c|c|c|c|c|c|c|c|}
\hline $\begin{array}{l}\text { Referenz- } \\
\text { autor, Jahr }\end{array}$ & $\begin{array}{l}\text { Thema, } \\
\text { Intervention }\end{array}$ & Studientyp & Kontrolle & n gesamt & $\begin{array}{l}\text { Zielparameter, } \\
\text { Beobachtungsdauer }\end{array}$ & $\begin{array}{l}\text { Ergebnis, } \\
\text { Bemerkungen }\end{array}$ & $\begin{array}{l}\text { Evidenzgrad, } \\
{ }^{*} \text { Oxford-Schema }\end{array}$ \\
\hline $\begin{array}{l}\text { Tania M et al., } \\
2015\end{array}$ & $\begin{array}{l}\text { Sicherheit und } \\
\text { Effektivität von } \\
\text { Daclatasvir/So- } \\
\text { fosbuvir mit und } \\
\text { ohne Ribavirin } \\
\text { bei HCV-Geno- } \\
\text { typ-3-Patienten }\end{array}$ & $\begin{array}{l}\text { retrospek- } \\
\text { tive Kohor- } \\
\text { tenanalyse }\end{array}$ & keine & 485 & $\begin{array}{l}\text { SVR 12, Beobachtung } \\
\text { über } 36 \text { Wochen }\end{array}$ & $\begin{array}{l}\text { Daclatasvir/Sofosbu- } \\
\text { vir mit und ohne } \\
\text { Ribavirin über } 24 \\
\text { Wochen ist sicher } \\
\text { und effektiv bei HCV- } \\
\text { Genotyp-3-Patienten } \\
\text { auch bei weit fortge- } \\
\text { schrittener Leberer- } \\
\text { krankung. }\end{array}$ & Level 3 \\
\hline $\begin{array}{l}\text { Ferenci P et al., } \\
2014\end{array}$ & $\begin{array}{l}\text { ABT-450/r-Om- } \\
\text { bitasvir und Da- } \\
\text { sabuvir mit und } \\
\text { ohne Ribavirin } \\
\text { bei HCV }\end{array}$ & $\begin{array}{l}2 \text { randomi- } \\
\text { sierte Pha- } \\
\text { se-3-Studien }\end{array}$ & keine & 724 & $\begin{array}{l}\text { SVR } 12 \text {, Beobachtung } \\
\text { über } 24 \text { Wochen }\end{array}$ & $\begin{array}{l}\text { ABT-450/r-Ombitas- } \\
\text { vir und Dasabuvir mit } \\
\text { und ohne Ribavirin } \\
\text { über } 12 \text { Wochen } \\
\text { führte zu hohen } \\
\text { SVR12Raten bei } \\
\text { therapienaiven HCV- } \\
\text { Genotyp-1-Patienten } \\
\text { ohne Zirrhose. }\end{array}$ & Level 1 \\
\hline $\begin{array}{l}\text { Poordad F } \\
\text { et al., } 2014\end{array}$ & $\begin{array}{l}\text { ABT-450/r-Om- } \\
\text { bitasvir und Da- } \\
\text { sabuvir mit Ri- } \\
\text { bavirin bei HCV } \\
\text { mit Zirrhose }\end{array}$ & $\begin{array}{l}\text { randomi- } \\
\text { sierte Open- } \\
\text { label-Phase- } \\
\text { 3-Studie }\end{array}$ & keine & 380 & $\begin{array}{l}\text { SVR 12, Beobachtung } \\
\text { über } 36 \text { Wochen }\end{array}$ & $\begin{array}{l}\text { ABT-450/r-Ombitas- } \\
\text { vir und Dasabuvir mit } \\
\text { Ribavirin über } 12 \text { und } \\
24 \text { Wochen führte zu } \\
\text { hohen SVR12-Raten } \\
\text { bei therapienaiven } \\
\text { und vortherapierten } \\
\text { HCV-Genotyp-1-Pa- } \\
\text { tienten mit Zirrhose. }\end{array}$ & Level 1 \\
\hline $\begin{array}{l}\text { Nelson DR } \\
\text { et al., } 2015\end{array}$ & $\begin{array}{l}12 \text { Wochen } \\
\text { Daclatasvir plus } \\
\text { Sofosbuvir bei } \\
\text { Patienten mit } \\
\text { HCV-Genotyp } 3\end{array}$ & $\begin{array}{l}\text { randomi- } \\
\text { sierte Open- } \\
\text { label-Phase- } \\
\text { 3-Studie }\end{array}$ & keine & $\begin{array}{l}152 \text { (101 } \\
\text { therapie- } \\
\text { naiv, } 51 \\
\text { vorbehan- } \\
\text { delt) }\end{array}$ & $\begin{array}{l}\text { SVR 12, Beobachtung } \\
\text { über } 24 \text { Wochen }\end{array}$ & $\begin{array}{l}12 \text { Wochen Daclatas- } \\
\text { vir plus Sofosbuvir } \\
\text { erreichte in } 95 \% \\
\text { SVR12 bei Patienten } \\
\text { mit HCV-Genotyp } 3 \\
\text { ohne Zirrhose und } \\
\text { wurde gut vertragen. }\end{array}$ & Level 1 \\
\hline $\begin{array}{l}\text { Afdhal N EG } \\
\text { etal., } 2015\end{array}$ & $\begin{array}{l}\text { Effekt der Lang- } \\
\text { zeit-Virussup- } \\
\text { pression mit } \\
\text { Sofosbuvir und } \\
\text { Ribavirin auf den } \\
\text { hepato-venösen } \\
\text { Druck bei HCV- } \\
\text { Patienten mit } \\
\text { Leberzirrhose } \\
\text { und portaler } \\
\text { Hypertension }\end{array}$ & $\begin{array}{l}\text { randomi- } \\
\text { sierte Open- } \\
\text { label-Studie }\end{array}$ & keine & 50 & $\begin{array}{l}\text { SVR 12, Änderung von } \\
\text { MELD, Child-Pugh und } \\
\text { HVPG, Beobachtung } \\
\text { über } 84 \text { Wochen }\end{array}$ & $\begin{array}{l}\text { Sofosbuvir und Riba- } \\
\text { virin über } 48 \text { Wochen } \\
\text { führte zu einer } \\
\text { SVR12-Rate von } 72 \% \\
\text { bei Patienten mit } \\
\text { HCV und portaler } \\
\text { Hypertension. Es } \\
\text { kam häufig zu einer } \\
\text { Verbesserung von } \\
\text { MELD und Child- } \\
\text { Pugh. Der HVPG re- } \\
\text { duzierte sich signifi- } \\
\text { kant bei Patienten } \\
\text { mit höherem MELD. }\end{array}$ & Level 2 \\
\hline $\begin{array}{l}\text { Lens S et al., } \\
2015\end{array}$ & $\begin{array}{l}\text { Assoziation von } \\
\text { schwerer porta- } \\
\text { ler Hypertension } \\
\text { und Dekompen- } \\
\text { sationsrisiko bei } \\
\text { Patienten mit } \\
\text { HCV, unabhän- } \\
\text { gig von einem } \\
\text { Therapieanspre- } \\
\text { chen }\end{array}$ & $\begin{array}{l}\text { retrospek- } \\
\text { tive Kohor- } \\
\text { tenanalyse }\end{array}$ & keine & 100 & $\begin{array}{l}\text { SVR12, HVPG, 1-, 5- } \\
\text { und 7-Jahres-Dekom- } \\
\text { pensationsrate, Beob- } \\
\text { achtungszeitraum: } 11 \\
\text { Jahre }\end{array}$ & $\begin{array}{l}\text { Patienten mit schwe- } \\
\text { rer portaler Hyper- } \\
\text { tension haben bis } 5 \\
\text { Jahre nach antiviraler } \\
\text { Therapie ein erhöh- } \\
\text { tes Dekompensati- } \\
\text { onsrisiko unabhängig } \\
\text { vom Therapieanspre- } \\
\text { chen. }\end{array}$ & Level 3 \\
\hline
\end{tabular}




\begin{tabular}{|c|c|c|c|c|c|c|c|}
\hline $\begin{array}{l}\text { Referenz- } \\
\text { autor, Jahr }\end{array}$ & $\begin{array}{l}\text { Thema, } \\
\text { Intervention }\end{array}$ & Studientyp & Kontrolle & n gesamt & $\begin{array}{l}\text { Zielparameter, } \\
\text { Beobachtungsdauer }\end{array}$ & $\begin{array}{l}\text { Ergebnis, } \\
\text { Bemerkungen }\end{array}$ & $\begin{array}{l}\text { Evidenzgrad, } \\
\text { * Oxford-Schema }\end{array}$ \\
\hline $\begin{array}{l}\text { Saxena V et al., } \\
2015\end{array}$ & $\begin{array}{l}\text { Sicherheit und } \\
\text { Effektivität von } \\
\text { Simeprevir/So- } \\
\text { fosbuvir bei } \\
\text { HCV-Patienten } \\
\text { mit kompensier- } \\
\text { ter und dekom- } \\
\text { pensierter Le- } \\
\text { berzirrhose }\end{array}$ & $\begin{array}{l}\text { retrospek- } \\
\text { tive nicht } \\
\text { randomi- } \\
\text { sierte kon- } \\
\text { trollierte } \\
\text { Kohorten- } \\
\text { studie }\end{array}$ & $\begin{array}{l}\text { Alters-, } \\
\text { Zentren-, } \\
\text { Child- } \\
\text { Pugh- und } \\
\text { MELD ge- } \\
\text { matchte } \\
\text { Patienten } \\
\text { ohne The- } \\
\text { rapie }\end{array}$ & 160 & $\begin{array}{l}\text { SVR } 12 \text {, Beobachtung } \\
\text { über } 24 \text { Wochen }\end{array}$ & $\begin{array}{l}\text { Eine Therapie mit Si- } \\
\text { meprevir/Sofosbuvir } \\
\text { mit und ohne Ribavi- } \\
\text { rin über } 12 \text { Wochen } \\
\text { hatte eine geringere } \\
\text { Effektivität und hö- } \\
\text { here Nebenwirkungs- } \\
\text { rate bei Patienten mit } \\
\text { Child-B/C-Zirrhose } \\
\text { als bei Child-A-Pa- } \\
\text { tienten. }\end{array}$ & Level 3 \\
\hline $\begin{array}{l}\text { Welker M-W } \\
\text { LS et al., } 2015\end{array}$ & $\begin{array}{l}\text { Laktatazidose } \\
\text { bei Patienten } \\
\text { mit HCV-assozi- } \\
\text { ierter Zirrhose } \\
\text { und Sofosbuvir/ } \\
\text { Ribavirin-Thera- } \\
\text { pie. }\end{array}$ & $\begin{array}{l}\text { prospektive } \\
\text { nicht kon- } \\
\text { trollierte } \\
\text { Kohorten- } \\
\text { studie }\end{array}$ & keine & 35 & $\begin{array}{l}\text { SVR } 12 \text {, Beobachtung } \\
\text { über } 84 \text { Wochen }\end{array}$ & $\begin{array}{l}\text { Antivirale Therapie } \\
\text { mit Ribavirin und } \\
\text { Sofosbuvir kann bei } \\
\text { HCV-Patienten mit } \\
\text { fortgeschrittener Zir- } \\
\text { rhose zur Laktatazi- } \\
\text { dose führen. Poten- } \\
\text { zielle Risikofaktoren } \\
\text { sind eine einge- } \\
\text { schränkte Nieren- } \\
\text { funktion und ein } \\
\text { höherer MELD/Child- } \\
\text { Pugh-Score. }\end{array}$ & Level 3 \\
\hline
\end{tabular}

b) Wie ist das Management der Patienten mit HCV-Infektion auf der Warteliste zur Nierentransplantation und zur Transplantation sonstiger Organe (Herz, Lunge, Pankreas, Darm)?

\begin{tabular}{|c|c|c|c|c|c|c|c|}
\hline $\begin{array}{l}\text { Referenz- } \\
\text { autor, Jahr }\end{array}$ & $\begin{array}{l}\text { Thema, } \\
\text { Intervention }\end{array}$ & Studientyp & Kontrolle & n gesamt & $\begin{array}{l}\text { Zielparameter, } \\
\text { Beobachtungsdauer }\end{array}$ & $\begin{array}{l}\text { Ergebnis, } \\
\text { Bemerkungen }\end{array}$ & $\begin{array}{l}\text { Evidenzgrad, } \\
{ }^{*} \text { Oxford-Schema }\end{array}$ \\
\hline $\begin{array}{l}\text { Ingsathit A } \\
\text { et al., } 2013\end{array}$ & $\begin{array}{l}\text { Überlebensvorteil } \\
\text { der Nierentrans- } \\
\text { plantation (NTx) } \\
\text { gegenüber der } \\
\text { Dialyse bei Patien- } \\
\text { ten mit Hepatitis C }\end{array}$ & Review & - & - & Mortalität & $\begin{array}{l}\text { HCV-Patienten } \\
\text { haben eine höhere } \\
\text { Mortalität unter } \\
\text { Dialyse als nach NTx. }\end{array}$ & Level 1 \\
\hline $\begin{array}{l}\text { Pockros PJ } \\
\text { et al., } 2016\end{array}$ & $\begin{array}{l}\text { Effektivität von } \\
\text { Ombitasvir/Parita- } \\
\text { previr/Ritonavir, } \\
\text { und Dasabuvir bei } \\
\text { Patienten mit } \\
\text { HCV-Genotyp-1- } \\
\text { Infektion und } \\
\text { stark einge- } \\
\text { schränkter Nie- } \\
\text { renfunktion oder } \\
\text { terminaler Nie- } \\
\text { reninsuffizienz. }\end{array}$ & $\begin{array}{l}\text { prospektive } \\
\text { Kohorten- } \\
\text { studie }\end{array}$ & keine & 20 & $\begin{array}{l}\text { SVR } 12 \text {, Beobachtung } \\
\text { über } 24 \text { Wochen }\end{array}$ & $\begin{array}{l}\text { Ombitasvir/Parita- } \\
\text { previr/Ritonavir, und } \\
\text { Dasabuvir führte zu } \\
\text { einer } 90 \% \text { igen } \\
\text { SVR12-Rate bei } \\
\text { Patienten mit HCV- } \\
\text { Genotyp-1-Infektion } \\
\text { und chronischer Nie- } \\
\text { renerkrankung CKD } \\
\text { Stadium } 4 \text { oder } 5 \text { und } \\
\text { wurde gut vertragen. } \\
\text { Bei Kombination mit } \\
\text { Ribavirin können } \\
\text { Dosisreduktionen } \\
\text { notwendig sein. }\end{array}$ & Level 3 \\
\hline
\end{tabular}




\begin{tabular}{|c|c|c|c|c|c|c|c|}
\hline $\begin{array}{l}\text { Referenz- } \\
\text { autor, Jahr }\end{array}$ & $\begin{array}{l}\text { Thema, } \\
\text { Intervention }\end{array}$ & Studientyp & Kontrolle & n gesamt & $\begin{array}{l}\text { Zielparameter, } \\
\text { Beobachtungsdauer }\end{array}$ & $\begin{array}{l}\text { Ergebnis, } \\
\text { Bemerkungen }\end{array}$ & $\begin{array}{l}\text { Evidenzgrad, } \\
{ }^{*} \text { Oxford-Schema }\end{array}$ \\
\hline $\begin{array}{l}\text { Roth D et al., } \\
2015\end{array}$ & $\begin{array}{l}\text { Grazoprevir plus } \\
\text { Elbasvir bei thera- } \\
\text { pienaiven und } \\
\text { vorbehandelten } \\
\text { HCV-Genotyp-1- } \\
\text { Patienten mit } \\
\text { chronischer Nie- } \\
\text { renerkrankung } \\
\text { Stadium 4-5 }\end{array}$ & $\begin{array}{l}\text { randomi- } \\
\text { sierte } \\
\text { Phase-3- } \\
\text { Studie }\end{array}$ & keine & 224 & $\begin{array}{l}\text { SVR 12, Beobachtung } \\
\text { über } 24 \text { Wochen }\end{array}$ & $\begin{array}{l}\text { Eine 12-wöchige The- } \\
\text { rapie mit Grazoprevir } \\
\text { plus Elbasvir hatte bei } \\
\text { therapienaiven und } \\
\text { vorbehandelten HCV- } \\
\text { Genotyp-1-Patienten } \\
\text { mit chronischer Nie- } \\
\text { renerkrankung Stadi- } \\
\text { um } 4 \text { - } 5 \text { eine niedrige } \\
\text { Nebenwirkungsrate } \\
\text { und war effektiv. }\end{array}$ & Level 1 \\
\hline $\begin{array}{l}\text { Nazario HE } \\
\text { et al., } 2015\end{array}$ & $\begin{array}{l}\text { Sofosbuvir und } \\
\text { Simeprevir bei } \\
\text { HCV-Genotyp-1- } \\
\text { Patienten mit ter- } \\
\text { minaler Nierenin- } \\
\text { suffizienz und } \\
\text { Dialyse oder GFR } \\
<30 \mathrm{~mL} / \text { min }\end{array}$ & $\begin{array}{l}\text { prospektive } \\
\text { Kohorten- } \\
\text { analyse }\end{array}$ & keine & 17 & $\begin{array}{l}\text { SVR 12, Nebenwirkun- } \\
\text { gen, Beobachtung } \\
\text { über } 24 \text { Wochen }\end{array}$ & $\begin{array}{l}\text { Eine Therapie mit } \\
\text { Sofosbuvir und Sime- } \\
\text { previr über } 12 \text { Wo- } \\
\text { chen erreichte } 100 \% \\
\text { SVR12 bei HCV-Ge- } \\
\text { notyp-1-Patienten } \\
\text { mit terminaler Nie- } \\
\text { reninsuffizienz und } \\
\text { Dialyse oder GFR } \\
<30 \mathrm{~mL} / \text { min und } \\
\text { wurde gut vertragen. }\end{array}$ & Level 3 \\
\hline $\begin{array}{l}\text { Englum BR } \\
\text { et al., } 2016 .\end{array}$ & $\begin{array}{l}\text { Einfluss des Spen- } \\
\text { der-HCV-Status } \\
\text { bei Lungentrans- } \\
\text { plantation }\end{array}$ & $\begin{array}{l}\text { retrospek- } \\
\text { tive Kohor- } \\
\text { tenanalyse }\end{array}$ & keine & 16893 & $\begin{array}{l}\text { medianes Überleben, } \\
\text { Beobachtungszeit- } \\
\text { raum: } 17 \text { Jahre }\end{array}$ & $\begin{array}{l}\text { Das Outcome nach } \\
\text { Lungentransplanta- } \\
\text { tion ist für HCV-ne- } \\
\text { gative Empfänger, } \\
\text { die eine Lunge von } \\
\text { einem HCV-positiven } \\
\text { Spender erhalten, } \\
\text { deutlich schlechter. }\end{array}$ & Level 3 \\
\hline
\end{tabular}

\section{Verlauf und Behandlung nach Lebertransplantation}

Siehe Evidenztabelle zu 2.

\section{Vermittlung HCV-positiver Spenderorgane}

Wann können HCV-positive Spenderorgane akzeptiert werden?

Expertenkonsens. 


\section{Transplantation anderer solider Organe (Niere, Herz, Lunge, Pankreas und Dünndarm) und Knochenmark- bzw. Stammzelltransplantation in HCV-positiven Patienten}

\begin{tabular}{|c|c|c|c|c|c|c|c|}
\hline $\begin{array}{l}\text { Referenz- } \\
\text { autor, Jahr }\end{array}$ & $\begin{array}{l}\text { Thema, } \\
\text { Intervention }\end{array}$ & Studientyp & Kontrolle & n gesamt & $\begin{array}{l}\text { Zielparameter, } \\
\text { Beobachtungsdauer }\end{array}$ & $\begin{array}{l}\text { Ergebnis, } \\
\text { Bemerkungen }\end{array}$ & $\begin{array}{l}\text { Evidenzgrad, } \\
{ }^{*} \text { Oxford- } \\
\text { Schema }\end{array}$ \\
\hline $\begin{array}{l}\text { Mehra MR } \\
\text { et al., } 2016\end{array}$ & $\begin{array}{l}\text { die } 2016 \text { Wartelis- } \\
\text { tenkriterien zur } \\
\text { Herztransplanta- } \\
\text { tion der Internatio- } \\
\text { nalen Gesellschaft } \\
\text { für Herz- und } \\
\text { Lungentransplan- } \\
\text { tation }\end{array}$ & Leitlinie & - & - & $\begin{array}{l}\text { Wartelistenkriterien zur } \\
\text { Herztransplantation }\end{array}$ & $\begin{array}{l}\text { Wartelistenkriterien } \\
\text { zur Herztransplan- } \\
\text { tation } 2016\end{array}$ & Level 1 \\
\hline $\begin{array}{l}\text { Torres HA } \\
\text { et al., } 2015\end{array}$ & $\begin{array}{l}\text { HCV-Infektion } \\
\text { bei Stammzell- } \\
\text { spendern und } \\
\text {-empfängern, } \\
\text { Empfehlungen der } \\
\text { amerikanischen } \\
\text { Gesellschaft für } \\
\text { Blut- und Stamm- } \\
\text { zelltransplantation }\end{array}$ & Leitlinie & - & - & $\begin{array}{l}\text { HCV-Infektion bei } \\
\text { Stammzellspendern } \\
\text { und -empfängern }\end{array}$ & $\begin{array}{l}\text { Empfehlungen zur } \\
\text { HCV-Infektion bei } \\
\text { Stammzellspendern } \\
\text { und -empfängern }\end{array}$ & Level 1 \\
\hline $\begin{array}{l}\text { Varma A } \\
\text { et al., } 2016\end{array}$ & $\begin{array}{l}\text { Outcome bei HCV } \\
\text { positiven Lym- } \\
\text { phom- und Mye- } \\
\text { lom-Patienten } \\
\text { nach autologer } \\
\text { Stammzelltrans- } \\
\text { plantation }\end{array}$ & $\begin{array}{l}\text { retrospek- } \\
\text { tive Kohor- } \\
\text { tenanalyse }\end{array}$ & keine & 64 & $\begin{array}{l}\text { Überleben, Komplikati- } \\
\text { onsrate, Beobachtungs- } \\
\text { zeitraum: } 16 \text { Jahre }\end{array}$ & $\begin{array}{l}\text { Das Überleben } \\
\text { der HCV-positiven } \\
\text { Lymphom- und Mye- } \\
\text { lom-Patienten nach } \\
\text { autologer Stammzell- } \\
\text { transplantation war } \\
\text { mit dem in der Litera- } \\
\text { tur vorbeschriebenen } \\
\text { Überleben von HCV- } \\
\text { negativen Patienten } \\
\text { vergleichbar. }\end{array}$ & Level 3 \\
\hline $\begin{array}{l}\text { Kyvernitakis } \\
\text { A et al., } 2016\end{array}$ & $\begin{array}{l}\text { HCV-Infektion } \\
\text { bei Stammzell- } \\
\text { transplantations- } \\
\text { Patienten im Zeit- } \\
\text { alter der direkt } \\
\text { antiviral wirksa- } \\
\text { men Therapie }\end{array}$ & $\begin{array}{l}\text { gemischt } \\
\text { retrospek- } \\
\text { tiv-prospek- } \\
\text { tive Kohor- } \\
\text { tenanalyse }\end{array}$ & keine & 64 & $\begin{array}{l}\text { 5-jahresüberleben, } \\
\text { Komplikationen, } \\
\text { Beobachtungszeit- } \\
\text { raum: } 6 \text { Jahre }\end{array}$ & $\begin{array}{l}\text { Die antivirale The- } \\
\text { rapie HCV-positiver } \\
\text { Stammzelltransplan- } \\
\text { tations-Patienten } \\
\text { verbessert das on- } \\
\text { kologische und das } \\
\text { hepatische Outcome. }\end{array}$ & Level 3 \\
\hline $\begin{array}{l}\text { Nakasone H } \\
\text { et al., } 2013\end{array}$ & $\begin{array}{l}\text { Einfluss der HCV- } \\
\text { Infektion auf das } \\
\text { Outcome nach al- } \\
\text { logener Stamm- } \\
\text { zelltransplantation }\end{array}$ & $\begin{array}{l}\text { retrospek- } \\
\text { tive Kohor- } \\
\text { tenanalyse }\end{array}$ & $\begin{array}{l}7695 \text { HCV- } \\
\text { negative } \\
\text { Stammzell- } \\
\text { transplan- } \\
\text { tations- } \\
\text { Patienten }\end{array}$ & 7831 & $\begin{array}{l}\text { Rekonstitutionsrate, 2- } \\
\text { Jahresüberleben Kom- } \\
\text { plikationen, Beobach- } \\
\text { tungszeitraum: } 3 \text { Jahre }\end{array}$ & $\begin{array}{l}\text { HCV positive Stamm- } \\
\text { zelltransplantations- } \\
\text { Patienten hatten eine } \\
\text { schlechtere Rekon- } \\
\text { stitutionsrate, ein } \\
\text { schlechteres 2-Jahres- } \\
\text { überleben und eine } \\
\text { erhöhte Rate an } \\
\text { Komplikationen. }\end{array}$ & Level 3 \\
\hline
\end{tabular}




\begin{tabular}{|c|c|c|c|c|c|c|c|}
\hline $\begin{array}{l}\text { Referenz- } \\
\text { autor, Jahr }\end{array}$ & $\begin{array}{l}\text { Thema, } \\
\text { Intervention }\end{array}$ & Studientyp & Kontrolle & n gesamt & $\begin{array}{l}\text { Zielparameter, } \\
\text { Beobachtungsdauer }\end{array}$ & $\begin{array}{l}\text { Ergebnis, } \\
\text { Bemerkungen }\end{array}$ & $\begin{array}{l}\text { Evidenzgrad, } \\
{ }^{*} \text { Oxford- } \\
\text { Schema }\end{array}$ \\
\hline $\begin{array}{l}\text { Tomblyn M } \\
\text { et al., } 2013\end{array}$ & $\begin{array}{l}\text { keine erhöhte } \\
\text { Mortalität bei } \\
\text { positivem HBV- } \\
\text { oder HVC-Serosta- } \\
\text { tus von Spender } \\
\text { oder Empfänger } \\
\text { bei allogener } \\
\text { Stammzelltrans- } \\
\text { plantation }\end{array}$ & $\begin{array}{l}\text { retrospek- } \\
\text { tive Kohor- } \\
\text { tenanalyse }\end{array}$ & $\begin{array}{l}256 \mathrm{HCV} \\
\text { negative } \\
\text { Stammzell- } \\
\text { transplan- } \\
\text { tations-Pa- } \\
\text { tienten } \\
\text { von HCV- } \\
\text { negativen } \\
\text { Spendern }\end{array}$ & $\begin{array}{l}416 \text { (33 } \\
\text { HCV-nega- } \\
\text { tive Stamm- } \\
\text { zelltrans- } \\
\text { plantations- } \\
\text { Patienten } \\
\text { von HCV- } \\
\text { positiven } \\
\text { Spendern, } \\
128 \text { HCV- } \\
\text { positive } \\
\text { Empfänger) }\end{array}$ & $\begin{array}{l}\text { Therapie-assoziierte } \\
\text { Mortalität, Überleben, } \\
\text { Inzidenz von Graft vs. } \\
\text { Host Disease (GvHD), } \\
\text { hepatische Toxizität, } \\
\text { Beobachtungszeit- } \\
\text { raum: } 8 \text { Jahre }\end{array}$ & $\begin{array}{l}\text { Die Therapie-asso- } \\
\text { ziierte Mortalität, } \\
\text { Überleben, Inzidenz } \\
\text { von Graft vs. Host } \\
\text { Disease und hepati- } \\
\text { sche Toxizität waren } \\
\text { bei allen Gruppen } \\
\text { ähnlich. }\end{array}$ & Level 3 \\
\hline $\begin{array}{l}\text { Arai } Y \text { at al., } \\
2016\end{array}$ & $\begin{array}{l}\text { Risikofaktoren } \\
\text { und Prognose bei } \\
\text { akuter hepati- } \\
\text { scher GvHD nach } \\
\text { allogener Stamm- } \\
\text { zelltransplantation }\end{array}$ & $\begin{array}{l}\text { retrospek- } \\
\text { tive Kohor- } \\
\text { tenanalyse }\end{array}$ & keine & 8378 & $\begin{array}{l}\text { Überleben, Inzidenz } \\
\text { akuter hepatischer } \\
\text { GvHD, Beobachtungs- } \\
\text { zeitraum: } 5 \text { Jahre }\end{array}$ & $\begin{array}{l}\text { Akute hepatische } \\
\text { GvHD war ein unab- } \\
\text { hängiger Risikofaktor } \\
\text { für geringeres Über- } \\
\text { leben und erhöhte } \\
\text { Tx-assoziierte Morta- } \\
\text { lität. }\end{array}$ & Level 3 \\
\hline $\begin{array}{l}\text { Evans AT } \\
\text { et al., } 2015\end{array}$ & $\begin{array}{l}\text { Fibrosierende } \\
\text { cholestatische } \\
\text { Hepatitis nach } \\
\text { allogener Stamm- } \\
\text { zelltransplantation }\end{array}$ & Fallserie & - & 3 & $\begin{array}{l}3 \text { Fälle von fibrosieren- } \\
\text { der cholestatischer He- } \\
\text { patitis nach allogener } \\
\text { Stammzelltransplanta- } \\
\text { tion }\end{array}$ & $\begin{array}{l}\text { In } 3 \text { Fällen war eine fi- } \\
\text { brosierende cholesta- } \\
\text { tische Hepatitis nach } \\
\text { allogener Stammzell- } \\
\text { transplantation mög- } \\
\text { licherweise mit MMF } \\
\text { assoziiert. }\end{array}$ & Level 4 \\
\hline $\begin{array}{l}\text { Fischler B } \\
\text { et al., } 2016\end{array}$ & $\begin{array}{l}\text { Therapie mit } \\
\text { Sofosbuvir und } \\
\text { Simeprevir bei } \\
\text { einem stammzell- } \\
\text { transplantierten } \\
\text { Teenager mit } \\
\text { chronischer } \\
\text { HCV-Infektion }\end{array}$ & Fallbericht & - & 1 & $\begin{array}{l}1 \text { Fall von antiviraler } \\
\text { Therapie mit Sofosbu- } \\
\text { vir und Simeprevir nach } \\
\text { allogener Stammzell- } \\
\text { transplantation. }\end{array}$ & $\begin{array}{l}\text { Ein wegen schwerer } \\
\text { Sichelzellanämie } \\
\text { stammzelltransplan- } \\
\text { tierter Teenager mit } \\
\text { chronischer HCV- } \\
\text { Infektion erreichte } \\
\text { unter antiviraler The- } \\
\text { rapie mit Sofosbuvir } \\
\text { und Simeprevir SVR. } \\
\text { Es traten periphere } \\
\text { Ödeme als Neben- } \\
\text { wirkung auf. }\end{array}$ & Level 4 \\
\hline $\begin{array}{l}\text { Thomas P } \\
\text { et al., } 2016\end{array}$ & $\begin{array}{l}\text { HCV-Therapie mit } \\
\text { Sofosbuvir und Si- } \\
\text { meprevir bei einem } \\
\text { pädiatrischen Pa- } \\
\text { tienten direkt nach } \\
\text { Nabelschnurblut- } \\
\text { transplantation }\end{array}$ & Fallbericht & - & 1 & $\begin{array}{l}1 \text { pädiatrischer Fall von } \\
\text { antiviraler Therapie mit } \\
\text { Sofosbuvir und Sime- } \\
\text { previr nach Nabel- } \\
\text { schnurbluttransplanta- } \\
\text { tion }\end{array}$ & $\begin{array}{l}\text { Eine wegen ALL nabel- } \\
\text { schnurbluttransplan- } \\
\text { tierte pädiatrische } \\
\text { Patientin erreichte } \\
\text { unter antiviraler The- } \\
\text { rapie mit Sofosbuvir } \\
\text { und Simeprevir über } \\
24 \text { Wochen mit The- } \\
\text { rapiestart } 88 \text { Tage } \\
\text { nach Tx SVR. }\end{array}$ & Level 4 \\
\hline $\begin{array}{l}\text { Pinana JL } \\
\text { et al., } 2016\end{array}$ & $\begin{array}{l}\text { erfolgreiche HCV- } \\
\text { Therapie mit So- } \\
\text { fosbuvir und Si- } \\
\text { meprevir in der } \\
\text { Frühphase eines } \\
\text { Stammzell-trans- } \\
\text { plantations- } \\
\text { Patienten }\end{array}$ & Fallbericht & - & 1 & $\begin{array}{l}1 \text { Fall von antiviraler } \\
\text { Therapie mit Sofosbu- } \\
\text { vir und Simeprevir nach } \\
\text { allogener Stammzell- } \\
\text { transplantation }\end{array}$ & $\begin{array}{l}\text { Eine wegen MDS } \\
\text { stammzelltransplan- } \\
\text { tierte } 62 \text {-jährige Pa- } \\
\text { tientin erreichte unter } \\
\text { antiviraler Therapie } \\
\text { mit Sofosbuvir und } \\
\text { Simeprevir über } 24 \\
\text { Wochen mit Therapie- } \\
\text { start } 30 \text { Tage nach } \\
\text { Tx SVR. }\end{array}$ & Level 4 \\
\hline
\end{tabular}




\begin{tabular}{|c|c|c|c|c|c|c|c|}
\hline $\begin{array}{l}\text { Referenz- } \\
\text { autor, Jahr }\end{array}$ & $\begin{array}{l}\text { Thema, } \\
\text { Intervention }\end{array}$ & Studientyp & Kontrolle & n gesamt & $\begin{array}{l}\text { Zielparameter, } \\
\text { Beobachtungsdauer }\end{array}$ & $\begin{array}{l}\text { Ergebnis, } \\
\text { Bemerkungen }\end{array}$ & $\begin{array}{l}\text { Evidenzgrad, } \\
{ }^{*} \text { Oxford- } \\
\text { Schema }\end{array}$ \\
\hline $\begin{array}{l}\text { Curry MP } \\
\text { et al., } 2015\end{array}$ & $\begin{array}{l}\text { Sofosbuvir und Ri- } \\
\text { bavirin verhindern } \\
\text { eine rekurrente } \\
\text { HCV-Infektion } \\
\text { nach LTx }\end{array}$ & $\begin{array}{l}\text { randomi- } \\
\text { sierte Open- } \\
\text { label-Phase- } \\
\text { 2-Studie }\end{array}$ & keine & 61 & SVR12 post-LTx & $\begin{array}{l}\text { Die Gabe von Sofos- } \\
\text { buvir und Ribavirin } \\
\text { prä-LTx kann eine } \\
\text { rekurrente HCV-In- } \\
\text { fektion nach LTx } \\
\text { verhindern. }\end{array}$ & Level 2 \\
\hline $\begin{array}{l}\text { Yu TM et al., } \\
2016\end{array}$ & $\begin{array}{l}\text { erhöhtes Risiko } \\
\text { hepatischer Kom- } \\
\text { plikationen bei } \\
\text { NTx-Patienten mit } \\
\text { chronischer HCV- } \\
\text { Infektion }\end{array}$ & $\begin{array}{l}\text { retrospek- } \\
\text { tive Kohor- } \\
\text { tenanalyse }\end{array}$ & $\begin{array}{l}3485 \\
\text { HBV/HCV- } \\
\text { negative } \\
\text { NTx-Pa- } \\
\text { tienten }\end{array}$ & $\begin{array}{l}4112 \text { ( } 352 \\
\text { HBV- und } \\
275 \text { HCV- } \\
\text { positive } \\
\text { NTx-Pati- } \\
\text { enten) }\end{array}$ & $\begin{array}{l}\text { Mortalität, Auftreten } \\
\text { einer Lebererkrankung } \\
\text { post-LTx, Beobach- } \\
\text { tungszeitraum: } 9 \text { Jahre }\end{array}$ & $\begin{array}{l}\text { HBV- oder HCV-posi- } \\
\text { tive NTx-Patienten } \\
\text { hatten eine erhöhte } \\
\text { Mortalität und ein } \\
\text { erhöhtes Risiko, ein } \\
\text { HCC zu entwickeln. }\end{array}$ & Level 3 \\
\hline $\begin{array}{l}\text { Abbas MH } \\
\text { et al., } 2015\end{array}$ & $\begin{array}{l}\text { Effekt einer HCV- } \\
\text { Infektion prä-NTx } \\
\text { auf die Entwick- } \\
\text { lung eines new- } \\
\text { onset Diabetes } \\
\text { mellitus post-NTx } \\
\text { bei ägyptischen } \\
\text { Nieren-Lebend- } \\
\text { spenden-Empfän- } \\
\text { gern }\end{array}$ & $\begin{array}{l}\text { retrospek- } \\
\text { tive Kohor- } \\
\text { tenanalyse }\end{array}$ & $\begin{array}{l}598 \mathrm{HCV}- \\
\text { negative } \\
\text { NTx-Pa- } \\
\text { tienten }\end{array}$ & 913 & $\begin{array}{l}\text { Inzidenz eines new-on- } \\
\text { set post-NTx, Beobach- } \\
\text { tungszeitraum: } 10 \text { Jahre }\end{array}$ & $\begin{array}{l}\text { Es gab eine positive } \\
\text { Korrelation zwischen } \\
\text { der Inzidenz eines } \\
\text { new- onset post-NTx- } \\
\text { Diabetes und einem } \\
\text { positiven HCV-Status } \\
\text { vor NTx. }\end{array}$ & Level 3 \\
\hline $\begin{array}{l}\text { Morales JM } \\
\text { et al., } 2015\end{array}$ & $\begin{array}{l}\text { Hepatitis } C \text { und } \\
\text { der Einfluss auf } \\
\text { NTx }\end{array}$ & Review & - & - & $\begin{array}{l}\text { Zusammenhang von } \\
\text { NTx, HCV-Infektion } \\
\text { und Lebererkrankung, } \\
\text { antivirale Therapie, } \\
\text { Komplikationen der } \\
\text { HCV-Infektion, NTx } \\
\text { von HCV-positiven } \\
\text { Spendern }\end{array}$ & $\begin{array}{l}\text { Das Patientenüberle- } \\
\text { ben und die Trans- } \\
\text { plantattoleranz sind } \\
\text { bei HCV-positiven } \\
\text { NTx-Patienten gerin- } \\
\text { ger. Die Zulassung In- } \\
\text { terferon-freier Thera- } \\
\text { pien kann den Verlauf } \\
\text { der Hepatitis C nach } \\
\text { NTx grundlegend } \\
\text { verändern. }\end{array}$ & Level 1 \\
\hline $\begin{array}{l}\text { Fabrizi F } \\
\text { et al., } 2014\end{array}$ & $\begin{array}{l}\text { Metaanalyse von } \\
\text { Beobachtungs- } \\
\text { studien zur Hepa- } \\
\text { titis C und Überle- } \\
\text { ben nach NTx }\end{array}$ & $\begin{array}{l}\text { Meta- } \\
\text { analyse }\end{array}$ & keine & 133530 & $\begin{array}{l}\text { Patienten- und Trans- } \\
\text { plantatüberleben }\end{array}$ & $\begin{array}{l}\text { HCV-positive Patien- } \\
\text { ten hatten eine er- } \\
\text { höhte Mortalität und } \\
\text { ein höheres Risiko des } \\
\text { Transplantatverlusts. }\end{array}$ & Level 1 \\
\hline $\begin{array}{l}\text { Burra P et al., } \\
2014\end{array}$ & $\begin{array}{l}\text { HCV-Infektion bei } \\
\text { terminaler Niere- } \\
\text { ninsuffizienz und } \\
\text { NTx }\end{array}$ & Review & - & - & $\begin{array}{l}\text { antivirale Therapie bei } \\
\text { NTx-Patienten }\end{array}$ & $\begin{array}{l}\text { Das Outcome nach } \\
\text { NTx ist der Dialyse } \\
\text { überlegen. Das Über- } \\
\text { leben nach NTx ist } \\
\text { jedoch bei HCV-nega- } \\
\text { tiven Patienten bes- } \\
\text { ser. Daher werden } \\
\text { Leitlinien zur antivira- } \\
\text { len Therapie für Pa- } \\
\text { tienten mit terminaler } \\
\text { Niereninsuffizienz } \\
\text { und NTx-Patienten } \\
\text { benötigt. }\end{array}$ & Level 1 \\
\hline $\begin{array}{l}\text { Singh N } \\
\text { et al., } 2012\end{array}$ & $\begin{array}{l}\text { Einfluss des HCV- } \\
\text { Status von Spen- } \\
\text { der und Empfän- } \\
\text { ger auf das Lang- } \\
\text { zeitüberleben } \\
\text { nach NTx }\end{array}$ & $\begin{array}{l}\text { retrospek- } \\
\text { tive Kohor- } \\
\text { tenanalyse }\end{array}$ & $\begin{array}{l}1897 \mathrm{HCV} \\
\text { negative } \\
\text { Spender } \\
\text { und Emp- } \\
\text { fänger }\end{array}$ & 2169 & $\begin{array}{l}\text { Überleben, Beobach- } \\
\text { tungszeitraum: } \\
16 \text { Jahre }\end{array}$ & $\begin{array}{l}\text { NTx-Patienten hatten } \\
\text { ein schlechteres } \\
\text { Überleben und ein } \\
\text { erhöhtes Risiko des } \\
\text { Transplantatverlusts } \\
\text { bei positivem HCV- } \\
\text { Status bei Spender } \\
\text { und Empfänger. }\end{array}$ & Level 3 \\
\hline
\end{tabular}




\begin{tabular}{|c|c|c|c|c|c|c|c|}
\hline $\begin{array}{l}\text { Referenz- } \\
\text { autor, Jahr }\end{array}$ & $\begin{array}{l}\text { Thema, } \\
\text { Intervention }\end{array}$ & Studientyp & Kontrolle & n gesamt & $\begin{array}{l}\text { Zielparameter, } \\
\text { Beobachtungsdauer }\end{array}$ & $\begin{array}{l}\text { Ergebnis, } \\
\text { Bemerkungen }\end{array}$ & $\begin{array}{l}\text { Evidenzgrad, } \\
{ }^{*} \text { Oxford- } \\
\text { Schema }\end{array}$ \\
\hline $\begin{array}{l}\text { Corouge M } \\
\text { et al., } 2016\end{array}$ & HCV und die Niere & Review & - & - & $\begin{array}{l}\text { antivirale Therapie bei } \\
\text { NTx-Patienten }\end{array}$ & $\begin{array}{l}\text { Patienten mit termi- } \\
\text { naler Niereninsuffi- } \\
\text { zienz und NTx-Patien- } \\
\text { ten sollten bevorzugt } \\
\text { mit direkt antiviral } \\
\text { wirksamen Substan- } \\
\text { zen behandelt } \\
\text { werden. }\end{array}$ & Level 1 \\
\hline $\begin{array}{l}\text { Sawinski D } \\
\text { et al., } 2015\end{array}$ & $\begin{array}{l}\text { erfolgreiche HCV- } \\
\text { Therapie mit } \\
\text { direkt antiviral } \\
\text { wirksamen } \\
\text { Substanzen bei } \\
\text { NTx-Patienten }\end{array}$ & $\begin{array}{l}\text { retrospek- } \\
\text { tive Kohor- } \\
\text { tenanalyse }\end{array}$ & keine & 20 & SVR12 & $\begin{array}{l}\text { Eine antivirale Thera- } \\
\text { pie mit direkt antiviral } \\
\text { wirksamen Substan- } \\
\text { zen führte bei } 20 \\
\text { NTx-Patienten zu } \\
\text { einer SVR12 von } \\
100 \% \text { und wurde } \\
\text { gut vertragen. }\end{array}$ & Level 3 \\
\hline $\begin{array}{l}\text { Kamar N } \\
\text { et al., } 2015\end{array}$ & $\begin{array}{l}\text { Effektivität und } \\
\text { Sicherheit von } \\
\text { Sofosbuvir-basier- } \\
\text { ter antiviraler } \\
\text { Therapie nach NTx }\end{array}$ & $\begin{array}{l}\text { prospektive } \\
\text { Kohorten- } \\
\text { studie/ } \\
\text { Pilotstudie }\end{array}$ & keine & 25 & SVR12 & $\begin{array}{l}\text { Eine Sofosbuvir- } \\
\text { basierte antivirale } \\
\text { Therapie führte bei } \\
25 \text { NTx-Patienten } \\
\text { zu einer SVR12 von } \\
100 \% \text { und wurde gut } \\
\text { vertragen. }\end{array}$ & Level 3 \\
\hline $\begin{array}{l}\text { Suarez-Ben- } \\
\text { jumea A } \\
\text { et al., } 2015\end{array}$ & $\begin{array}{l}\text { neue antivirale } \\
\text { Medikamente bei } \\
\text { HCV-infizierten } \\
\text { NTx Patienten }\end{array}$ & Fallstudie & keine & 3 & SVR12 & $\begin{array}{l}3 \text { HCV-positive NTX- } \\
\text { Patienten wurden } \\
\text { erfolgreich mit einer } \\
\text { Sofosbuvir-basierten } \\
\text { antiviralen Therapie } \\
\text { behandelt. }\end{array}$ & Level 4 \\
\hline $\begin{array}{l}\text { Doucette KE } \\
\text { et al., } 2016\end{array}$ & $\begin{array}{l}\text { Outcome von } \\
\text { Lungentransplan- } \\
\text { tation bei Emp- } \\
\text { fängern mit } \\
\text { HCV-Infektion }\end{array}$ & $\begin{array}{l}\text { retrospekti- } \\
\text { ve Kohor- } \\
\text { tenanalyse }\end{array}$ & $\begin{array}{l}443 \mathrm{HCV}- \\
\text { negative } \\
\text { Lungen- } \\
\text { transplan- } \\
\text { tationspa- } \\
\text { tienten }\end{array}$ & 470 & $\begin{array}{l}\text { 1-, 3- und 5-Jahres- } \\
\text { überleben, Beobach- } \\
\text { tungszeitraum: } 25 \text { Jahre }\end{array}$ & $\begin{array}{l}\text { HCV beeinflusste } \\
\text { nicht das Outcome } \\
\text { nach Lungentrans- } \\
\text { plantation. }\end{array}$ & Level 3 \\
\hline $\begin{array}{l}\text { Trakroo S } \\
\text { et al., } 2015\end{array}$ & $\begin{array}{l}\text { erfolgreiche Thera- } \\
\text { pie einer chroni- } \\
\text { schen HCV-Infek- } \\
\text { tion mit direkt } \\
\text { antiviral wirksamen } \\
\text { Substanzen bei } \\
\text { einem Herztrans- } \\
\text { plantat-Empfänger }\end{array}$ & Fallbericht & keine & 1 & SVR12 & $\begin{array}{l}\text { Ein herztransplantier- } \\
\text { ter HCV-positiver } \\
\text { Patient konnte erfolg- } \\
\text { reich antiviral mit } \\
\text { Simeprevir und Sofos- } \\
\text { buvir über } 12 \text { Wochen } \\
\text { behandelt werden. }\end{array}$ & Level 4 \\
\hline
\end{tabular}




\section{Interaktionen mit Calcineurin-Inhibitoren oder mTor-Inhibitoren}

\begin{tabular}{|c|c|c|c|c|c|c|c|}
\hline $\begin{array}{l}\text { Referenz- } \\
\text { autor, Jahr }\end{array}$ & $\begin{array}{l}\text { Thema, } \\
\text { Intervention }\end{array}$ & Studientyp & Kontrolle & n gesamt & $\begin{array}{l}\text { Zielparameter, } \\
\text { Beobachtungsdauer }\end{array}$ & $\begin{array}{l}\text { Ergebnis, } \\
\text { Bemerkungen }\end{array}$ & $\begin{array}{l}\text { Evidenzgrad, } \\
{ }^{*} \text { Oxford- } \\
\text { Schema }\end{array}$ \\
\hline $\begin{array}{l}\text { Burgess S } \\
\text { et al., } 2015\end{array}$ & $\begin{array}{l}\text { Medikamenten- } \\
\text { interaktionen mit } \\
\text { direkt antiviral wirk- } \\
\text { samen Substanzen } \\
\text { für Hepatitis C: } \\
\text { Bedeutung für HIV } \\
\text { und Transplanta- } \\
\text { tions-Patienten }\end{array}$ & Review & - & - & $\begin{array}{l}\text { Interaktionen und } \\
\text { Nebenwirkungen }\end{array}$ & $\begin{array}{l}\text { Keine der direkt antivi- } \\
\text { ral wirksamen Substan- } \\
\text { zen ist frei von Interak- } \\
\text { tionen. Das sollte beim } \\
\text { Einsatz dieser Medika- } \\
\text { mente berücksichtigt } \\
\text { werden, um Nebenwir- } \\
\text { kungen möglichst } \\
\text { gering zu halten. }\end{array}$ & Level 1 \\
\hline EASL, 2015 & $\begin{array}{l}\text { EASL-Empfehlun- } \\
\text { gen zur Therapie } \\
\text { der Hepatitis C } \\
2015\end{array}$ & Leitlinien & - & - & Therapie der Hepatitis C & $\begin{array}{l}\text { Empfehlungen zur The- } \\
\text { rapie der Hepatitis C. }\end{array}$ & Level 1 \\
\hline $\begin{array}{l}\text { Kwo PY } \\
\text { et al., } 2015\end{array}$ & $\begin{array}{l}\text { Neue Hepatitis-C- } \\
\text { Medikamente: Sub- } \\
\text { stanzklassen und } \\
\text { im Transplantations- } \\
\text { setting relevante } \\
\text { Interaktionen und } \\
\text { Metabolismus, The- } \\
\text { rapieoptionen bei } \\
\text { dekompensierter } \\
\text { Zirrhose und bei } \\
\text { terminaler Nieren- } \\
\text { insuffizienz }\end{array}$ & Review & - & - & $\begin{array}{l}\text { Direkt antiviral wirksa- } \\
\text { me Substanzen bei LTx, } \\
\text { dekompensierter Zir- } \\
\text { rhose und bei terminaler } \\
\text { Niereninsuffizienz }\end{array}$ & $\begin{array}{l}\text { Direkt antiviral wirksa- } \\
\text { me Substanzen haben } \\
\text { eine bessere Verträg- } \\
\text { lichkeit und Effektivi- } \\
\text { tät post-LTx. Medika- } \\
\text { menteninteraktionen } \\
\text { müssen beachtet wer- } \\
\text { den. Bisher sind keine } \\
\text { notwendigen Dosisan- } \\
\text { passungen bei chroni- } \\
\text { scher Nierenerkran- } \\
\text { kung bekannt. Die } \\
\text { Therapie bei dekom- } \\
\text { pensierter Zirrhose ist } \\
\text { schwierig. }\end{array}$ & Level 1 \\
\hline $\begin{array}{l}\text { Pellicelli AM } \\
\text { et al., } 2014\end{array}$ & $\begin{array}{l}\text { Sofosbuvir plus } \\
\text { Daclatasvir für } \\
\text { post-LTx rekurrente } \\
\text { Hepatitis C }\end{array}$ & $\begin{array}{l}\text { prospektive } \\
\text { Kohorten- } \\
\text { studie }\end{array}$ & keine & 12 & $\begin{array}{l}\text { SVR12, Beobachtung } \\
\text { über } 36 \text { Wochen }\end{array}$ & $\begin{array}{l}\text { Sofosbuvir plus Dacla- } \\
\text { tasvir hatte eine hohe } \\
\text { Effektivität bei LTx-Pa- } \\
\text { tienten und interagier- } \\
\text { te nicht mit der Im- } \\
\text { munsuppression. }\end{array}$ & Level 3 \\
\hline $\begin{array}{l}\text { Kwo PY } \\
\text { et al., } 2014\end{array}$ & $\begin{array}{l}\text { Ein Interferon- } \\
\text { freies antivirales } \\
\text { Therapieregime } \\
\text { für Hepatitis C } \\
\text { nach LTx }\end{array}$ & $\begin{array}{l}\text { Open-label- } \\
\text { Phase- } \\
\text { 2-Studie }\end{array}$ & keine & 34 & $\begin{array}{l}\text { SVR12, Beobachtung } \\
\text { über } 36 \text { Wochen }\end{array}$ & $\begin{array}{l}\text { Eine } 24 \text {-wöchige anti- } \\
\text { virale Therapie mit } \\
\text { Ombitasvir-ABT-450/r } \\
\text { und Dasabuvir mit Ri- } \\
\text { bavirin hatte eine hohe } \\
\text { SVR-Rate bei geringer } \\
\text { Nebenwirkungsrate } \\
\text { bei LTx-Patienten mit } \\
\text { rekurrenter HCV-Ge- } \\
\text { notyp-1-Infektion. }\end{array}$ & Level 2 \\
\hline
\end{tabular}




\section{AG 6: Ko-Infektion bei Hepatitis-C-Virusinfektion}

\section{HBV-/HCV-Ko-Infektionen}

Literatur wurde aus der vorherigen Leitlinie übernommen.

\section{HIV-/HCV-Ko-Infektionen}

\begin{tabular}{|c|c|c|c|c|c|c|c|}
\hline $\begin{array}{l}\text { Referenz- } \\
\text { autor, Jahr }\end{array}$ & $\begin{array}{l}\text { Thema, } \\
\text { Intervention }\end{array}$ & Studientyp & Kontrolle & n gesamt & $\begin{array}{l}\text { Zielparameter, } \\
\text { Beobachtungsdauer }\end{array}$ & $\begin{array}{l}\text { Ergebnis, } \\
\text { Bemerkungen }\end{array}$ & $\begin{array}{l}\text { Evidenzgrad, } \\
{ }^{*} \text { Oxford-Schema }\end{array}$ \\
\hline $\begin{array}{l}\text { Lo Re V } \\
\text { et al., } 2014\end{array}$ & $\begin{array}{l}\text { hepatische De- } \\
\text { kompensation } \\
\text { bei antiretroviral } \\
\text { behandelten HIV/ } \\
\text { HCV-ko-infizier- } \\
\text { ten Patienten } \\
\text { im Vergleich zu } \\
\text { HCV-mono-infi- } \\
\text { zierten Patienten }\end{array}$ & $\begin{array}{l}\text { retrospek- } \\
\text { tive Kohor- } \\
\text { tenstudie }\end{array}$ & $\begin{array}{l}6079 \text { HCV- } \\
\text { Mono-In- } \\
\text { fektion }\end{array}$ & 10359 & $\begin{array}{l}\text { Inzidenz von hepati- } \\
\text { scher Dekompensation, } \\
\text { Beobachtungszeitraum: } \\
13 \text { Jahre }\end{array}$ & $\begin{array}{l}\text { Die Inzidenz von he- } \\
\text { patischer Dekompen- } \\
\text { sation war bei HIV/ } \\
\text { HCV-ko-infizierten } \\
\text { Patienten höher als } \\
\text { bei HCV-Mono-Infek- } \\
\text { tion. }\end{array}$ & Level 3 \\
\hline $\begin{array}{l}\text { Fierer DS } \\
\text { et al., } 2013\end{array}$ & $\begin{array}{l}\text { schnelle Progres- } \\
\text { sion zu dekom- } \\
\text { pensierter Zirrho- } \\
\text { se, LTx und Tod } \\
\text { bei HIV-infizier- } \\
\text { ten Männern } \\
\text { nach primärer } \\
\text { HCV-Infektion }\end{array}$ & $\begin{array}{l}\text { prospektive } \\
\text { Kohorten- } \\
\text { studie }\end{array}$ & keine & 15 & $\begin{array}{l}\text { Inzidenz von dekom- } \\
\text { pensierter Zirrhose, } \\
\text { LTx und Tod, Beobach- } \\
\text { tungszeitraum: } 8 \text { Jahre }\end{array}$ & $\begin{array}{l}4 \text { von } 15 \text { HIV-infizier- } \\
\text { ten Männern entwi- } \\
\text { ckelten eine dekom- } \\
\text { pensierte Zirrhose } \\
\text { nach primärer HCV- } \\
\text { Infektion. }\end{array}$ & Level 3 \\
\hline $\begin{array}{l}\text { Kirk GD } \\
\text { et al., } 2013\end{array}$ & $\begin{array}{l}\text { HIV, Alter und } \\
\text { Schwere der } \\
\text { HCV-assoziierten } \\
\text { Lebererkrankung }\end{array}$ & $\begin{array}{l}\text { retrospek- } \\
\text { tive Kohor- } \\
\text { tenstudie }\end{array}$ & keine & 1176 & $\begin{array}{l}\text { HIV-Infektion, Alter und } \\
\text { Schweregrad der Leber- } \\
\text { fibrose, Beobachtungs- } \\
\text { zeitraum: } 5 \text { Jahre }\end{array}$ & $\begin{array}{l}\text { Die HIV/HCV-ko-infi- } \\
\text { zierten Patienten wie- } \\
\text { sen ähnliche Leberfi- } \\
\text { brosestadien auf wie } \\
\text { ein Jahrzehnt ältere } \\
\text { HCV-mono-infizierte } \\
\text { Patienten. }\end{array}$ & Level 3 \\
\hline $\begin{array}{l}\text { Mira JA } \\
\text { et al., } 2013\end{array}$ & $\begin{array}{l}\text { Benefits von SVR } \\
\text { nach peg-IFN } \\
\text { plus RBV bei HIV/ } \\
\text { HCV-ko-infizier- } \\
\text { ten Patienten mit } \\
\text { kompensierter } \\
\text { Zirrhose }\end{array}$ & $\begin{array}{l}\text { prospektive } \\
\text { Kohorten- } \\
\text { studie }\end{array}$ & keine & 166 & $\begin{array}{l}\text { Inzidenz von hepati- } \\
\text { scher Dekompensation, } \\
\text { Überleben }\end{array}$ & $\begin{array}{l}\text { SVR nach peg-IFN plus } \\
\text { RBV reduziert die Inzi- } \\
\text { denz der hepatischen } \\
\text { Dekompensation und } \\
\text { verbessert das Ge- } \\
\text { samtüberleben bei } \\
\text { HIV/HCV-ko-infizierten } \\
\text { Patienten mit kompen- } \\
\text { sierter Zirrhose. }\end{array}$ & Level 3 \\
\hline
\end{tabular}




\section{Akute Hepatitis C bei Patienten mit bekannter HIV- bzw. HBV-Infektion}

\begin{tabular}{|c|c|c|c|c|c|c|c|}
\hline $\begin{array}{l}\text { Referenz- } \\
\text { autor, Jahr }\end{array}$ & $\begin{array}{l}\text { Thema, } \\
\text { Intervention }\end{array}$ & Studientyp & Kontrolle & n gesamt & $\begin{array}{l}\text { Zielparameter, } \\
\text { Beobachtungsdauer }\end{array}$ & $\begin{array}{l}\text { Ergebnis, } \\
\text { Bemerkungen }\end{array}$ & $\begin{array}{l}\text { Evidenzgrad, } \\
\text { *Oxford-Schema }\end{array}$ \\
\hline $\begin{array}{l}\text { Konerman } \\
\text { MA et al., } \\
2014\end{array}$ & $\begin{array}{l}\text { Fibroseprogres- } \\
\text { sion bei HIV/ } \\
\text { HCV-ko-infizier- } \\
\text { ten Erwachsenen }\end{array}$ & $\begin{array}{l}\text { prospektive } \\
\text { Kohorten- } \\
\text { studie }\end{array}$ & keine & 435 & $\begin{array}{l}\text { Risikofaktoren der } \\
\text { Fibroseprogression }\end{array}$ & $\begin{array}{l}\text { Fibroseprogression ist } \\
\text { häufig bei HIV/HCV- } \\
\text { ko-infizierten Patien- } \\
\text { ten. Persistierend } \\
\text { erhöhte Serumtrans- } \\
\text { aminasen könnten ein } \\
\text { Risikofaktor sein. }\end{array}$ & Level 3 \\
\hline $\begin{array}{l}\text { Basu P } \\
\text { et al., } 2015\end{array}$ & $\begin{array}{l}\text { SOF/LDV vs. SOF/ } \\
\text { SMV bei akuter } \\
\text { Hepatitis C }\end{array}$ & $\begin{array}{l}\text { prospektive } \\
\text { randomi- } \\
\text { sierte Open- } \\
\text { label-Pilot- } \\
\text { studie }\end{array}$ & keine & 29 & $\begin{array}{l}\text { SVR12, Beobachtung } \\
\text { über } 20 \text { Wochen }\end{array}$ & $\begin{array}{l}\text { SOF/LDV und SOF/ } \\
\text { SMV erreichten hohe } \\
\text { SVR12-Raten bei } \\
\text { akuter Hepatitis C. }\end{array}$ & Level 2 \\
\hline $\begin{array}{l}\text { Martinello } \\
\text { M et al., } \\
2015\end{array}$ & $\begin{array}{l}\text { SOF/RBV über } 6 \\
\text { Wochen ist nicht } \\
\text { effektiv bei Pa- } \\
\text { tienten mit aku- } \\
\text { ter oder kürzlich } \\
\text { erworbener } \\
\text { HCV-Infektion }\end{array}$ & $\begin{array}{l}\text { prospektive } \\
\text { Kohorten- } \\
\text { studie }\end{array}$ & keine & 19 & $\begin{array}{l}\text { SVR12, Beobachtung } \\
\text { über } 18 \text { Wochen }\end{array}$ & $\begin{array}{l}6 \text { Wochen SOF/RBV } \\
\text { war sicher und gut } \\
\text { verträglich, aber die } \\
\text { Effektivität war sub- } \\
\text { optimal bei Patienten } \\
\text { mit akuter oder kürz- } \\
\text { lich erworbener HCV- } \\
\text { Infektion. }\end{array}$ & Level 3 \\
\hline $\begin{array}{l}\text { Fierer DS } \\
\text { et al., } 2015\end{array}$ & $\begin{array}{l}\text { SOF zur Behand- } \\
\text { lung der akuten } \\
\text { Hepatitis C bei } \\
\text { HIV-infizierten } \\
\text { Männern }\end{array}$ & Fallserie & keine & 13 & $\begin{array}{l}\text { SVR12, Beobachtung } \\
\text { über } 36 \text { Wochen }\end{array}$ & $\begin{array}{l}\text { SOF/RBV über } 12 \text { Wo- } \\
\text { chen war hoch effek- } \\
\text { tiv zur Behandlung } \\
\text { der akuten Hepatitis } \\
\text { C bei HIV-infizierten } \\
\text { Männern. }\end{array}$ & Level 4 \\
\hline
\end{tabular}


4. Therapie der chronischen Hepatitis C bei HBV/HCV-ko-infizierten Patienten

\begin{tabular}{|c|c|c|c|c|c|c|c|}
\hline $\begin{array}{l}\text { Referenz- } \\
\text { autor, Jahr }\end{array}$ & $\begin{array}{l}\text { Thema, } \\
\text { Intervention }\end{array}$ & Studientyp & Kontrolle & n gesamt & $\begin{array}{l}\text { Zielparameter, } \\
\text { Beobachtungsdauer }\end{array}$ & $\begin{array}{l}\text { Ergebnis, } \\
\text { Bemerkungen }\end{array}$ & $\begin{array}{l}\text { Evidenzgrad, } \\
\text { *Oxford-Schema }\end{array}$ \\
\hline $\begin{array}{l}\text { Yu ML } \\
\text { et al., } 2013\end{array}$ & $\begin{array}{l}\text { anhaltende HCV- } \\
\text { und HBsAg-Clea- } \\
\text { rance bei HCV/ } \\
\text { HBV-ko-infizier- } \\
\text { ten Patienten } \\
\text { nach peg-IFN al- } \\
\text { pha-2a und RBV- } \\
\text { Therapie }\end{array}$ & $\begin{array}{l}\text { prospektive } \\
\text { Follow-up- } \\
\text { Studie }\end{array}$ & $\begin{array}{l}110 \mathrm{HBV}- \\
\text { Mono- } \\
\text { Infektion }\end{array}$ & 207 & $\begin{array}{l}\text { SVR, Beobachtung über } \\
5 \text { Jahre }\end{array}$ & $\begin{array}{l}\text { Eine Therapie mit } \\
\text { peg-IFN alpha-2a und } \\
\text { RBV erreichte eine } \\
\text { stabile HCV SVR und } \\
\text { eine hohe Rate an } \\
\text { HBsAG-Clearance bei } \\
\text { HCV/HBV-ko-infizier- } \\
\text { ten Patienten. }\end{array}$ & Level 3 \\
\hline $\begin{array}{l}\text { Wahle RC } \\
\text { et al., } 2015\end{array}$ & $\begin{array}{l}\text { HBV-Reaktivie- } \\
\text { rung nach HCV- } \\
\text { Therapie bei HBV/ } \\
\text { HCV-ko-infizier- } \\
\text { ten Dialysepati- } \\
\text { enten }\end{array}$ & $\begin{array}{l}\text { prospektive } \\
\text { Kohorten- } \\
\text { studie }\end{array}$ & keine & 10 & $\begin{array}{l}\text { HBV-Reaktivierung, } \\
\text { Beobachtung über } \\
48 \text { Monate }\end{array}$ & $\begin{array}{l}\text { Eine HCV-Therapie bei } \\
\text { HBV/HCV-ko-infizier- } \\
\text { ten Dialysepatienten } \\
\text { könnte eine HBV- } \\
\text { Reaktivierung begüns- } \\
\text { tigen. }\end{array}$ & Level 3 \\
\hline $\begin{array}{l}\text { Collins JM } \\
\text { et al., } 2015\end{array}$ & $\begin{array}{l}\text { HBV-Reaktivie- } \\
\text { rung unter er- } \\
\text { folgreicher HCV- } \\
\text { Therapie mit } \\
\text { SOF/SMV }\end{array}$ & Fallstudie & keine & 2 & HBV-Reaktivierung & $\begin{array}{l}2 \text { Fälle einer HBV-Re- } \\
\text { aktivierung unter er- } \\
\text { folgreicher HCV-The- } \\
\text { rapie mit SOF/SMV }\end{array}$ & Level 4 \\
\hline $\begin{array}{l}\text { Ende AR } \\
\text { et al., } 2015\end{array}$ & $\begin{array}{l}\text { Fall einer fulmi- } \\
\text { nanten HBV-Re- } \\
\text { aktivierung mit } \\
\text { konsekutiver LTx } \\
\text { unter HCV-Thera- } \\
\text { pie mit SMV/SOF }\end{array}$ & Fallbericht & keine & 1 & HBV-Reaktivierung & $\begin{array}{l}\text { Fall einer fulminanten } \\
\text { HBV-Reaktivierung } \\
\text { mit konsekutiver LTx } \\
\text { unter HCV-Therapie } \\
\text { mit SMV/SOF }\end{array}$ & Level 4 \\
\hline
\end{tabular}

\section{Therapie der chronischen Hepatitis C bei HIV/HCV-ko-infizierten Patienten}

\begin{tabular}{|c|c|c|c|c|c|c|c|}
\hline $\begin{array}{l}\text { Referenz- } \\
\text { autor, Jahr }\end{array}$ & $\begin{array}{l}\text { Thema, } \\
\text { Intervention }\end{array}$ & Studientyp & Kontrolle & n gesamt & $\begin{array}{l}\text { Zielparameter, } \\
\text { Beobachtungsdauer }\end{array}$ & $\begin{array}{l}\text { Ergebnis, } \\
\text { Bemerkungen }\end{array}$ & $\begin{array}{l}\text { Evidenzgrad, } \\
{ }^{*} \text { Oxford-Schema }\end{array}$ \\
\hline $\begin{array}{l}\text { Osinusi A } \\
\text { et al., } 2015\end{array}$ & $\begin{array}{l}\text { LDV/SOF bei } \\
\text { HCV-Genotyp-1- } \\
\text { Patienten und } \\
\text { HIV-Ko-Infektion }\end{array}$ & $\begin{array}{l}\text { open-label, } \\
\text { single-cen- } \\
\text { ter, Phase- } \\
\text { 2b-Pilot- } \\
\text { studie }\end{array}$ & keine & 50 & $\begin{array}{l}\text { SVR12, Beobachtung } \\
\text { über } 24 \text { Wochen }\end{array}$ & $\begin{array}{l}\text { LDV/SOF über } 12 \\
\text { Wochen führte zu } \\
\text { hohen SVR-Raten bei } \\
\text { HCV-Genotyp- } \\
\text { 1-Patienten und } \\
\text { HIV-Ko-Infektion. }\end{array}$ & Level 2 \\
\hline $\begin{array}{l}\text { Naggie S } \\
\text { et al., } 2015\end{array}$ & $\begin{array}{l}\text { LDV/SOF bei } \\
\text { HIV-1-ko-infi- } \\
\text { zierten HCV- } \\
\text { Patienten }\end{array}$ & $\begin{array}{l}\text { multizentri- } \\
\text { sche Open- } \\
\text { label-Studie }\end{array}$ & keine & 335 & $\begin{array}{l}\text { SVR12, Beobachtung } \\
\text { über } 24 \text { Wochen }\end{array}$ & $\begin{array}{l}\text { LDV/SOF über } 12 \\
\text { Wochen führte zu } \\
\text { hohen SVR12-Raten } \\
\text { bei HIV-1-ko-infizier- } \\
\text { ten HCV-Genotyp-1 } \\
\text { oder 4-Patienten. }\end{array}$ & Level 2 \\
\hline $\begin{array}{l}\text { Rockstroh JK } \\
\text { et al., } 2014\end{array}$ & $\begin{array}{l}\text { SOF/RBV zur } \\
\text { Therapie von } \\
\text { HIV/HCV-ko-infi- } \\
\text { zierten Patienten } \\
\text { mit HCV-GT1 - } \\
\text { 4-Infektion: } \\
\text { PHOTON-1 } \\
\text { und 2-Studie }\end{array}$ & $\begin{array}{l}2 \text { multizen- } \\
\text { trische } \\
\text { Open-label- } \\
\text { Phase-3- } \\
\text { Studien }\end{array}$ & keine & 498 & $\begin{array}{l}\text { SVR12, Beobachtung } \\
\text { über } 36 \text { Wochen }\end{array}$ & $\begin{array}{l}\text { Eine Therapie mit } \\
\text { SOF/RBV über } 12 \text { oder } \\
24 \text { Wochen erreichte } \\
\text { bei HIV/HCV-ko-infi- } \\
\text { zierten Patienten mit } \\
\text { HCV-GT1 - 4-Infek- } \\
\text { tion ähnlich hohe } \\
\text { SVR12-Raten wie bei } \\
\text { Patienten mit HCV- } \\
\text { Mono-Infektion. }\end{array}$ & Level 1 \\
\hline
\end{tabular}




\begin{tabular}{|c|c|c|c|c|c|c|c|}
\hline $\begin{array}{l}\text { Referenz- } \\
\text { autor, Jahr }\end{array}$ & $\begin{array}{l}\text { Thema, } \\
\text { Intervention }\end{array}$ & Studientyp & Kontrolle & n gesamt & $\begin{array}{l}\text { Zielparameter, } \\
\text { Beobachtungsdauer }\end{array}$ & $\begin{array}{l}\text { Ergebnis, } \\
\text { Bemerkungen }\end{array}$ & $\begin{array}{l}\text { Evidenzgrad, } \\
\text { * Oxford-Schema }\end{array}$ \\
\hline $\begin{array}{l}\text { Sulkowski MS } \\
\text { et al., } 2014\end{array}$ & $\begin{array}{l}\text { SOF/RBV zur } \\
\text { HCV-Therapie } \\
\text { bei HIV-Ko- } \\
\text { infektion }\end{array}$ & $\begin{array}{l}\text { multizentri- } \\
\text { sche Open- } \\
\text { label-Phase- } \\
\text { 3-Studie }\end{array}$ & keine & 223 & $\begin{array}{l}\text { SVR12, Beobachtung } \\
\text { über } 36 \text { Wochen }\end{array}$ & PHOTON-1 & Level 1 \\
\hline $\begin{array}{l}\text { Molina JM } \\
\text { et al., } 2015\end{array}$ & $\begin{array}{l}\text { SOF/RBV zur } \\
\text { HCV-Therapie } \\
\text { bei HIV-Ko- } \\
\text { Infektion }\end{array}$ & $\begin{array}{l}\text { multizentri- } \\
\text { sche Open- } \\
\text { label-Phase- } \\
\text { 3-Studie }\end{array}$ & keine & 275 & $\begin{array}{l}\text { SVR12, Beobachtung } \\
\text { über } 36 \text { Wochen }\end{array}$ & PHOTON-2 & Level 1 \\
\hline $\begin{array}{l}\text { Del Bello DP } \\
\text { et al., } 2014\end{array}$ & $\begin{array}{l}\text { Real-World Da- } \\
\text { ten zur Therapie } \\
\text { von HIV-positi- } \\
\text { ven Patienten } \\
\text { und HCV-Geno- } \\
\text { typ-1-, 2- und 3- } \\
\text { Infektion mit } \\
\text { SOF/SMV-halti- } \\
\text { gen Regimen }\end{array}$ & $\begin{array}{l}\text { retrospek- } \\
\text { tive Kohor- } \\
\text { tenanalyse }\end{array}$ & keine & 78 & $\begin{array}{l}\text { SVR12, Beobachtung } \\
\text { über } 36 \text { Wochen }\end{array}$ & $\begin{array}{l}\text { Eine Therapie mit } \\
\text { SOF/SMV ist sicher } \\
\text { und effektiv bei HIV- } \\
\text { positiven HCV-Geno- } \\
\text { typ-1-ko-infizierten } \\
\text { Patienten mit Fibrose } \\
\text { oder kompensierter } \\
\text { Zirrhose. }\end{array}$ & Level 3 \\
\hline $\begin{array}{l}\text { Wyles DL } \\
\text { et al., } 2015\end{array}$ & $\begin{array}{l}\text { DCV plus SOF } \\
\text { bei HIV-1-ko- } \\
\text { infizierten } \\
\text { HCV-Patienten }\end{array}$ & $\begin{array}{l}\text { Open-label- } \\
\text { Studie }\end{array}$ & keine & 151 & $\begin{array}{l}\text { SVR12, Beobachtung } \\
\text { über } 24 \text { Wochen }\end{array}$ & $\begin{array}{l}\text { DCV plus SOF erreich- } \\
\text { te SVR12 Raten von } \\
97 \% \text { nach } 12 \text { Wochen } \\
\text { und } 76 \% \text { nach } 8 \text { Wo- } \\
\text { chen bei Therapie-nai- } \\
\text { ven HIV-1-ko-infizier- } \\
\text { ten HCV-Patienten. }\end{array}$ & Level 2 \\
\hline $\begin{array}{l}\text { Sulkowski MS } \\
\text { et al., } 2015\end{array}$ & $\begin{array}{l}\text { Ombitasvir, Pari- } \\
\text { taprevir, Ritona- } \\
\text { vir, Dasabuvir } \\
\text { und Ribavirin zur } \\
\text { HCV-Therapie } \\
\text { bei HIV-1-Ko- } \\
\text { Infektion }\end{array}$ & $\begin{array}{l}\text { randomi- } \\
\text { sierte } \\
\text { Open-label- } \\
\text { Pilotstudie }\end{array}$ & keine & 63 & $\begin{array}{l}\text { SVR12, Beobachtung } \\
\text { über } 36 \text { Wochen }\end{array}$ & TURQUOISE-I & Level 2 \\
\hline $\begin{array}{l}\text { Rockstroh JK } \\
\text { et al., } 2015\end{array}$ & $\begin{array}{l}\text { Effektivität und } \\
\text { Sicherheit von } \\
\text { Grazoprevir und } \\
\text { Elbasvir bei HCV/ } \\
\text { HIV-Ko-Infektion }\end{array}$ & $\begin{array}{l}\text { nicht ran- } \\
\text { domisierte } \\
\text { Open-label- } \\
\text { Studie }\end{array}$ & keine & 218 & $\begin{array}{l}\text { SVR12, Beobachtung } \\
\text { über } 24 \text { Wochen }\end{array}$ & $\begin{array}{l}\text { C-EDGE CO- } \\
\text { INFECTION }\end{array}$ & Level 2 \\
\hline $\begin{array}{l}\text { German P } \\
\text { et al., } 2015\end{array}$ & $\begin{array}{l}\text { Interaktionen } \\
\text { zwischen LDV/ } \\
\text { SOF und antire- } \\
\text { troviralen Medi- } \\
\text { kamenten }\end{array}$ & $\begin{array}{l}\text { randomi- } \\
\text { sierte } \\
\text { Cross-over- } \\
\text { Studie }\end{array}$ & keine & 96 & $\begin{array}{l}\text { Medikamenteninterak- } \\
\text { tionen, Beobachtung } \\
\text { über } 10 \text { Tage }\end{array}$ & $\begin{array}{l}\text { Interaktionen zwi- } \\
\text { schen LDV/SOF und } \\
\text { antiretroviralen Medi- } \\
\text { kamenten }\end{array}$ & Level 2 \\
\hline
\end{tabular}




\section{LTX bei HCV/HIV-Ko-Infektion}

\begin{tabular}{|c|c|c|c|c|c|c|c|}
\hline $\begin{array}{l}\text { Referenz- } \\
\text { autor, Jahr }\end{array}$ & $\begin{array}{l}\text { Thema, } \\
\text { Intervention }\end{array}$ & Studientyp & Kontrolle & n gesamt & $\begin{array}{l}\text { Zielparameter, } \\
\text { Beobachtungsdauer }\end{array}$ & $\begin{array}{l}\text { Ergebnis, } \\
\text { Bemerkungen }\end{array}$ & $\begin{array}{l}\text { Evidenzgrad, } \\
\text { *oxford-Schema }\end{array}$ \\
\hline $\begin{array}{l}\text { Sawinski, D } \\
\text { et al., } 2015\end{array}$ & $\begin{array}{l}\text { Outcome von } \\
\text { HIV + LTx-Patien- } \\
\text { ten im Vergleich } \\
\text { zu HCV + oder } \\
\text { HIV/HCV-ko-infi- } \\
\text { zierten LTx- } \\
\text { Patienten }\end{array}$ & $\begin{array}{l}\text { retrospek- } \\
\text { tive Kohor- } \\
\text { tenanalyse }\end{array}$ & $\begin{array}{l}22926 \\
\text { HCV-/HIV- }\end{array}$ & $\begin{array}{l}43987 \\
(20829 \\
\mathrm{HCV}+, 72 \\
\mathrm{HIV}+, 160 \\
\mathrm{HCV} / \mathrm{HIV}- \\
\text { Ko-Infek- } \\
\text { tion) }\end{array}$ & $\begin{array}{l}\text { Mortalität, Beobach- } \\
\text { tungszeitraum } 21 \text { Jahre }\end{array}$ & $\begin{array}{l}\text { Das Outcome von HIV } \\
+ \text { LTx-Patienten war } \\
\text { besser als das von } \\
\text { HCV + oder HIV/HCV- } \\
\text { ko-infizierten LTx- } \\
\text { Patienten. }\end{array}$ & Level 3 \\
\hline $\begin{array}{l}\text { Leroy V } \\
\text { et al., } 2015\end{array}$ & $\begin{array}{l}\text { Effektivität von } \\
\text { SOF/DCV bei } \\
\text { Patienten mit } \\
\text { FCH nach LTx }\end{array}$ & $\begin{array}{l}\text { prospektive } \\
\text { Kohorten- } \\
\text { studie }\end{array}$ & keine & 23 & $\begin{array}{l}\text { SVR12, Beobachtung } \\
\text { über } 36 \text { Wochen }\end{array}$ & $\begin{array}{l}\text { SOF/DCV oder SOF/ } \\
\text { RBV führt zu einer } \\
\text { signifikanten klini- } \\
\text { schen Verbesserung } \\
\text { und hohen SVR12- } \\
\text { Raten bei Patienten } \\
\text { mit FCH nach LTx. }\end{array}$ & Level 3 \\
\hline $\begin{array}{l}\text { Herzer Kate } \\
\text { al., } 2015\end{array}$ & $\begin{array}{l}\text { DCV/SOF } \pm \text { RBV } \\
\text { ist sicher und } \\
\text { effektiv bei LTx- } \\
\text { Patienten mit } \\
\text { HCV-Rekurrenz }\end{array}$ & $\begin{array}{l}\text { prospektive } \\
\text { Kohorten- } \\
\text { studie }\end{array}$ & keine & 87 & $\begin{array}{l}\text { SVR12, Beobachtung } \\
\text { über } 36 \text { Wochen }\end{array}$ & $\begin{array}{l}\text { DCV/SOF } \pm \text { RBV ist } \\
\text { sicher und effektiv } \\
\text { bei LTx-Patienten mit } \\
\text { HCV-Rekurrenz. }\end{array}$ & Level 3 \\
\hline $\begin{array}{l}\text { Antonini TM } \\
\text { et al., } 2015\end{array}$ & $\begin{array}{l}\text { SOF-basierte } \\
\text { Therapieregime } \\
\text { bei HIV/HCV- } \\
\text { ko-infizierten } \\
\text { LTx-Patienten }\end{array}$ & $\begin{array}{l}\text { prospektive } \\
\text { Kohorten- } \\
\text { studie }\end{array}$ & keine & 16 & $\begin{array}{l}\text { SVR12, Beobachtung } \\
\text { über36 Wochen }\end{array}$ & $\begin{array}{l}\text { SOF/DCV erzielte } \\
\text { exzellente Ergebnisse } \\
\text { bei HIV/HCV-ko-infi- } \\
\text { zierten LTx-Patienten. }\end{array}$ & Level 3 \\
\hline $\begin{array}{l}\text { Forns X } \\
\text { et al., } 2015\end{array}$ & $\begin{array}{l}\text { SOF compassio- } \\
\text { nate use-Pro- } \\
\text { gramm für } \\
\text { Patienten mit } \\
\text { schwerer rekur- } \\
\text { renter Hepatitis } \\
\text { C nach LTx }\end{array}$ & $\begin{array}{l}\text { prospektive } \\
\text { Kohorten- } \\
\text { studie }\end{array}$ & keine & 104 & $\begin{array}{l}\text { SVR12, Beobachtung } \\
\text { über } 60 \text { Wochen }\end{array}$ & $\begin{array}{l}\text { SOF/RBV erreicht } \\
\text { hohe SVR-Raten bei } \\
\text { Patienten mit schwe- } \\
\text { rer rekurrenter Hepa- } \\
\text { titis C nach LTx. }\end{array}$ & Level 3 \\
\hline $\begin{array}{l}\text { Grant JL } \\
\text { et al., } 2016\end{array}$ & $\begin{array}{l}\text { erfolgreiche } \\
\text { SOF- basierte } \\
\text { Therapie bei } \\
\text { HIV/HCV-ko- } \\
\text { infizierten LTx- } \\
\text { Patienten }\end{array}$ & $\begin{array}{l}\text { prospektive } \\
\text { Kohorten- } \\
\text { studie }\end{array}$ & keine & 8 & $\begin{array}{l}\text { SVR12, Beobachtung } \\
\text { über } 24 \text { Wochen }\end{array}$ & $\begin{array}{l}\text { Eine SOF-basierte } \\
\text { Therapie erreichte } \\
\text { hohe SVR12-Raten } \\
\text { bei HIV/HCV-ko-infi- } \\
\text { zierten LTx-Patienten. }\end{array}$ & Level 3 \\
\hline $\begin{array}{l}\text { Miro JM } \\
\text { et al., } 2013\end{array}$ & $\begin{array}{l}\text { Re-LTx bei } \\
\text { HIV-infizierten } \\
\text { Patienten }\end{array}$ & $\begin{array}{l}\text { retrospekti- } \\
\text { ve Kohor- } \\
\text { tenstudie }\end{array}$ & keine & 37 & $\begin{array}{l}\text { Überleben, Beobach- } \\
\text { tungszeitraum } 15 \text { Jahre }\end{array}$ & $\begin{array}{l}\text { Das Überleben nach } \\
\text { Re-LTx bei HIV-infizier- } \\
\text { ten Patienten war } \\
\text { schlecht. Bei HIV/HCV- } \\
\text { ko-infizierten Patien- } \\
\text { ten war das Outcome } \\
\text { bei negativer HCV- } \\
\text { RNA zum Zeitpunkt } \\
\text { der Re-LTx besser. }\end{array}$ & Level 3 \\
\hline
\end{tabular}




\section{Prophylaxe bei HIV/HCV- bzw. HBV/HCV-Ko-Infektion}

\begin{tabular}{|c|c|c|c|c|c|c|c|}
\hline $\begin{array}{l}\text { Referenz- } \\
\text { autor, Jahr }\end{array}$ & $\begin{array}{l}\text { Thema, } \\
\text { Intervention }\end{array}$ & Studientyp & Kontrolle & n gesamt & $\begin{array}{l}\text { Zielparameter, } \\
\text { Beobachtungsdauer }\end{array}$ & $\begin{array}{l}\text { Ergebnis, } \\
\text { Bemerkungen }\end{array}$ & $\begin{array}{l}\text { Evidenzgrad, } \\
{ }^{*} \text { Oxford-Schema }\end{array}$ \\
\hline $\begin{array}{l}\text { Dickson- } \\
\text { Spillmann M } \\
\text { et al., } 2015\end{array}$ & $\begin{array}{l}\text { Rate an HIV- und } \\
\text { Hepatitis-Infek- } \\
\text { tionen bei Pa- } \\
\text { tienten mit He- } \\
\text { roinabhängigkeit }\end{array}$ & $\begin{array}{l}\text { retrospek- } \\
\text { tive Kohor- } \\
\text { tenanalyse }\end{array}$ & keine & 1313 & $\begin{array}{l}\text { Rate an HIV- und Hepa- } \\
\text { titis-Infektionen, Beob- } \\
\text { achtungszeitraum: } \\
10 \text { Jahre }\end{array}$ & $\begin{array}{l}\text { Testung und Präven- } \\
\text { tion für Infektions- } \\
\text { krankheiten und För- } \\
\text { derung der HAV- und } \\
\text { HBV-Impfung bei } \\
\text { Heroinabhängigen } \\
\text { sollten fortgeführt } \\
\text { werden. }\end{array}$ & Level 3 \\
\hline $\begin{array}{l}\text { Jansen K } \\
\text { et al., } 2015\end{array}$ & $\begin{array}{l}\text { hohe Prävalenz } \\
\text { und Inzidenz von } \\
\text { Ko-Infektionen } \\
\text { mit HBV, HCV } \\
\text { und Syphilis und } \\
\text { niedrige HBV- } \\
\text { Impfraten bei } \\
\text { homosexuellen } \\
\text { Männern mit HIV }\end{array}$ & $\begin{array}{l}\text { prospektive } \\
\text { Kohorten- } \\
\text { studie }\end{array}$ & keine & 1843 & $\begin{array}{l}\text { Prävalenz und Inzidenz } \\
\text { von Ko-Infektionen mit } \\
\text { HBV, HCV und Syphilis } \\
\text { und HBV-Impfraten, } \\
\text { Beobachtung über } \\
4 \text { Jahre }\end{array}$ & $\begin{array}{l}\text { Es werden bessere } \\
\text { Impfkampagnen } \\
\text { und Kampagnen zur } \\
\text { Prävention von STI } \\
\text { benötigt. }\end{array}$ & Level 3 \\
\hline $\begin{array}{l}\text { Falade- } \\
\text { Nwulia O } \\
\text { et al., } 2015\end{array}$ & $\begin{array}{l}\text { HBV-Infektion } \\
\text { bei HIV-infizier- } \\
\text { ten und nicht } \\
\text { HIV-infizierten } \\
\text { homosexuellen } \\
\text { Männern }\end{array}$ & $\begin{array}{l}\text { retrospek- } \\
\text { tive Kohor- } \\
\text { tenanalyse }\end{array}$ & keine & 2375 & HBV-Infektion & $\begin{array}{l}\text { Effektive HAART ist } \\
\text { mit einer niedrigeren } \\
\text { HBV-Infektion assozi- } \\
\text { iert. }\end{array}$ & Level 3 \\
\hline $\begin{array}{l}\text { Hope VD } \\
\text { et al., } 2016\end{array}$ & $\begin{array}{l}\text { HIV-, HBV- und } \\
\text { HCV-Risiko bei } \\
\text { Männern mit } \\
\text { iv-Anabolikage- } \\
\text { brauch }\end{array}$ & $\begin{array}{l}\text { retrospek- } \\
\text { tive Kohor- } \\
\text { tenanalyse }\end{array}$ & keine & 2979 & $\begin{array}{l}\text { HIV-, HBV- und HCV- } \\
\text { Risiko, Beobachtungs- } \\
\text { zeitraum: } 21 \text { Jahre }\end{array}$ & $\begin{array}{l}\text { Die Prävalenz von } \\
\text { parenteral übertrage- } \\
\text { nen Virusinfektionen } \\
\text { hat mit der Zeit bei } \\
\text { Männern mit iv-Ana- } \\
\text { bolikagebrauch zuge- } \\
\text { nommen. Die HIV- } \\
\text { Prävalenz ist nun mit } \\
\text { der bei iv-Drogen- } \\
\text { abusus vergleichbar. }\end{array}$ & Level 3 \\
\hline $\begin{array}{l}\text { STIKO, } \\
2015\end{array}$ & $\begin{array}{l}\text { Empfehlungen } \\
\text { der STIKO }\end{array}$ & Empfehlung & - & - & $\begin{array}{l}\text { Empfehlungen der } \\
\text { STIKO }\end{array}$ & $\begin{array}{l}\text { Empfehlungen der } \\
\text { STIKO }\end{array}$ & Level 1 \\
\hline $\begin{array}{l}\text { Mena G et } \\
\text { al., } 2015\end{array}$ & $\begin{array}{l}\text { HBV- und HAV- } \\
\text { Impfung bei } \\
\text { HIV-infizierten } \\
\text { Erwachsenen }\end{array}$ & Review & - & - & $\begin{array}{l}\text { HBV- und HAV-Imp- } \\
\text { fung bei HIV-infizierten } \\
\text { Erwachsenen }\end{array}$ & $\begin{array}{l}\text { Hauptursache für } \\
\text { Impfversagen bei } \\
\text { HIV-Patienten ist die } \\
\text { Immunsuppression. }\end{array}$ & Level 1 \\
\hline $\begin{array}{l}\text { Lopes VB } \\
\text { et al., } 2013\end{array}$ & $\begin{array}{l}\text { Langzeit-An- } \\
\text { sprechraten auf } \\
\text { eine erfolgreiche } \\
\text { HBV-Impfung bei } \\
\text { HIV-Patienten }\end{array}$ & $\begin{array}{l}\text { retrospekti- } \\
\text { ve Kohor- } \\
\text { tenanalyse }\end{array}$ & keine & 155 & $\begin{array}{l}\text { HBV-Impfansprechen, } \\
\text { Beobachtung über } 5 \\
\text { Jahre }\end{array}$ & $\begin{array}{l}\text { Die Dauer effektiver } \\
\text { anti-HBs-Level ist mit } \\
\text { der Höhe des Antikör- } \\
\text { pertiters nach der } \\
\text { Primärimmunisierung } \\
\text { assoziiert. }\end{array}$ & Level 3 \\
\hline $\begin{array}{l}\text { O’Bryan TA } \\
\text { et al., } 2015\end{array}$ & $\begin{array}{l}\text { HIV-Virämie } \\
\text { während einer } \\
\text { HBV-Impfung } \\
\text { verkürzt die } \\
\text { Dauer der pro- } \\
\text { tektiven Antikör- } \\
\text { pertiter }\end{array}$ & $\begin{array}{l}\text { retrospek- } \\
\text { tive Kohor- } \\
\text { tenanalyse }\end{array}$ & keine & 186 & Anti-HBs-Titer & $\begin{array}{l}\text { Eine niedrige HIV-Vi- } \\
\text { ruslast bzw. unterhalb } \\
\text { der Nachweisgrenze } \\
\text { zum Zeitpunkt der } \\
\text { HBV-Impfung ist mit } \\
\text { einer längeren Impf- } \\
\text { ansprechdauer asso- } \\
\text { ziiert. }\end{array}$ & Level 3 \\
\hline
\end{tabular}




\begin{tabular}{|c|c|c|c|c|c|c|c|}
\hline $\begin{array}{l}\text { Referenz- } \\
\text { autor, Jahr }\end{array}$ & $\begin{array}{l}\text { Thema, } \\
\text { Intervention }\end{array}$ & Studientyp & Kontrolle & n gesamt & $\begin{array}{l}\text { Zielparameter, } \\
\text { Beobachtungsdauer }\end{array}$ & $\begin{array}{l}\text { Ergebnis, } \\
\text { Bemerkungen }\end{array}$ & $\begin{array}{l}\text { Evidenzgrad, } \\
{ }^{*} \text { Oxford-Schema }\end{array}$ \\
\hline $\begin{array}{l}\text { Fuster } \mathrm{F} \\
\text { et al., } 2016\end{array}$ & $\begin{array}{l}\text { CD4 / CD8-Ratio } \\
\text { als Prädiktor für } \\
\text { das Ansprechen } \\
\text { auf eine HBV- } \\
\text { Impfung bei } \\
\text { HIV-Patienten }\end{array}$ & $\begin{array}{l}\text { prospektive } \\
\text { Kohorten- } \\
\text { studie }\end{array}$ & keine & 245 & $\begin{array}{l}\text { Impfansprechen, Beob- } \\
\text { achtung über } 2 \text { Jahre }\end{array}$ & $\begin{array}{l}\text { Die CD4 / CD8-Ratio } \\
\text { war mit einer positi- } \\
\text { ven Serokonversion } \\
\text { assoziiert. }\end{array}$ & Level 3 \\
\hline $\begin{array}{l}\text { Shouval D } \\
\text { et al., } 2015\end{array}$ & $\begin{array}{l}\text { gesteigerte Im- } \\
\text { munantwort auf } \\
\text { die HBV-Imp- } \\
\text { fung durch Im- } \\
\text { munisierung mit } \\
\text { einer Pre-S1/Pre- } \\
\text { S2/S-Vaccine }\end{array}$ & Review & - & - & HBV-Impfantwort & $\begin{array}{l}\text { Eine Immunisierung } \\
\text { mit einer Pre-S1/Pre- } \\
\text { S2/S-Vaccine steigert } \\
\text { die Immunantwort } \\
\text { auf die HBV-Impfung }\end{array}$ & Level 1 \\
\hline $\begin{array}{l}\text { Piroth L et } \\
\text { al., } 2015\end{array}$ & $\begin{array}{l}\text { HBV-Impfung } \\
\text { bei HIV-infizier- } \\
\text { ten Patienten } \\
\text { mit isoliertem } \\
\text { anti-HBc-Anti- } \\
\text { körper }\end{array}$ & $\begin{array}{l}\text { prospektive } \\
\text { Kohorten- } \\
\text { studie }\end{array}$ & keine & 54 & HBV-Impfantwort & $\begin{array}{l}\text { ANRS HB EP03 } \\
\text { CISOVAC }\end{array}$ & Level 3 \\
\hline
\end{tabular}

\section{AG 7: Hepatitis C-Virusinfektion bei Kindern und Jugendlichen}

\section{Akute Hepatitis $C$}

Die Literatur wurde aus der Vorversion der Leitlinie übernommen.

\section{Chronische Hepatitis C}

a) Wie wird die Diagnose im Kindesalter gestellt?

b) Welche Therapiemöglichkeiten und -ziele bestehen bei einer Hepatitis C im Kindesalter?

c) Mit welchen Medikamenten bestehen im Kindes- und Jugendalter Therapieerfahrung?

d) Welche prophylaktischen Maßnahmen sind im Kindesalter sinnvoll?

Die Literatur wurde aus der Vorversion der Leitlinie übernommen. 
8.7 Oxford Centre for Evidence-Based Medicine 2011 Levels of Evidence

\begin{tabular}{|c|c|c|c|c|c|}
\hline Question & $\begin{array}{l}\text { Step } 1 \\
\left(\text { Level } 1^{*}\right)\end{array}$ & $\begin{array}{l}\text { Step } 2 \\
\text { (Level 2*) }\end{array}$ & $\begin{array}{l}\text { Step } 3 \\
\text { (Level 3*) }\end{array}$ & $\begin{array}{l}\text { Step } 4 \\
(\text { Level 4*) }\end{array}$ & $\begin{array}{l}\text { Step } 5 \\
\text { (Level 5) }\end{array}$ \\
\hline $\begin{array}{l}\text { How common is the } \\
\text { problem? }\end{array}$ & $\begin{array}{l}\text { Local and current } \\
\text { random sample } \\
\text { surveys (or censuses) }\end{array}$ & $\begin{array}{l}\text { Systematic review of } \\
\text { surveys that allow } \\
\text { matching to local } \\
\text { circumstances** }\end{array}$ & $\begin{array}{l}\text { Lacal non-random } \\
\text { sample** }\end{array}$ & Case-series** & $\mathrm{n} / \mathrm{a}$ \\
\hline $\begin{array}{l}\text { Is this diagnostic or } \\
\text { monitoring test ac- } \\
\text { curate? (Diagnosis) }\end{array}$ & $\begin{array}{l}\text { Systematic review of } \\
\text { cross sectional studies } \\
\text { with consistently } \\
\text { applied reference } \\
\text { standard and blinding }\end{array}$ & $\begin{array}{l}\text { Individual cross } \\
\text { sectional studies with } \\
\text { consistently applied } \\
\text { reference standard } \\
\text { and blinding }\end{array}$ & $\begin{array}{l}\text { Non-consecutive } \\
\text { studies, or studies } \\
\text { without consistently } \\
\text { applied reference } \\
\text { standards** }\end{array}$ & $\begin{array}{l}\text { Case-control studies, } \\
\text { or poor or non-inde- } \\
\text { pendent reference } \\
\text { standard** }\end{array}$ & $\begin{array}{l}\text { Mechanism-based } \\
\text { reasoning }\end{array}$ \\
\hline $\begin{array}{l}\text { What will happen if } \\
\text { we do not add a } \\
\text { therapy? (Prognosis) }\end{array}$ & $\begin{array}{l}\text { Systematic review } \\
\text { of inception cohort } \\
\text { studies }\end{array}$ & $\begin{array}{l}\text { Inception cohort } \\
\text { studies }\end{array}$ & $\begin{array}{l}\text { Cohort study or } \\
\text { control arm of } \\
\text { randomized trial* }\end{array}$ & $\begin{array}{l}\text { Case-series or case- } \\
\text { control studies, or } \\
\text { poor quality prognos- } \\
\text { tic cohort study** }\end{array}$ & $\mathrm{n} / \mathrm{a}$ \\
\hline $\begin{array}{l}\text { Does this interven- } \\
\text { tion help? (Treatment } \\
\text { Benefits) }\end{array}$ & $\begin{array}{l}\text { Systematic review } \\
\text { of randomized trials } \\
\text { or } n \text {-of- } 1 \text { trials }\end{array}$ & $\begin{array}{l}\text { Randomized trial or } \\
\text { observational study } \\
\text { with dramatic effect }\end{array}$ & $\begin{array}{l}\text { Non-randomized con- } \\
\text { trolled cohort/follow- } \\
\text { up study** }\end{array}$ & $\begin{array}{l}\text { Case-series, case- } \\
\text { control studies, or } \\
\text { historically controlled } \\
\text { studies** }^{*}\end{array}$ & $\begin{array}{l}\text { Mechanism-based } \\
\text { reasoning }\end{array}$ \\
\hline $\begin{array}{l}\text { What are the COM- } \\
\text { MON harms? (Treat- } \\
\text { ment Harms) }\end{array}$ & $\begin{array}{l}\text { Systematic review of } \\
\text { randomized trials, } \\
\text { systematic review of } \\
\text { nested case-control } \\
\text { studies, n-of-1 trial } \\
\text { with the patient you } \\
\text { are rasing the Ques- } \\
\text { tion about, or obser- } \\
\text { vational studv with } \\
\text { dramatic effect }\end{array}$ & $\begin{array}{l}\text { Individual randomized } \\
\text { trial or (exceptionally) } \\
\text { observational study } \\
\text { with dramatic effect }\end{array}$ & $\begin{array}{l}\text { Non-randomized con- } \\
\text { trolled cohort/follow- } \\
\text { up study (post-marke- } \\
\text { ting surveillance) } \\
\text { provided there are } \\
\text { sufficient numbers to } \\
\text { rule out a common } \\
\text { harm. (For long-term } \\
\text { harms the duration of } \\
\text { follow-up must be }\end{array}$ & $\begin{array}{l}\text { Case-series, case-con- } \\
\text { trol, or historically } \\
\text { controlled studies** }\end{array}$ & $\begin{array}{l}\text { Mechanism-based } \\
\text { reasoning }\end{array}$ \\
\hline $\begin{array}{l}\text { What are the RARE } \\
\text { harms? (Treatment } \\
\text { Harms) }\end{array}$ & $\begin{array}{l}\text { Systematic review of } \\
\text { randomized trials or } \\
\mathrm{n} \text {-of- } 1 \text { trial }\end{array}$ & $\begin{array}{l}\text { Randomized trial or } \\
\text { (exceptionally) obser- } \\
\text { vational study with } \\
\text { dramatic effect }\end{array}$ & sufficient.) $)^{* *}$ & & \\
\hline $\begin{array}{l}\text { Is this (early detec- } \\
\text { tion) test worthwhile? } \\
\text { (Screening) }\end{array}$ & $\begin{array}{l}\text { Systematic review of } \\
\text { randomized trials }\end{array}$ & Randomized trial & $\begin{array}{l}\text { Non-randomized con- } \\
\text { trolled cohort/follow- } \\
\text { up study** }\end{array}$ & $\begin{array}{l}\text { Case-series, case- } \\
\text { control, or historically } \\
\text { controlled studies** }\end{array}$ & $\begin{array}{l}\text { Mechanism-based } \\
\text { reasoning }\end{array}$ \\
\hline \multicolumn{6}{|c|}{$\begin{array}{l}\text { OCEBM Levels of Evidence Working Group. "The Oxford } 2011 \text { Levels of Evidence”. } \\
\text { Oxford Centre for Evidence-Based Medicine. http://www.cebm.net/index.aspxßo=5653 } \\
\text { Level may be graded down on the basis of study quality, imprecision, indirectness (study PICO does not match questions PICO), because of inconsistency } \\
\text { between studies, or because the absolute effect size is very small; Level may be graded up if there is a large or very large effect size. }\end{array}$} \\
\hline
\end{tabular}

